\title{
What is Water? \\ The History and Crisis of a Modern Abstraction
}

\author{
By James (Jamie) Linton, M.A. \\ A thesis submitted in partial fulfilment of the requirement for \\ the degree of Doctor of Philosophy \\ Department of Geography and Environmental Studies, \\ Carleton University
}

(C) September, 2006

J.I. Linton 


$\begin{array}{ll}\begin{array}{l}\text { Library and } \\ \text { Archives Canada }\end{array} & \begin{array}{l}\text { Bibliothèque et } \\ \text { Archives Canada }\end{array} \\ \begin{array}{l}\text { Published Heritage } \\ \text { Branch }\end{array} & \begin{array}{l}\text { Direction du } \\ \text { Patrimoine de l'édition }\end{array} \\ \begin{array}{l}\text { 395 Wellington Street } \\ \text { Ottawa ON K1A ON4 }\end{array} & \begin{array}{l}\text { 395, rue Wellington } \\ \text { Ottawa ON K1A ON4 } \\ \text { Canada }\end{array}\end{array}$

Your file Votre référence ISBN: 978-0-494-23294-1 Our file Notre référence ISBN: 978-0-494-23294-1

NOTICE:

The author has granted a nonexclusive license allowing Library and Archives Canada to reproduce, publish, archive, preserve, conserve, communicate to the public by telecommunication or on the Internet, loan, distribute and sell theses worldwide, for commercial or noncommercial purposes, in microform, paper, electronic and/or any other formats.

The author retains copyright ownership and moral rights in this thesis. Neither the thesis nor substantial extracts from it may be printed or otherwise reproduced without the author's permission.
AVIS:

L'auteur a accordé une licence non exclusive permettant à la Bibliothèque et Archives Canada de reproduire, publier, archiver, sauvegarder, conserver, transmettre au public par télécommunication ou par l'Internet, prêter, distribuer et vendre des thèses partout dans le monde, à des fins commerciales ou autres, sur support microforme, papier, électronique et/ou autres formats.

L'auteur conserve la propriété du droit d'auteur et des droits moraux qui protège cette thèse. $\mathrm{Ni}$ la thèse ni des extraits substantiels de celle-ci ne doivent être imprimés ou autrement reproduits sans son autorisation.
In compliance with the Canadian

Privacy Act some supporting forms may have been removed from this thesis.

While these forms may be included in the document page count, their removal does not represent any loss of content from the thesis.
Conformément à la loi canadienne sur la protection de la vie privée, quelques formulaires secondaires ont été enlevés de cette thèse.

Bien que ces formulaires aient inclus dans la pagination, il n'y aura aucun contenu manquant.

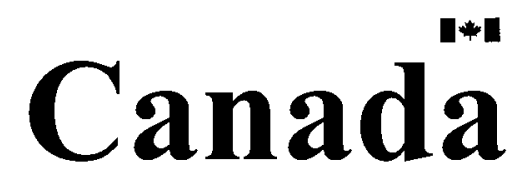




\begin{abstract}
Recently, water has been plunged into a critical state of affairs. Widespread talk of the worldwide water "crisis" reflects growing anxiety about the adequacy of water resources to sustain human populations and the adequacy of human institutions to sustain hydrological integrity. While the predominant response has been to seek ways of improving the efficiency with which water is applied to human purposes, the water crisis also suggests the need to examine critically the fundamental relationship between people and water in the modern world. In this thesis, I apply a relational-dialectical approach to investigate this relationship and to analyse the particular kind of water that this relationship produces. "Modern water", as I call it, is an abstraction proliferated in discursive and material practices that have the effect of concealing water's essential social nature. Key moments in the history of this abstraction are drawn from the hydrological sciences and their association with the modern state, to show how modern water internalizes the simultaneous eradication and presence of people. Such a contradiction, I argue, has made it inevitable that there should be a water crisis. Deliberately reinvesting water with social content - providing a means by which people may get (back) into the water - is suggested as a means of addressing this crisis.
\end{abstract}




\section{Acknowledgements}

I am grateful to everyone associated with the Department of Geography and Environmental Studies at Carleton University. This thesis is the product of the time I have spent at the Department and I hope it reflects well on everyone involved, of whom I will mention only a few here. Under Simon Dalby's engaging and inspiring supervision, I have been encouraged to produce what I feel is the best work of which I am capable and one could not ask more of a supervisor. Special thanks are due to lain Wallace, who has assisted with this project from its beginning, and whose teaching and mentorship have done much to provide the intellectual foundation that made it possible. For his helpful advice in the early going and for sending useful articles my way, I want to thank Mike Brklacich. Sean Carey provided helpful hydrological advice, and I am grateful to Gennady Ozornoy for his help translating portions of a Russian paper in hydrology. My fellow graduate students have contributed substantially to the process resulting in this dissertation, and I am particularly grateful to Andrew Baldwin in this regard. And were it not for the benevolent presence of Hazel Anderson, I most certainly would not have completed anything on time.

Beyond the Carleton Campus, I drew much advice and encouragement from Bill Nuttle, and am especially grateful for his comments on an earlier draft of the thesis. I also want to acknowledge David Brooks' interest in this work as well as his having directed me towards several readings that I have found most helpful.

My wife, Deb Vuylsteke, and my children, James Jules (JJ) and Samantha (Sammy), have my enduring gratitude for allowing me to pursue graduate studies and for putting up with my many inconveniences to them while writing the thesis. Deb moreover contributed substantially with helpful advice and with editorial comments on an earlier draft. 


\section{Table of Contents}

Part I - History of Modern Water...............................................................................................1

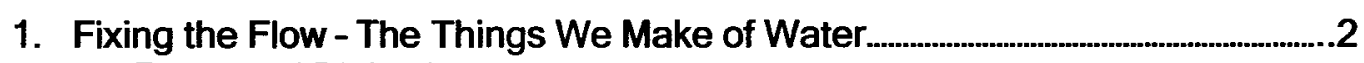

Relational Dialectics.................................................................................................................................6

Relational Dialectics of Water ....................................................................................... 14

Social Nature ....................................................................................................................................21

Excursions and Incursions...............................................................................................................34

Introducing Modern Water............................................................................................................39

Downstream from Here ............................................................................................................................49

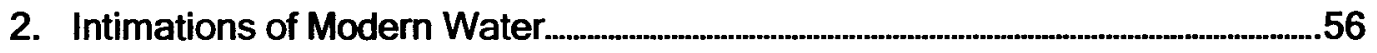

Introduction........................................................................................................................56

Critiques of Modern Water Structures and the Changing

Water Paradigm ............................................................................................................57

Water History...........................................................................................................................70

Cultural Ecology of Water................................................................................................... 80

"Water" is for Fighting Over - the Political Ecology of Water...............................87

Fighting the water market.....................................................................................................90

Social construction of drought and water scarcity................................................93

Post-colonialism and Imperial Water.......................................................................................97

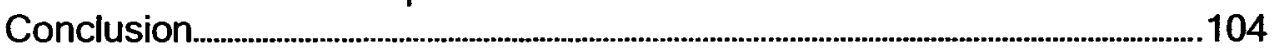

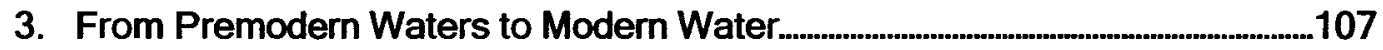

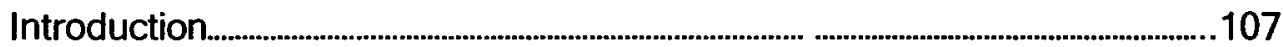

Waters in Historical Context................................................................................................108

Premodern waters in classical natural history and philosophy...................118

Premodem waters in folklore and religion.................................................................131

Premodern waters of the mineral spring.................................................................139

"All this is no concern of mine" - Scientific Hydrology

and Modern Water........................................................................................................144

Conclusion - A Manifesto for Modern Water......................................................................... 156

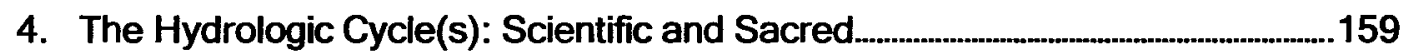

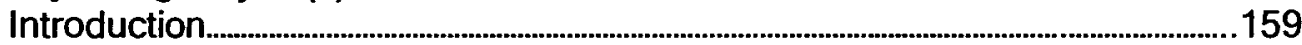

Conventional History of the (Scientific) Hydrologic Cycle........................................ 164

The origin of springs.................................................................................................170

Closing the hydrologic cycle - the foundation of

quantitative hydrology..............................................................................................................179

The (Sacred) Hydrologic Cycle and the Wisdom of God...........................................183

Conclusion .............................................................................................................................193 
5. Constructivist History of the (Hortonian) Hydrologic Cycle.................................198

Introduction

Constructivist History of Science...............................................................................200

Horton 1931............................................................................................................................208

Carrying the Hydrologic Cycle Forward from 1931 .................................................219

Consolidating Hydrological Identity ……………………………..........................219

Picturing the Hydrologic Cycle...............................................................................225

Projecting the Hydrologic Cycle Backward from 1931............................................236

Conclusion - The Fate of Perreault....................................................................................241

6. Reading the Resource: Modern Water, the Hydrologic Cycle and the State......244

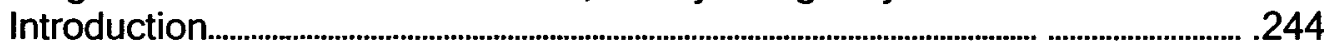

Water Becomes a "Resource".........................................................................................245

The Hydrologic Cycle and the "Complete Control" of Water Resources..........253

Conclusion: Modern Water and the State................................................................260

7. Culmination: Global Water

Introduction .......................................................................................................2.265

From Modern Water to Global Water......................................................................269

Global water goes west: the International Hydrological Decade.........................275

Conclusion ..............................................................................................................................................281

Part II - The Constitutional Crisis of Modern Water

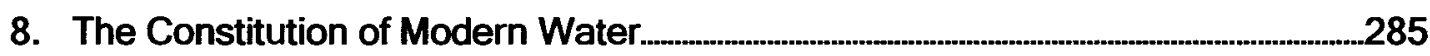

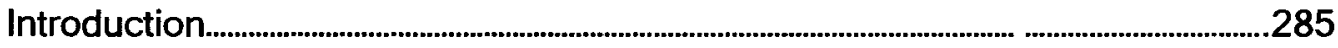

The Modern Constitution .................................................................................................288

Adding Water to the Modern Constitution..........................................................293

The constitution and the hydrologic cycle....................................................................298

Conclusion ............................................................................................................................

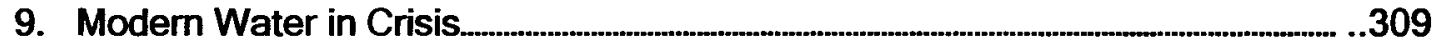

Introduction .............................................................................................................................309

For an Instant Crisis, Just Mix People and Water............................................................312

From Problem to Crisis...............................................................................................320

The Global Water Crisis of the 1990's..............................................................................328

Sustaining Modern Water - The New "Global Water Regime" ....................................345

Water as a scarce resource and an economic good..........................................349

Integrated Water Resources Management...................................................................352

Conclusion ........................................................................................................................................357 
10. Hydrolectics.............................................................................................................360

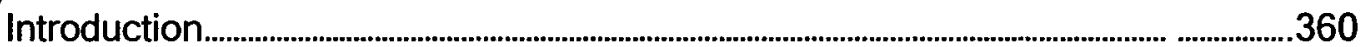

Principles of Hydrolectics...................................................................................................368

Practicing Hydrolectics........................................................................................................................374

Practical Hydrolectics...................................................................................................375

Analytical Hydrolectics..................................................................................................382

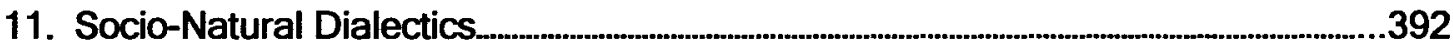

The End of (Social) Nature...........................................................................................396

Hybrid Ontologies.......................................................................................................................................402

A Slight Diversion Across the Geographical Divide...............................................................408

Socio-Natural Dialectics................................................................................................................415

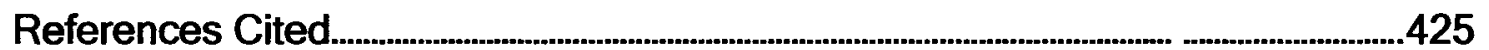




\section{List of Figures}

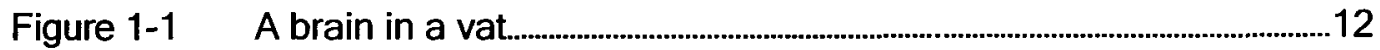

Figure 1-2 "The World's Water System".................................................................................43

Figure 1-3 World Water Reserves................................................................................................44

Figure 1-4 Modern Water Reduced to its Essence............................................................45

Figure 1-5 The Hydrologic Cycle

Figure 2-1 "Characteristics of Externally and Locally Derived Soil and Water Conservation Technologies"............................................................................82

Figure 3-1 Dalton's Atomic Symbols......................................................................................116

Figure 3-2 Painting of the Roman Aqueducts by Zeno Deimer............................119

Figure 3-3 “Social Calibration of Nilometer Readings".................................................149

Figure 4-1 Kircher's Depiction of the Origins of Springs and Rivers..................176

Figure 5-1 Horton's Illustration of the Hydrologic Cycle...........................................209

Figure 5-2 The Hydrologic Cycle as an Expression of the Basic Water Balance Equation .....................................................................................................217

Figure 5-3 Hydrologic Science = the Hydrologic Cycle .........................................224

Figure 5-4 "The Hydrologic Cycle" from Meinzer (1942)........................................230

Figure 5-5 "The Hydrologic Cycle" from American Society of Civil Engineers (1949) ...............................................................................................................233

Figure 6-1 "Precipitation and the Hydrologic Cycle" ......................................................257

Figure 6-2 "How the Water Cycle is Measured"

Figure 7-1 The Hydrologic Cycle and the Production of Global Water...........267

Figure 8.1 Can You Find the People in This Picture?

Figure 9-1 "The World's Water Supply"

Figure 9-2 Juxtaposition of Two Abstractions: Water Supply vs. Population...................................................................................................3

Figure 9-3 “Availability of Freshwater in 2000 "................................................................318 


\section{Part I - History of Modern Water}




\section{Fixing the Flow - The Things We Make of Water}

Water is nothing but what we make of it. This is not a particularly novel statement. The philosopher and historian of religions, Mircea Eliade, wrote that water "is fons et origio, the source of all possible existence...; it will always exist, though never alone, for water is always germinative, containing the potentiality of all forms in their unbroken unity." (Eliade 1958:188, 189) Everyone knows that we can't exist without water. But neither can water, as fons et origio, exist without us; we give to water that which enables it to realize its potential. All by itself, water is supremely, implacably, untractably fluid, fluctuating, fleeting. People mix language, meaning, and gods with water to give it life and transcendence: "Water has a nearly unlimited ability to convey metaphors", writes Ivan Illich. (Illich 1985:24) "Of all the elements in the environment, [water] is the most suited to convey meaning in every aspect of human life", writes the sociologist, Veronica Strang. (Strang 2004:61) "We made every living thing of water", says the Qu'ran. (21:30) At the same time, water mixes with people to give us life and transcendence: "The body of a normal man weighing 65 kilograms (about 145 pounds) contains approximately 40 litres (about 42 quarts) of water", reports the Encyclopaedia Britannica. (15 ${ }^{\text {th }}$ ed. 28:683) "Only in contemplation of [water] do I achieve true self-forgetfulness and feel my own limited individuality merge into the universal", writes Thomas Mann. (quoted in Chorley and Kates 1969a;b:1) This mixing of water and people constitutes both parties through a hydrosocial process that gives rise to every possibility that is latent in water and in ourselves. "Yes, as everyone knows," wrote Herman Melville, "meditation and water are wedded forever." (Melville 1972:94) 
Water is an ambiguity that is impossible to pin-down. In an effort to get at the futility of identifying the absolute truth of things, Neitzsche described "the world" as "an unstable foundation of running water." (quoted in Gare 1995:58) If pinningdown the world is so difficult, how much more difficult it must be to fix the flow that Neitzsche used to illustrate the very principle of intractability! Nevertheless, we do seem compelled to pin things down, water included. This habitual urge seems to be in our particular nature, intellectual heirs that we are of the European enlightened tradition. Much of what I have to say in this essay is about the possibilities and the problems associated with efforts to pin down water. Of all "things", water is among the least cooperative of subjects to be contained in words and deeds. When we do contrive to retard the flow for long enough to substantiate it in language, represent it in numbers, or confine it in Euclidian spaces, water transforms itself and slips into impermanence - reservoirs rise and fall; winter comes along and the stuff turns to ice, sublimates and gets spirited away on the first available breeze. Even $\mathrm{H}_{2} \mathrm{O}$, that pregnant compound that emerged from the eighteenth century laboratories of Henry Cavendish and/or Antoine Lavoisier, ${ }^{1}$ is shockingly promiscuous; it goes and bonds with almost everything it meets once it escapes the lab!

1 "The water controversy" - the question of whether Cavendish or Lavoisier was the first to "discover" the essence of water (as a chemical compound of hydrogen and oxygen), has been at times the subject of a fierce debate in the history of science. (e.g. Huxley 1907[1877]: Chapter titled "The Chemical Composition of Pure Water"; Ball 2001:141-147) 
The main theme of the thesis concerns how "we" in the modern ${ }^{3}$ West have tended to reduce water to a particular kind of abstraction. I am concerned with the way that we typically see, understand, represent, and relate to, water, and how we have managed to concretize this particular relation in everyday language as well as scientific discourse; in numbers as well as in space. Our particular habit of abstracting, fixing, containing, and relating to water, I call "modern water." While modern water is singularly useful, I will argue that it should nevertheless be understood as a contrivance of limited utility. The mistaking of modern water for water itself, and the attempt to apply it universally, has given rise to many problems - problems that indicate the need for radical change in the way water is conceptualized. These problems and this need comprise a kind of water crisis, one that is rooted more in the intransigence of modern water than the scarcity of water itself.

2 By "we" I mean those who, like myself, understand themselves to be the heirs - and critics - of a tradition described as Western thought. This tradition is typically represented by narratives of the development of the intellect through the major epochs of Western history: " .... ancient and Classical Greece, the Hellenistic era and imperial Rome, Judaism and the rise of Christianity, the Catholic Church and the Middle Ages, the Renaissance, Reformation, and Scientific Revolution, the Enlightenment and Romanticism and onward to our own compelling time." (Tarnas 1991:xiii-xiv) The argument that this is a tradition "whose sum and consequence we all bear within ourselves" (ibid. xiv) is strengthened by the vehemence with which we may reject it.

${ }^{3}$ Here and below, "modern" is used mainly in two related senses, both of which are necessarily imprecise. In an historical sense, it corresponds approximately to "our own compelling time" as identified in the footnote above. Because I have located the more salient historical origins of modern water in the Scientific Revolution (approximately the seventeenth century) and Enlightenment (approximately the eighteenth century), this may be considered the beginning of the modern period for our purposes. In an epistemological sense, "modern" corresponds approximately to the "view of nature" that has characterized Western thought during this historical period. That many different views of nature have obtained throughout this period is fully acknowledged, however a modern view may be generalized, even if very loosely, as something related to, but fundamentally distinct from what went before. As Collingwood has argued: "The modern view of nature owes something both to Greek and to Renaissance cosmology, but it differs from each in fundamental ways." (Collingwood 1945:9) Note that for Collingwood, "Renaissance" includes the (late sixteenth and seventeenth century) developments in the history of Western thought usually associated with the Scientific Revolution. 
Any effort to pin water down once and for all is bound to cause problems because the only thing that we know for sure about water is that it changes, depending on the circumstances. The circumstances may be described in meteorological or environmental terms; water freezes to ice when it falls to a temperature of zero degrees Celsius. But the circumstances are also undeniably of a social nature. Water experts have estimated that humankind now diverts and makes use of over half the available water flowing in the Earth's rivers. (Postel et al. 1996) Practically every body of water on the planet bears traces of human influence in the form of anthropogenic substances such as chlorinated organic compounds. (Linton 1997) Recent research has shown that everywhere it falls on this planet, snow is laden with particulates and other forms of human pollution such that "pure as the driven snow is almost impossible to find." (NASA 2003)

In making the claim that water is nothing but what we make of it, the idea that water is a product of social circumstances goes beyond the anthropogenic alteration of the hydrologic cycle or human adulteration of $\mathrm{H}_{2} \mathrm{O}$. The meanings of water, the ways that it becomes part of our lives, the methods by which it is known and represented to us and even the material forms that we give it and by which we relate to it, are constituted by social processes in conjunction with the process of water itself. To answer the overarching question in provisional terms, we might say that water is an ongoing collaboration, or conversation, between people and the ineffable process that is only slightly approximated by what many of us habitually call "the hydrologic cycle." 


\section{Relational Dialectics}

The idea of such a conversation is an important aspect of the dialectical approach that I take to water, to people, and to the mutual (hydro-social) relations that constitute us. Considering people and water in this way, both water and people are involved in the business of making each other, a business whose history can be traced, but whose future can hardly be predicted. This is an approach that I hope not to lose sight of throughout the writing of this essay. $I$ apply it in a very direct fashion (employing the term, "hydrolectics") in the penultimate chapter. In the mean time, I'm afraid there will be lots of meanders and diversions; ideas will condense, only to evaporate into apparent nothingness; there will perhaps be occasional spurts of brilliance, but these will be interspersed with seemingly endless expanses of aridity... You will have to bear with me.

For those who willingly subscribe to it, a dialectical approach might infuse the way a writer presents arguments, much like a sense of humour infuses a conversation. It is just as difficult to describe dialectics as to describe a sense of humour, so I hope that my approach will stitch together the pages that follow while revealing itself in the process of their getting written and read. I say this, partly because my exposition of dialectics can't survive without the words and the syntax, the story and the illustrations, the writer and the reader - and the (inevitable) contradictions

- that make it what it is. Nevertheless, I owe it to all these various parties to try and explain what I mean more clearly: 
"Dialectics" is a term that has been used to describe various approaches to reasoning and discoursing since ancient Greek times. (Mautner 1996:140-1). Even within the Marxist tradition, where it is most frequently located today, there are many divergent interpretations of dialectics. (Bhaskar 1999; Castree 1996:344). The particular dialectical practice that has influenced me the most is that of David Harvey, which Harvey describes as a "relational and dialectical approach to things" (1974:271),“a dialectical and relational approach" (1996:6), "relational dialectics" (1996:7) and a "relational conception of dialectics." $(2000: 15)^{4}$ Placing emphasis on the relational aspect of dialectics is especially important to me as, fundamentally, I subscribe to the view that things become what they are in relation to other things in an overall process that can be described as one of mutual becoming. The landscape makes the river what it is, which changes the landscape, which changes the river, which changes the landscape... ${ }^{5}$ Or, in fluvial geomorphological terms: “Bed morphology exerts a control on the processes and it generates a hydraulic environment where processes are initiated that will feed back onto the form... Form influences processes that will result in a modification of the form." (Roy and Lane 2003:111, 120) Or, as the breaking waves said to the sand, and the sand replied: "I would be nothing without you."

\footnotetext{
${ }^{4}$ The best introduction to, and summary of, Harvey's relational-dialectical approach is found in Chapter 2 of Harvey (1996). Noel Castree offers useful discussion of Harvey's dialectical approach as it is applied in critical human geography in Castree (1996).

${ }^{5}$ A similar dialectic pertains for rivers and people, as suggested by (historian of fluvial hydraulics), Helmut Schuerlein's "one great principle ${ }^{n}$ of fluvial hydraulics: ${ }^{4}$ Take the river seriously and consider it as a partner not as a servant." (Scheuerlein 1987:185)

6 This idea came from a song titled "I Could Be Nothing", performed by a band from Port Elgin, Ontario, named Great Lakes Swimmers; the song was written by band member, Tony Dekker; it is on the CD titled "Bodies and Minds", published by Harbour Songs, 2005.
} 
In a relational-dialectical view, the nature of "things" is contingent on the circumstances in which they become. Capital, to take a well known example, is something that owes its existence as a thing to other things like resources, labour and tools when these are brought into relation in a particular mode of production. The same may be said of resources, labour and tools, all of which become what they are in relation to each other, and to the specific mode of production that brings them into a particular kind of relation. Thus, dialectically speaking, things are always understood to be in relation to other things and to the processes that bring them together. But the particular way in which things are related is also an important aspect of dialectical thinking: Rather than having an independent and stable existence, things are, dialectically speaking, constituted internally by these very relations and processes, a form of constitution which makes them very dependent and unstable indeed. Resources, for example are always changing in relation to changes in the technologies and other social circumstances - such as the availability of capital and labour - that make various aspects of the environment resourceful; forms of labour are always changing in relation to changes in resources and technologies and the availability of capital; technologies are always changing in relation to changes in capital, resources and labour... The instability of such things within the dynamic process of capitalism serves perhaps as the best example of the dialectical principle that the only true constant is change itself. ${ }^{7}$

\footnotetext{
7 This paragraph represents my interpretation of large portions of Ollman (1993); Harvey (1996:46-
} 68) and Harvey (1974). 
What might be called the thingness of things is thus an important facet of dialectical thinking. Relational dialectics doesn't deny things their place in a limited, historical sense, but gives ontological priority to processes. David Harvey puts it like this:

"Dialectical thinking emphasizes the understanding of processes, flows, fluxes, and relations over the analysis of elements, things, structures, and organized systems... for dialecticians hold that elements, things, structures, and systems do not exist outside of or prior to the processes, flows, and relations that create, sustain, or undermine them. ${ }^{n}(1996: 49)$

For the most part, the dialectical approach has been applied by Marxists to gain critical and practical understandings of the things that arise out of what are construed as mainly social processes, the most notable of which is capitalism itself. One of the reasons why I find Harvey's relational dialectics appealing is because he deliberately uses a dialectical approach to gain understandings of things and processes that are less-obviously social in nature, such as aspects of the physical environment. (e.g. Harvey 1996) I will return to discuss the question of the proper object(s) of dialectical investigation in the concluding chapter. For now, let me say that things like water, which are often called "natural", may be understood in no less relational and dialectical terms than things like capital, which we acknowledge more readily as being the product of social relations.

This way of understanding things is seriously at odds with the contention that the only route by which we can discover their true nature begins by presuming 
a radical distinction between us and them. Although this contention has become a matter of common sense, it has a definite history, often associated with the name of Rene Descartes, who is widely acknowledged as one of the chief architects of the modern age. Descartes bequeathed to us "a conception of mind lying outside the purview of physics." (Mautner 1996:133) As pure thinking substance, the mind is made ontologically distinct from the body, which, like the rest of nature, is considered a form of extended substance. Thus, for Descartes, "it is certain that I am really distinct from the body, and can exist without it." (quoted in Mautner 1996:136) For Descartes and his intellectual heirs, the way things are properly known - the doctrine of objective knowledge - flows necessarily from this fundamental, ontological separation between thinking substance and extended substance. Thus, the mind (thinking substance) applies itself formally to the various objects (things, or extended substance) that constitute nature so as to produce true (scientific) knowledge.The sociologist of science and all-round gadfly, Bruno Latour, has written a history of this way of understanding things, in which he conjures the image of "a brain in a vat."

"By Descartes' time, [an earlier acceptance of relativistic certainty], based on the number of relations established with the world, was already in the past, a once passable path now lost in a thicket of brambles. Descartes was now asking for absolute certainty from a brain-in-a-vat, a certainty that was not needed when the brain (or the mind) was firmly attached to its body and the body thoroughly involved in its normal ecology." (Latour 1999:4) 
I am fond of the image of a brain-in-a-vat because it allows me to imagine

Descartes' brain floating in a vat of water (See Figure1.1). Water has a remarkable capacity to connect us with the world. The ancient Romans (at least the male freemen) didn't go to the public baths primarily to wash their private bodies of the dirt of the city; they attended the baths to cement a civic bond. "Cleanliness was a shared civic experience," writes the urbanist, Richard Sennett, "and a public bath was the most popular building a ruler could erect. The baths mixed the enormous diversity of the city together in a common nakedness." (Sennett 1994:139) But just as it has the capacity to bind things together, water has an equal capacity to undothe world completely, ${ }^{8}$ even if only to allow it to be put together again in some new and improved way, as Noah, or John the Baptist probably would agree.

The significance of the Biblical flood was that it ended after 40 days and 40 nights, allowing things to get established on a sounder footing thereafter. The significance of baptism by submersion is in the act of receiving the initiate as a child of God upon her emergence from below the water's surface. It would have been entirely pointless had the flood lasted forever, and rather cruel to hold the initiate underwater indefinitely; but returning to Descartes' brain, that seems to be what he had in mind!

\footnotetext{
${ }^{8}$ The distinction noted here fits Ivan Illich's description of "the age-old ambiguity of water, which is a surface and a depth, which can wash off dirt from the skin, by flowing, but also purify the depths of the soul with just a touch. These are totally different activities, washing and purifying." (quoted in Caley 1992:246)
} 


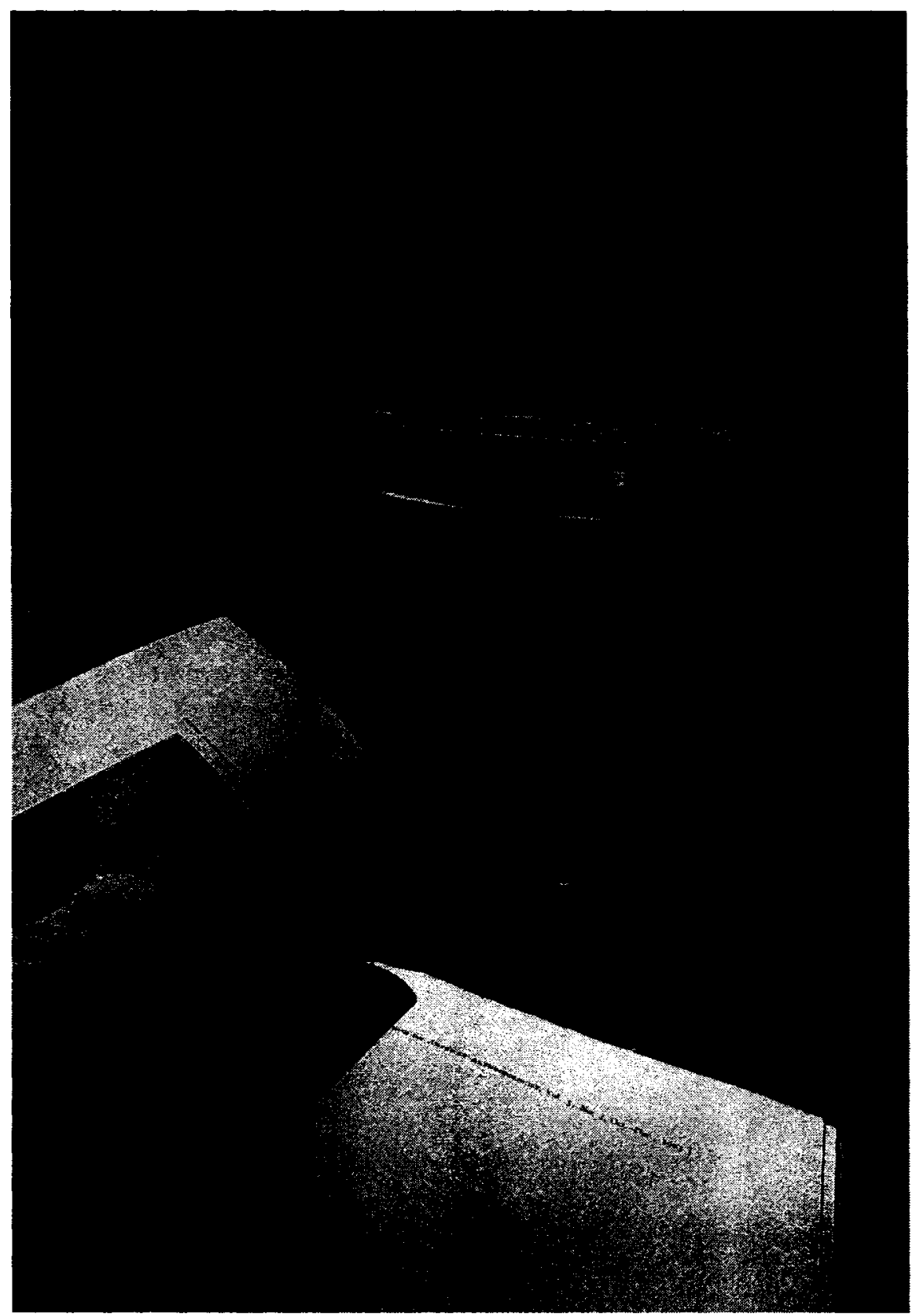

Figure 1-1 - A Brain in a Vat (reproduced from Miller 1994:115) (This isn't Descartes' brain, but that of John Wesley Powell, a famous water visionary and overseer of water in the late nineteenth century United States of America. The relevance of this particular brain-in-a-vat to the topic at hand will become apparent upon reading Chapter 6, particularly footnotes 6 and 10.) 
We have to agree on the impossibility of such a position: A brain can't survive in a vat, and it certainly can't learn anything there. A brain is what it is and can develop into what it might be only in relation to the body of which it is part, and only in relation to the world outside and through the body, of which the body and the brain are part, and only in relation to all the other brains, bodies and worlds that are floating around in the cosmic, public bath. ${ }^{9}$

Imagining that we can know the world as brains-in-vats is - as another science studies scholar, Donna Haraway, has famously put it - a "god trick." (Haraway 1999) Only by a concentrated act of abstraction can we imagine a position from which it is possible to know the one and true world. Such a position, for mortals at least, is impossible. For Harraway, the only truthful way we can know things is from our own particular, embodied positions - positions that are unavoidably embedded in the world - by saying that all knowledge is "situated." (Haraway 1999) The important point that I take from Haraway's idea of situated knowledge is that we myself in particular - can only know things from the embodied, enculturated, matriculated, gendered and privileged position that I inhabit. To this, I would add that my position is always changing and accordingly, the circumstances in which I know things, as well as the things themselves, are never permanently fixed.

\footnotetext{
$9{ }^{~ " T h e ~ w o r l d " ~ a s ~ M a u r i c e ~ M e r l e a u ~ P o n t y ~ w r o t e ~ i n ~ P h e n o m e n o l o g y ~ o f ~ P e r c e p t i o n, ~ " i s ~ i n s e p a r a b l e ~}$ from the subject, but from a subject which is nothing but a project of the world, and the subject is inseparable from the world, but from a world which the subject itself projects." (quoted in Varela, Thompson and Rosch 1991:4). The relational-dialectical approach that I have in mind is consistent with this "fundamental circularity in scientific method" or "deep circularity" between mind-body and world developed by Varela, Thompson and Rosch. (1991)
} 


\section{Relational Dialectics of Water}

It might seem that this permanent state of uncertainty should be a very difficult position from which to write an academic thesis. However I intend to show that it makes an excellent foundation for the investigation of water. I am by no means the first to think this way. Heraclitus' famous dictum that you can't step into the same river twice suggests a very long line of people who take water to be, if anything, the very principle of taking nothing for granted. You can't step into the same river twice because with each new step, both you and the river have changed; and in the dance of stepping and flowing, both the river and you can't help but change each other. We may step gingerly, as did Siddhartha, who merely crossed the river on numerous occasions and contemplated it sufficiently to irrevocably change himself, and a good portion of the world (if we consider the influence of the Buddha's teachings). We may also take heavy steps: Placing a dam in a river is a heavy step, but in a dialectical sense, not fundamentally different from merely crossing it. That we change the river with a dam is perhaps obvious. That we, in association with the river and the dam, change ourselves by placing the one within the other, is something that others who think dialectically have elaborated in a way that has helped me arrive at my understanding of the relationship between water and people. Karl Wittfogel, about whom more will be said below (in Chapter 2), begins his classic study of the political economy of ancient "hydraulic societies" as follows:

"Contrary to the popular belief that nature always remains the same - a belief that has led to static theories of environmentalism and their equally static rejections - nature changes profoundly whenever man, in response to simple or 
complex historical causes, profoundly changes his technical equipment, his social organization and his world outlook. Man [sic ${ }^{10}$ never stops affecting his natural environment. He constantly transforms it; and he actualizes new forces whenever his efforts carry him to a new level of operation." (Wittfogel 1957:11)

Wittfogel devotes the bulk his study to showing how human society is changed in a particular way as a result of certain changes that it makes to nature. Wittfogel's argument, in a nutshell, is that because of the high degree of social coordination necessary to build and maintain large hydraulic structures like dams and irrigation systems, hydraulic society is characterized by despotic political regimes. I will criticize some aspects of Wittfogel's study below, but his basic dialectical approach to the relationship between water and people is one that I share. The environmental historian, Donald Worster, has applied the same approach in writing a history of the modern, twentieth-century hydraulic society of the Western United States. Worster's position is,

"to regard nature as participating in an unending dialectic with human history, seeing the two, that is, as intertwined in an ongoing spiral of challenge-responsechallenge, where neither nature nor humanity every achieves absolute sovereign authority, but both continue to make and remake each other...

In the case of irrigation, an ecological view of history would hold that aridity has been a crucial, though not a rigidly deterministic experience for people to deal with. Whenever they attempted to overcome that condition, they gave a new shape to the environment, creating artificial rivers with dams, aqueducts, and the like. But it was not simply a one-way process of humans re-creating nature. Society, even in its so-called triumphs, inescapably came to bear the mark of the

\footnotetext{
${ }^{10}$ This is the first and only time that I will highlight the way humanity, or society, is gendered male in a great deal of writing that deals with the relationship between people and nature. The corollary that nature is implicitly gendered female in such writings will be noted in several places, but the reader should note that this is always the case whenever "man" is used to signify humanity or society.
} 
desert and of its own effort to overcome the environmental exigencies there." (Worster 1985:22)

The dialectical understanding of water and people that Wittfogel and Worster describe in their writing is applied mainly to gain critical insight into the constitution of societies in places like ancient China and India and in modern America, and it is these societies that are the main subject of their respective inquiries. One distinction of my study is that I am mainly interested in gaining critical insight into how this relation constitutes water in the modern, Western world. Of course, the constitution of modern water both reflects, and contributes to, the constitution of modern society, and so I won't be able to avoid wading into this particular stream of thought myself.

In the process of explaining somewhat more concretely what I mean by a dialectics of water, I should warn that the text that follows is flooded with wordplay, as might be expected of an effort to get to the bottom of something so perfectly bottomless as water. Playing with words, my intention is to write of something that is between and beyond the mutually constituting abstractions of nature and culture. Here, I join a growing crowd of wordwarping geographers who feel at home with some rather odd metaphors, which, in Bruce Braun's words, "strive to capture this sort of relationality: networks, webs, assemblages, rhizomes, cyborgs, topologies, cartographies." (2002:266; see also Castree 2005:223-242) Furthermore, I am prone to literally mixing water with the things of which it is made by playing with the prefix, "hydro"; thus hydrosocial relations, hydrolectics, hydreification and the like. 
Alluding to such linguistic liberality, Sarah Whatmore has taken note of a "shift in the vocabularies of cultural geography [that] promises to be particularly important for the terms on which the human and the non-human are admitted into geographical analysis, permitting more promiscuous and volatile configurations of the social and the material that complicate the labored divisions and rapprochements between culture and nature."(Whatmore 2002:166) I appreciate that for some readers, such promiscuity may seem lacking in humour; it might even strike some as blasphemous. But as Donna Haraway has been careful to observe, "Blasphemy has always seemed to require taking things very seriously." (2004:7)

A relational-dialectical approach permits the simultaneous assertion of the seriousness and the unnaturalness of things like water. Flowing from its emphasis on processes, is the assertion that "change and instability are the norm and that the appearance of the stability of 'things' or systems is what has to be explained." (Harvey 1996:54) ${ }^{11}$ But explaining things this way doesn't mean that they are not real or important. Harvey even makes a "claim for the superiority of the dialectical view, precisely because it allows for an understanding of 'things' and systems as if they are real and stable as special case of the proposition that processes are always at work creating and sustaining 'things' and systems." (1996:61-62) Furthermore, as Harvey points out, such things and systems may internalize such a wide range of relations and processes as to become "endowed with causal

\footnotetext{
11 "If, as is intuitively obvious, the physical world around us appears to be constituted by what [the philosopher of science, A.N.] Whitehead calls 'permanences' - relatively stable configurations of matter and things - then the issue of how such permanences are maintained yet also integrated into a dynamic world of processes becomes a critical subject of analysis." (Harvey 1996:55)
} 
powers." (1996:82) Relational dialectics, in other words, offers a particularly useful approach for critical investigations of the thingness of things.

A relational dialectics of water takes as its starting point that, in every particular instance, water is nothing but what we make of it. This formulation, with which I began the chapter, might now be seen as the hydrological imperative of a relational-dialectical view of things. However, in the first instance, water - i.e. the "it" of which we make every particular instance of water - is construed herein as a process. The specific ontology of this water process is something that l'm not yet prepared to specify, except to say that it is that out of which every specific instance of water gets abstracted. ${ }^{12}$ The term "reification" is often used in dialectical discourse to describe the way abstractions can be misconstrued as fixed, stable things in themselves. ${ }^{13}$ To say that something has been reified means that it has acquired a kind of concreteness, which can misdirect attention from the processes and relations that make it what it is, to the apparent concreteness of the thing itself. ${ }^{14}$ Instead of underlying processes, the reification of things gives ontological priority to the things themselves, and thereby allows for changes in internal

\footnotetext{
12 There's a somewhat more substantial discussion of the water process in the concluding chapter. ${ }^{13}$ Reification has been defined as "the turning of something into a thing or object; the error which consists in treating as a 'thing' something which is not one. Hypostatization, treating an abstract entity as if it were concrete, is a case in point." (Mautner 1996:479)

14 This is a "fallacy" characteristic of the kind of scientific investigations inspired by Cartesian method. The philosopher of science, Alfred North Whitehead, described "the fallacy of misplaced concreteness" as "one example of a general danger inherent in modern science... It fixes attention on a definite group of abstractions, neglects everything else, and elicits every scrap of information and theory which is relevant to what it has retained. The method is triumphant provided the abstractions are judicious. But, however triumphant, the triumph is within limits." (quoted in Daly and Cobb 1989:36)
} 
relations to be misconstrued as external change. While dialecticians tend to use the concept of reification to describe an epistemological error, it is hardly considered in this way by most contemporary producers of knowledge, whether in the natural or the social sciences. Bertell Ollman, a philosopher whose work has influenced Harvey, notes:

"In the view which currently dominates the social sciences, things exist and undergo change. The two are logically distinct. History is something that happens to things; it is not part of their nature. Hence the difficulty of examining change in subjects from which it has been removed at the start." (Ollman 1993 29, and quoted in Harvey 1996:62)

In applying a relational-dialectical approach to water, I want to show that in every instance, what counts as water has a social history and is subject to change as a consequence of changes in the social processes that make and unmake it. As a concise way of describing the act as well as the thing by which water gets abstracted and fixed, I will use the term "hydreification". Accordingly, water gets hydreified as an "element", a "resource", a "commodity", a "chemical compound", a "gift of God", a "source of life" or indeed as any-thing that imbues water with an essential, intrinsic quality, or ascribes to it a particular nature. Hydreifications tend to get held fast in recursive webs of social processes involving things like language, religious practices, the circulation of capital, laws of the state, municipal infrastructure, social customs, international trade, the production of electricity, bottles... Because such fixations - like hydro reservoirs and bottled water are the product of mixing the water process with social processes, they perform a kind of political work in the sense that they strengthen some social relations while making 
it difficult for others to establish or sustain themselves. To treat - and treat of water as a bottled commodity, for example, permits some people to sell it; to treat of water as a resource allows some people to use it as a means to whatever ends they may have the economic and technological capacity to effect. In either case, myriad alternative, potential meanings and relations with water may get ignored or shunted aside, and along with them, the people for whom such meanings and relations may be constitutive of life and livelihood. The business of hydreification, in other words, is hardly just an intellectual performance; in each instance, it allows for certain hydrosocial realities while making it difficult or impossible for others to spring to life. The meanings of water that get fixed in any particular time and place can thus be seen as a function of the relative power of different social actors. As a corollary to the power relations that get internalized in any particular hydreification, studying the business of hydreification may be regarded as a fundamentally critical project: the implication of investigating how water and society hang together is to show that they can be taken apart and reconstituted in different ways.

Harvey uses the example of the nation state to show how things hang together and how they may be taken apart: "[T]he nation state," he points out, is

"a relatively recent product of concentrated power in human history, has just such an air of a permanence precisely because it successfully internalizes a wide range of desires and beliefs, discourses, social relations, and institutional and material practices and has thereby become an entity endowed with causal powers. But, as the case of the Soviet Union so well demonstrates, it would be equally silly to accept those causal powers as permanently given, independent of how social processes produce entities." (1996:82) 
Modern water has the potential to lubricate social processes in ways that are conducive to socio-political and hydrosocial health. But this is by no means always the case. Like the nation state, modern water isn't above criticism, and any discomfort occasioned by the spectre of its dissolution needs to be tempered with an awareness of the wealth of potential reconstruction that it might unleash. Having asserted from the beginning that water is what we make of it, the political (or practical) significance of this potential might be obvious: The world is full of water problems; these problems are entirely of our making; a dialectical approach offers one way of responding creatively to them.

Finally, to move along toward the next section, dialectics offers a useful way of considering what might be called the social nature of water. "Social nature" is a term that has been used by many geographers in recent years to describe the increasingly unavoidable fact that nature, in both material and conceptual senses, is a product of social relations. ${ }^{15}$ Increasingly, scholars and non-scholars alike are coming to an understanding that nature is what we make of it.

\section{Social Nature}

The work of literary scholars, anthropologists, cultural historians, and critical theorists over the past several decades has yielded abundant evidence that 'nature' is not nearly so natural as it seems. Instead, it is a profoundly human construction. This is not to say the nonhuman world is somehow unreal or a mere figment of our imaginations - far from it. But the way we describe and understand

${ }^{15}$ A good introduction to "social nature" in academic geography is Castree and Braun 2001. Although he backs off from use of the term "social nature" somewhat, Castree 2005 is also an excellent introduction, as are Braun and Castree 1998a, 1998b and Braun 2002. 
that world is so entangled with our own values and assumptions that the two can never be fully separated. What we mean when we use the word 'nature' says as much about ourselves as about the things we label with that word. (Cronon 1995b:25)

Like all things understood dialectically, new ideas emerge in relation to social and natural processes and these processes are affected by the emergence of new ideas. Ideas crystallize out of the socionatural flux, have the effect of changing society-and-nature, and help forge a new set of socionatural circumstances out of which new ideas are formed. There is no beginning to this process that we know of, and no end that we hope for. So let's jump-in to consider the historically-andgeographically specific idea/ology that nature and society are remain separate, distinct entities. "This separation" as William Leiss points out, "is as old as human society itself; but only in Western society was it elevated to the status of a conscious principle for the orientation of human behaviour." (Leiss 1974:xi) As noted above in our discussion of Rene Descartes and his brain, this principle became methodically entrenched with the development of modern scientific practice in Western Europe beginning approximately in the seventeenth century. The "Scientific Revolution" ${ }^{16}$ represents a more or less deliberate intellectual disentanglement from a world where the nature of things was revealed directly in ancient texts (Shapin 1996:65-117) ${ }^{17}$ and indirectly in the resemblances and

\footnotetext{
${ }^{16}$ The term "revolution" is something of a misnomer. Steven Shapin points out that "no house is ever built of entirely virgin materials", suggesting that the new natural philosophy that emerged with the likes of Francis Bacon and Rene Descartes retained important aspects of earlier philosophy. (Shapin 1996:66-67)

17 Shapin describes the contemporary philosophical sentiment thus: "What was said to be overwhelmingly wrong with existing natural philosophical traditions was that they proceeded not from the evidence of natural reality but from human textual authority. If one wished to secure truth
} 
correspondences between things (Foucault 1970) ${ }^{18}$, to a world where only men

who applied objective methods to pursue and probe her could reveal nature's

secrets. (Merchant 1980) Nature thus became widely conceived, and materialized,

about the natural world, one ought to consult not the authority of books but the authority of individual reason and the evidence of natural reality." (1996:68-69)

${ }^{18}$ Foucault describes a rupture between what he calls the "Renaissance" episteme" and the "Classical episteme" occurring approximately in the middle of the seventeenth century. The former is characterized by an epistemological stance whereby: "To search for a meaning is to bring to light a resemblance. To search for the law governing signs is to discover the things that are alike. The grammar of beings is an exegesis of these things... The nature of things, their coexistence, the way in which they are linked together and communicate is nothing other than their resemblance. And that resemblance is visible only in the network of signs that crosses the world from one end to another." (Foucault 1970:29) Within such a knowledge regime, or episteme, language is not an arbitrary system; there was no fundamental ontological gap - no incommensurability - between words, or signs, and things, and thus the reality of things could be found in the sign itself. The latter (Classical) regime of knowledge, in contrast, was dominated by the ideology of representation, which acknowledged an ontological gap between words and things but sought to bridge it by the relationship of signification. (see Golinsky 1998:152-3). Although Foucault's periodization of this epistemological shift is questionable, his distinction between "Renaissance" and "Classical" epistemes is a useful contribution to understanding modern approaches to nature. I also want to add that this distinction is particularly interesting from a hydrological perspective: In a universe of resemblances, to search for meaning and find the nature of things is "to bring to light a resemblancen - a process comprising a variety of hermeneutical methods, of which the detection of correspondences and sympathies, ranks among the most important. In accordance with the doctrine of resemblance, "sympathy creates communication between our bodies and the heavens, and transmits the movement of the planets to the affairs of men." (1970:29) But sympathy also allows for, and authorizes communication between our bodies and entities inhabiting the sub-lunary world as the foundation of our knowledge thereof. In an epistemological regime that accords to sympathy the status of a legitimate mode of knowing, "Divination is not a rival form of knowledge; it is part of the main body of knowledge itself... (1970:32) With respect to hydrological knowledge, an obvious implication of this premodern (Renaissance) episteme is in its according legitimacy to the irreducibly human nature of divined water. Here the human body is the instrument, the movement of the divining rod the sign, of the sympathetic intuition of water. Such a mode of knowing water is entirely illegitimate in a regime of knowledge that denies the epistemological validity of such sympathies. Divined water, thought the scientists, had to be obliterated root and branch in order for modern water to take form. Simon Schama gives a particularly telling account of how the members of the Acdademie Royale staged a public experiment in the 1690s, the aim of which was to ridicule a legendary water diviner. (Schama 1995:350-352) The systematic effort to deny the legitimacy of divined water has been carried on over the centuries. In the 1920s, the International Association of Scientific Hydrology was established, the word "scientific" being appended in order to distinguish the field "from the charlatans and simpletons who, with the help of all sorts of rods, tried to find water and called themselves hydrologists." (Volker 1983:52) But despite all efforts to the contrary, the practice, and popular faith in, water divining as persisted, even in the most modern, industrialized nations, and well into the twentieth century. Raymond Furon reports, for example, that there were 25,000 diviners working in the United States in the 1960s. (Furon 1967:119-122) The persistence of divined water is perhaps best explained in the terms appropriate to its (non-scientific) nature as offered by Schama: "For though we may measure it with our mathematics, it is the vital sap of green trees and the pulse of our blood that will, in the end, reveal its circulation." (Schama 1995:352) 
as a separate and distinct realm - the "other" to man/society, a thing that could be laid bare by the application of formal methods and incisive tools. The residence of nature and society in separate spheres, which do not admit of internal relations, is a core intellectual commitment of modernity.

The world that is produced by the conceptual, material and discursive tools of bisection and individuation has long begun to show signs of falling apart - or rather coming together. These signs were apparent to some by the early twentieth century, as the "telluric force" ${ }^{19}$ that humankind had become, began to destabilize the bedrock of eternal, external nature. In the 1920s, A.N. Whitehead reported the prevalence of "a muddled state of mind" arising from the fabrication of a kind of nature that no longer fit the model. "The increased plasticity of the environment for mankind, resulting from the advances in scientific technology, is being construed in terms of habits of thought which find their justification in the theory of a fixed environment." (Whitehead 1925:105) Whitehead did much to unfix the environment by, among other things, interpreting the theories of relativity and quantum mechanics for an audience that went beyond the purveyors of theoretical physics. And it has been due in part to the changing "habits of mind" occasioned by inuring ourselves to such an uncertain physical world that today, nature's "plasticity" is taken in a conceptual as well as a material sense.

19

Earlier for some, as for G.P. Marsh, who applied term "telluric force" to humankind. (Marsh 1864) There were many, many others who adopted this perspective (indeed, it could be construed as one of the three themes identified by Clarence Glacken in his study of the history of the concept of nature) including Marx who was highly attentive to the anthropogenic production of "second nature", but was less directly interested in its destabilizing function (environmentally or conceptually) than a Marsh or a Whitehead. 
It is within the urgent intellectual discussion that necessarily ensues under such unstable conditions that I situate this essay. But while I'm still in the mode of framing what follows, it is important to say that in addition to the material and intellectual crisis of nature, the idea that nature and society are separate, distinct entities subject to different methods of acquiring knowledge, is increasingly felt as well as thought to be untenable. The main reason for this growing discomfort is, it seems, an apprehension that the psychic as well as the material effects of this separation are not conducive to good health: The health of nations is torn apart by the demands of an economic sphere that has long been methodically separated, or disembedded, from the social relations that give it meaning (Polanyi 2001); the health of human communities is compromised by the injustices permitted in the name of such things as natural resources, natural advantage and natural selection, which in an increasingly globalized world are no longer tolerable (Daly and Cobb 1989; Stiglitz 2002); the health of the collective of human and other living things as well as the organisms constituting it is under such strain "that the ability of the planet's ecosystems to sustain future generations can no longer be taken for granted." (Millennium Ecosystem Assessment Board 2005:2) If health is wholeness, the separation of nature and society represents a constitutional error of the first order. That we, or rather some of us, have survived, even thrived, under this misapprehension attests to the magnitude of the imbalance that has to be corrected, or the degree of healing that needs to take place.

Whether or not one agrees with my concise version of the malaise of modernity, a growing number of people are engaged in rethinking and reconstituting relations 
between society and nature. The present effort to do so is but one momentary drop in a tidal wave of scholarly (and more general) endeavour to dissolve and reconstitute these things. This intellectual movement is discernible in a wide variety of academic disciplines, as suggested in the quote by the geographer and environmental historian, William Cronon given at the beginning of this section. ${ }^{20}$ My own views on the reconstitution of the relationship between society and nature have been informed by readings in environmental history, philosophy, anthropology and the history and philosophy of science, among other fields. ${ }^{21}$ But it is in the more recent geographical literature exploring the meaning and materiality of nature that has been most influential in orienting the present study. ${ }^{22}$

Writing and thinking in the geographic tradition could arguably be defined as attending to the question of the place(s) of "nature and culture in Western thought", to quote from the subtitle of Clarence Glacken's classic study in the history of the

\footnotetext{
20

The quote is drawn from Cronon's introductory chapter of a collection of papers presented at a multi-disciplinary conference contributing to the general intellectual project he describes as "nothing less than rethinking the meaning of nature in the modern world." (Cronon 1995b:24) The critical geographical work done under the banner of "social nature" draws from, and contributes to this project. Braun and Castree make reference to work produced by "anthropologists, cultural analysts, ethnographers of science, philosophers, and sociologists as part of what is now a genuinely interdisciplinary concern with how societies recraft the natural." (Braun and Castree 2001:xii)

21 Some examples of the literature that has been influential in my own approach to social nature from these fields, respectively, include: Cronon 1983,1995, 1991; Schama 1995; White (1995); Soper 1995, 1996; Hayles 1995; Escobar 1995, 1996, 1999, 2001; Golinsky 1998; Levins and Lewontin 1985. Castree and Braun have noted how "Over the past fifteen [now twenty] years an exciting, diverse, interdisciplinary field of critical theory has emerged which.... seeks to explain and illustrate the many ways in which nature is constructed and reconstructed within modern and late modern societies." (1998:4)

22 Particularly: Harvey (1996): Braun and Castree (1998a); Castree and Braun (2001); Braun (2002); Castree (1995, 2000; 2001a; 2001b; 2003; 2005); Demeritt (1994; 2001a, 2001b, 2002); Swyngedouw $(1996,1999,2004)$.
} 
idea of nature. (Glacken 1967) David Livingstone has suggested that for over a century, the practice of academic geography is rooted the ideal of bringing nature and society "under one conceptual umbrella." (Livingstone 1992:177) Whether such an ideal is possible or even desirable is questionable. ${ }^{23}$ In any case, academic geography can fairly lay claim to being more hospitable to those interested in the relations between nature and society than perhaps any other discipline. (Castree 2005:45-107) Sarah Whatmore has even argued that geography "stakes its disciplinary identity on being uniquely concerned with the interface between human culture and natural environment." (Whatmore $2002: 165)^{24}$

For approximately the last dozen years, geographers who have made this "interface" their main interest have done so under the banner of "social nature." Although it comprises many different approaches, broadly speaking, "social nature" differs from earlier work exploring the relationship between nature and society by subjecting the very concept and identity of nature to critical scrutiny. Margaret Fitzsimmons, who brought the term into academic geographical discourse in 1989 ,

\footnotetext{
${ }^{23}$ This debate itself has sparked a good deal of geographical thought. For a good general discussion, see Castree 2005.

${ }^{24}$ Similar formulations hold that "geography is widely accepted as a discipline that provides "knowledge about the earth as the home of humankind." (Johnston 1986, quoted in Hubbard et al. 2002:11); "Geography explores the relationship between the Earth and its peoples through the study place, space, and the environment." (Welsh Department of Education and Science 1990, quoted in Hubbard et al. 2002:11); Today, as Richard Peet argues, for many geographers the discipline boils down to "the study of the relations between society and the natural world." (Peet 1998:1)
} 
defined "social nature" in terms of "the geographical and historical dialectic

between societies and their material environments." (1989:106)

"Consider the proposition that Nature as we know it was invented in the differentiation of city and countryside, in the differentiation of mental and manual labor, and in the abstraction of contemporary culture and consciousness from the necessary productive social work of material life. Try to see Nature, like History, Geography, and Space, as a material, practical and conceptual reconstitution and reification of what are essentially social relationships." (Fitzsimmons 1989:108)

The notion that nature should be seen as a "reification of what are essentially social relationships" differs considerably from the approach to nature embodied in other branches of geographical research. Growing concerns about human impacts on the environment beginning in the 1960s gave rise to what Noel Castree has termed "people and environment" and "ecocentric" approachs to "the naturesociety problematic" in geography. While these differ in important respects ${ }^{25}$, Castree points out they are both based on a presupposition that nature is, "at some level, fixed and/or universal". (Castree 2001:5) Beginning around the time of

\footnotetext{
25 The "people and environment" perspective has roots in nineteenth century geography and is associated more recently with efforts to re-integrate physical and human aspects of geography to tackle "the big questions of our era concerning the problems and possibilities resulting from human alteration of natural resources, environments and organisms." (Castree:2001:2) Castree argues that it is "intellectually limited" because it equates nature with "environmental problems" and excludes other important human-nature relations like agriculture, forestry and other sites of nature such as the human body. He also argues it is politically biased because the knowledge it produces is technocratic, and tends to serve dominant interests. Castree includes studies in resource management and in the promotion of sustainable development in this category. Critical geographers are hostile to this approach, for among other things, it "wrongly assumes that it's possible to know nature 'as it really is', such that when people interact with nature they are dealing with things that are, inter alia, non-social." (2001:4) According to Castree, the "ecocentric" approach is of more recent providence and "urges a fundamental respect for, and need to get back to, nature." This approach is associated with the "green movement" and calls for a "profound critique and dismantling of existing systems of production and consumption. (2001:3)
} 
Fitzimmons' intervention, nature has been brought into geographical discourse in a radically different way: Social nature...

“...sees nature as inescapably social. Here the argument is that nature is defined, delimited, and even physically reconstituted by different societies, often in order to serve specific, and usually dominant, social interests. In other words, the social and the natural are seen to intertwine in ways that make their separation - in either thought or practice - impossible." (Castree 2001:3)

Social nature, in other words, treats of nature in a critical sense, as an outcome of social relationships rather than as some-thing about which it is our main duty to gain and apply objective knowledge. The theoretical approaches that inform this "nature-sceptical stance"26 differ markedly from the more positivist approaches that characterized earlier geographies of people and nature. (Peet 1998:23-27; Unwin 1992:Ch. 5) Castree and Braun highlight three main "theoretical tools", that have been particularly useful to geographers who take a nature-sceptical stance: Marxist political economy, poststructuralism, and science studies. (Castree and Braun 1998) Because my approach to water is influenced by all three, a brief description of each is in order:

Marxism and the production of nature - My indebtedness to Marxist thought in orienting an approach to water has already been suggested above in the discussion of relational dialectics. Marxism embodies a tradition that has long

\footnotetext{
26 This is a term used by the philosopher Kate Soper, and quoted by Castree to describe the tendency of geographic orientation to nature in the 1990s. (Castree 2005:89-90) The question of "nature-sceptical" vs. "nature-endorsing" approaches is discussed in Chapter 11.
} 
complicated dualistic treatments of nature and culture, and has been an inspiration for many others who have engaged in a critique of modern ideas of nature, including David Harvey, Neil Smith, Noel Castree and Erik Swyngedouw. ${ }^{27}$ The mixing together of labour with the earth in Marx's theorization of the production process, creates "a whole world of new relations between people and nature [in which the separation of] natural history from social history becomes extremely problematic." (Williams 1980:76) The Marxist tradition thus encourages an approach that thoroughly historicizes nature. From Gyorgy Lukacs, we are thus given to understand:

"Nature is a societal category. That is to say, whatever is held to be natural at any given stage of social development, however this nature is related to man and whatever form his involvements with it takes, i.e. nature's form, its content, its range and its objectivity are all socially conditioned." (quoted in Young 1991:399)

Among several elaborations of the Marxist approach to nature, Neil Smith's 1984 book Uneven Development should be mentioned as having had a important impact on critical geography and social nature in particular. (Johnston et al. 2000:643-644; Braun and Castree 2001:xi) Smith draws on Marxist economics and on the work of other theorists to argue that space is not simply a field or container in which things happen, but is socially constituted, or produced by social relations. The production of space, in turn, "is premised on a more basic production process, one which sounds even more quixotic and which jars our traditional acceptance of what had

\footnotetext{
27 All of the publications listed in the bibliography under these authors' names would serve as examples.
} 
hitherto seemed self-evident." This basic production process Smith defines as "the production of nature..." (Smith 1984:xii) By this process, nature is re-made by society through the mediation of labour and capital. The production of nature is a material phenomenon: "[S]pecific pieces of matter the world over are produced (that is, their form is changed) according to the abstract laws, needs, forces and accidents of capitalist society." (Smith 1984:62) Moreover, as capitalism extends its reach worldwide, a larger and larger portion of the planet is remade in its image: "No part of the earth's surface, the atmosphere, the oceans, the geological substratum or the biological superstratum are immune from transformation by capital." (Smith 1984:56) For Smith, as the world becomes increasingly commodified under global capitalism, nature is altered - produced. The production of nature thesis offers a useful explanation of how and why anthropogenic changes in the material world have taken place on such wide scale. It addresses what is "arguably the single most important process... of capitalist restructuring in which reconfigurations of the environment, and the politics associated with the construction of new 'natures', take centre-stage." (Swyngedouw 2000:267)

Poststructuralism and Discourses of Nature - Smith criticizes reified concepts of 'universal nature' or 'human nature' in terms of "ideologies". (Smith 1984:17) This critical project has been eclipsed more recently by the emergence of poststructural critiques of nature. Poststructural analysis looks beyond the relations of production to consider how the meanings and materiality of nature are constructed in discursive practices; it gives attention to how discourses "infuse our relation with 
nature at every turn, including even at the micro level of knowledge and practice." (Castree and Braun 1998:17) Through such critical study, the power-interests that underlie and sustain particular representations of what is 'natural' are laid bare and contested. Poststructuralist approaches have been effective not only in challenging dominant ideas about what is natural; they have also "invited us to view the very idea of nature - the idea of that which has standardly been opposed to culture - as itself a cultural formation." (Soper 1995:6)

One of the main objects of such (poststructural) analysis is to 'deconstruct', or 'historicize' representations of nature - to make visible the particular discourses that have the effect of enframing nature in particular ways, so as to legitimize certain socio-natural relations while denying others. Among the more notable studies to have applied this kind of analysis is Bruce Braun's The Intemperate Rainforest, in which the argument that "nature's externality is merely an effect produced through the discursive and material practices of everyday life" (Braun 2002:x) is applied to an historical-geographical study of the British Columbia coastal rainforest. Braun considers discursive practices (including visual discourses) that have enframed the forest in such a way as to permit certain extractive and recreational activities while erasing and excluding "the spatial and economic practices" of First Nations groups. $(2002: 8)^{28}$ In showing how "... what counts as the forest is an effect of power" (2002:9), Braun illustrates how some-

\footnotetext{
28

His specific focus is the forest of Clayoquot Sound on Vancouver Island and the Nuu-chah-nulth people who inhabit this place.
} 
thing that is usually understood to be naively and naturally given - i.e. the forest actually gets made in such a way that it internalizes specific social relations and interests.

Although modern water is rooted in particular places and times (see especially Chapters 4-6), my study differs from Braun's in that it is focused on a presumed-tobe-universal concept rather than a particular place. I therefore consider a very wide (eclectic) range of histories and discourses that contribute to the apparent nature of water. Despite these differences, I hope to do for water something like what Braun has done for the forest.

Science Studies - Another field of intellectual activity that is complicating traditional views of nature these days, is described variously as "science studies" (Latour 2000), "the sociology of scientific knowledge" (Castree and Braun 1998), and "science and technology studies." (Schneider 2001) Science studies refers, broadly speaking, to analysing the production of scientific knowledge as a social phenomenon. With origins often associated with the work of the philosopher of science Thomas Kuhn (1970), science studies are constructionist in the sense that scientific practice and the knowledge that it produces are understood as the effect of scientific discourses and practices rather than a reflection or representation of an independent, objective, non-social reality. Science studies examine how scientific practices are embedded in historical, social and cultural contexts and how the knowledge that they produce reflects these contextual circumstances. 
Among the key questions that scholars in science studies are most concerned with relate to the "epistemological deadlocks", the dangers and absurdities that arise from the modern, Western dichotomy of nature and culture, a dichotomy that is greatly strengthened in modern scientific practice. (Biagioli 1999:xv; Latour 1993; Sardar 2001)

The pursuit and entrapment of water in scientific practice is an important aspect of my thesis insofar as I intend to show the extent to which modern water is an effect of scientific discourse. I have accordingly approached the history of water science below (especially in Chapter 5) from a "constructivist history of science perspective", which is rooted in science studies. (Golinsky 1998)

While there are important differences and contradictions between the three approaches described above ${ }^{29}$ I have found them all useful when considering the nature of water. That the discussion below rubs together dialectics with discourses and (inscription) devices reflects a rather syncretistic approach, which seems only appropriate to the question at hand.

\section{Excursions and Incursions}

Before finishing this introductory chapter with a more concrete discussion of what I mean by "modern water", I want to acknowledge a portion of the work done by

\footnotetext{
${ }^{29}$ Harvey (1996:46-95) can be read as a discussion of the difficulties inherent in making relationaldialectics compatible with post-structuralism.
} 
geographers that relates more or less to my topic. The present effort differs from most previous geographic excursions into the bog of hydrosocial relations by explicitly setting out to denaturalize water. In an important respect however, I share a common goal with earlier researchers: Among those of another generation were geographers who considered water as a kind of medium for the conviviality of things and of people that otherwise are presumed to occupy separate worlds. "In no other major area of geographic concern" wrote Richard Chorley and Robert Kates in 1969, "has there been such a coalescence of physical and human geography, nor has there developed a dialogue comparable to that which exists between geographers and the many disciplines interested in water." (Chorley and Kates 1969a;b:4) In an earnest effort to reconcile, if not to integrate, the two houses of their discipline, Chorley and Kates argued that "the study of water provides a logical link between an understanding of physical and social environments...

The reader of this volume is thus confronted by one of the great systems of the natural world, the hydrologic cycle, following water through its myriad paths and assessing its impact on earth and man. The hydrologic cycle is a great natural system, but it should become apparent that it is increasingly a technological and social system as well. It has been estimated that $10 \%$ of the national wealth of the United States is found in capital structures designed to alter the hydrologic cycle: to collect, divert, and store about a quarter of the available surface water, distribute it where needed, cleanse it, carry it away, and return it to the natural system... The social and political system is also pervasive and equally complex, when one reflects on the number of major decision makers involved in the allocation and use of the water resources." (Chorley and Kates 1969a;b:3-4)

\footnotetext{
${ }^{30}$ The paper from which this quote is taken introduces a book edited by Chorley that was titled Water, Earth and Man: A Synthesis of Hydrology, Geomorphology, and Socio-Economic Geography, (Chorley 1969) This book is judged by Noel Castree to have been one of the few, and
} 
The idea that (the study of) water is conducive to a blending of the natural and social categories corresponding to the two major branches of academic geography goes back even further, approximately to the moment when the discipline bifurcated. In his 1931 Presidential address to the British Association of Geographers, Halford Mackinder suggested water as "the central theme of geography", noting that "essentially both Physical and Human Geography are concerned with the carriage and storage of energy on the surface of this earth, and the vehicle is the Protean element, water." (quoted in Matless 1992:585) A dozen years later, and a continent away, Gilbert White instigated a highly successful programme of study that integrated hydrological with social phenomena to produce what might be called a hydro-social approach to floods. (White 1945) White's work on floods has given rise to a school of geographic research that attends to the importance of social relations in the perception and management of floods and other "natural hazards". (Hewitt 1983; Progress in Human Geography 1997) White's subsequent elaboration of the "range of choice" approach to water (and other resources) provided a means of investigating the influence of social perception on the ways people make decisions concerning the appraisal and management of resources. (White 1961; Wescoat 1987) These and other (e.g. Cosgrove and Petts 1990a) explorations of the links between water and society have provided examples of how water can be used to promote dialogue and even

perhaps the only geographic project of its day to call for "a new focus on human-environment interactions" in response to growing contemporary concerns about human impact on the environment. (Castree 2005:72) Castree and others have regarded the failure of other geographers to pursue this approach to human-environment interactions as a lost opportunity for the discipline as a whole. (ibid.) This assessment provides a good argument for my contention that a focus on water might provide the discipline with a productive means of relating the various aspects of the geographic enterprise. (see Chapter 11) 
collaboration between physical and human geographers, between "those committed to physical geography as a natural science and those taking a social science or humanities perspective to geography." (Cosgrove and Petts 1990b:xv)

Nevertheless, while it may have been true that "physical" and "human" geographers were never closer than when studying water, the question of what they were studying was presumed to be unproblematic. This presumption is reflected, to cite one example, in the rather offhand way in which Chorley and Kates are able to describe the hydrologic cycle as "a great natural system.". (1969:3) The question of the "naturalness" of the hydrologic cycle is something to which I shall devote a numbing volume of words in chapters below. But in general, the point I intend to make is that the water(s) of physical geography and the water(s) of human geography are the same in the sense that in each instance, the water(s) in question are produced at the confluence of the water process and the practice of an intellectual discipline. Whether bringing the nature of water under critical scrutiny in this fashion may be conducive to more productive collaboration among practitioners of different kinds of geography I can't say for sure. However I will make an effort in the concluding chapter to describe a way of proceeding on the basis that physical and human geography are related dialectically, and are in this sense interrelated parts of the same process. At the very least, I hope that my essay might be regarded by those who identify themselves as geographers - either physical or human - as a well-intentioned effort to identify some of the impediments to such collaboration. 
It has not been until geographers have begun to apply more critical theory - such as the three approaches identified above - to the study of hydrosocial relations that a more productive exploration of the social nature of water has become evident within the discipline. Adopting a broadly Marxist and poststructuralist orientation, Dennis Cosgrove was able to claim in 1990 that "as with all brute facts of our existence, humans culturally appropriate water, and invest it with meanings...It is through the meanings that we give to water and to its geographical manifestations - in rivers, streams and lakes - that we come to understand it and to exert forms of human control over its inherent nature." (Cosgrove 1990:2) While Cosgrove recognizes water's "inherent nature", what is important here is that unlike for Chorley and Kates, this nature, though real, is unspecifiable. What really counts for Cosgrove is the "meanings" that water and its "geographical manifestations" take on from their involvement with people.

The more recent work by geographers in what I would call the social nature of water applies critical approaches to break down the ideological and discursive bifurcation of water/nature and society. Water itself provides a compelling tool for geographers and others interested in dissolving the boundaries of the world we have made for ourselves. A solvent for the deconstruction of space, a way of confounding the separation of nature and society, a process that challenges and wears down the substance of everything, water is the ideal metaphor for breaking down modern structures, essences, boundaries and fixtures. For the most part, the critical investigation of water in geography has been applied to the urban 
environment, especially in the field of urban political ecology. (e.g. Gandy 2002; Bakker 2003a; Swyngedouw 2004; Kaika 2003; 2005; Antipode 2003; and for a review see Braun 2005) ${ }^{31}$ To a lesser extent, the social nature of water has been explored by geographers and others in non-urban environments, such as in the modemization of hydroagricultural systems in Spain (Swyngedouw 1999); and in discourses of "wetlands" (Giblett 1996) as well as in critical examination of hydrosocial phenomena such as drought, desertification and floods. (See Chapter 2)

This essay is intended as a contribution to the idea social nature. At the very least, I hope to convince the reader that the nature of every instance of the thing we call water "is indeed social through and through", to borrow an important phrase from Braun and Castree. (1998b:xiii) Of all "things", it seems to me that water is a marvellous way of exploring this idea. Water flows. "The intellectual importance of things that flow", writes the geographer Mark Whitehead, "is that they force us to look beyond the seemingly static objects which are routinely studied within the humanities and social sciences, to consider the processes which constitute, challenge and reform the world around us." (Whitehead 2005) ${ }^{32}$

\section{Introducing Modern Water}

\footnotetext{
31 More examples are discussed in Chapter 2.

32 Simarly, Braun has noted how, in recent studies of urban nature (e.g. Gandy 2002, Swyngedouw 2004, Kaika 2005) water has proved "particularly useful to think with" because tracing its flows can "explode any understanding of city and countryside as discrete places." (2005:637)
} 
To a large extent, my thesis is comprised of a relational-dialectical investigation of what I call "modern water", the particular pinning-down of the ineffable flow that we in the modern West take to be natural. I want to examine the (mainly social) processes by which this hydreification has arisen and become invisible to us. By tracing these processes, I aim to make modern water visible in a way that allows for the reconstitution of waters in different ways. I have already hinted at what I mean by modern water. However, much as the owner of a new electrical gadget might appreciate a section titled "A few quick points on how to use this thing" at the beginning of a lengthy manual, it seems appropriate that I should provide the following introductory remarks:

- Modern water can be defined as the dominant way of knowing and relating to water, originating in Western Europe and North America, and operating on a global scale by the later part of the twentieth century. Modern water's historicity is suggested by Derek Gregory when he writes that towards the end of the nineteenth century, "a new discourse of hydrology and hydraulic engineering emerged which translated 'nature' into mathematical formulae. In these there would be no place for 'local' knowledge and the hydraulics of irrigation channels and the mechanics of dam construction could be made the same the world over." (2001:96-97) $)^{33}$

\footnotetext{
33 In several places below, particularly in Chapter 2, I consider what might be described as a postcolonial approach to modern water, a topic that deserves a separate study. For the most part, the hegemony of modern water is treated below more in terms of the globalization of scientific discourse. (see especially Chapter 7)
} 
- The notion of translating "'nature' into mathematical formulae" suggests the predominant discursive practice in which modern water has incubated and proliferated, for it tends to be made known and represented scientifically. Modern water is made known as an abstract, isomorphic, measurable quantity that may be represented as $\mathrm{H}_{2} \mathrm{O}$, and as the entity that constitutes the hydrologic cycle. (Figures 1-2 and 1-3) These ways of knowing and representing reflect an understanding of water that makes it essentially the same thing, regardless of spatial, historical and cultural circumstances. The fundamentally scientific nature of water is reflected in the standard definition of the term:

water...1a: the liquid that descends from the clouds as rain, forms streams, lakes, and seas, issues from the ground in springs, and is a major constituent of all living matter and that when pure consists of an oxide of hydrogen $\mathrm{H}_{2} \mathrm{O}$ or $\left(\mathrm{H}_{2} \mathrm{O}\right) \mathrm{x}$ in the proportion of 2 atoms of hydrogen to one atom of oxygen and is an odourless, tasteless, very slightly compressible liquid which appears bluish in thick layers, freezes at $0^{\circ} \mathrm{C}$ and boils at $100^{\circ} \mathrm{C}$, has a maximum density at $4^{\circ} \mathrm{C}$ and a high specific heat, contains very small equal concentrations of hydrogen ions and hydroxide ions, reacts neutrally, and constitutes a poor conductor of electricity, a good ionizing agent, and a good solvent... (Webster's Third New International Dictionary: 2581)

\footnotetext{
${ }^{34}$ Here are two other standard definitions of "water":

water... 1. Colourless transparent tasteless scentless compound of oxygen and hydrogen in liquid state convertible by heat into steam and by cold into ice, kinds of liquid consisting chiefly of this seen in sea, lake, stream, spring, rain, tears, sweat, saliva, urine, serum, etc...." (Concise Oxford Dictionary, Fifth edition: 1471)

"Water - Water $(\mathrm{H} 2 \mathrm{O})$ occurs in the atmosphere and above and below the Earth's surface as a liquid, solid or gas. It is continually changing state (e.g, by freezing/thawing, evaporation/condensation) and location (eg, by gaseous, liquid or glacier flow). All water is involved in a continuous hydrologic cycle, of which evaporation into the atmosphere from oceans, lakes, rivers and land surfaces and transpiration through plant leaves may be considered the first phase. This moisture is transported, often great distances, by winds and is precipitated, as rain or snow, upon water and land surfaces." (Marsh 1985:s.v. Water)
} 
- Modern water's universality - its irrelevance to particular temporal, spatial, ecological and cultural circumstances - may be represented by means of diagrams and tables, such as that of the "World's Water System" (Figure 1.2) and "Water Reserves on the Earth" (Figure 1.3). Figure 1.4 is a representation of modern water in its most abstract and reduced form. The reduction of (modern) water to $\mathrm{H}_{2} \mathrm{O}$ permits comparison of all possible waters by acts of quantification, an example of which is represented by the basic water balance equation: Rainfall = Evaporation + Runoff. (See Figure 5.2) The water balance equation is a mathematical expression of a very familiar means of representing (modern) water; the hydrologic cycle, one depiction of which is given in Figure 1.5 . 


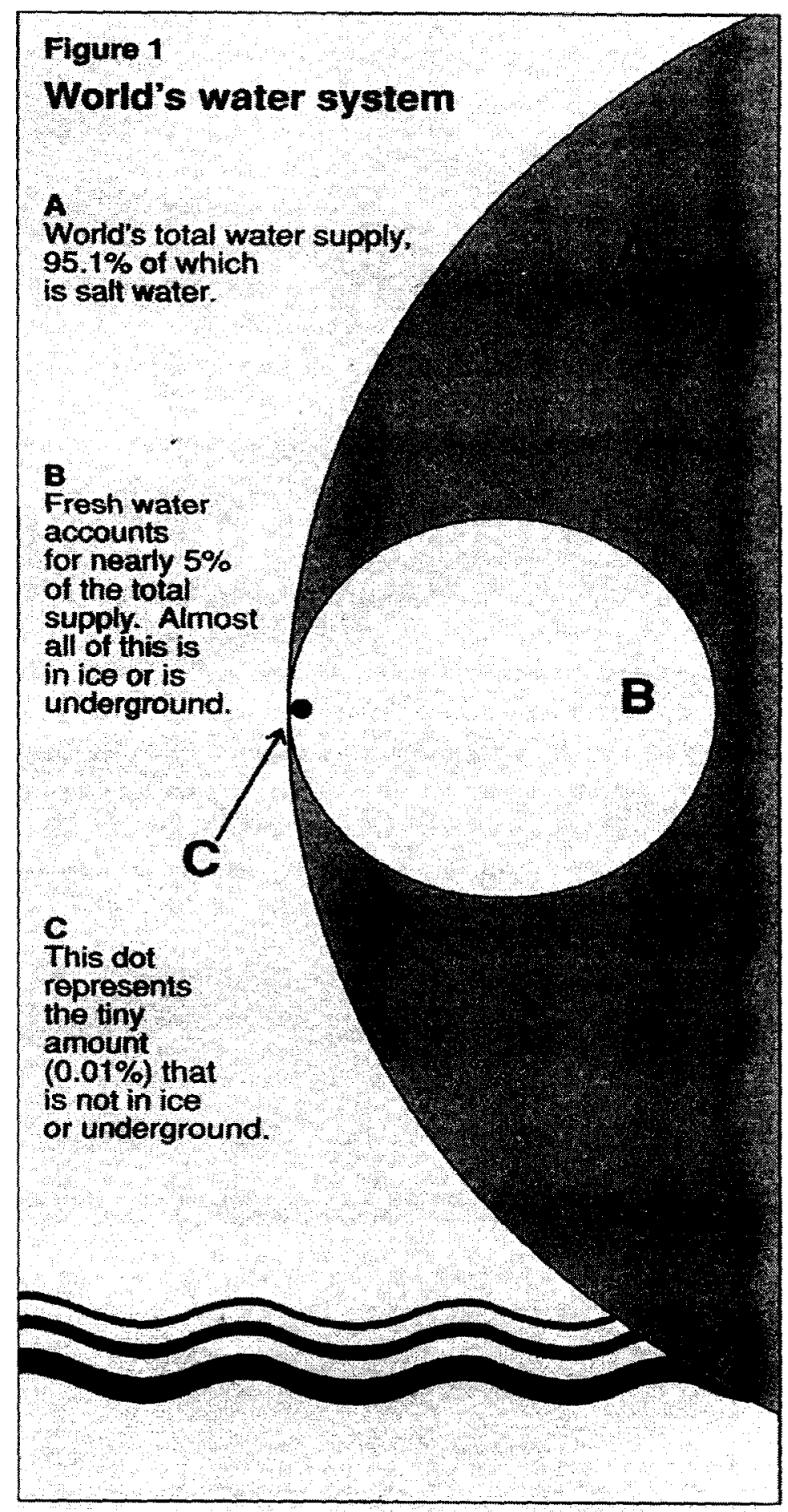

Figure 1-2 - "World's Water System" (reproduced from Environment Canada 1992:1) 
Table 9. World water reserves

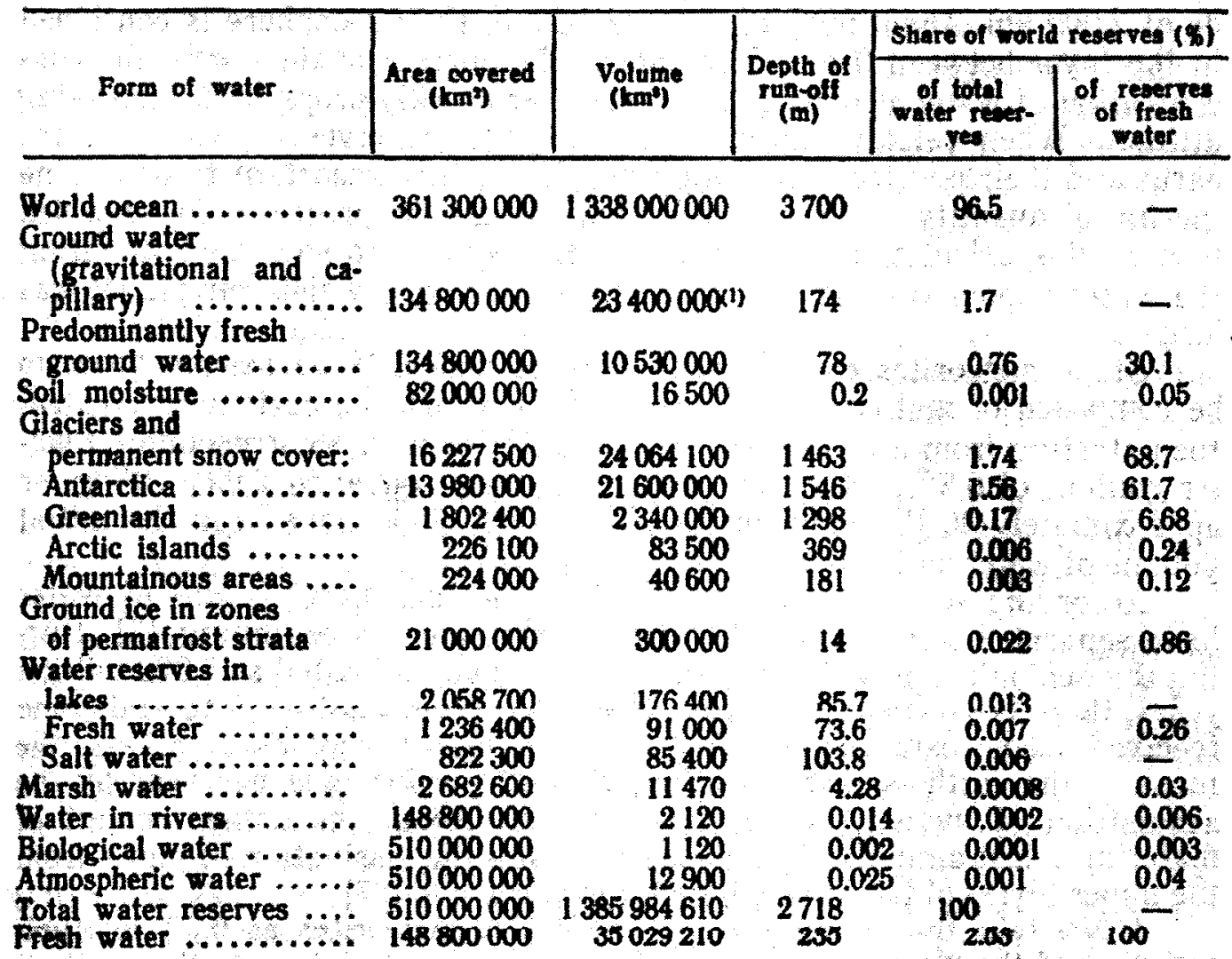

(1) Not taking into secount ground-water reserves in Antaretica, broadly estimated at 2 million $\mathrm{km}^{\mathbf{3}}$ (including about 1 million $\mathrm{km}^{2}$ of predominantly fresh water).

Figure 1-3 - World Water Reserves (reproduced from Korzun et al. 1978:43) 


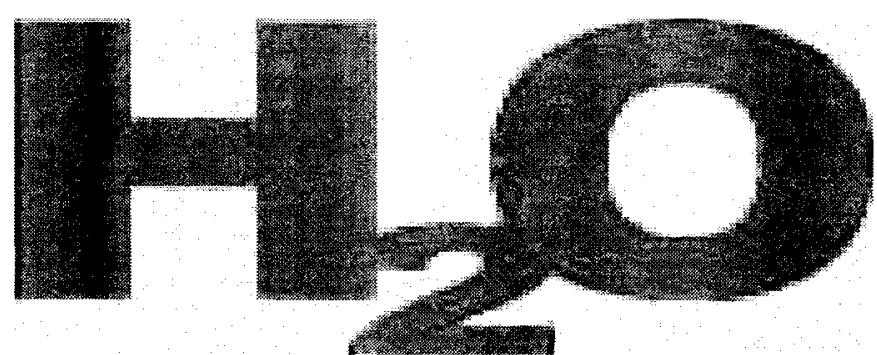

Figure 1-4 - Modern water reduced to its essence

\section{ROUND AND ROUND AND ROUND IT GOES}

The pathway of water as it moves in its various phases through the atmosphere, to the earth, over and through the land, to the ocean, and back to the atmosphere is known as the hydrologic cycle (Figure 1.1).

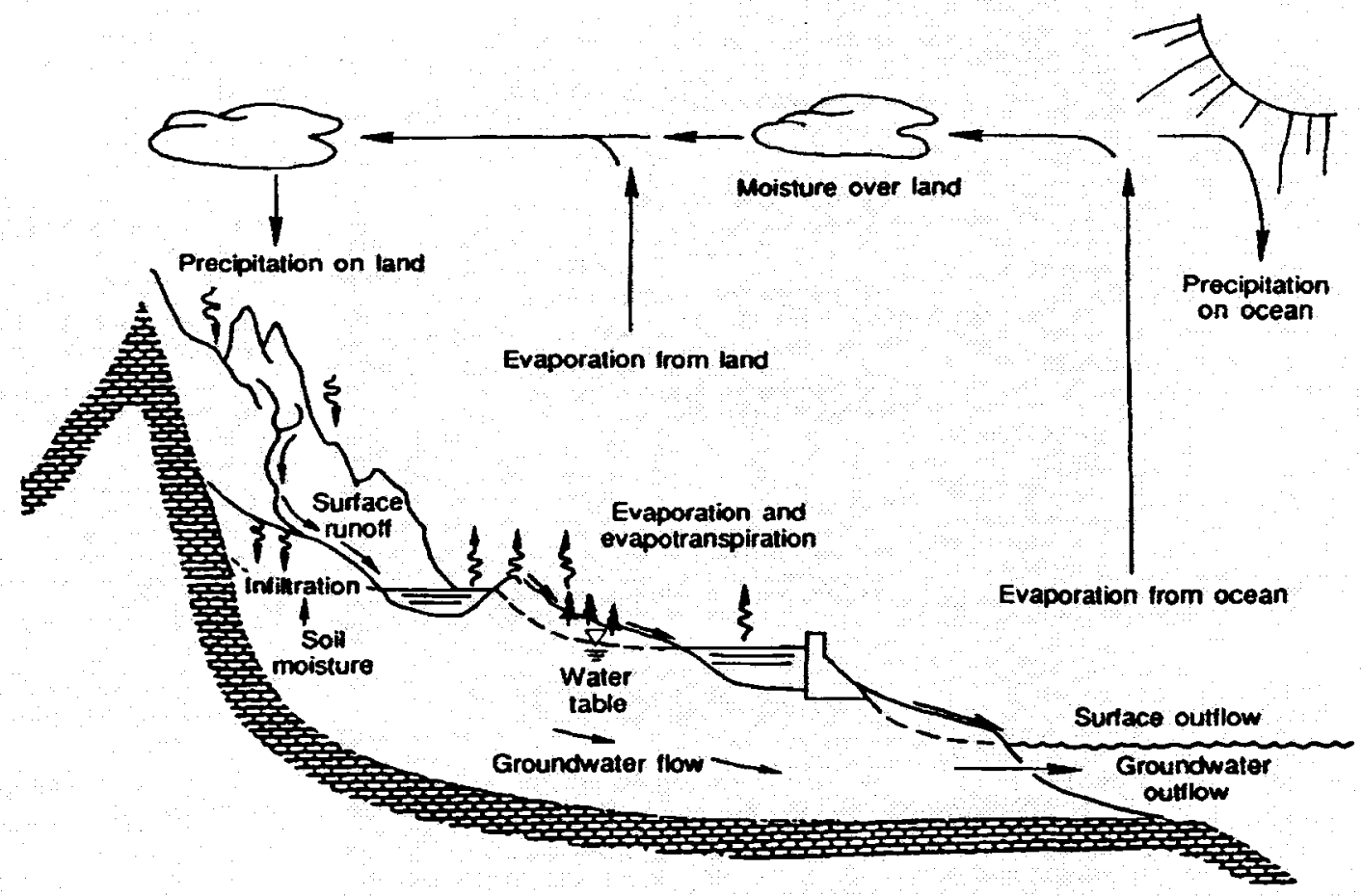

FIGURE 1.1 Elements of the hydrologic cycle. SOURCE: Reprinted, by permission, from Chow et al. (1988). Copyright 1988 by McGraw-Hill, Inc.

Figure 1-5 - The Hydrologic Cycle (text and diagram reproduced from National Research Council 1991:18) 
- Although we can (and shall) trace the path of $\mathrm{H}_{2} \mathrm{O}$ back to the late eighteenth century, and the scientific hydrologic cycle to perhaps a century later (albeit with important antecedents), modern water is suggested in the notion that $\mathrm{H}_{2} \mathrm{O}$ and the hydrologic cycle have always existed, however they required the application of proper (scientific) method to be brought to light (or discovered). ${ }^{35}$ Of course, the universality of modern water is "true" in a sense: Water didn't change its essence when the chemists pronounced it a compound. And it didn't behave any differently when the hydrologists put it through the hydrologic cycle. However, to equate this (way of understanding and representing water's) essence and behaviour with the nature of water itself is to tread modern water. $^{36}$

- Modern water is made thoroughly susceptible to material constraint, control, and manipulation. The control of water is the physical manifestation of its modern intellectual abstraction; it materializes our legendary distaste for mud and swamps. (Giblett 1996) A hydrological statement might help to illustrate this point: "Hydrology provides the basis for deciding the most rational way of developing a river basin by integrated planning of the use of water resources, which invariably requires changing the distribution of water in space and time."

\footnotetext{
${ }^{35}$ Kuhn 1990 offers an illuminating critique of concept of "natural kind", and particularly of the use of water by philosophers (notably Hilary Putnam) as an example of a natural kind.

36

Must it be stated that water was always $\mathrm{H}_{2} \mathrm{O}$, even before it was recognized as such? Of course this assertion (that water was always $\mathrm{H}_{2} \mathrm{O}$ ) is characteristic, even definitive, of modern water. Modern water reduces ALL water to this essential substance, this homogeneous chemical compound, both spatially and temporally. Thus all water was, is, and always will be $\mathrm{H}_{2} \mathrm{O}$. That we find it necessary to say this is distinctly modern.
} 
(Nemec 1976:335) Modern water is what makes it possible to presume its universal susceptibility to spatial and temporal (re)distribution. It follows that modern water has been produced by, and has helped produce, as one professional water manager has put it, a culture that excels in "pushing rivers around". (quoted in Worster 1985:266)

- Just as it is often constrained from blending with the earth, modern water doesn't mix very well with people. Even though it flows constantly through our bodies and our psyches, ${ }^{37}$ water has nevertheless been banished in the modern cosmos to the Cartesian realm of extended substance. Society and modern water are externally related as two independent and intransigent categories; water may be understood as affecting society and society may be understood as affecting water, but neither may be understood as being fundamentally (internally) changed as a result of these exchanges.

- Another characteristic of modern water - one that might be obvious to geographers - can be described as its deterritorialization. The philosopher Bernard Kalaora has noted how the conquest of water through the science of abstraction and the techniques of control has broken relations that otherwise bind specific groups of people to the waters of particular territories. (Kalaora 2001) A corollary of the placelessness of modern water (perhaps symbolized

\footnotetext{
37 The material flow is relatively obvious. That water constitutes an important part of our thoughts and dreams is perhaps revealed in the impossibility of proceeding very far along the stream of life without producing watery metaphors. For a good dive into the flow of water through the human psyche, read Bachelard 1983.
} 
by the tap) is the transfer of control of water to placeless discourses of

hydrological engineering, infrastructural management and economics. ${ }^{38}$ Water, as described by the anthropologist Veronica Strang, has been "dematerialized", rendered "a metaphorical abstraction... in which it ceases to be particular to any place or group." Thus de-territorialized and de-materialized, modern water "denies the reality of local, specific human-environmental relationships and alienates the medium through which individuals can identify with a locale and its other inhabitants." (Strang 2004:246)

Other characteristics of modern water are likely to materialize in the following rendition of its history. For now, we might consider the way Donald Worster describes the Friant-Kern Canal (a water diversion from the Sierra Mountains through the Great Central Valley of California) as a useful description of our subject:

"Quite simply, the modern canal, unlike a river, is not an ecosystem. It is simplified, abstracted Water, rigidly separated from the earth and firmly directed to raise food, fill pipes, and make money. Along the Friant-Kern Canal, as along many others like it, tall chain-link fences run on either side, sealing the ditch off from stray dogs, children, fishermen (there are no fish anyway), solitary thinkers, lovers, swimmers, loping hungry coyotes, migrating turtles, indeed from all of nature and of human life except the official managerial staff of the federal Bureau of Reclamation. Where the canal passes under highways large, ominous signs are posted: "Stay alive by staying out." The intention of the signs, of course, is to promote public safety by warning the innocent of the dangers of drowning, of being sucked into siphons by the swift current. However their darker effect is to

\footnotetext{
${ }^{38}$ Kalaora describes this in terms of a "deresponsabilisation" by which people have left responsibility for water relations to experts. (Kalaora 2001:1)
} 
suggest that the contrived world of the irrigation canal is not a place where living things, including humans, are welcome." (Worster 1985:5)

This passage might be taken as illustration of how the characteristics of modern water - its intellectual abstraction, scientific specification, material containment, and its alienation from society and from the rest of non-human nature - hang together: The modern idea of water as an objective, homogenous, ahistorical entity devoid of cultural content is complemented by its physical containment and isolation from people, and reinforced by modern techniques of management that have enabled most of us to survive without having to think much about it. Part of what I want to argue is that modem water has entered a critical phase wherein each of these characteristics is recognized as untenable, or unsustainable; and, as a result, it has begun to fall apart. That this crisis is forcing us to think about, and get involved with, water in ways to which we are not accustomed, is perhaps the underlying premise, and motivation, for the present work.

\section{Downstream from Here}

I intend for this essay to flow in the following fashion: The argument is presented in three parts:

Part I (Chapters 1-7) is an investigation of modern water, which I have called its "history". In Chapter 2, we consider a broad range of recent literature that suggests the need to reflect critically on the particular nature of water that has been dominant in modern, Western society. I have rather arbitrarily categorized this 
literature under five headings: Critiques of modern water structures and the 'changing water paradigm'; water history; cultural ecology of water; political ecology of water; and post-colonialism and imperial water. My aim here is to present an outline of the wide variety of work that intimates a critique of modern water and the need to reflect on water's social nature in light of contemporary problems and concerns.

Having provided a rationale for a critical examination of modern water, in Chapter 3 , we begin to investigate its history by considering an article written by an historian of science named Christopher Hamlin. (Hamlin 2000) Hamlin has identified a transition from an empirical emphasis on diverse "premodern waters", which were regarded as heterogeneous entities exhibiting different properties and qualities, to a modern "essentialist conception of water itself", a transition that appears to have taken place throughout the industrialized world by the end of the nineteenth century. (2000:321) While I am in agreement with Hamlin's analysis, I have broadened the argument somewhat by describing how the consideration of what might (anachronistically) be called "hydrological" questions has always promoted an 'essentialist conception of water', and how the emergence of a scientific (or quantitative) practice of hydrology beginning in the late seventeenth century has been instrumental in giving birth to modern water.

In Chapters 4 and 5, we dive into the historiography of water science in order to explore modern water's history in greater depth. Here, developments in the hydrologic sciences are approached in a critical fashion to show how some of the 
more salient hydrological features of the modern world have been constructed. In a relational-dialectical sense, this business of construction occurs where the social processes entailed in scientific practice meet up with natural processes to produce specific concepts, ideas, representations and material manifestations of nature. In this case, the practice in question can be described in terms of "scientific hydrology", while the natural process involved could be described approximately as the circulation of water on earth. Together, they have produced variations of one of the most familiar formal representations of modern water - the hydrologic cycle. Partly because of this familiarity and partly because of its centrality to hydrology - a science that is oriented exclusively to the study of water - we shall investigate the hydrologic cycle in considerable depth.

Three different histories of the hydrologic cycle are presented, each describing a somewhat different thing, the first two in Chapter 4 and the third in Chapter 5 . The first history presented (and the one most commonly told), is usually related by modern-day hydrologists. This is the history of what might be called the "scientific" hydrologic cycle, the one that has always existed and was known intuitively to a host of ancient savants, but awaited the application of correct scientific method in order to be truly revealed for the natural system that it is. The second history is the story of how natural philosophers in the tradition of natural theology (or physicotheology) constructed what I call the "sacred" hydrologic cycle to buttress their theological arguments. This history would hardly be known had it not been for the geographer Yi Fu Tuan, who published a unique study on the subject in 1968 
(Tuan 1968a). The differences between the scientific and the sacred hydrologic cycles and the difference between the histories that animate them are explained mainly in terms of the distinctions between the epistemological approachs of modern hydrology and physico-theology.

The third history of the hydrologic cycle, offered in Chapter 5, is rather my own. I call it a "constructivist" history of the hydrologic cycle because in writing this history, I treat the hydrologic cycle as a concept that was deliberately constructed in, rather than revealed through scientific practice. The hydrologic cycle that it describes is different from the scientific and sacred versions discussed above; it is a concept whose origin is specific to a particular time and place, and yet has succeeded in obliterating its origins by virtue of having been planted firmly in the soil of nature by its progenitor. For want of a better term, I have called it the "Hortonian" hydrologic cycle after the hydrologist who first presented it. This history presents the argument that the modern hydrologic cycle with which we are all familiar was invented in a particular time and place and for a specific purpose that had a great deal to do with constituting hydrology as a scientific discipline. As a hydreification, it has been highly successful.

In Chapter 6, the links between modern water, the hydrologic cycle and the modern state are explored from a relational-dialectical perspective. The main argument in this chapter is to show how modern water and the modern (capitalist) state are internally related. Essentially, the state, allied with the hydrologic cycle, has promoted the discourse and the materiality of modern water as a "resource", 
while water resources have strengthened the apparatus of the state and helped facilitate circulation of the hydrologic cycle as a representation of the nature of water. This rather complex set of relations is illustrated by showing how the hydrologic cycle became implicated in the mid-twentieth century state-sponsored project to re-engineer the fluvial topography of the United States. The hydrologic cycle provided a particularly serviceable means of representing water in a way that could be exploited by those who sought to survey and control its behaviour. To borrow a term used by James $\mathrm{C}$. Scott, the hydrologic cycle has helped make water "legible" to central planners and government agencies charged with the duty of rationalizing the country's water resources. (Scott 1998)

Chapter 7 concludes the first part of the essay with a discussion of what might be considered the culmination of modern water - the abstraction and representation of the earth's total hydrological stocks and flows, which I call "global water". Global water, is latent in modern water, and its assessment was always implicit in the (scientific) hydrologic cycle. The most reliable methods of calculating the world's quantity of water were developed and refined by hydrologists working in the Soviet Union, where the state's needs for aggregated hydrological data were particularly demanding. These methods began to be transferred to Western hydrological practice via international collaborative efforts, the most notable of which was the International Hydrological Decade (1964-1974). While most hydrologists working in the United States and other English-speaking countries were committed to hydrological investigation on the scale of the drainage basin, "global hydrology" 
eventually became an accepted practice, such that by the 1990 s, global water had achieved scientific credibility and growing popular currency in the West.

As modern water's culmination, global water presents a way of knowing and representing water that does not mix well with people. In Part II of the essay, we shift from an historical to a more philosophical mode to elaborate on this fundamental incompatibility. The articulation of modern water with people - the way modern water relates to people - now becomes the focus of my argument. In Chapter 8,1 argue that while it was certainly produced in relation to social (i.e. scientific) practice, modern water is nevertheless taken to be entirely independent of social relations. This fictional independence is at the core of what is considered here in terms of the "Constitution" of modern water. The constitutional metaphor is taken from Bruno Latour. (Latour 1993) My main purpose in this chapter is to identify the philosophical commitments that are necessary to produce, from the ephemeral flux of the water process, water's essential, modern identity. By describing its constitution as a set of commitments that evacuate the social content of water, I hope to shed some light on the kind of difficulties that arise when attempts are made to reintroduce modern water to society.

What happens when modern water - particularly global water - gets reintroduced to society is the main theme of Chapter 9 , which deals substantively with the "water crisis", an issue that became a major global concern in the 1990s. The argument here is that a kind of philosophical crisis is produced when global water 
is juxtaposed with another abstraction - human population. As abstractions, global water and human population cannot be related dialectically, and so their juxtaposition produces an inevitable crisis of scarcity. In contrast to the way the water crisis is usually presented - i.e. as a measurable consequence of fixed water supplies and growing human populations - my aim here is to show how modern water itself establishes the epistemological conditions that inevitably give rise to crisis. The crisis that I present is therefore not the water crisis per se, but the crisis of modern water.

The reconstitution of water in a way that deliberately recognizes, or restores, its social nature is the subject of Chapter 10. Here, the term "hydrolectics" is used to describe an approach to water that redefines what it is in relation to social as well as hydrological circumstances. In setting out something of a program of research and political action on water, I make a distinction here between analytical and practical hydrolectics. The overall objective of this program is to facilitate the adoption of more flexible, fluid hydrosocial relations. Together, water and people constitute an astonishing potential for changing each other in mutually healthy ways. A hydrolectical approach aims to help us exploit this potential.

Chapter 11 concludes the essay with a discussion of the way in which this -. investigation of water fits into the geographical literature more broadly, and in particular, how it might be seen to contribute to the project that as been described as "social nature. 


\section{Intimations of Modern Water}

"In light of the real or perceived risks of water crises, a review of the way in which the hydrological cycle, water management, water politics, and water economics are understood and theorized is long overdue." (Swyngedouw 2004:9)

\section{Introduction}

In this chapter we consider a range of (mostly scholarly) literature that suggests the need to reflect critically on what we in the modern West mean and do when we talk about and manage water. To some extent, critical scholars have explicitly acknowledged problems with a concept of water that holds it to be an abstract, placeless, ahistorical and asocial resource. Most frequently, however, the recent scholarship pertaining to water merely intimates the need to identify and question the understanding that I have identified as modern water. For the most part, the research and writing discussed below treats of water indirectly, as an aspect or component of the discourses and the materiality of things like traditional ${ }^{1}$ water management practices (including soil and water conservation, irrigation, land use and agricultural practices generally), modern techniques of water manipulation and management, and the incidence of drought, desertification, and water scarcity. The fields and disciplines that constitute this body of literature are diverse and overlapping. I have arbitrarily, categorized them under five headings: critiques of

\footnotetext{
1 Traditional is a problematic term. I use it here and elsewhere to signify practices that are rooted in specific cultures and places, and which have evolved or been adapted over long periods of time. Berkes quotes Hunn to define traditions as "enduring adaptations to specific places... Traditions are the products of generations of intelligent reflection tested in the rigorous laboratory of survival. That they have endured is proof to their power." (Berkes 1999:5) By this definition, modern, Western water management techniques may be considered traditional. However in this sentence and elsewhere I distinguish them from non-modern traditional practices.
} 
modern water structures and the "changing water paradigm", water history, cultural ecology of water, political ecology of water, and post-colonialism and water.

My purpose here is not to present an exhaustive catalogue of what amounts to an enormous volume of work, but rather to provide an indication of its relevance to my project. I intend to present this body of literature as an initial step towards a critique of modern water generally, and particularly the manner in which it encourages the imagination and management of water as some-thing independent of its social context. My broader intention - as will be made manifest in subsequent chapters is to contribute in a theoretical fashion to what I see as the upshot of this critique: the recognition and restoration of the place of society in water and the place of water in society.

\section{Critiques of modern water structures and the "changing water paradigm"}

"Nothing alters a river as totally as a dam" (McCully 1996:10)

That modern water is becoming less invisible - perhaps even obvious - is reflected most clearly in a growing body of work challenging the conventional (twentieth century) approach to managing water by means of control structures such as dams, levees, drainage and inter-basin diversions. Physical structures such as these internalize a way of relating to water that separates it from people and from the rest of the environment and that makes it readily subject to total manipulation and control. In internalizing and producing the control of water, such structures 
have come to represent and reproduce the abstraction of modern water. Dams and the like are indeed, concrete abstractions.

The increasingly critical stance taken with respect to water control structures mainly reflects growing environmental concerns. The ecological implications of treating water as a resource that may be manipulated without regard to other aspects of the natural environment - particularly its biological components - have presented a significant challenge to the traditional paradigm of water management. As the hydrologist William Nuttle has observed, "Water management is no longer concerned just with securing the benefits of water extracted from the natural water cycle to supply cities and farms and with intervening in this cycle to mitigate flood damage. Water in its natural cycle provides us with other benefits, by supporting ecosystems that constitute a valuable resource in their own right." (Nuttle 2002a: 513) This view of water - as a process that supports and sustains a plethora of ecological services - contradicts the conventional practice of accounting for and managing water as a hydrological abstraction. ${ }^{2}$ At the same time, to the extent that people are recognized more and more as part of the natural environment, the material abstraction and containment of water is also seen as injurious to human health and social relations.

2 This challenge is reflected in growing interest in the field of "ecohydrology". This field has been defined by William Nuttle (2002b:805) as "the subdiscipline shared by ecological and hydrological sciences that is concerned with the effects of hydrological processes on the distribution, structure and function of ecosystems, and on the effect of biological processes on the elements of the water cycle." 
As the most striking fixtures of modern water control, large dams have received protracted criticism. Few structures symbolize modernity - and its association with the containment of water - as do "large dams" (dams exceeding 15 metres in height from foundation to crest). Writer and river activist Patrick McCully has justly described them as "much more than simply machines to generate electricity and store water. They are concrete, rock and earth expressions of the dominant ideology of the technological age: icons of economic development and scientific progress..." (McCully 1996:2-3) In terms of the number of structures built, the 1960s and 1970s marked the zenith of the large dam era: over 45,000 have been built worldwide - all but 5000 of them since 1950 - to generate electricity, store water for irrigation and regulate the flow of rivers. (World Commission on Dams 2000:8)

The inauguration of the 221-metre-high Hoover Dam on the Colorado River in 1935 heralded the era of "super dam." From 1950 to 1995 , the number of super dams (dams exceeding 150 metres in height) grew from 10 to 305 . (McCully 1996:6) The amount of water impounded behind dams quadrupled between 1960 and 2000; it has been estimated that from three to six times as much water is now held in artificial reservoirs as occurs in all the world's "natural" rivers. (Millennium Ecosystem Assessment 2005:18) Over 400,000 square kilometres - an area about the size of California - has been inundated by reservoirs worldwide. Some of these reservoirs are so massive as to induce earthquakes, and taken altogether, their redistribution of the weight of the earth's crust is thought by some geophysicists to 
have a slight but measurable impact on the shape of Earth's gravitational field, the tilt of her axis and the speed at which we rotate around it. (McCully 1996:7)

By the 1960s, a good deal of scientific evidence had accumulated to show that that the construction and operation of modern water control structures produced "observable effects upon soil moisture, sediment movement, water quality, or other aspects of natural water resources as well as upon social systems." (Wescoat and White 2003:2) By the early 1980s, concerns about the disruptive ecological, cultural and socio-economic implications of the large-scale manipulation of water were becoming impossible to ignore politically. In 1984, the publication of Goldsmith and Hildyard's monumental study, The Social and Environmental Effects of Large Dams, precipitated a flood of concern about the effects of large dams that continues to flow to the present. (Goldsmith and Hildyard 1984) Goldsmith and Hildyard assembled an enormous volume of data "demonstrating that big dams and water projects have not only failed to achieve [their] basic objectives but are also leaving a legacy of unsurpassed cultural destruction, disease, and environmental damage." (Blackwelder in foreword to Goldsmith and Hildyard 1984) While the judgement that large dams had failed to achieve their basic objectives is certainly open to dispute, the recognition that they were less environmentally and socially benign than had been thought previously became widespread. There followed an outpouring of critical work in the late 1980 s and 1990 s, ranging from global assessments of the environmental and social costs of large dams and water control techniques (Clarke 1990; Pearce 1992; McCully 
1996) to focused investigations of their social and environmental impacts in specific places including the western USA (Worster 1985; Reisner 1986), northern Quebec (McCutcheon 1991), and India (Shiva 1988; 2002), among many others.

The impact of large dams on aquatic ecosystem functions has been an important theme of this critical reassessment. As noted in the turn-of-the-century report of the World Commission on Dams, "The current state of knowledge indicates that large dams have many, mostly negative, impacts on ecosystems. These impacts are complex, varied and often profound in nature. In many cases dams have led to the irreversible loss of species populations and ecosystems." (World Commission on Dams 2000:74) Of equal or greater significance for the fate of modern water has been in the revelation that in addition to their benefits, large dams have had profoundly negative social consequences flowing directly or indirectly from the effects of dams the hydrological regime. As we will see in Chapter 6, the large dams of the twentieth century represent a technology that is deeply embedded in the social fabric of the modern state. Large dams and water projects both reflect and produce the social relations that are contemporary and local to their construction. But where these technologies have been applied outside the social and hydrological context in which they were developed, their effects on "the entire cultural-ecological regime" have been particularly - and most obviously disruptive. (Bennett:1974:55) ${ }^{3}$ The social effects of altering the hydrologic regime

\footnotetext{
${ }^{3}$ In an ecological sense, "the suitability in tropical regions of large reservoirs designed for a temperate ecology" has been recognized as a central concern. (Bennett 1974:48) For a general critique of the unsuitability of imposing hydro-social relations and technologies that have been
} 
vary enormously depending on historical, geographical and hydro-climatic

circumstances. In general, they have been shown to include significant impacts on human health, massive economic dislocation resulting from changes in the hydrologic regime and - as a consequence of the relocation of an estimated 40 to 80 million people occasioned by the construction of dams since the Second World War - significant psychological effects and changes in power relations of the people affected. (Goldsmith and Hildyard 1984; World Commission on Dams 2000: ch. 4)

Dams are particularly instrumental to, and symbolic of, what has been described as the modern, twentieth-century water management paradigm. (Gleick 1998c) This (modem water) paradigm is characterized by three main features: First, it is coincident with a period of enormous increases in water withdrawals. ${ }^{4}$ Over the course of the twentieth century worldwide withdrawals of water from lakes, rivers and subterranean sources increased approximately seven-fold. ${ }^{5}$ Over the same period, the world's human population approximately tripled, making the increase in water use over twice that of population growth. Second, the conventional water paradigm is characterized by an emphasis on physical solutions to water resource

developed in modern, industrial societies upon other cultures in different hydro-climatic regions, see Clarke 1991.

${ }^{4}$ The term water withdrawal refers to the act of removing water from its 'natural' source for human purposes. For many of these purposes (e.g. cooling thermal power generators, municipal water use, large portions of irrigation water) water that is withdrawn is returned to the basin of origin. Water withdrawal is contrasted with water "consumption", which refers to water that is 'lost' to evaporation in, or embodied in, the process of producing agricultural or industrial products, and which is therefore transferred from - and is not available for reuse in - its original basin.

5 The most marked increase in water withdrawals occurred in the period from around 1940 to 1990. (Gleick 1998c:10-12) 
problems, specifically by engineering increases in water supply to meet anticipated growth in demand. In general, water resource problems have been reduced to finding the physical means to furnish users - farmers, industries, cities, households - with additional water supplies. The conventional strategy of water management has been to calculate the expected growth in demand for water, and to match expectations with increased water supplies: "The water management problem then becomes an exercise in coming up with ways of bridging this anticipated gap." (Gleick 1998c:6) Bridging the gap in this fashion has necessarily entailed the construction of physical infrastructure (dams, diversions, canals, pipelines, etc.) to bring supplies of water to the location of use. A similar strategy has been applied for managing water's "resistance" in the form of such things as flood control and drainage of wetlands. Here too, physical solutions (storage dams, levees, drainage projects) have been engineered to address what have been regarded as "problems" that are physical in nature. Third, the traditional water paradigm is strongly associated with central state planning, funding, and administration of water projects. The centralization and concentration of state control over water in the twentieth century was evident in all parts of the world, including regimes as diverse as the United States and the former Soviet Union. (Worster 2006)

\footnotetext{
${ }^{6}$ Water lends itself particularly well to Zimmermann's classic distinction between the resourcefulness and the resistance of things. In his functional view, things become resources in relation to social circumstances. Similarly, they may offer resistances to social goals depending on the particular conditions of society. (Zimmermann 1933; 1951)
} 
By the early 1990s however, there were indications that a fundamental change had taken place in the management of water resources. The rate of global increase in water withdrawls began to fall in the late 1980 s, with actual reductions of total withdrawals occurring in some places - most notably in the United States beginning around this time. (Gleick 1998c:10-13) The reasons for this change were several: By the mid-1980s, physical resource constraints were apparent in many parts of the world where water supplies were already being exploited to capacity. The marginal cost of increasing supplies grew enormously, and it became a truism among water management professionals that 'the next water project costs twice as much as the last water project.' In an era of growing fiscal restraint and reduced state investment in public works, these costs became prohibitive for most governments, and the pace of - for example - large dam construction fell rapidly. Second, as already noted, the ecological costs of manipulating water (which had been considered negligible) were recognized beginning in the 1970s, and became more salient with the growth of the environmental movement. By the 1990s, international coalitions of environmentalists had formed to militate against the construction of water mega projects in many countries, often to considerable effect. $^{7}$ These campaigns were especially significant in that they made no radical distinction between the environmental and the social impacts of mega projects; rather, the expected change in hydraulic regime occasioned by water

\footnotetext{
${ }^{7}$ The successful campaign - mounted by environmentalists in New York and other States in coalition with the Cree and Inuit of northern Quebec - to halt the Grande Baleine Project in the early 1990s provides a good example. (See McCutcheon 1991:159-163) A global campaign to assist local opponents of the Sardar Sarovar project on the Narmada River in India instigated a project review that contributed substantially to a decision by the World Bank to withdraw project funding from this and other large dam projects. (Morse and Berger 1992)
} 
megaprojects was shown to have inevitable direct and indirect social costs that in many cases outweighed the expected social benefits.

For all these reasons, the pace of dam construction slowed markedly, particularly in North America and Europe, where the most economically attractive hydropower and multipurpose sites had already been fully developed (World Commission on Dams 2000:9). Worldwide lending for large irrigation projects had plummeted by the 1990s, and in the United States, the Bureau of Reclamation made an historical announcement in 1993 that it would initiate no more federally funded water supply projects (Postel 1999:62-63). The dissolution of the Soviet Union practically negated the possibility that planned large-scale water projects (such as the southward diversion of Siberian Rivers) would ever be realized. By the mid-1990s, the postponement or cancellation of these and other large projects ${ }^{8}$ and as noted, the decision by international lending agencies like the World Bank to withdraw support for others ${ }^{9}$ provided further signals that an important change was underway. While it is perhaps still too early to declare the end of the large dam era, there seems little question that the heyday of the water megaproject is drawing to

\footnotetext{
8 Including the Franklin Dam in Australia, Nam Choan in Thailand, Nagymaros in Hungary, Silent Valley in India, Babaquara in Brazil, Katun in Russian and Serre de la Fare in France. (McCully 1996:21) A Canadian example would be the decision by the Government of Quebec in 1994 to postpone Phase III of the James Bay Project. It should be noted however, that a revised version of phase III is moving forward, with the (albeit highly contested) consent and participation of the Crees of Northern Quebec. (Desbiens 2004)

9 Examples include the enormous Sardar-Sarovar project on the Narmada River in India and the Arun-3 hydroelectric project in Nepal. As noted rather caustically by McCully: "The World Bank now appears willing only to fund huge dams in countries with repressive regimes which can ensure popular resistance is crushed." (McCully 1996:21)
} 
a close. ${ }^{10}$ In places like Sweden and Norway, almost all the remaining free-flowing rivers are now protected by legislation from further dam construction (McCully 1996:26). And in the United States - where the big dam era began - at the turn of the twenty-first century, more old dams were actually being decommissioned for economic and environmental reasons than new ones were being built (World Commission on Dams 2000:10). ${ }^{11}$

These decisions signal what many regard as a paradigmatic change in water management now taking place on a global scale. Essentially, this change entails the recognition that instead of solving water resource problems by building infrastructure to augment supplies, efforts must be redirected toward "living within water's limits" by improving the efficiency with which available water is used. (Postel 1992; see also Postel 1999 and Gleick 1998c) Scholars with a specific interest in water management have described the shift from a period of "water development" prior to the 1970s and "water management" in the 1970s and 1980s, to an emphasis on "sustainable water management" in the 1990s. (Mitchell and Shrubsole 1994:61-62). Others have stressed the "need for a change of water paradigm" to promote "truly integrated water resources management." ${ }^{12}$ (Figuertes,

\footnotetext{
${ }^{10}$ Perhaps the main exception is China, where the pace of large-dam construction continues to grow.

${ }^{11}$ Note the book published in 2002: Watershed: The Undamming of America. (Grossman 2002) The privilege of being able to free American rivers, it should be stressed, is granted to some extent by virtue of the relocation of certain hydro-intensive industrial activities and hydro-electrical generation itself to other (notably poorer, but also including northern Canada) countries, where the arrival of the new water paradigm is less evident.

12

"Integrated water resources management" (IWRM) is a term that became prominent in the 1980s and is used by many water experts to describe an approach to managing water that takes into
} 
Rockstrom and Tortajada 2003:229) In all these assessments, a "virtually

exclusive emphasis on managing the supply of water has been replaced by a

much broader perspective that increasingly recognizes the role of managing water demands." (Kreutzwiser 1995:270) Peter Gleick, a water expert who gained world renown for, among other things, documenting the world's water crisis (see Chapter 9), describes the "changing water paradigm", as seen by many enlightened water experts at the turn of the $21^{\text {st }}$ century:

Water resources management approaches around the world are changing dramatically. This "changing water paradigm" has many components, including a shift away from sole, or even primary reliance on finding new sources of supply to address perceived new demands, a growing emphasis on incorporating ecological values into water policy, a re-emphasis on meeting basic human needs for water services, and a conscious breaking of the ties between economic growth and water use. A reliance on physical solutions continues to dominate traditional planning approaches, but these solutions are facing increasing opposition. At the same time, new methods are being developed to meet the demands of growing populations without requiring major new construction or new large-scale water transfers from one region to another. More and more water suppliers and planning agencies are beginning to explore efficiency improvements, implement options for managing demand, and reallocating water among users to reduce projected gaps and meet future needs." (Gleick 2000a:127, my emphasis)

This new water paradigm is regarded as a necessary response to what is perceived as a "global crisis" of water scarcity. I will argue that what is in crisis is modern water itself, the particular way of understanding and relating to water that is embodied and fixed in the old paradigm. For the purpose of my argument, the more significant aspect of the new paradigm is that it shifts attention to the social

consideration all possible aspects of water values and uses for a particular region (usually a river basin), including ecological as well as socio-economic values and uses. A critique of IWRM is discussed in Chapter 9. 
side of the hydrosocial equation: In addition to managing water, the point is now to manage society so that its demands for, and impacts on, water resources are mitigated. ${ }^{13}$ Influencing the dynamics of demand is now of equal importance to engineering additional water supplies. Notwithstanding this important change, neither the water nor the people involved in the new paradigm have been altered. What has changed is the focus of technocratic interest; from supply to demand; from water to people. While the "changing water paradigm" entails a profound critique of conventional water resources management, it hardly addresses the nature of the water (resources) taken for granted in modern water management discourse, nor the need to consider water as some-thing that cannot but occur in the context of the specific cultural and social circumstances that give it meaning and form. Projects like the "new era of water conservation" (Postel 1992), "sustainable water management" (Mitchell and Shrubsole 1992:64) and the overriding "objective of increasing the productive use of water" - which constitutes the main thrust of the new "water paradigm" (Gleick 1998:19) - are presented as essentially technical solutions to a suite of ever-more-apparent water-related problems. $^{14}$

\footnotetext{
${ }^{13}$ The main policy tools put forward for accomplishing this goal are economic incentives (cutting subsidies for water use, full-cost pricing, conservation pricing, pollution taxes, establishing markets for water, etc.) and other public policy initiatives to enhance the use of water efficient technologies and to shift production from sectors with low water productivity (GDP per unit of water used) to high water productivity. (Gleick 1998c)

14

These prescriptions may be regarded as an application of "ecological modernization" to the problem of water management. Ecological modernization is a process grounded in the conviction that the solution to perceived ecological problems rests in reflexive applications of modern science and technology; it emphasizes the technological innovations and institutional reforms that can and must take place for contemporary societies to deal with environmental (including water) problems. (Mol and Sonnefeld 2000:4-5) At its core, ecological modernization is a "social scientific and policyoriented approach" carrying the conviction "that contemporary societies have the capability of
} 
One reason, perhaps, for the failure to recognize the social nature of water in the new paradigm is because the technologies and structures under scrutiny are fundamentally the product of our own (modern, Western) cultural accommodation with water. The notion of substituting one technological approach (i.e. water conservation, demand management, water-use efficiency) for another (i.e. management of supply) merely reinforces the modern relation between people and water. The nature of water itself is taken for granted in this work because the water in question is modern, which makes it invisible in the eyes of most contemporary observers, especially the ones most expert in its management. Being in such close proximity brings little advantage when it comes to finding new meanings in things. "Whoever discovered water," as the anthropologist, Clifford Geertz has observed, "it was not a fish." (Geertz 1996:259)

By contrast, scholars in other fields have turned their attention to water issues in a way that more explicitly addresses what I would call the social nature of water. The main reason for this - what makes these observers able to see the social nature of water more clearly than the critics of modern water structures and proponents of the new water paradigm - is that the water they consider is more distant in either historical or cultural contrast with our own way of relating to water. We will now examine this research in the following sections of this chapter. 


\section{Water History}

Water history is a term used here to describe interest among scholars, as well as more popular writers, in past and unfolding relations between people and water. ${ }^{15}$ This category includes the research of historians, geographers, anthropologists and others who have focused on the history of water, or more precisely, on societies for which water has been a defining feature. I have somewhat arbitrarily divided this work into two categories: research on large-scale, centralized "hydraulic societies"; and the study of smaller-scale, "indigenous" or "traditional" water systems. Both are of interest to me because they tell stories of water and society in ways that - unlike the way we see (or fail to see) modern water - treat the separation of these two categories as problematic.

The classic study of hydraulic society is Karl Wittfogel's Oriental Despotism. (1957) Wittfogel described the historical-dialectical relationship between constructing and maintaining large-scale irrigation and the construction and consolidation of centralized, bureaucratic state power in a variety of historical and geographic settings, including the ancient irrigation civilizations of China, Egypt, Mesopotamia and India. "In hydraulic economy" he wrote, "man extended his power over the arid, the semiarid, and certain humid parts of the globe through a governmentdirected division of labor and a mode of co-operation not practiced in agrarian

\footnotetext{
15 There has been quite an upwelling of interest among scholars in this field in the last decade. The International Water History Association, formed in 2001, is perhaps the best indication of this. Many of the hundreds of papers presented at the three international conferences organized by the Association deal with water in a way that I would describe as its social nature. A three-volume set of many of these papers was published recently under the general title "A History of Water." (Tvedt and Jakobsson 2006; Coopey and Tvedt 2006 and Tvedt and Oestigaard 2006)
} 
civilizations of the non-hydraulic type." (Wittfogel 1956:156) He studied how, in associating themselves with religious leaders and through developing economies with redistributive features, elites in hydraulic societies were able to entrench their powers, eventually developing "despotic" regimes. The implications of Wittfogel's study for social theory have been the subject of much controversy ${ }^{16}$ and do not interest us here directly. Of more immediate interest is his development of the Marxian idea ${ }^{17}$ that society and nature unfold in a dialectical process that makes it impossible to consider one without the other when writing the history of either. ${ }^{18}$

For Wittfogel, the transformation of the hydraulic environment produced changes in society, which brought further changes in non-human nature, and so on; "an ongoing spiral of challenge-response-challenge," as Donald Worster has put it, "where neither nature nor humanity ever achieves absolute sovereign authority, but both continue to make and remake each other." (Worster 1985:22) Wittfogel's dialectical approach to the relationship between society and water (nature) upheld a fundamental distinction between the two, but is nevertheless important to the idea of the social nature of water. It begs the question of how people and water produce each other in modern society and whether variants of hydraulic society can be found existing today. Donald Worster has addressed this very question;

\footnotetext{
${ }^{16}$ For a summary of this see Worster (1985:22-30)

${ }^{17}$ Marx describes the labour process as "a process between man and nature, a process by which man, through his own actions, mediates, regulates, and controls the metabolism between himself and nature...[Man] sets in motion the natural forces which belong to his own body, his arms, legs, head, and hands, in order to appropriate the materials of nature in a form adapted to his own needs. Through this movement he acts upon external nature and changes it, and in this way he simultaneously changes his own nature..." (quoted in Swyngedouw 2004:15) 18

Wittfogel's nature-society dialectic is introduced in Chapter 1.
} 
elaborating on Wittfogel's terms and approach, he has described the American west as "a modern hydraulic society, which is to say, a social order based on the intensive, large-scale manipulation of water and its products in an arid setting... The hydraulic society of the West...is increasingly a coercive, monolithic, and hierarchical system, ruled by a power elite based on the ownership of capital and expertise." (1985:7)

While Wittfogel and Worster are concerned primarily with the impacts of the largescale manipulation of water on society ${ }^{19}$, others have dwelt on the (harmful) environmental impacts of hydraulic societies in the past. Much of this work can be seen as an adjunct to the above-mentioned critique of modern hydrological manipulation, as it is often couched in terms of 'lessons learned from the past' about the 'unsustainability' of large-scale water projects. The water expert and environmental writer Sandra Postel has drawn from the research of environmental historians and other scholars (including Wittfogel) to consider the four "great irrigation societies" of the past - the Mesopotamian, Nile, Indus and Yellow River civilizations - plus the Hohokam society of what is now south-central Arizona. With the exception of ancient Egypt's system of basin irrigation, which "proved inherently more stable from an ecological, political, social, and institutional perspective than that of any other major irrigation-based society in human history" (1999:35) all the major irrigation societies were apparently doomed to "collapse" by

\footnotetext{
19 This applies less to Worster, for whom modern hydraulic society is also seen as an environmental disaster.
} 
a variety of causes. Depending on the particular case, these hypothesized causes included climate change, salination of soils, population pressures, silt deposits in canals and fields, droughts and floods. "The overriding lesson from history", Postel argues "is that most irrigation-based civilizations fail." (Postel 1999:12)

While it may contain some useful lessons for modern irrigation societies, there is a major problem with this kind of assessment. In addition to downplaying the fact that these "civilizations" actually survived, or rather co-evolved, over many hundreds if not thousands of years, it suggests a fixed relationship between people and water pertaining through all of history, from ancient Mesopotamia to modern Missouri. Something of the same problem occurs with Wittfogel. Despite asserting a dialectical relation between nature and society, his work tends to emphasize the commonalities of hydraulic society over vast scales of time and space, which has the effect of fixing the dialectical relation in rather rigid terms.$^{20}$ Wittfogel's hydraulic society thesis, perhaps despite his intentions, tends to lean towards a form of hydrological determinism. While attending to the question of the role of water in shaping human history, Wittfogel takes water itself for granted, and has little to say about the role of human history in shaping it. ${ }^{21}$ This presupposition is

\footnotetext{
${ }^{20}$ Wittfogel identified numerous types of hydraulic society, however, as Bennett has noted, "the notion of centralization stemming from the control of water and waterworks pervades the classification and thus translates it into a general theory of sociopolitical development." (Bennett 1974:45)

21 By proclaiming "modern hydraulic society", Worster appears to do the same. "Water has been critical to the making of human history...", he states. "To write history without putting any water in it is to leave out a large part of the story. Human experience has not been so dry as that." (1985:19) One could hardly disagree that water has been critical to human history, but what is of equal importance to us here is that human history has been critical to the nature of water. As discussed in
} 
revealed the way Wittfogel describes the nature of water in a section titled "the specific qualities of water", the relevant parts of which are quoted below:

"Water is heavier than most plants. It can nevertheless be much more conveniently managed. Unhampered by the cohesiveness of matter and following the law of gravity, water flows automatically to the lowest accessible point in its environment. Within a given agricultural landscape, water is the natural variable par excellence.

... The human operator who has to handle water deals with a substance that is not only more mobile than other agronomic variables, but also more bulky. This last quality presents special difficulties whenever man tries to utilize large agglomerations of moisture; and this he is prone to do whenever natural and technological conditions permit. No operational necessity compels him to manipulate either soil or plants in cooperation with many others. But the bulkiness of all except the smallest sources of water supply creates a technical task which is solved either by mass labor or not at all." (1957:15)

"The specific qualities of water", particularly its "bulkiness", determine the fixed natural circumstances from which hydraulic society must proceed through the centralized command of "mass labor": "If irrigation farming depends on the effective handling of a major supply of water, the distinctive quality of water - its tendency to gather in bulk - becomes functionally and institutionally decisive. A large quantity of water can be channelled and kept within bounds only by the use of mass labor; and this mass labor must be coordinated, disciplined, and led..." (Wittfogel 1957:18) Wittfogel doesn't deny that "the smallest sources of water supply" have produced small-scale, decentralized agricultural economies in arid regions. But he gives these very short shrift, arguing that they "were reduced to 'hydraulic society.' 
insignificance, if they were not completely annihilated" by the dynamic forces of hydraulic society. (ibid.)

For Wittfogel, the essential "specific qualities of water" determined the essential nature of hydraulic society. By presuming the fixed nature of water itself, the variety of human relations with water gets obscured in an historical trope that produces a rather one-dimensional dialectic. That the identity of water in history is more complex than Wittfogel admits is suggested by some of his critics.

Challenging the hydraulic society thesis, some historians studying large-scale water systems have argued that they were a consequence rather than a cause of dynastic state organization (Adams 1974; Worster 1985:344 ff.6; Diamond 1999:283-4), while others have argued that these systems were characterized by a much greater variety of scales of organization, modes of cooperation and types of social relations than Wittfogel allowed. (Downing and Gibson 1974; Smith 1978:910; Ward 1997: ch. 3) More empirically based historical research has suggested "there is no such thing as irrigation society. There are many varieties of society practicing irrigation, and many forms of irrigation." (Hunt and Hunt 1974:131) Inasmuch as they attend to the more specific social and hydrological circumstances that have been subsumed under the rubric "irrigation society" or "hydraulic society", these critiques, it could be argued, offer at least an implicit rejection of the presumed universal nature of water throughout history. 
A more explicit recognition that water itself has a history is found in studies that focus on small-scale water systems. Instead of "hydraulic societies", this large and growing body of research offers fewer broad, sweeping generalizations about relations between people and water in the past. Even where their attention has been focused on the classic irrigation civilizations, instead of monolithic hydraulic societies, it tends to find "many village-scale irrigation works which are sustained by cooperative labor." (Bennett 1974:44-45) It is well beyond the scope of this chapter to render an exhaustive review of this work; what is important here is to show how it suggests the need to consider modern water as a distinct (historical) entity.

Scholarly interest in what have been described in terms of "traditional irrigation systems" (Geertz 1972), "the local subsistence mode" of irrigation (Worster 1985), and "indigenous irrigation systems" (Groenfeldt 1991) constitutes a very broad field of research. Like the study of hydraulic societies, this work has often been taken up by critics of modern water projects to illustrate the ecological and social virtues of small-scale, community-based water systems ${ }^{22}$. (e.g. Goldsmith and Hildyard 1984:285-343) While in this context, traditional water management systems are usually characterized as socially equitable, locally autonomous and ecologically stable, some scholars have stressed the uniqueness of each and have identified problems with making any of these generalizations. (e.g. Mosse 1995:147; Mosse

\footnotetext{
${ }^{22}$ Here, I take "system" as meaning an integrated set of relations involving people and water in a specific, geographic setting.
} 
2003) Among these systems, several classic ${ }^{23}$ examples stand out, including the qanats (a groundwater supply technology supporting traditional irrigation systems thought to originate in Iran), the subak, or water temple system of irrigation in Bali, the tank (artificial water harvesting and storage) systems of Sri Lanka and southern India, the chinampas (water regulation and artificial island agricultural) system of the pre-Hispanic Mexico valley, and the community water tribunals of the huertas (intensively farmed garden) regions in southern Spain. ${ }^{24}$

Although they are often studied in the past, aspects of all these systems have survived to the present, albeit not without having been adapted to suit contemporary social and economic circumstances; they may thus be described as "indigenous" in the sense that they constitute "local practices, as distinct from interventions imposed from outside", despite that they may have been derived from hydrosocial practices in other places. (Scoones, Reij and Toulmin 1996:10) To describe these practices as 'systems' suggests that they are understood and represented by researchers in ways that, for my purpose, indicate their most salient feature: they integrate water and society, hydraulic technique and culture, the water process and relations of power, such that that one term of the dyad can not be understood without - and depends for its existence on - the other. As much may be said of any irrigation system - including those characteristic of the modern

\footnotetext{
23 "Classic" because of the frequency with which they appear in the water history literature.

24 To cite only a few examples: For the qanats, see Wulff (1968); Pazwash (1983). For the subak system of Bali see Geertz (1972). However note that Lansing $(1987$; 1991) has pointed out that the more relevant locus of analysis for Balinese water management (or hydrosocial relations) is the water temple rather than the subak. For Sri Lankan tanks see Goldsmith (1982). For tanks in Tamil Nadu, India see Mosse (1995 and particularly 2003). For traditional water management and irrigation systems in pre-Hispanic Mexico Valley see Naranjo and Bobee (2001) For the water tribunals of southern Spain see Ward (1997:ch. 2)
} 
state $^{25}$, and in this sense at least, the distinction between traditional and modern is problematic. Nevertheless, perhaps because of the degree to which they differ from modern systems, the traditional examples tend to draw out these links in an explicit way: Consider for example what Geertz has written of the subak system ${ }^{26}$ in Bali:

"T]he subak is at once a technological unit, marked out by the collectively owned dam and canal; a physical unit, an expanse of terraced land with a defined border around it; and a social unit, a corporation consisting of people owning land in that expanse, serviced by the dam and canal. It is also... a religious unit... The focus of [the ritual system of water distribution in the subak] is a rice-goddess cult whose precise content [includes] special ceremonies at special times, and specific altars, gods, offerings, and prayers. These various ceremonies are symbolically linked to cultivation in a way which locks the pace of that cultivation into a firm, explicit rhythm." (Geertz 1972:29,30)

More recently, another anthropologist (Lansing 1987, 1991) has challenged and revised Geertz' assessment of Balinese irrigation systems, putting less emphasis on the autonomy of the relatively small subaks and stressing instead the role of the traditional regional water temples in integrating water allocation and social interaction:

"T]he social units that set cropping patterns and irrigation schedules are usually not individual subaks but regional water temples...thus the practical management of irrigation is embedded within the hierarchical structure of the water temples... Altogether it is clear that the productive process involves intricate systems of

\footnotetext{
${ }^{25}$ Worster (1985) is perhaps the best description of the cultural embededdness of a modern irrigation system.

26

Wittogel saw the traditional irrigation (subak) system of Bali as an example of centralized, hydraulic society. (Wittfogel 1957:53-54) This view has been refuted by most if not all subsequent researchers, who have seen it as either a "decentralized" model, in which each subak is an autonomous unit (e.g.Geertz 1972) or as a system controlled by the institution of water temples, separate from the state. (Lansing 1987)
} 
social control extending over hundreds, even thousands of hectares of irrigated fields." (Lansing 1991:44,48,49)

Both Geertz' and Lansing's ethnographies of water describe a society in which human-water relations define people and water in a way that renders them materially and conceptually inseparable. Moreover, in these and other examples, the very presence, allocation and disposition of water cannot be understood apart from the social relations in which it is embedded. Consider what David Mosse says of the tank system in southern India:

"Tank irrigation in Tamil Nadu has a long and complex history throughout which systems of 'community management' have expressed and been underwritten by local and regional relations of power and patronage. Inscriptions on tank bunds (crescent-shaped earthen dams) and in temples which go back to the centuries BC...only demonstrate the political importance of the construction and maintenance of these public resources. Water has always been a political as well as a natural resource, and the operation of tank systems regulating its flow have been influenced by changing configurations of power at both village and state level." (Mosse 1995:146)

While the subak (or water temple) and tank systems are among the best known examples (see also Goldsmith 1982), it needs to be stressed that researchers have described an array of indigenous hydrosocial relations, each having coevolved in the unique hydrological and social circumstances in which it was developed. At the risk of boring the reader with another rather lengthy quote, something of the wealth of this research (and its relevance to water issues of the present) is suggested by Bennett, who summarized work done by historical anthropologists up to the mid-1970s: 
"The sheer variety of structures created for obtaining and better utilizing water in prehistoric and early historic societies deserves more attention than it has received from contemporary hydraulic engineers. Such societies developed suitable water control systems for every precipitation pattern in climates ranging from desert aridity to variable humidity, and the functions of many of these structures were misunderstood for generations... As archaeological work uncovers a greater variety and intensity of water-control systems, few opportunities appear to have been missed by prehistoric peoples... The variety of these structures, relying on delicate small-scale adjustments to local conditions, contrasts with a modern philosophy, which emphasizes large-scale projects of stereotypic design. (Bennett 1974:37, 38-39)

The contrast with modern water structures - and with the 'modern philosophy' that underlies them - that Bennett alludes to is important: While historical, anthropological, and other research has explored the nature of indigenous water systems and philosophies in history, the unmarked social nature of modern water has sometimes been taken for granted as that against which all these other systems may be contrasted. Ironically, such a presumption presents the same problem as the research on hydraulic society, which emphasizes the essential similarities between all large, centralized irrigation systems, including those of the twentieth century. In both cases, the nature of modern water itself is presumed to be self-evident. That modern water reflects an indigenous water system that deserves to be investigated in its own right is perhaps the most important conclusion that I draw from these studies.

\section{Cultural Ecology of Water}

Fikret Berkes defines cultural ecology as "an ethnological approach that sees the modes of production of societies around the world as adaptations to their local environments." (Berkes 1999:47) I take this rather loose definition to include 
several related fields, including human ecology, ethnoecology, ethnoscience, anthropology and traditional ecological knowledge. (Berkes 1999:37, 47-51) Work in what might be called the cultural ecology of water overlaps in many ways with what I have described as water history, but might be distinguished in the sense that it deals more explicitly with traditional knowledges of, and relations with water practiced by different people in contemporary settings. It also overlaps with, or includes, work in the cultural ecology of land management, soil conservation, and other related fields in which water plays an important role, often described conveniently in terms of soil and water conservation, or SWC. The practical thrust of much of this work stems from recognition that models of soil and water conservation and management developed in the context of the industrialized world have often proved hydrologically and socially inappropriate in many third world settings. As an alternative, the study of "traditional", or "indigenous" systems of water use and resource management is seen as the most appropriate place to begin when promoting equitable and sustainable development in the agricultural sector. (Pawluk, Sandor and Tabor 1992:298; Brooks 2002) These "indigenous" systems are often described in contrast to "external", or "conventional" water and resource management systems. Researchers have contrasted "external" with "local" soil and water conservation (SWC) technologies in Africa, stressing basic differences in the origin, purpose, and features of design, temporality of construction, type of labour demands, etc. (see Figure 2.1) Here, indigenous SWC techniques are defined as "the sum of practices involved in managing soil and water in agricultural settings [and]...must therefore be situated 
within a social and economic understanding of the role of technology, the rationale and purpose of its design." (Scoones, Reij and Toulmin 1996:10-11) Furthermore, "Unlike conventional engineering designs of SWC structures which are specified in technical manuals and extension handbooks with precise dimensions and design requirements, local SWC techniques are much more flexible." Thus "ethnoengineering" is a result of "adaptive performance" rather than universal (timeless and placeless) response to a technical design problem. (1996:12)

Characteristics of externally and locally derived SWC technologies

\begin{tabular}{|c|c|c|}
\hline Characteristics & External & Local \\
\hline Designed by & $\begin{array}{l}\text { Engineers and development } \\
\text { planners }\end{array}$ & Local farmers \\
\hline Designed for & Soil conservation & $\begin{array}{l}\text { Multiple, depending on setting } \\
\text { (including soil/water harvesting, } \\
\text { conservation, disposal) }\end{array}$ \\
\hline Design features & $\begin{array}{l}\text { Standardized in relation to slope } \\
\text { features }\end{array}$ & $\begin{array}{l}\text { Flexible, adapted to local micro- } \\
\text { variation }\end{array}$ \\
\hline Construction & One-time & $\begin{array}{l}\text { Incrementally (fitting with } \\
\text { household labour supply) }\end{array}$ \\
\hline Labour demands & High & Variable, generally low \\
\hline Returns & $\begin{array}{l}\text { Long-term environmental } \\
\text { investment }\end{array}$ & Immediate returns \\
\hline Project setting & $\begin{array}{l}\text { Large-scale, campaign approach; } \\
\text { food-for-work/cash-for-work/ } \\
\text { employment-based safety-net } \\
\text { programmes, etc }\end{array}$ & $\begin{array}{l}\text { Longer term support to } \\
\text { indigenous innovation; } \\
\text { participatory research and farmer- } \\
\text { to-farmer sharing }\end{array}$ \\
\hline
\end{tabular}

Figure 2-1- Characteristics of externally and locally derived Soil and Water Conservation technologies (reproduced from Scoons, Reij and Toulmin 1996:24) 
As suggested by the table shown in Figure 2.1, most of these studies contrast traditional, or indigenous water relations against "externally" derived models of water management. The place of modern water in this scheme is in the presuppositions built into the "external" scientific models propounded by development agencies whose expertise is grounded in Western experience and relations with water as an abstract resource. The practicality of utilizing a more locally-based (indigenous), socially-relational view of water is suggested in cases where the cultural ecology of water is being put to work in a development setting. For example, "the potential for development projects building directly onto existing indigenous farmer-managed irrigation schemes" in parts of Africa has been shown to be very great. (Adams 1996:156) Also, interest among scholars and development professionals in traditional systems of water harvesting - such as the tank system described briefly above - suggests the practical benefits of building on water traditions. ${ }^{27}$ (El Sammani and Dabloub 1996; Mohamed 1996; Brooks 2002; Seenivasan 2003; Falkenmark 2005) As a final example, precipitation patterns in semi-arid and arid areas differ markedly from those in temperate regions; often a large volume of total annual rainfall is precipitated in very few high-intensity events. People who have relied on this rainfall have developed a wide range methods to capture and store water until the next rainy season. These techniques have become enmeshed with local culture and customs in important ways. "Even though

\footnotetext{
27 Although as Mosse (1995 and 2003) and others have stressed, these (tank) and other "traditional" hydrosocial systems have evolved over the centuries, and continue to do so in a variety of ways, such that the appeal to "traditional" water systems is problematic if it serves to romanticize or fix hydrosocial relations in a mythical past. See also Adams (1996:155).
} 
these traditional water harvesting systems can look precarious and casual in the eyes of modern technologists," write Ferroukhi and Chokkakula,

"they have been perfectly sustainable for centuries. The reason for this is that they are compatible with local lifestyles, local institutional patterns and local social systems. They represent a fund of solid experience gained through generations..." (Ferroukhi and Chokkakula 1996:91)

An important general trend in the social sciences of recent years has been integrating analysis of resource management with social systems. (Berkes 1999:51-55) Consistent with this trend, research in what I am calling the cultural ecology of water treats water as something that can not be divorced from questions involving local power relations, religious worldviews, cultural values, economic practices, and other social circumstances providing the context in which water is given meaning and is "managed". As Groenfeldt has stated of the variety of "indigenous irrigation" practices in Asia, the "physical properties of water" are universal, a condition that imposes certain "universal management functions" such as the need to mobilize labour, to allocate water and to institute methods of resolving disputes. Unlike Wittfogel, however, the "physical properties of water" do not determine a homogeneous social response. "The solutions to these universal problems..." he stresses, "are unique to each indigenous system, depending upon the particular social and cultural traditions, the particular physical setting, and the particular individuals concerned." (Groenfeldt 1991:117)

The work cited here reflects a growing recognition of the value, appropriateness, functionality, sustainability and efficiency of traditional relations that people in 
different parts of the world under different hydro-climatic conditions have evolved with water. In light of this recognition, and at a time of growing concern about the sufficiency and sustainability of water resources generally, it is hardly surprising that researchers have drawn attention to these accommodations, and in general, to the effectiveness of traditional modes of water use and water conservation in different parts of the world: in Africa (Reij et al. 1996; Scoones et al. 1996) and Asia (Groenfeldt 1991; Pawluk et al. 1992;), to the variety and sustainability of successful adaptations of cultural practices to the hydrological conditions of semiarid regions (Fairhead and Leach 1996; Swift 1996; Leach and Mearns 1996b), and of the sustainable yet productive exploitation of wetlands and coastal areas (for examples see Berkes 1999:72-75).

In most of these and similar studies, the relations that water - or with landscapes whose salient feature is the scarcity or intermittency of water - have co-evolved with people are set against exogenous models and prescriptions for water and land management imposed by central agencies, development institutions and Western-educated or inspired resource managers. This is expressed, for example, in terms of the opposition between "ecological" and "industrial" modes of water management (Goldsmith and Hildyard 1984:Vol. 1, Ch. 26) or between "indigenous irrigation" and "modern agricultural development". (Groenfeldt 1991) The misguided tendency of some state planners and development experts to ignore, and even to "target" these "indigenous, traditional systems" for replacement by modern techniques has been highlighted (e.g. Groenfeldt 1991:114,115) along 
with the resiliency, despite these incursions, of traditional water relations and systems. By the mid 1990s, researchers in cultural ecology and other fields especially political ecology - had mounted a powerful challenge to these models and to the conventional thinking about problems such as desertification, soil erosion and land management practices in arid regions. (e.g. Leach and Mearns 1996a; Stott and Sullivan 2000; Forsyth 2003) Among the many aspects of this critique, the application of geographically and culturally inappropriate ecological ideas and experiences - such as arose out of the North American dustbowl of the 1930s - on subsequent thinking about soil erosion in Africa, has been stressed. (Leach and Mearns 1996b:17)

The research of anthropologists studying human-water relations has brought similar concerns to the forefront in a variety of case studies from Zimbabwe (Derman 1998), Arizona (Whitely and Masayesva 1998), the Sonora Desert of New Mexico (Bowden 1977), northern Quebec (Ettinger 1998), Washington State (Greaves 1998), Palestine (Hassoun 1998), and the borderland between the United States and Mexico (Berry 2000), among others. Articulating a common theme in all these studies, Donahue and Johnston have highlighted the need to investigate links between how water gets managed and the power and interests of those who define what it is:

"What different cultural meanings does water have for the contending parties, and how do these meanings complicate mediation among the various interests? How are some social actors able to impose their definition of water on other social actors with different but equally legitimate definitions? In other words, how 
is power used in the service of one or another of the cultural definitions of water? (Donahue and Johnston 1998:339):

The question of how power is "used in the service of one or another of the cultural definitions of water" is one of the questions directly addressed by a number of researchers working in the field of political ecology, as summarized briefly below. Before turning to this however, I want to stress how in the work described as the cultural ecology of water, the emphasis is on identifying the value and virtues of indigenous, non-Western systems. Even where these have been threatened or destroyed by the imposition of Western models and "conventional" ideas about land use and water management, the nature of those models and conventions the 'cultural definition of water' in the West, as it were - has remained unexamined in its own right.

\section{"Water" is for fighting over - the Political Ecology of Water}

While resources such as soils, forests and oil have been the main focus of research in the field that identifies itself as political ecology ${ }^{28}$, questions involving

\footnotetext{
${ }^{28}$ Political ecology draws from political economy and (more recently) has employed post-structural insights on the social construction of nature to produce a diverse field of critical study of environmental issues. Bryant (1991:165) describes the field in terms of an '[l]nquiry into the political sources, conditions, and ramifications of environmental change ${ }^{n}$. Originally focusing on ecological questions in Third World regions, research in political ecology is increasingly concerned with nature-society relations in all parts of the world. Among its central aims is to analyse questions of access to and control of resources and how these impinge on environmental sustainability and socio-economic livelihood. (Watts 2000:257; see also Johnston et al. 2000:590, Castree and Braun 1998:11-12) To the more foundational class-based and historical materialist analyses of how different people gain or lose access to resources, have been added research on the way scientific and development discourses relate to these questions. "[R]ecent observations in political ecology", notes Fiona Mackenzie, "demonstrate how struggles over material resources - the means of production - are simultaneously struggles over the symbolic meanings of these resources, over the
} 
various aspects of access to and control of water are of growing interest. Much of this work takes up the same issues addressed in the history and cultural ecology of water: the cultural embeddedness of local, or traditional approaches to water management and water conservation, the social and environmental sustainability of these practices, their adaptability to changing environmental and economic circumstances, etc. However, research in the political ecology of water foregrounds a number of critical questions relating to the political, economic and discursive circumstances impinging on hydrosocial relations. Questions involving whose understanding of water - and whose mode of relating and gaining access to it - attains dominance, is what I want to highlight here. As Vandana Shiva has argued, the way water is conceptualized and represented is instrumental in determining who gains access to it and on what terms. This necessarily produces conflict over the meaning and definition of water, a kind of conflict that she describes as "water wars" - "paradigm wars - conflicts over how we perceive and experience water..." (Shiva 2002:ix)

One of the key tasks of political ecology is to analyse and politicize the ecological categories and suppositions that are often taken for granted in expert environmental discourse, so as to reveal the social location of the interests and privileges, advantages and disadvantages they entail. (See particularly Forsyth 2003) Discourses of water resources management, water conservation, urban water services, drought and desertification are good candidates for critical analysis 2000:697) 
in the political ecology tradition because they often tend to internalize the interests and advantages of privileged groups while dismissing or rendering mute the hydrosocial needs of the disadvantaged. (Stott and Sullivan 2000) "[T]he water problem", as Swyngedouw has shown, "is not merely a question of management and technology, but rather, and perhaps in the first instance, a question of social power." (2004:175) With particular respect to the politics of urban water provision, Swyngedouw has stressed: "[T]he technocratic discourse and argumentation help to obfuscate the issues of power and control and help to formulate the water problem as one that is determined by the power over nature rather than by the power of one social group over another... It is quite clear that the technological argument belongs to the arsenal of discourses, if not ideologies, developed and advocated by those who hold power. ${ }^{n}(2004: 176)^{29}$ Political ecology is a particularly useful approach for deconstructing the political and cultural implications of such expert discourses that presume to know and speak for the nature of water, forcing us to recognize their inherent political content. Although he was no political ecologist, a very slight variation of Mark Twain's much-too-often-repeated quote might serve as an apt subtitle for the political ecology of water: "Whiskey's for drinking but "water's" for fighting over." (I have added the inverted commas around "water's")

\footnotetext{
${ }^{29}$ Note the statement by C.S. Lewis: “"What we call Man's power over Nature turns out to be a power exercised by some men over other men with Nature as its instrument." (quoted in Worster 1985:50)
} 
"Water" is for fighting over, partly because of the different social relations that various definitions and discourses of water entail. The very fact that people are fighting over water, over the way that it is to be defined, deployed and distributed, at once confirms and poses a challenge to the universality of modern water. A couple of examples will be given here, both of which have been the subject of attention in political ecology: critiques of the commodification of water, and analysis of the social construction of drought and water scarcity.

\section{Fighting the Water Market}

Much of the recent work falling within what might be described as the political ecology of water responds critically to the post-Fordist commodification of water and the privatization and marketization of water and water services ${ }^{30}$, particularly in urban environments (Bakker1999, 2003a, 2003b; Swyngedouw 2000; Kaika 2003, 2005) but also in a more general sense (Ward 1997; Petrella 1998; Biro 2002; Shiva 2002; Ferrari-Comeau and Chalecki 2002; Barlow and Clarke 2002; Strang 2004) Since the mid-1980s, the invasion of common and public water resources and services by market forces is among the themes of greatest concern among those interested in water. Aaron T. Wolf has noted that over the past

\footnotetext{
30 By commodification I mean the hydreification of water as a commodity, as illustrated for example in the growing commerce in bottled water and the sale of bulk water. Marketization refers to the application of market principles as a means of allocating or conserving water, even if under the management of public authorities, as for example in the application of various pricing mechanisms for water services. Privatization refers to the shift from common property, or stateowned water services to the private sector, as was the case with respect to the privatization of municipal water services under the government of the U.K.'s Margaret Thatcher. The categories may overlap, as for example when a private company obtains the right to abstract groundwater (in the case where groundwater is a public good) this entails both commodification and privatization.
} 
couple of decades "no global water policy meeting has neglected to pass a resolution which, among others, defined water as an 'economic good." (Wolf 2003:174) Over approximately the same period, critical scholars, water activists and communities around the world have responded by declaiming this identity. People in all parts of the world have acted to defend their communities from the incursions of privatization in the water sector in a fashion that Karl Polanyi might have cited as a prime example of the "self protection of society." (Polanyi 2001) ${ }^{31}$ Arguing from within a critical political ecology perspective, Eric Swyngedouw summarizes many of these concerns:

"The recent shift towards turning $\mathrm{H}_{2} \mathrm{O}$ into a commodity has dramatically changed the social and political meaning and cultural valuation of water. First of all, water is turned into profits and capital accumulation by private or public/private institutions... Second, non-economic uses and functions of water then have to be regulated by governmental institutions that often face serious opposition, conflict or other constraints in the face of powerful private agencies... Third, this shift inevitably entails a change in the geometry of social power. Private actors and companies become much more powerful voices in strategic water-related decisions, at the expense of other civil society organizations or of the state. Fourth, while the water cycle operates along temporal rhythms that are part of the larger environmental system, it nevertheless is increasingly forced to operate [in accordance with business cycles]. Fifth, the privatized nature of crucial parts of the water cycle diminishes the transparency of decision-making procedures and limits access to data and information... Finally, water production and distribution becomes incorporated into an increasingly global economy in which investment flows, financial capital markets, and investment decisions shape the contours within which the urban water economy operates. In sum, the shift from public good to private commodity alters the choreography of power through which the urban socio-hydrological cycle is organized." (Swyngedouw 2004:41)

\footnotetext{
31 In addition to the more scholarly works cited above, Barlow and Clarke (2002) have produced an influential polemic against the privatization of water. For a good account of the single most renowned "fight" involving the privatization of municipal water services to date (in Cochabamba, Bolivia) see Finnegan (2002). In the wake of the wars between the water privateers and activists for public water in the $1990 \mathrm{~s}$, a variety of creative approaches to maintaining water services within the public sphere are at play. (Balanya et al. 2005a)
} 
"Turning $\mathrm{H}_{2} \mathrm{O}$ into a commodity", it might be pointed out, is preceded by another act; namely, that by which water was turned into $\mathrm{H}_{2} \mathrm{O}$. Both of these transformations are made possible and sustained by modern water, a habit of thought by which water is made essentially some-thing. But by the same token, the recognition of, and resistance to, changes in hydrosocial relations entailed by water's privatization and commodification is tantamount to an acknowledgement of water's social nature and its constitutional entanglements with people. Such an acknowledgement poses a challenge to modern water itself, or at least brings to light its transparency. The notion that by merely putting a price on water or by privatizing water services, nothing more significant than greater efficiencies in its allocation and use may be effected, is seen through by critics who recognize that essentializing water as an "economic good" has the potential of producing hydrosocial relations that are even less wholesome than the ones they are meant to address. ${ }^{32}$ The need to "reclaim public water" not only in a discursive sense, but in the sense of having people get involved in water decisions at a local level, has been the main lesson learned from a decade of fighting water privatization.

(Balanya et al. 2005a) The social neglect of water that is sanctioned by the modern paradigm - the "deresponsibilisation" of water as Kalaora has put it (Kalaora 2001) - is regarded more and more by critics as an aberration. (See Strang 2004) “The water crisis", as Colin Ward has noted, demands that we approach water problems not as a crisis of water as such, but as a "crisis of social responsibility." (Ward 1997)

32 See discussion of the new "Global Water Regime" in Chapter 9. 


\section{Social Construction of Drought and Water Scarcity}

Political ecology makes an important contribution to understanding the social construction of apparently 'natural' processes such as drought and water scarcity. (Johnston 2003) In contrast with conventional resource management, which seeks to identify "the essence of the problem and point toward essential solutions" political ecology has the strength of focusing on "analysis of discourse and ideology, seeking to define new ways of collapsing the nature/society duality and presenting a coherent view of hybrid environmental problems such as drought." (Downing and Bakker 1997:13) In other words, the notion of drought as a "natural" disaster or "natural" hazard is increasingly challenged by awareness of the political, economic and discursive contexts in which it is always embedded. Drought is, as Blaikie et al. have put it is "the product of the social, political, and economic environment..." (Blaikie et al.1994:3) ${ }^{33}$ The notion of drought as a natural disaster depends on an acceptance of modern water, which allows something like drought to be perceived simply as a consequence of its absence. The socio-economic circumstances, technological changes, income disparities, geographies of power, commercial activities and demographic factors that convert a shortfall of water into "drought" - the social causes of drought - can be largely ignored when water is seen in terms of volumes of precipitation and streamflow

\footnotetext{
33 The critique of discourses of drought can be seen as one aspect of the social construction of resource scarcity. For over two decades, geographers and others have elaborated the social construction of the scarcity of resources (as well as generalized scarcity). (e.g. Harvey 1974, Sandbach 1980, Xenos 1989, Ross 1996; Watts 2000:262) This critical analysis of scarcity has been especially responsive to perceived, 'Malthusian' threats of imminent depletions of nonrenewable resources beginning in the 1970s. (see Chapters 8 and 9)
} 
rather than in relation to the social circumstances that make it what it is. By challenging the apparent naturalness of drought and water scarcity, research in political ecology is in effect challenging modern water.

To link this with the theme discussed above, the material production ${ }^{34}$ and discursive construction ${ }^{35}$ of water scarcity has been shown to promote the commodification and privatization of water services. (Bakker 1999; Kaika 1999, 2003,2005 ) This kind of analysis follows a line of thought set out by Smith over twenty years ago, who described the relation between commodity production and "produced scarcity in nature." (Smith 1984:60) More recently, Swyngedouw has written:

"A climate of actual, pending, or imagined water crisis serves not only to instigate further investment in the expansion of the water-supply side... but also fuels and underpins drives towards commodification. As the price signal is hailed as a prime mechanism to manage 'scarcity', the discursive construction of water as a 'scarce' good becomes an important part of a strategy of commodification, if not privatization." (2004:47)

Representing water as something devoid of social content - i.e. as a part of nature, a natural resource, or commodity - allows nature to be used as the explanation for water scarcity instead of, for example, the lopsided distribution of water services in cities (with poor sections being disproportionately underserviced). Given the antisocial nature of modern water, nature always takes the blame as "the principal 'cause' of water scarcity rather than the particular political economic configurations

\footnotetext{
${ }^{34}$ Through, for example limiting or shutting down municipal water services.

${ }^{35}$ Through, for example public campaigns describing water shortage as a "natural" rather than a distributional problem.
} 
through which water becomes urbanized [or otherwise made available to people]." (Swyngedouw 2004:47) Recognition of water's social nature, by contrast, draws critical attention to the socio-economic circumstances that occasion every instance of water scarcity.

The specific historical contexts in which 'drought' has been critically analysed in political ecology have varied from the "Yorkshire drought" of the mid-1990s in England (Haughton 1998; Bakker 1999; Bakker 2003a), to the "the social construction of drought as a disaster" in rural Queensland and New South Wales, Australia (Stehlik et al. 2000:38), the California drought of the late 1980s (Nevarez 1996) and the drought affecting the city of Athens between 1989 and 1991. (Kaika 2003; 2005). These analyses treat drought as a partially discursive construction that is shown to serve specific social, political and economic interests. They show, respectively, how the construction of drought bears on the privatization of water services, how the meaning and effects of drought vary between men and women in an affected agricultural region, how discourses of drought serve to authorize large scale state water projects, and how drought helps produce a climate of crisis that helps promote the commodification of water.

"Water scarcity" has also been considered as a social artefact brought on by changes in demand for and use of water associated with industrialization, commercialization and technological change. It has been argued, for example, that private ownership of groundwater rights and growing reliance on commercial crops 
have been instrumental in producing "socially constructed scarcity" in the Canary Islands (Aguilera-Klink et al. 2000), and that the shift from traditional rainfall capture techniques to widespread dependence on desalination technologies in the Virgin Islands has been a cause of water scarcity. (Johnston 1998) Elsewhere, it has been shown that the displacement of traditional irrigation schedules brought on by Green Revolution techniques of continuous cropping of rice in parts of Asia have had the effect of producing general water scarcities where none existed before the introduction of these technologies. (Lansing 1991:3) The growing incidence of water scarcities induced by the proliferation of golf courses in Southeast Asia (indeed, in all places easily accessible to the world's Westernized urban class) might also be mentioned in this context.

In an article introducing "The Political Ecology of Water", Barbara Rose Johnston (2003) gives a number of illustrations of the "manufacture" of water scarcities in different parts of the world (including industrialized countries like the United States). These show the extent to which water scarcity has been produced as a result of social factors: the increased water demands entailed in western-style industrial development and economic growth; the ecological and social effects of large dams and other hydraulic structures; surface and groundwater pollution; and the effective "enclosure" of formerly successfully managed common water resources to fit the demands of industrial capitalism and in the case of many developing countries, structural adjustment requirements imposed by international financial institutions. (2003:74-85) The latter demands have included the 
privatization of public water services, which, as Johnston points out with the case of the privatization and commercialization of water services in South Africa, resulted in over 2 million South Africans being evicted from their homes for failing to pay water bills. $(2003: 85)$ The point of these various critiques is certainly not to question the reality of water or the real human suffering that arises when people do not have adequate access to it. As with work revealing the social construction of drought, their purpose is to highlight the extent to which any instance of water scarcity needs to be considered as a social rather than a natural phenomenon.

\section{Post-colonialism and Imperial Water}

"Imperialism" wrote Edward Said, "after all is an act of geographical violence through which virtually every space in the world is explored, charted, and finally brought under control." (Said 2000:297) Of few things does this ring more true than for water. (see Worster 2006) Bringing water under epistemological and material 'control' in colonial settings was a major imperial undertaking and a process that contributed to the development and diffusion of modern water. The role of the colonial state - particularly British India, British and French Egypt and other European colonial holdings in North Africa - in helping produce modern water has been highlighted by some historians, insofar as it contributed to a corps of hydraulic-engineers whose expertise in evacuating the (indigenous) cultural content of water and replacing it with the water balance equation could be, and 
was, applied in country after country. ${ }^{36}$ Here, I want to draw attention to critical research that has focused on (mainly) European attempts to modernize traditional water relations in a colonial context. I also want to consider research dealing with contemporary efforts to revive or sustain traditional water relations in the face of pressures from the post-colonial state, international development agencies, and private interests that seek to continue the process of hydrological modernization. To me, the interest in this work intimates the opportunity if not the need for a focused investigation of modern water as a discourse against which alternative and resistant discourses of water need to contend.

The work that I have in mind blends with political ecology in the sense that it approaches water and hydrological management as politically contested, or contestable, discourses. But I make reference to post-colonialism for two main reasons: Most of this work originates in or examines colonial and post-colonial India, and is informed by a strong sense of the colonial experience as having produced the hydrological and water-resource discourses against which precolonial as well as contemporary society must contend. (Shiva 1988:67-77; Shiva 2002; Mosse 1995, 2003; Arnold and Guha 1995; Hardiman 1995; Gilmartin 1994,1995; Whitcombe 1995; Seenivisan 2003) Second, its approach is mainly to consider the influence of colonial hydrological hegemony in a discursive sense -

\footnotetext{
${ }^{36}$ Worster refers to this collective as an "international fraternity of hydraulic engineers" who understood that "they were engaged in a mission of conquest that was going on in all the arid parts of the world - in India, Egypt, the Sahara, Australia." (1985:143-156) The experience gained by hydraulic engineers in colonial settings was applied in the western United States, which sent scores of hydrologists and engineers on field trips to India to learn the tricks of the trade.
} 
the contrast between traditional and imperial hydrological relations is presented in terms of contrasting discourses - and the contemporary struggle to restore, reclaim or revise traditional water relations is seen in terms of asserting knowledges of and relations with water that directly challenge modern hydrological discourse.

Derek Gregory, who among geographers is perhaps its most important exponent, has described post-colonialism as a "critical politico-intellectual formation that is centrally concerned with the impact of colonialism and its contestation on the cultures of both colonizing and colonized peoples in the past, and the reproduction and transformation of colonial relations, representations and practices in the present." (Gregory 2000:612). The constitution of the present in the colonial past is an important theme of post-colonial studies, and suggests how this approach may be relevant to an examination of modern water. In the encounter between European and non-European cultures in the colonial context, indigenous relations with water were often liquidated and replaced by western hydrological discourses (including the water control structures by which they achieved material form). Because the imposition of what might be called "imperial water" upon such people and places had a profound impact on hydrological discourse generally, modern water is in part the legacy of imperialism. Moreover, because colonial water discourses are "still abroad in the world" (Gregory 2001:85) constituting and informing the ways water and its relations with people are conceptualized and 
managed, we inhabit the "colonial present", as Gregory has put it in a recent study of a different topic. (Gregory 2004) $)^{37}$

Most post-colonial studies have been of the former British Empire, with a notable concentration of interest in British colonial India. (Millner 2000:669) It is perhaps no coincidence that British India in the nineteenth century provides most studied example of imperial water. (Whitcombe 1995:240) "[T]he wonderful history of irrigation in India"38 featured hydraulic works of such "bold and magnificent conception ${ }^{\mathrm{n} 9}$ that they were legendary in their own time, serving as a model for hydraulic engineers and water planners even in the industrialized world. (Worster 1985:143-156) In the most general sense, over the course of the history of British colonial India, these 'bold and magnificent' hydraulic works replaced indigenous hydrological relations to various degrees in different places. In the early years of the empire, there was a tendency to adapt traditional systems of irrigation to the growing commercial and productive needs of the colonial state. But in order to expand production to supply the home market and raise sufficient state revenues (Whitcombe 1995), the imposition of a new hydrological discourse was deemed necessary, as described by Gregory in a passage, part of which has already been quoted in Chapter 1:

\footnotetext{
${ }^{37}$ Gregory's The Colonial Present is a post-colonial analysis of Western hegemony in Afghanistan, Palestine and Iraq. (Gregory 2004)

${ }^{38}$ From "Immense Canal system: Achievement in India", The Times, 11 December, 1928. Quoted in Whitcombe 1995:237)

39 From the Punjab Irrigation Manual (n.d.), quoted in Gilmartin 1994:1132.
} 
"For this, water had to be 'disenchanted' so that [quoting Worster] 'all mystery disappears from its depths, all gods depart, all contemplation of its flow ceases'. This involved not only filtering cultural residues from 'water' but also replacing them with others. Thus, in the second half of the nineteenth century a new discourse of hydrology and hydraulic engineering emerged which translated 'nature' into mathematical formulae. In these there would be no place for 'local' knowledge and the hydraulics of irrigation channels and the mechanics of dam construction could be made the same the world over." (Gregory 2001:96-7)

The "filtering of cultural residues" is a significant operation and effect of modern water, and suggests how an examination of the imposition of imperial hydrological relations constituted modern water's advance guard in the nineteenth century. ${ }^{40}$ But the process by which European hydrological discourse engulfed local waters in colonial India was complex. As David Mosse is careful to remind us, the popular notion of an equilibrated, harmonious system of traditional water relations disrupted by colonial rule sacrifices important historical nuances to a somewhat romanticized notion of hydro-social transformation. ${ }^{41}$ A highly nuanced history of

\footnotetext{
40

A couple of examples from British India: First, Hardiman's (1995) study of the withering of smallscale "community-based systems of irrigation" that had been common in many arid and piedmont regions of India as long ago as $700 \mathrm{BC}$. Focusing on the Baglan region, he argues that the colonial state was interested only in large-scale irrigation works that could be centrally controlled to maximize revenue production, and shows how "The state, therefore neglected the small systems... Without proper attention, the canal systems disintegrated quickly." (1995:189-190) Second, as noted above, the fate of the tank system of southern India has also received a great deal of attention from historians and cultural ecologists. Much of this research is focused on the "crippling effect" of modernity, in the form of colonialism, on the traditional tank system, (but see footnote below). Contemporary struggles to maintain or restore the system are hampered by the legacy of colonial hydrological discourse, particularly insofar as it disregards or ignores the social bonds by which the tank system is constituted. "The centralized administration introduced by the British colonial rule had almost wiped out the role of the community in conserving and developing [the tanks]." And the problem has worsened under the post-colonial state: "Even in free and independent India it is [sic] continued to be even more retrogressive in keeping people and locals away in matters related to the tanks...The decay of tanks represents the typical death of a village ecosystem... The tank management systems which are directly related to the village social systems are breaking down across the state..." (Seenivasan 2004:8, and personal correspondence) 41

Mosse's study of the tank system in southern India points out that these have always been subject to uncertainty, political contestation, and vulnerability - even in pre-colonial times. He
} 
what might be termed a traditional-imperial water nexus is offered by David Gilmartin, who has studied the process by which the British colonial state in the late nineteenth century administered large modern water diversion and distribution canals in the Indus basin, while at the same time allowing, and indeed relying on, traditional, heterogeneous, locally-administered water systems remaining in place in the downstream communities that received the water. (Gilmartin 1994,1995) The British described these downstream regimes as "beyond the outlet", with the "outlet" of the canal representing the boundary between modern and traditional water relations:

"British canal administration was therefore marked by a strong tendency to view the canal outlet as the great theoretical divider of the irrigation system, with a system of rational environmental control operating on one side, and a world of indigenous, customary and kin-based community organization operating on the other. Even as indigenous communities were rigidly excluded from influence over the main, scientific irrigating system, their domination over the disposal of water 'beyond the outlet' was largely accepted as an inevitable fact of colonial irrigation." (Gilmartin 1995:226-7)

From Gilmartin's research we learn that, for a time, these structures of local organization survived, and while they were increasingly characterized by instability and internal conflicts, ${ }^{42}$ the "bonds of local community" nevertheless provided a

leaves no doubt however, that the overall effect of the colonial era was to aggravate these problems and promote neglect of the traditional tank system. (Mosse 2003)

42 That is to say, they did not operate according to an idealized vision of community organization. Gilmartin does not raise the question of whether such instability and internal conflict might have been associated with the effects of colonization, or indeed with the introduction of modern water in the basin. However, his remarks on the eventual breakdown of these local systems would certainly suggest this to be the case. (see Gilmartin 1995:229-230 and below) 
means of water distribution and allocation that the British found useful. Ultimately,

however, modern water relations overran the community-based regimes:

"[Their] increasing dependence on relations with an irrigation bureaucracy for securing the most critical of productive resources for the local environment water - guaranteed that a meaningful definition of the environment that was purely local was impossible, as was, therefore, a structure of encapsulated, 'natural', local communities operating in their outlet-defined spaces. By trying to incorporate indigenous 'natural' communities into a larger hydraulic model, the colonial state thus undercut the local environmental foundations for the very local communities that it professed to rely on." (Gilmartin 1995:230)

The point in discussing this here is to highlight how research from a post-colonial

perspective has identified distinctions between traditional and modern water

management regimes that are still relevant in many parts of the world. Donald

Worster has recently noted that by means of such critical analysis: "People

became more aware that imperial water was more often than not water diverted

away from traditional agrarian users: Hispanic farmers or Native Americans in

North America; village farmers in other parts of the world." (2006:13) But the most

43

Elsewhere Gilmartin (1994) offers an interesting study of how advances in river hydrology in colonial India - specifically the science of silt management and control - had the effect of breaking traditional social bonds with water in the sense that it freed canal management from a reliance on community organization. The engineer, R.G. Kennedy made a series of studies late in the nineteenth century, which yielded a reliable scientific formula for the slope and water velocity that could be maintained in an unlined canal channel without causing silting or scouring. This formula, in effect, allowed engineers to define mathematically what were known as "regime channels," or canals in which the rate of silting balances that of scouring during continued periods of operation. This had the effect of radically changing social relations with water, as it meant, "that large-scale annual silt clearances should be viewed not as a normal part of canal operation, but as evidence in flaws in canal design. Annual silt clearances, in such a view, only perpetuated the problems that caused heavy silting. As one engineer put it in 1916: 'Mr. Kennedy's work was to explain scientifically that silt clearances were a hopeless task.' A new 'scientific' view of canal operation thus transformed the role of indigenous labor in canal maintenance. ... Regular mobilization of labor for clearance was replaced by constant scientific monitoring, management, and remodelling. As one engineer commented: "An irrigation system in its parts comprises a very delicate machine..." In the case of silt control, therefore, labor mobilized by "communities" could be replaced, to a very large extent, by more sophisticated techniques of scientific adaptation to a changing environment..." (Gilmartin 1994:1137-1138) 
salient feature of imperial water is perhaps less the enormity of the physical diversions it comprises than transformation of hydro-social relations and hydrological discourses that it sustains. ${ }^{44}$ Modern water is implied or intimated in every critique of imperial water. To the extent that we inhabit a colonial present, an understanding of modern water may be of value in strengthening the political relevance of these critiques.

\section{Conclusion}

In this chapter, I have identified research in a variety of fields that suggests the possibility, if not the need, to give critical attention to modern water - the hegemonic, yet unmarked nature of water in the western, industrialized world. In the case of literature critical of the structures and techniques for managing water that dominated the twentieth century, it is recognized that a "paradigm change" in the way water is exploited and managed is in order. However, because it comes from within the modern water paradigm itself, the possibilities for change envisioned are limited by the constraints of our own (modern, technocratic) social relations with water. The new water paradigm thus calls for what is essentially a modification of the techniques for managing water that, it may be argued, have given rise to the very problems that it seeks to address. By calling for increasing

\footnotetext{
44 The global disciplining of humanity by means of modern water is suggested in the testimony of Michael Straus (US President Harry Truman's commissioner of reclamation) who described the control of water "as a prerequisite of all development and elevation of living standards" and who vaunted that "the American concept of comprehensive river basin development... has seized the world imagination. Yellow, black, and white men of various religions in all manner of garb are seeking to emulate the American pattern of development." (quoted in Worster 2006:11)
} 
the efficiency with which water is used, the fundamental terms of the relationship between people and water remain invisible and unchallenged. For research in what I have described as the history and cultural ecology of water, the relationship between water and society is recognized as seamless; there is shown to be a wide variety of waters and social relations with water in different historical and cultural circumstances. But while the social nature of water is recognized here as it pertains to other cultures, the social nature of modern water is only implied as that against which "traditional" or "indigenous" systems of irrigation, water conservation, water harvesting and distribution, etc. are described and judged.

In the case of the political ecology of water, modern water comes under increasing pressure as the presuppositions underlying conventional approaches to water management and discourses of issues such as drought and water scarcity are shown to be inseparable from the hydro-social relations in which they are embedded. Moreover, differences between traditional and modern systems and the interests involved in each are highlighted in political-economic analysis of water, along with the effects of projecting Western hydrological discourses onto specific people and places so as to construct natures that give rise to problems such as water scarcity. In the post-colonial research discussed, the distinction between traditional and modern hydro-social relations is recognized as a critical factor in the political ecology of water. In all of these categories, the social nature of water is recognized, however it is made evident for the most part in what are perceived to be "indigenous", "traditional" or "pre-colonial" cultures and water 
systems. In the case of political ecological critiques of commodification and water problems such as drought and water scarcity, the nature of water that is constituted in expert environmental and hydrological discourse comes closest to being revealed as what I would call a distinct form of hydreification. Overall, however, while the (social) nature of water in dominant, Western discourse is often implied or intimated in all these fields, it is not directly considered in its own right. Most of what follows in the rest of this thesis is intended as an attempt to offer just such a consideration - in other words, to bring the social nature of modern water to light. We will begin in the next chapter by arguing that the modern, Western way of seeing and relating to water has a history. 


\section{From Premodern Waters to Modern Water}

"[F]or not only does the way an epoch treats water and space have a history: the very substances that are shaped by the imagination - and thereby given explicit meanings - are themselves social creations to some degree." (Illich 1985:4)

"The obscurity of the olden days, which illegitimately blended together social needs and natural reality, meanings and mechanisms, signs and things, gave way to a luminous dawn that cleanly separated material causality from human fantasy. The natural sciences at last defined what Nature was, and each new emerging scientific discipline was experienced as a total revolution by means of which it was finally liberated from its prescientific past, from its Old Regime." (Latour 1993:35)

\section{Introduction}

Like the water systems of "indigenous" and "traditional" peoples studied by cultural ecologists and others, modern water takes shape within the context of the particular ensemble of social relations that makes it what it is. Modern water, in other words, is as deeply embedded in the matrix of modern, Western culture and history as the subak or water temple system is in Balinese history, or the tank system in the history of southern India. However - and this also seems to be the case for the people of Bali and Tamil Nadu - we do not regard it this way ourselves. To us, water exists in a way that has nothing at all to do with our culture; it is something that we simply take for granted as having always been there in the same way that it discloses itself to us today. But modern water is deliberately non-social and non-historical in a way that the waters of other places and times are not. Its distinguishing, yet unmarked, feature is that it is disclosed to us primarily through modern scientific practice - we have learned to know water in 
the way that we do through scientific discourse and modes of representation. As the dominant epistemological mode of Western culture, scientific practice has produced a distinctive way of understanding and representing water that makes it appear timeless, natural, and unaffected by the contingencies of human history. A relational-dialectical approach would hold that any such entity must have human relations existing in an historical dimension. It is to these relations and this dimension to which we turn our attention in this chapter.

The approach that will be used here is historical and comparative; to gain insight into modern water we will consider ways that people in the West have represented and related to water in the more distant (pre-scientific) past, and contrast it with ways that water became known through emerging practices of modern science, particularly in the fields now known as chemistry and hydrology.

\section{Waters in Historical Context}

"Following dream waters upstream, the historian will learn to distinguish the vast register of their voices." (Illich 1985:7)

As pointed out in Chapter 2, the history of water is a field of growing interest to historians, geographers, and anthropologists among many others. Among the literature that may be included in this category are several works suggesting a fundamental historical change in the way water was generally perceived and understood in the West - a change that corresponds approximately with the modern period from the seventeenth to the late-nineteenth century. This change 
has been described in a variety of terms; "the paradigm change from waters to water" (Hamlin 2000), "the conquest of water" (Goubert 1986) the change by which "the waters of forgetfulness" were transformed to " $\mathrm{H}_{2} \mathrm{O}$ " (lllich 1985) and the transition "From tangible water to $\mathrm{H}_{2} \mathrm{O}$ ". (Kalaora 2001)

Ivan Illich's monograph, $\mathrm{H}_{2} \mathrm{O}$ and the Waters of Forgetfulness, may be read as an incitement toward alternative ways of knowing and relating to water. (Illich 1985) For Illich, water is known to us moderns as a scientific abstraction, a way of knowing that entails the loss of a capacity to know and experience it as "stuff". Here, the notion of "this ineffable stuff called water" (1985:8) is constitutionally ambiguous, able to disclose itself in practically infinite ways. In treating of the historicity of water as "stuff", Illich laments the modern loss of peoples' capacity to know the waters "of the deep imagination...that stuff which can gurgle, and chant and sparkle and flow and rise in a fountain and come down as rain...but also comes down [among the Lacandon Indians in the south of Mexico] as the souls of women who have died and who seek reincarnation." (quoted in Cayley 1992:246) ${ }^{1}$ Treating of the history of water, he acknowledges, may seem like a strange endeavor because we have grown accustomed to a way of imagining "Water itself [which] has no history". (1985:4). Illich hints at the histories of far richer, socially impregnated waters of cultures that differed markedly from our own. Even our tendency to naturalize water's beauty - "the natural beauty of water...the beauty

\footnotetext{
${ }^{1}$ Those familiar with Bachelard's meditation on Water and Dreams will recognize Illich's main source of inspiration for $\mathrm{H}_{2} \mathrm{O}$ and the Waters of Forgetfulness. (Bachelard 1983.)
} 
intrinsic to $\mathrm{H}_{2} \mathrm{O}$ " (1985:3) - is subjected to a rather hard-eyed scrutiny, whereby it is shown how less abstract modes of apprehending may reveal water in vastly different ways.

Notwithstanding Illich's seminal (to me at least) book, most who have worked on the history of the concept of water in such a broad, historical fashion have approached the subject as a facet of the history of science, specifically the history of chemistry and of public health. (Hamlin 2000:314) In the following sections I will draw critically from an article by historian of science Chistopher Hamlin, which offers a particularly useful place to begin our consideration of the historical development of modem water. (Hamlin 2000) This article considers how at earlier stages in Western history, water was represented in four different literary traditions; classical natural philosophy, classical natural history, folklore and religion, and the medical literature promoting mineral springs. Examining these traditions, Hamlin has identified a transition from an empirical emphasis on diverse "premodern waters", which were regarded as heterogeneous entities exhibiting different properties and qualities, to a modern "essentialist conception of water itself" - a transition that he argues had taken place throughout the industrialized world by the end of the nineteenth century. (2000:321) The main contribution that I wish to add to Hamlin's thesis is to elaborate on an idea that is found in nascent form in his article: that an "essentialist conception of water itself" not only destroyed the irreducible variety of waters encountered in premodern times, but 
had the effect of disembedding these waters from the myriad social contexts and relations that had constituted them in the first place.

According to Hamlin and others (e.g. Illich 1985; Goubert 1986; Kalaora 2001) the pivotal moment of this change from different waters as heterogeneous entities to water as an essential substance, was its identification as a compound of hydrogen and oxygen by proto-chemists in the late eighteenth century. ${ }^{2}$ The naming of water as a chemical compound overturned a tradition of belief - generally upheld for some two thousand years - by which water was understood as an "element". Here a brief diversion into classical natural philosophy is in order, as the classical idea of an element differs from its modern namesake, especially as applied to water. Thales of Miletus $\left(7^{\text {th }}\right.$ to $6^{\text {th }}$ century $\mathrm{BC}$ ), who is usually considered the first philosopher in the Western tradition, held that all of material reality was derived from a single elemental substance/process -- water. Thales propounded the view that water - perhaps owing to its mutability from solid to liquid to gas, its formlessness and its association with life - was nothing less than the fundamental basis of everything encountered in the universe. (Ball 2001:118-119; Sambursky 1962:20-21) Both substance and process, "the watery principle"3, as Hamlin puts it

2 In what I regard as a particularly insightful passage, lllich likens "the $\mathrm{H}_{2} \mathrm{O}$... which industrial society creates" to "a discordant sound that is foreign to waters... .a fluid with which archetypal waters cannot be mixed." (1985:7)

3 According to the classicist, R.G. Tanner, water comprised "a vital principle." The $1^{\text {st }}$ century BC Roman engineer-architect Vitruvius - who devoted one of his ten books to water - described water as "the first principle of all things" and something which possesses a vital "power" of which "all things are composed." (Vitruvius 1999:96) Here, Vitruvius harkens back to Thales philosophy of water. As Tanner points out, the vital principle of the water element survived long after Vitruvius: "Though the notion of one material substance as the originator of life later disappeared, it left a 
(2000:316), was considered by Thales to be the fundamental element of which the world was made. ${ }^{4}$ Although subsequent Milesian thinkers argued for air rather than water, the various monistic elementary theories were effectively overturned by Empedocles ( $5^{\text {th }}$ century $\mathrm{BC}$ ), who was the first to put forward the classic doctrine of four elements: earth, water, air and fire. Empedocles considered these as "four primal divinities, of which are made all structures in the world." (Encyclopaedia Britannica, $11^{\text {th }}$ ed., s.v. "Empedocles") (Sambursky 1962:32)

Aristotle refined Empedocles' doctrine by, among other things, assigning each element to a place in the cosmos, with earth at the centre (or bottom), surrounded (or overlain) by water, then air and fire. Furthermore, he postulated that each element was produced by a particular combination of four primary qualities: heat, coldness, dryness and moistness. Accordingly, earth was formed of coldness and dryness; water, of coldness and moistness; air, of heat and wetness and fire, of dryness and heat. In Aristotle's view, the contiguous elements underwent transubstantiation - they were, in his words, "transformed into one another" (quoted in Sambursky 1962:32) - by means of undergoing changes in quality. Water, for example, was transformed into air by replacing coldness with heat (i.e. by heating it to as to produce what we now know as water vapour); and was

permanent legacy to philosophy. All these elements - water, fire and air - have the quality of being in constant motion, and all at times appear to initiate capricious spontaneous motion in the eyes of men unschooled in the laws of modern physics and chemistry. Such autonomous willed motion seemed to affirm the substance was alive, sentient and purposeful." (Tanner 1987:30)

4 From a relational-dialectical perspective, it is not difficult to see how this "watery principle" might have been construed as the fundamental constitutive process out of which the myriad 'things' of this world are spun. 
condensed into earth by replacing wetness with dryness (i.e. by producing ice which was regarded as a kind of earth). Similarly, air became water by cooling (condensing) it, and earth became water by wetting (rarefying) it. (Ball 2001:119127) According to the Aristotelian scheme, all matter comprised of wetness and coldness was understood as the water element, an element that was nevertheless subject to change in relation to differing qualitative circumstances. This elementary concept was, as Hamlin points out, "very much an antiessentialist view," one that differed substantially from the modern concept of an element as an irreducible and intransigent substance. (Hamlin 2000:316) Hamlin also contends that the vast differences between empirical waters found in antiquity, were usually understood not in terms of mixtures of various substances with elemental water, but as qualities that inhered uniquely in each separate instance of water: "Though there was disagreement on the subject", Hamlin points out that these qualities "were not necessarily conceived as adventitious substances or imposed states, but rather as properties unique to a particular water, often unanalyzable, inimitable, and utterly non-reductive." (2000:317)

While enduring increasing competition, the basic Aristotelian fourfold classification of the elements remained the canonical understanding of the nature of matter throughout Roman, medieval and Renaissance times and was not definitively overthrown until the late eighteenth century. ${ }^{5}$ Even Robert Boyle, one of the

\footnotetext{
5 It is impossible to assign precise dates to changes in intellectual history. Of course, at any given time, a wide variety of (often mutually contradictory) ideas may pertain. For example, ancient, medieval and Renaissance traditions of witchcraft, astrology, alchemy, etc. remained very much
} 
leading figures in what is widely known today as the seventeenth century "Scientific Revolution", considered water a mutable element, observing; "it seems evident that water may be transmuted into all the other elements." (quoted in Ball 2001:133) As late as the 1770 s, water was still commonly held to be an element in the classical sense. (2001:141) Thus, for some two-thousand years, at least in discourses of natural history and philosophy, water retained an identity that was at once elementary, unstable (in its transmutation into the other two proximate elements, air and earth), and heterogeneous (in its unique manifestation in different places and circumstances). Perhaps it was the very ambiguity of premodern water(s) that allowed it such longevity. In any case, such an animal as this was doomed to extinction in the face of the radical change of intellectual climate associated with the rise of modern scientific practice.

Antoine Lavoisier, perhaps the most important figure in the foundation of modern chemistry, is usually ${ }^{6}$ credited with being the first to describe water in the fashion that has found its way into The Concise Oxford English Dictionary, as a

alive in some quarters well into the eighteenth century, and in some cases, beyond. (Dear 2001:29) Hence the difficulty of signifying specific eras or historical periods of thought by terms such as the classical era, the modern era, the Scientific Revolution, and so on. But despite the uncertainties, it remains useful to apply such categories, albeit in a careful, limited sense. Shapin (1996: ch. 1) describes an uneasiness among some historians of science with the Scientific Revolution as a distinct historical category. Nevertheless, that natural philosophers in the late sixteenth and seventeenth centuries clearly believed that "they were proposing some very new and very important changes in knowledge of natural reality and in the practices by which legitimate knowledge was to be secured" suggests that "it is possible to write about the Scientific Revolution unapologetically and in good faith." (1996:5) As I have found it useful to revert to these and other gross modes of periodization below, it needs to be borne in mind that these are always intended as approximations at best.

6 Allusion to "the water controversy" was made in Chapter 1. Some (mainly English) partisans have claimed that "the weight of evidence appears strongly in favour of [Henry] Cavendish." (Huxley 1907:100) 
"Colourless transparent tasteless scentless compound of oxygen and hydrogen..."

(1964:1471). Lavoisier showed that such a compound could be synthesized "made artificially and from scratch" as he put it - by burning an element that he subsequently named "hydrogen"7; and that it could be broken down by the simple means of rusting (oxidizing) iron filings in a beaker of water. "Thus", Lavoisier declared in 1783 , "one is led still more nearly inevitably to conclude that water is not a simple substance at all, not properly called an element, as had always been thought." (quoted in Ball 2001:145) It was another half century before the water molecule became represented as " $\mathrm{H}_{2} \mathrm{O}$ ", a compound comprising a single atom of oxygen linked with two atoms of hydrogen. However, it seems the signal move in the dethronement of water from its position as "lord over all" the other elements, as Pliny the Elder had described it in the $1^{\text {st }}$ century ${ }^{8}$, took place in Lavoisier's laboratory. This exercise might thus be regarded as a singularly powerful instance of the production of local knowledge that was - eventually - made to engulf the entire hydrosphere. ${ }^{9}$

\footnotetext{
7 And thus combining it with another element, which he subsequently named "oxygen." ${ }^{8}$ In his Natural History (Pliny 1938, Book XXXI:379) be attributed to the particular form of discourse that he initiated - a new chemical nomenclature through which he and his colleagues articulated what has become known as the "chemical revolution". "On one reading, Lavoisier's radical challenge to the chemistry of his time appears to be embodied in a series of innovative factual claims, concerning the non-existence of phlogiston..., the reinterpretation of combustion as a process of oxidation, the designation of water as a compound, and so on. But, as a complementary part of their program, Lavoisier and his allies also advanced a new nomenclature for chemical substances and a new model of chemical discourse as a 'demonstrative' process of reasoning akin to geometry." (Golinsky 1998:117) Golinsky reports that a rival British chemist exclaimed "we cannot speak the language of the new Nomenclature, without thinking as its authors do." (1998:118)
} 
John Dalton, another key figure in the founding of modern chemistry, effectively took up from where Lavoisier left off by "providing a graphic image of what atoms do when they combine, as hydrogen and oxygen do, to form a compound like water." (Ball 2001:147). Dalton made an important contribution to the advancement (and the propagation) of scientific chemistry by drawing molecules; he rendered the first visual representation of the water molecule (Figure 3.1), so enabling us to envision modern water's essential identity. ${ }^{10}$
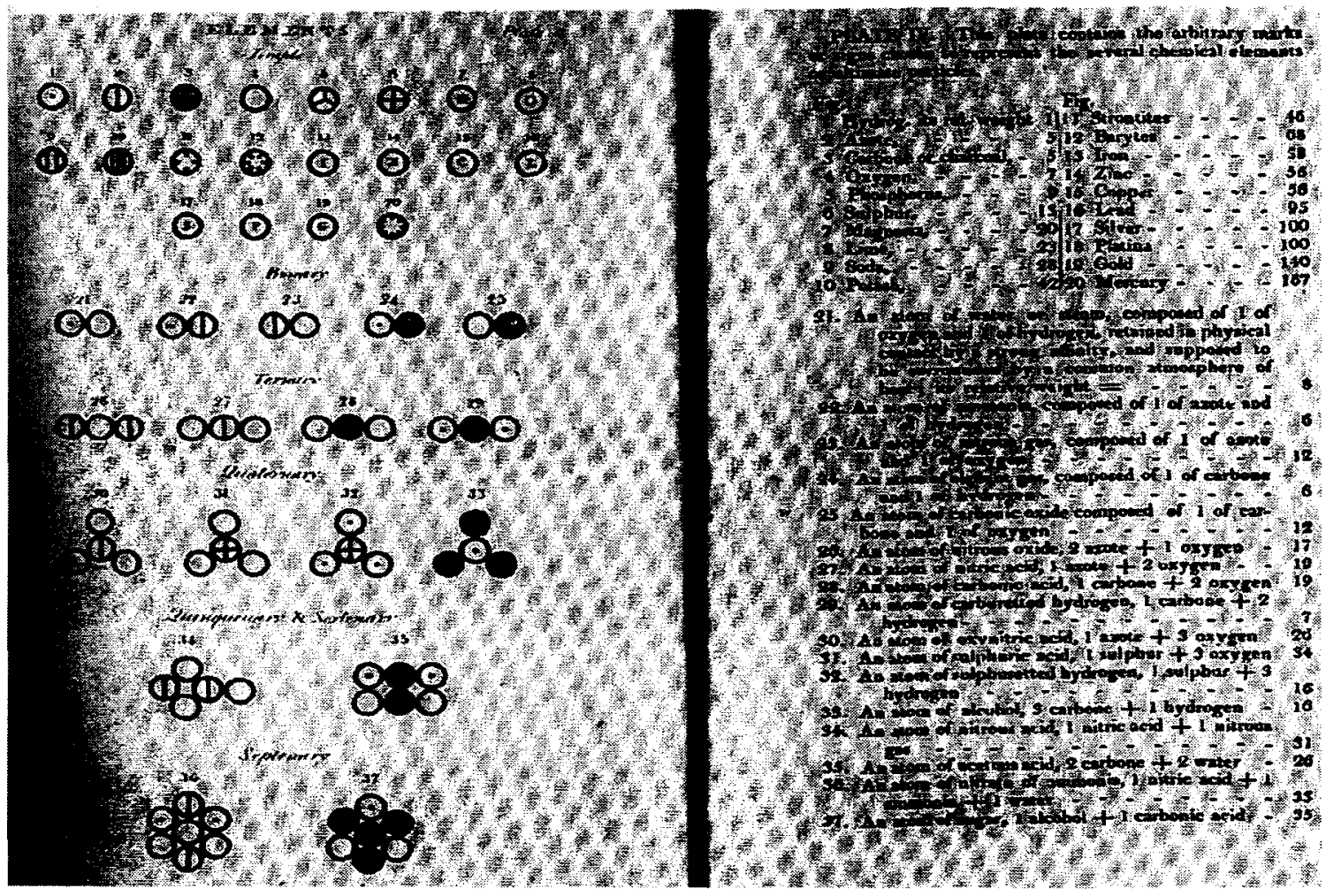

Figure 3-1 - Dalton's atomic symbols from his A New System of Chemical Philosophy, published in 1808 (reproduced from Knight 1996:157)

(Water is depicted fourth row from top at left, annotated by Dalton as follows: "An atom of water or steam, composed of 1 of oxygen and 1 of hydrogen, retained in physical contact by a strong affinity, and supposed to be surrounded by a common atmosphere of heat; its relative weight $=8 . "$ )

\footnotetext{
10

Dalton's depiction of the water molecule underwent several changes before it achieved its current/stable form by the mid-nineteenth century. (Ball 2001:147-150)
} 
Dalton, moreover proved by experimentation that water retains this essential identity when it vaporizes, rather than being transformed into air as had hitherto been the most popular understanding of these things. ${ }^{11}$

Hamlin offers a useful assessment of the effect of the (new) way of understanding and representing water that became increasingly common from the late eighteenth century onward:

"A richer and deeper range of conceptions of water and its effects on the body existed before the achievements of Lavoisier et al. A paradigm shift in the concept of water occurred... in which water went from an [sic] class of infinitely varied substances to a monolithic substance containing a greater or lesser concentration of adventitious ingredients, known as 'impurities.' A vocabulary stressing qualitative and geographic uniqueness gave way to a dichotomous determination in which water was pure or impure...

That premodern paradigm took as its normative starting point the apology we now make that water is never found pure in nature. It did not necessarily reject an understanding of water as a basic substance, known as simple, common, or sweet water, which might be more or less 'good' according to circumstances in which it was found. But it was more interested in how waters were different than in the ways they were the same... Waters were aspects of the histories of places. While there were general types, there was also a sense of infinite variation; waters had qualities or properties that went far beyond taste and salubrity and even beyond the poorly marked borders of the natural." (Hamlin 2000:315, my emphasis)

That premodern waters were 'aspects of the histories of places' and that they had qualities that transcended 'the poorly marked borders of the natural' is of central importance to my argument. In scientific chemistry, the nature of water was defined as some thing to which all waters could be reduced $-\mathrm{H}_{2} \mathrm{O}-$ a basic chemical compound that drove out all the socially specific qualities of different

\footnotetext{
11 This experimentation is described in more detail in the next chapter.
} 
waters. The shift from the "premodern paradigm" to modern water was the product of an epistemological revolution; it occurred as a consequence of a particular way of knowing and representing water in modern scientific practice - a practice that presumed a fundamental separation between the natural and the social. By contrast, the "premodern waters" that disclosed themselves to people in the West prior to the chemical revolution were of an entirely different nature, owing to the different epistemological contexts in which they were sustained. As already noted, Hamlin argues that premodern waters can be identified in four such contexts classical natural philosophy; classical natural history; folklore and religion; and medical discourse, particularly the promotion of mineral springs. He offers a somewhat sketchy summary of the way premodern waters were sustained in these four contexts. (2000:316-321) While it is well beyond the scope of this chapter to produce an exhaustive study of what Hamlin describes as the "premodern paradigm", I want to examine each of these four contexts more carefully, and examine critically the overall thesis that "there was a sense of infinite variation" in the waters encountered and described before the eighteenth century. In addition to helping clarify what I mean by modern water, this will set the stage for considering some of the other factors that have contributed to the shift that Hamlin identifies.

"Premodern waters" in classical natural history and philosophy

A painting by Zemo Diemer (Figure 3.2) depicts the convergence of five aqueducts - the Anio Novus superimposed on the Claudia in left foreground; the Marcia, Tepula and Julia likewise borne on a single arcade on the right - and the Via Latina 
as they would have appeared around AD 100, crossing the Campagna with Rome in the background. ${ }^{12}$

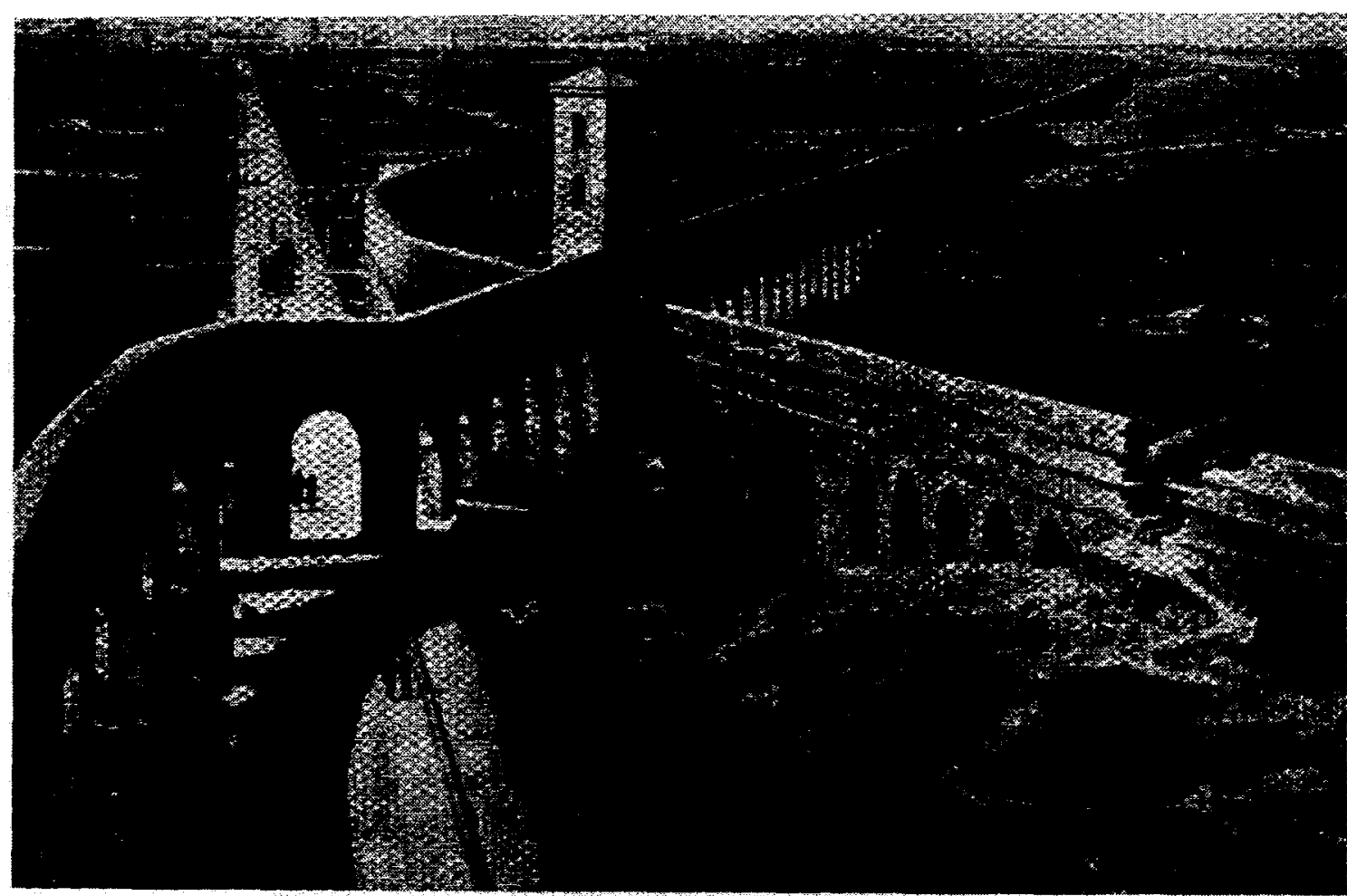

Figure 3-2 - Painting of the Roman aqueducts by Zeno Diemer, n.d. (reproduced from Biswas 1970:92)

To some, the painting serves as an illustration of how, despite contemporary philosophical professions of respect for "a passive or adaptive attitude toward nature....and for the genius loci of natural objects...ancient landscapes have been markedly transformed by man... and can even be dominated by man's engineering achievements." (Tuan 1968ab:180; see also Glacken 1967:116) However, the painting can be read in an entirely different way; for the aqueducts respect the integrity of the different waters they carry by

\footnotetext{
${ }^{12}$ While the painting gives the impression that Roman aqueducts were characterized by magnificent above-ground structures, some $80-90 \%$ of the combined length of all eleven aqueducts was in fact "underground and out of sight." (Hodge 2000a:67)
} 
maintaining separate conduits for each. From a modern perspective, the inefficiencies involved in maintaining separate channels for each kind of water may appear striking. But the very concept of the efficient transportation of water overlooks the importance of distinguishing between the water(s) that are to be transported. Diemer's painting suggests that the Romans were more attentive to the differences between waters than to the question of disposing of water in the most efficient way.

"Why so many aqueducts?" asks the classicist Trevor Hodge; "Given that the conduit was often only partially filled, why not simply divert into it more water from a new source instead of building a whole new aqueduct? The Roman practice of keeping their aqueducts separate no doubt sprang from a recognition of the different quality of water from different sources." (Hodge 2000a:90) According to Frontinus, who might be described as Rome's water commissioner at the end of the first century: "It was determined...to separate them all and then to allot their separate functions so that first of all Marcia should serve wholly for drinking purposes, and then that the others should each be assigned to suitable purposes according to their special qualities..." (Frontinus 1961:421) Recognition of these "special qualities" appears to have included a respectful attitude toward the genius loci of particular waters, particularly those of certain springs. Considering the Aqua Virgo (which was eventually to supply the famous Trevi Fountain in Rome) for example, at least three classical authors are known to have commented on its purity, with Pliny the Elder reporting that "it refused to mingle with the waters of a 
nearby stream sacred to Hercules, and therefore was named Virgin." Another (Cassiodorus) writes: "Purest and most delightful of all streams glides along the Aqua Virgo, so named because no defilement ever stains it." (quoted in Pinto 1986:7) A general "hostility to blended waters" which is evident in writings from Hippocrates to Vitruvius, thus found material expression in the very structure of the aqueducts: "Pity towards the deities of individual springs and medical strictures against blended waters would have obliged Roman engineers to conduct supplies through separate channels to the city wherever possible. ${ }^{.13}$ (Tanner 1987:30, 31)

That the Romans regarded their aqueducts in a manner not unlike the way we moderns do - as marvellous feats of human engineering - is readily apparent. Frontinus' famous boast is cited in practically every historical treatment of the aqueducts and ancient water management more generally: "With such an array of indispensable structures carrying so many waters, compare, if you will, the idle Pyramids or the useless, though famous, works of the Greeks!" (Frontinus 1961:357-359) However, in addition to the fact that they carried premodern waters, the repetition of such claims tends to obscure some important distinctions of the waters of ancient Rome. For one thing, the waters of the aqueducts flowed freely from the fountains and baths of Rome, through the streets of the city and into the Tiber. There were no taps, no technical means of stopping these waters. Nor was

\footnotetext{
${ }^{13}$ Tanner describes how the waters from two different sources were made by the Romans to flow for a length of $7 \mathrm{~km}$ in the same channel, and then were separated again into two channels bearing the same proportions of the original supplies. "[l]t is hard to see why the division was made in the same proportion as the previous mixture unless it was thought that the waters were living beings withdrawing from an embrace rather than an inert and passive divisible substance." (Tanner 1987:32)
} 
this merely a matter of technical deficiency; containing water was even proscribed in law, out of respect (according to one classicist) for the principle that "the free flow of water remains a necessary condition of its proper use." (Tanner 1987:34) ${ }^{14}$

Another consideration that is obscured by our tendency to modernize the aqueducts is that they seem to have been regarded by contemporary Romans in a way that complicates a distinction between the natural and the artificial. The Romans usually referred to their aqueducts in terms of the different waters they carried; not in terms of the structures that carried them. Thus the first aqueduct built was aqua Appia, named after Appius Claudius Crassus, the Censor who brought this particular water, drawn from springs some ten kilometres to the west, into the city in the $4^{\text {th }}$ century BC. (Frontinus 1961:339-341) Other aqueducts carrying spring waters were similarly referred to by the waters they carried; some were named after the person responsible for bringing them into the city (e.g. aqua Marcia, after Marcius), others after the attributes of their waters (e.g. aqua Tepula, or "tepid water"), and still others in accordance with stories surrounding the location of the spring from which they were supplied (e.g. aqua Virgo). Two of the eleven Roman aqueducts carried water drawn from the Anio River. When the first was built in the third century $\mathrm{BC}$, it was simply called Anio, the name of the river itself. When a second aqueduct carrying water from the Anio was constructed some 300 years later, it was given the name Anio Novus, or "New Anio." (ibid. 343-

\footnotetext{
14 In a discussion of the ends of water conservation, Robert Horton (1931:192) refers to "the old Roman law 'Aqua currit et debet currere ut currere solebat' - water may be used as it flows and only as it flows." It seems reasonable to conjecture that, in addition to showing respect, such a law might have been adopted to proscribe (illegal) water takings.
} 
355) The social nature of Rome's water is suggested by noting that there was no common distinction made between the aqueducts and the "waters" or "rivers" that they carried. Moreover these anthropogenic waters/rivers were distinct in ways that, whether rooted in local legend or practical application, can only be appreciated in relation to their historical and cultural contexts.

Attention to different waters is still found in modern, Western society, especially where this is recognized as having commercial advantages, as in bottled spring waters. But the commodification of specific waters remains marginal to the homogeneous tendency of modern water. In contrast, one cannot help but be struck by the extent to which "the different kinds of water were a subject of close interest" (Hodge 2000b:96-7) not only to the Romans, but all societies of antiquity. This attention to difference is particularly apparent in the category of writing described by Hamlin as classical natural history. ${ }^{15}$ Hamlin relies for the most part on two Roman sources: Book 8 of Vitruvius' Ten Books of Architecture, published around 30 B.C. and Pliny the Elder's Natural History, published a century later. Both draw from Greek as well as contemporary writers (and Pliny draws from Vitruvius) to offer encyclopaedic compendiums of virtually everything known including everything that had ever been written or was known to them by word of mouth - of the variety of waters in the classical world. These authors pay a great deal of attention to the (often astonishing) variety of waters, particularly those

\footnotetext{
15 Natural history - "a former branch of knowledge embracing the study description and classification of natural objects..." (Webster's Third New International Dictionary.1507) Note the distinction from natural philosophy, "the study of nature in general", a branch of knowledge that evolved into modern natural science. (ibid.)
} 
occurring in the form of springs, drawn from wells and encountered in rivers, and, occasionally in the diversity of hydro-meteorological phenomena such as rain. The list of the contents of Book XXXI of Pliny's Natural History provides a useful (and to modern readers, a rather amusing) illustration: ${ }^{16}$

"Remarkable facts as to waters... Differences in waters... Medicinal properties: what sorts of waters are good for the eyes, what sorts produce fertility, what sorts cure insanity, what sorts gall-stone, what sorts wounds, what sorts protect the embryo, what sorts remove tetter, which make dye for wools, which for human beings, which produce memory, which forgetfulness, which keenness of sense, which slowness, which a musical voice, which dislike of wine, which intoxication... Remarkable waters: waters in which all objects sink, in which no objects; waters that kill...; waters that turn into stone, or produce stones... Health-giving property of waters...; differences of waters according to kinds of earth; variation of springs with the seasons." (Pliny 1938, Vol. 1:141)

Pliny also makes observations on "The marvels of many waters", including those specific waters in which everything sinks, or floats; waters that offer prophesies, harbour poisonous fish, kill everything that touches them, corrode bronze and iron, nurture unique flora, turn to stone the land they irrigate, grow rocks, turn into stone whatever is thrown into them, etc. (1938, Book XXXI:391-395) And should anyone think "that some of these statements are incredible," avows Pliny, "he has to learn that in no sphere does Nature show greater marvels." (ibid.:391) For our purposes, it is most important to take note of the expressly social nature of these waters. Like the waters of the Roman aqueducts, these premodern waters of springs and rivers

\footnotetext{
16

We might read this list in a manner similar Foucault's reading of a passage putatively from "a certain Chinese encyclopedia", which reading famously set Foucault to pondering The Order of Things. (Foucault 1970:preface. See also Gregory 2004:1-2) Like the Chinese dictionary, Pliny's natural history of water seems humorous to us, the effect of a very wide epistemological gulf between reader and writer.
} 
were understood in - we might say they were constituted by - the social context and relations through which they became known. The hydrological marvels described by Pliny, as well as the more mundane attributes of the various waters he describes, are always in relation to people, their productive activities (as in waters that serve particular industrial purposes), and principally, their health. The effects of the various waters on the bodies of the people who internalize them constitute the most important means of knowing such waters and ascribing significance to them: "[T]he human system (and not just its senses)" as Hamlin notes, "was seen as the most sophisticated instrument in a qualitative assessment of waters." (Hamlin 2000:318) The distinction between subjective and objective modes of knowing water is well illustrated in the contrast between these premodern waters and $\mathrm{H}_{2} \mathrm{O}$.

However, it must be acknowledged that when he moves to discussing what would today be described as more general hydrological phenomena, Pliny shifts from the variety of "waters" to "water" in general. In the case cited below, he elaborates on the commonly-held notion of what might be called a subterranean hydrologic cycle (see chapter 4) and gives an answer to the perennial question why the sea remains at the same level despite the constant inflow from rivers:

Water permeates the earth everywhere, inside, outside, above, along connecting veins running in all directions, and breaks through to the highest mountain summits - there it gushes a in siphons, driven by pneuma (spiritus) and forced out by the weight of the earth; it would seem that the water is never in danger of falling; on the contrary, it bursts through to high places and summits. Hence, it is 
clear why the seas never grow from the daily influx of river water. (quoted in Biswas 1970:140)

Pliny reverts to a discussion of "waters" when he turns to describing the qualities of various rivers. (1938:353) It may be said that, depending on the specific sort of question investigated in Pliny's Natural History, the variety of "waters" - manifested in relation to different people and places - gives way to the nature of "water" which manifests as a process of nature. A similar observation can be made of Vitruvius. Like Pliny, and owing to his ultimate concern with the water supply of towns, Vitruvius is greatly interested in "the characteristics of waters" associated with different springs. Of these, "it is hardly to be wondered at that in the great immensity of the earth itself there are indeed countless varieties of sap to be found, and that when water's power flows through the veins of these earths it arrives at the heads of springs adulterated, and thus for this reason fountains are made diverse and various according to their types, because of the discrepancy of heir localities and the dissimilar characteristics of their regions and soils." (Vitruvius 1999:103) But when he turns to discussing phenomena such as rainfall and streamflow, he speaks of water as a process, and he speaks in what almost seem like modern, hydrological terms. (1999:98) $)^{17}$

Both Pliny and Vitruvius therefore, address questions relating to the timeless and placeless nature and behaviour of water as well as the culturally-and

\footnotetext{
17 Many modern hydrologists have credited Vitruvius as the first person to have a "true" understanding of the hydrologic cycle. (See Chapter 5)
} 
geographically contextualized nature of particular waters. This difference might be explained in terms of the distinction between natural history and natural philosophy. Natural history has been defined as "a former branch of knowledge embracing the study, description and classification of natural objects..." and natural philosophy as "the study of nature in general" (Webster's Third New International Dictionary: 1507$)^{18}$ As natural historians, classical writers attended to the geographical and cultural diversity of waters as specific things, while as natural philosophers, they treated of the nature of the water process in general. Moreover despite Hamlin's assertions to the contrary, it has to be admitted that Aristotle and other authors he mentions in the category of "classical natural philosophy" were equally or more attentive to the nature and behaviour of water in general (hydrological) terms than to the heterogeneity of specific waters.

The instances of specific waters found in the early natural histories, it may be said, occurred where the water process described in classical natural philosophy met with particular social processes (such as the functioning of human bodies, engagement of people in various industrial and agricultural activities, etc.) that gave meaning to the specific waters described in classical natural history. The early attention given to the water process generally, corresponds to an interest that can be traced to the earliest stages of Western philosophy - in questions involving things such as the origin of springs and rivers, the cause of floods, the

\footnotetext{
18

Describing the distinction between these fields in the seventeenth century, Shapin writes "[Inquiries] into what sorts of things existed in nature and into the causal structure of the natural world were referred to, respectively, as "natural history" and "natural philosophy." (1996:6)
} 
cause of rainfall, the reason why sea levels remain constant despite the inflow of rivers, the process of what is now called evaporation, the source and disposition of water flowing in the ground, why the Nile floods later in the year than other (European) rivers known at the time, etc.. (Adams 1938:426-432) Today, we describe these as hydrological questions in deference to the modern branch of science - hydrology - that addresses them. "The importance of hydrology to many of mankind's most basic activities made such studies of interest to the earliest natural philosophers." (Britannica 6:194) And to the extent that water was considered in relation to such questions, it was water in general - or the general process of water - that natural philosophy addressed itself to.

Hamlin argues that, "The natural historian's view of waters as many, however is fully compatible with the philosopher's..." (2000:317) While this is undoubtedly true, the inclusion of water in general - as well as an empirical attention to specific waters - in the "premodern paradigm" suggests that rather than a simple temporal shift from premodern waters to an essentialist idea of water itself, the more salient move has been from natural history as a legitimate approach to the study of water(s) to an exclusive reliance on natural philosophy - and its heirs in modern scientific disciplines like chemistry and hydrology - as the accepted mode of knowing and representing water. In other words, ways of knowing waters that are reflected in the category described as classical natural history are no longer valid they strike us as odd, or even ridiculous - just as the notion that engineers would 
go to great lengths to keep the flow of different streams in separate aqueducts despite the obvious efficiencies that would be gained by combining their flows.

The demise of natural history was a long and complex process associated with the reciprocal process by which modern scientific practice came to be accepted as the authoritative approach to gaining and representing natural knowledge. ${ }^{19}$ Works like Pliny's Natural History were popular throughout the Renaissance, when interest in restoring the glories of classical antiquity was reflected in a reverence for classical texts. (Dear 2001:44) But by the turn of the seventeenth century - at the beginning of the era now described as the Scientific Revolution - natural philosophers were beginning to show a disdain for such works. William Gilbert (1544-1603) for example, dismissed the testimony of traditional natural historians such as Pliny as "the maunderings of a babbling hag." (quoted in Shapin 1996:88) Such dismissal is suggestive of how, eventually, modern science managed to render water in a way that has driven out its heterogeneity and its salient social nature. ${ }^{20}$ The social

\footnotetext{
${ }^{19}$ Two phases in this demise may be noted. The period known as the Scientific Revolution is associated with reforming natural history, "purifying it" by driving out its now-apparently ridiculous assertions and testimonials. "The techniques of intellectual quality control recommended for a reformed natural history could be used to winnow out testimonial wheat from chaff..." (Shapin 1996:138) Natural history (reformed) continued to thrive in the eighteenth and (to a lesser extent) nineteenth centuries, only becoming "a former branch of knowledge" (see ftnt. 15) and "The Forgotten Science" (Worster 1994:286) in the twentieth century.

${ }^{20}$ The epistemic recontextualization of the study of water - from waters in natural history to water in natural philosophy and natural science - is illustrated by taking note of the tendency among practitioners of modern hydrologic science to pick from among the classic texts certain themes that are consistent with their views and to reject others that have seemed to them irrelevant. For example, Vitruvius' observations of the gross behaviour of water have been championed as prescient by hydrologists interested in locating the origins of the concept of the hydrologic cycle, while his observations of the idiosyncratic qualities of particular spring waters and their effects on the local inhabitants have been completely ignored. (See Chapter 4) It can also be noted that even when water is described in the universal (i.e. as water), classical writers tend to imbue it with forces, meanings and significance that contrasts strongly with the stripped-down raw material that water
} 
nature of premodern waters, it may be surmised, was able to coexist alongside the more abstract notion of the natural water process in natural philosophy because these waters internalized both social and natural water processes. The modern separation of nature and society at the hands of the early practitioners of scientific method made such an intermingling of society and nature impossible, leaving an asocial hydrological discourse the only valid way of knowing and representing water.

An association may thus be noted between the disenchantment of waters and the demise of natural history as a valid means of knowing and representing the natural world. Knowledge of other natural phenomena, it might be noted, underwent a transition similar to that occurring for water. By the early eighteenth century for example, naturalists began to dispute the plurality of symbolic, emblematic, or portentous (i.e. social) meanings that had traditionally been associated with things like hurricanes and floods:

"They claimed that meteorological phenomena did not possess other than "natural" significance. Meteors were to be divested from [sic] their spectacularity and treated as ordinary products of the material world... The general trend was...toward an epistemic recontextualization of prodigious meteors, i.e., toward a complete evacuation of their "non-scientific" meaning." (Jankovic 1998:8,9)

has become in modern (scientific) discourse. Thus, along with the elements of fire and air, Seneca ascribes to water a "principle of life", about which he was in agreement with Pliny and Cicero. (Seneca 1972:82-83) And Vitruvius - alluding to Thales' cosmogeny of water as "the principle of all things" - justifies devoting an entire book on the subject of water (in his opus on architecture) with the assertion that "all things consist of the power of water." (1999:86) These aspects of water that were apparent to Seneca and Vitruvius have been completely expunged from the modern, hydrological exegesis of their writings. 
The evacuation of non-scientific meaning - or the "disenchantment of the world" as Max Weber described it - can be regarded as one of the major themes of the intellectual history of the seventeenth and eighteenth centuries, when modern scientific practice began to emerge from natural philosophy. ${ }^{21}$ Like hurricanes and floods, as water was increasingly fed through scientific discourse, its cultural content was filtered out. ${ }^{22}$

\section{Premodern Waters in Folklore and Religion}

Folklore and religion are extremely broad, overlapping and rather arbitrary categories. Particularly for the modern reader, the special attributes and qualities of spring waters discussed by the likes of Pliny and Vitruvius might just as well fall into the category of folklore as natural history. Such categories however provide a useful heuristic approach for gaining an understanding of distinctions between different modes of relating to water. Hamlin asserts that "The more we know of the subject...the more it becomes clear that the investment of local waters with some kind of sacred status was important, widespread, and varied in nature." (2000:319) Approaching this question from the perspective of a comparative study of religions,

21 The natural "mechanical" philosophy of Descartes (particularly by way of its substitution of the machine for organic metaphors) had the effect of taking much of the wonder out of nature; as Max Weber famously wrote, it was responsible for "the disenchantment of the world." (quoted in Shapin 1996:36) Carolyn Merchant's The Death of Nature ... can be read as an extended essay on this theme. See also Leiss (1974)

22 It needs to be stressed (once again) that a variety of discourses pertained simultaneously, such that the cultural associations with phenomena like premodern waters persisted long after the advent of scientific objectivity and dualism among natural philosophers. With respect to meteorological phenomena Jancovic's thesis, shows how - especially in more popular and rural discourses - "a qualitative, non-instrumental interest in meteorological phenomena - especially those that were unusual, sudden, and destructive - persisted long after the barometer and thermometer became meteorological instruments..." (Jancovic 1998:5) 
Eliade makes a generalization that is reminiscent of Thales' cosmogeny: "To state the case in brief, water symbolizes the whole of potentiality; it is fons et origio, the source of all possible existence..." (1958:188) What I want to stress here is that the sacred status and symbolic potentiality of water has been manifested in myriad ways as the water process has become mixed with different cultural practices and processes.

The variety of the spiritual qualities of local waters in folklore and religion is particularly striking. Along with stripping it of its sacred qualities, modern water, it may be anticipated, has almost entirely destroyed what might be called the geography of the sanctity of water. ${ }^{23}$ Hamlin makes reference to the 10,000 nymphs (the resident divinities of the springs of ancient Greece) identified by Hesiod as perhaps the best-known example in the classical literature. (2000:319) Throughout the ancient world, the waters of specific springs and rivers were associated with deities and honoured with rites of worship, propitiation and offerings, of which the tossing of coins in fountains remains a common vestige. (Tanner 1987:29; Hastings 1921:704-719)24 The powers and qualities ascribed to the specific waters of ancient springs varied with the site - from sources of spiritual

\footnotetext{
${ }^{23}$ Recall that this chapter deals with water history in the Western world. This statement clearly doesn't apply to the Ganges River, to cite one well known example of present-day sacred waters. But even in the West, modern water has not completely driven out hydrolatry, as anyone who visits the grotto at Lourdes must be aware.

24 In the Encyclopaedia of Religion and Ethics, Hastings commences his article on "Water, Water Gods" in ancient civilizations by stating the matter in distinctly modern terms: "Since water is a first need of man in a primitive state of culture, it is little wonder that it is regarded as possessed of mana [spirit] and that it figures prominently in magico-religious cult." (Hastings 1921:704)
} 
danger, healing, or purification to the more profane influences on the body as already noted from the accounts given by Pliny.

The cult of water - or "hydrolatry" - has been described as "a single religious motif spanning the whole Eurasian continent and beyond..." from Greek times to the modern age, and until very recently in some places. (Rattue 1995:10) But it was manifested in ways that were far from uniform and had everything to do with the specific historical and cultural relations in which they occurred. While some general principle of "the sacredness of water as such" appears to have prevailed widely, the myriad water cults were founded on what Eliade describes as "the local epiphany, or the manifestation of a sacred presence in some particular watercourse or spring." (1958:199) The significance of this "sacred presence" has to be understood in every instance from an historical-geographical perspective. An historian of holy wells, James Rattue points out that a peculiar aspect of the Greek worship of springs, not repeated in later cultures, was in "their power to inspire prophecy." Unlike sacred springs among many other cultures, the Greeks did not appear to make offerings to their wells. The Romans adopted many formerly Greek well sites but "reinterpreted the prophetic powers of the wells and turned them into inspirers of poetry." (Rattue 1995:26) In the later Empire, Rattue suggests many of the same springs and wells were incorporated into the mystery religions, secret cults that afforded initiates a mode of religious experience not sanctioned by the state. (1995:26) 
The Christianisation of waters that had been held sacred to pre-Christian cultures is a common theme in the study of hydrolatry, and offers a good example of how different waters coalesce at the confluence of the water process and different social processes. After the "fruitless persecution" of water cults by the Church in the Middle Ages, many of the "pagan" springs extant throughout the classical world were Christianized, reinvested with new layers of religious significance. (Eliade 1958:200) In England, during the reign of the Saxon King Edgar, a cannon was issued exhorting "That every priest industriously advance Christianity, and extinguish heathenism, and forbid the worship of fountains." (Bord and Bord 1985:19) Similar edicts continued to be issued into the twelfth century, but in the face of its continued popularity, hydrolatry was eventually accepted by the Church and incorporated into Christian observances. A variety methods were used "to accomplish this takeover": Water from holy wells was used for baptism with baptisteries built at many ancient well sites; wells were dedicated to Christian saints, thenceforth bearing their names; and in some cases, churches were built nearby or actually constructed overtop of sacred wells. (Bord and Bord 1985:1920; Rattue 1995) Holy springs were thus reinvested with meaning, and became "an accepted, established part of the Church's spiritual weaponry..." (Rattue 1995:88)

However, incorporating sacred waters into the catechism, if not the body, of the Church did not preclude sacred wells and springs from serving more prosaic and profane purposes. The 'spiritual' uses of holy waters (e.g. for baptism) blended rather seamlessly with their continued use for medicinal purposes, and did not 
even preclude them from such mundane applications as furnishing supplies of water for growing medieval towns. (Hamlin 2000:319; Rattue 1995:97-100) The premodern waters of springs thus dissolved certain categories and distinctions such as sacred and profane - that seem natural to us today. Moreover, in their infusion of medieval society, they simultaneously held together and were constituted by contemporary social relations. Rattue emphasizes the social embeddedness of hydrolatry in medieval England: "Wells were part of [a] battery of social control and protection mechanisms. Some were haunted, others bottomless, all were awesome....and a little fearsome. The rituals in which they played a prominent part helped reinforce communal and group unity, and the position of the Church as the prime medium of cultural expression." (1995:97)

Depending on the particular place, sacred waters withstood the onslaught of the Reformed church, the relative depopulation of the countryside, and the incursions of modern science for a surprisingly long time. Lavoisier's reduction of water to a chemical compound has been suggested as the most decisive moment in stripping waters of their "mythology." (Goubert 1986:3) But the process of cleansing waters of their sacred qualities occurred over centuries. "Water retained its sacred, purifying role for a long time," writes Ladourie, "whether this was reflected in the mineral springs...or quite simply in the holy water at the entrance to our churches." (Ladourie 1985:2). Indeed, due to their chorological and cultural idiosyncrasies, Hamlin suggests that sacred waters had the effect of "offsetting the universalizing tendencies of the incipient science of chemistry." (Hamlin 2000:319) 
But it was the weakening of the social relations that had held them in place that seems to have extinguished water's sacred qualities in most locales by the late nineteenth century. Or so we may conclude if it is permissible to generalize from Rattue's study of the history of holy wells in England:

"The social functions of holy wells can hardly have altered since the middle ages; yet these functions were largely being provided by a whole new series of social mechanisms. Local community solidarity was the casualty of the 'Great Change', and was nationalized into national politics and, later, the Welfare State, after the 1867 and 1885 Reform Acts. Church-organized youth groups, schools and scouts, trade unions and political parties provided new class- or age-based forms of social solidarity." (Rattue 1995:130)

With the growth of scientific medicine, another vital social function of the springs

fell into disuse, as reflected upon by a writer living in the vicinity of Brampton,

England in 1841:

"The water is still of the most pellucid clearness, sweet to the taste, though much neglected, full of fallen leaves and haunted by vermin... The present generation, however, have ceased to avail themselves of the medicinal properties of the waters, which have lost their virtue, or are eclipsed by the superior abilities of the Medical Practitioners to whose charge the health of Brampton is consigned." (quoted in Rattue 1995:130)

Additionally, the expansion of water treatment and distribution systems - the materialization of modern water - in urban centres must be counted among the factors that stripped spring waters of their sacred and special qualities. In her study of traditional and folkloric waters in England, Dorothy Hartley lists several dozen locally-known English springs of the past (1964:29-32) which are 
representative of the "thousands of others"25 that have been lost to modernity, along with their known qualities, curative powers and cultural associations. "What a stream of interest we lost" she comments ruefully, "when we had water "laid on", blended, ready mixed and chemically purified." (Hartley 1964:17, 32)

So far, we have been considering the investment of local spring waters with sacred and spiritual qualities. The natural history of premodern waters also describes the waters of different rivers, which were often regarded as unique, such that they would not mingle with the waters of lakes or other rivers. (Tozer 1971:267-272) Deep spiritual, emotional and cultural attachments to the waters of specific rivers are also evident in many writings. Each of the major, and many of the minor rivers of antiquity were considered deities in themselves, or were associated with a particular god or gods, and each was imbued with its own myths, cultural, economic and religious traditions and sacraments. (Tanner 1987; Schama 1995:256-267) There were, for example, the Champier brothers, Renaissance geographers "who in the sixteenth century produced a comprehensive anthology of the myths and legends associated with the entirety of known streams: the crystalline waters of the Auvergne that could wash away cataracts of the eye; those which could naturally polish pebbles so that they sparkled like true

${ }^{25}$ Rattue claims there were over 8,000 holy wells in England. (Rattue 1995) Researchers have listed nearly a thousand holy wells on the Scottish mainland alone, some 1,200 in Wales, and at least 3000 in Ireland. (Bord and Bord 1985:24) Bord and Bord describe "A Gazetteer of 200 Ancient and Holy Wells which Still Survive in England, Wales, Scotland and Ireland." (Bord and Bord 1985:149-207) 
brilliants..." (Shama 1995:349) Consider how this differs from modern geographies of water!

According to Tanner, because rivers and springs were considered "sacred beings" in ancient and Classical times, people often expressed concern about angering them by means of channelling or damming their waters. Even the act of bridging rivers and (the very common practice of) adorning springs was considered in some places contrary to the wishes of the waters. (Tanner 1987:34) Of course, given that a great deal of damming, bridging, draining, channelling and adornment did take place throughout ancient and Classical times, such statements have to be read with care. There is no doubt however that the urge to manipulate water in the modern sense of exploiting it as a resource was at least tempered by recognition of its sacred dimension and an appreciation of social context in which sacred waters were sustained. The Roman historian Tacitus (early 2 nd century AD) "calls attention to the effect of religious belief in preserving the natural order, mentioning popular objections to diversions of rivers on the ground that nature herself had made the best provision for their sources, their courses, and their mouths." (Glacken 1967:134-135) In a discussion in the Roman Senate about whether to divert rivers tributary to the Tiber for purposes of flood control, Tacitus reports the protests of people from the affected region: "Nature", they said...

"had made the best provision for the interests of humanity, when she assigned to rivers their proper mouths - their proper courses - their limits as well as their origins. Consideration, too, should be paid to the faith of their fathers, who had hallowed rituals and groves and altars to their country streams. Besides, they 
were reluctant that Tiber himself, bereft of his tributary streams, should flow with diminished majesty." (quoted in Glacken 1967:135)

That the premodern waters of springs and rivers articulated themselves differently with people in different places suggests the need for what Hamlin terms "a chorographic science" of waters. "In a chorographic science, focused on the uniqueness of a locality rather than on the general characteristics of a group of objects, the lore of sacred waters [would be] a valuable indication of the uniqueness - here the divinely generated uniqueness - of a particular place." (1990:319-320 $)^{27}$ This notion of a chorographic science of waters might be regarded in dialectical terms as the study of how water becomes what it is in different historical and geographical circumstances. In any case, the thought of such a science is difficult to reconcile with the science of modern water, rendering as it does the undifferentiated stuff $\left(\mathrm{H}_{2} \mathrm{O}\right)$ occurring in a universal form (the hydrologic cycle) that leaves behind all chorographic and cultural uniqueness.

\section{Premodern Waters of the Mineral Spring}

The fourth discourse in which Hamlin argues premodern waters were sustained (and that in which he finds the concept best represented) is found in "the enormous and virtually unvisited mineral water literature, which begins to appear in the $16^{\text {th }}$ century and dies away in the mid $19^{\text {th }}$. (Hamlin 2000:320) This discourse

\footnotetext{
${ }^{26}$ Tacitus reports that for whatever reason, "the motion of Piso, 'that nothing be changed,' was agreed to." (quoted in Glacken 1967:135)

${ }^{27}$ For the application of such a "chorographic science" to meteorology, see Jankovic (1998)
} 
is mainly associated with the testimony of medical practitioners interested in the effects of various waters on human health. As already suggested, we could certainly reach further back in time for illustrations of the diversity encountered in various waters and their effects on the human body. Hippocrates' Airs, Waters, and Places - often taken as the foundational text in the medical sciences explicitly treats of "waters" in their plurality, stressing their various effects on the bodies and their influences on the cultures of peoples in different parts of the ancient world. (Glacken 1967:82-88) Vitruvius, Pliny and others reflect how these concerns prevailed in Roman times (Tanner 1987:30-31) and testimonials of cures and explanations of the physiological effects of different waters are found in a wide variety of medieval and Renaissance sources. (Rattue 1995)

The outpouring of mineral water analyses identified by Hamlin as having occurred from the $16^{\text {th }}$ century on appears to have been the result of the growing need to render personal testimonials and unsubstantiated explanations into 'proofs' that accorded more with the standards being developed in the nascent chemical and medical sciences. (Hamlin 1990:21) The period beginning in the $16^{\text {th }}$ century is associated with a general shift in discourse from holy wells to mineral waters, a shift that can be associated with the emergence of markets for mineral waters and for the commercial services of salubrious springs. Competition between the promoters of various springs gave rise to the need for a means of comparing different waters so that their promoters could make certain claims about their respective benefits. There thus arose the concept of systematic water analysis: 
"Ideally, a water analysis simply translated [the putative qualities of waters] into the universal language of science, the better to allow the promoter [of a particular mineral spring] to highlight the uniqueness of the spring and distinguish its water from anything available elsewhere." (Hamlin 1999:320)

Elsewhere, Hamlin has written a history of the struggle between different communities of proto-scientists over which could legitimately claim authority to explain the differences between various mineral waters, or to use Hamlin's expression, over who could legitimately "speak for water". (Hamlin 1990) Of interest to us here is that the eventual victory of the chemists over the "medical

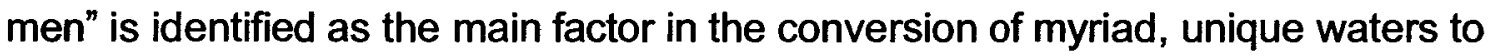
universal, modern water. Hamlin quotes the physician John Barker, from his Treatise on Cheltenham Water, (1786) who insisted, "that there are specific properties in almost every mineral water, wherein it differs from every other of the same class. Nay, there are qualities in the water, and even in the spirit of every common spring, whereby it is peculiarly different, in many respects, from all others." Barker, however, cautioned that the chemists could never "elucidate things of so high a nature ${ }^{n}$. (quoted in Hamlin 1990:57) The eventual dominance of chemistry, Hamlin argues, had the effect of driving out these things of "so high a nature" from water. "Oddly...", he remarks of the substance to which water was reduced by the chemists, "the new compound was more elemental than the old element". (2000:321) The differences between what had formerly been regarded as "waters" could now be explained in terms of $\mathrm{H}_{2} \mathrm{O}$ plus whatever adventitious 
substances were found mixed within it. While certain minerals continued to be seen as desirable components of the admixture, chemistry, and later, bacteriology, shifted an entire discourse from an effort to locate the intrinsic properties of different waters to "the quest for pure water." (Baker 1949)

While the influence of scientific chemistry was clearly a pivotal factor in the reduction of premodern waters to essential "water", this is far from the only explanation to be sought. Hamlin points out that even the chemists, though they may not have seen the same things in the water that Barker saw, nevertheless upheld the notion of distinctive "waters" long after the advent of $\mathrm{H}_{2} \mathrm{O}$, indeed up to the middle of the nineteenth century in Britain and during the next half century elsewhere in the industrialized world: "We do not know fully", admits Hamlin, "why waters ceased to be many and became one (albeit, one with contaminants); and equally why attention shifted from variability to uniformity." (2000:321)

The need for further explanation suggests that we consider the advent of modern water in discourses outside the history of medicine and chemistry. It has already been noted that in certain contexts, such as natural philosophy, the variety of waters gives way to considerations of the nature of water itself in writing that predates the advent of chemistry. Furthermore, it must be admitted that the nineteenth century demise of "many waters" is not as clear-cut as Hamlin suggests. In other contexts, we find that attention to different waters remained very 
much alive well into the twentieth century. ${ }^{28}$ For example, the treatment of disease by internal and external application of "natural mineralized waters of reputed value" remained a subject of scientific interest until at least 1930 in Great Britain. (Gordon and Thompson 1930:24) This field, described as "hydrology", was centrally concerned with the peculiar, local qualities of various "waters" and dealt with the question of how their medicinal effects "are due to water, pure and simple, and to what extent they are modified by the peculiar properties of the various 'waters' found at the different spas." (1930:73) As long as the primary identity of water could legitimately be detected by an instrument as complex and heterogeneous as the human body, the variety of waters seems to have been held to be entirely natural. However, as water became construed as something that could be accounted for exclusively in quantitative terms, using modern scientific instruments, all heterogeneity was eventually removed, leaving only the essential substance.

28

Another example is found in the attention to the variety of waters encountered by people involved in various industrial processes for which water quality was of the utmost importance. For example, Canada's federal Department of Mines conducted an inquiry into "The Industrial Waters of Canada" between 1934 and 1940. The study covered all industrial uses of water, and was concerned about water quality "not because of environmental concerns, but because dissolved or suspended materials in water could cause operating problems for manufacturers and resource extracting industries, thereby increasing production costs." (Gossage 1985:104; see also The Permutit Company 1943) As a matter of speculation, it would seem that the widespread adoption of more effective techniques to purify water - known as "water conditioning technologies" (The Permutit Company 1943) - after the Second World War, has curtailed the industrialists' concerns with the qualities of different "waters" as these technologies produce a kind of water that is useful for the purposes of most industrial applications. It is relevant to note that the variety of waters encountered in the context of industrial applications can be traced far back into history. To cite one example, Agricola's interest in waters stemmed from his concerns to promote mineralogy and mining. His written works, including De re metallica, published posthumously in 1556, revealed his fascination for classifying and describing water according to quality, taste, colour and provenance and occurrence such as in springs, wells, rain, show melt, oceans, lakes and swamps. In a letter written in 1546, he appended a dictionary of earth science and mining terms, translated from Latin to German, in which there are included "no less than 27 definitions of different waters." (Pfannkuch 1987:46) 
As we will see in Chapter 5 , modern water has been constituted, in part, by the expulsion of practices such as those described in the paragraph above, from the field of "scientific hydrology", and by the reservation of the title of "hydrology" to scientific practices that deal with quantities of water, "pure and simple". In the process of becoming identified as the one and only "scientific hydrology" it was necessary to get rid of "the peculiar properties of...various 'waters" that had been the subject of less 'scientific' hydrological practices since ancient times. The most expedient way of accomplishing this was to consider water exclusively in its quantitative dimension. But we are getting slightly ahead of the argument. The salient point here is to stress the need to look beyond Hamlin's focus on water in the history of medicine, chemistry and public health in order to reveal a more complete, albeit more complex, picture of the emergence of modern water.

\section{"All this is no concern of mine" - Scientific Hydrology and Modern Water}

At the outset, a broader historical context might be identified to help explain the apparent shift from "many waters" to "one" that Hamlin has identified as having taken place in Britain by 1850 and elsewhere in the industrialized world over the next half century. This time period corresponds to the advanced stages of the industrial revolution and the emergence of industrial capitalism in these very places. These momentous changes in political economy brought new demands on water - particularly as a source of power and a factor of production and on ways of knowing and accounting for water that would allow it to serve these demands. 
Also, the migration of people from rural to urban areas associated with the rise of industrialism inevitably had a profound effect on the way water was regarded. Social relations with water are inevitably transformed as people move from one place to another. In the mass movement of people from countryside to the city especially when served by piped water through urban distribution systems - those relations, it may be said, are attenuated in a pronounced way. In his study of the urbanization of water, Goubert describes this process in terms of "the conquest of water." (Goubert 1986) But he points out that in order to be conquered, water was first "besieged by science and technology" (1986:24) - thus through science and technology a new way of conceptualizing and relating to water emerged that internalized profound intellectual as well as material consequences for water as well as for people.

To provide a more sufficient explanation of the conceptual shift from premodern waters to abstract modern water requires that we consider the history of scientific traditions other than chemistry and public health. The conquest of water must also be considered in relation to the development of the hydrological sciences. This suggests a somewhat different periodology from that presented by Hamlin; it locates the historical origins of modern water somewhat earlier, namely in the midseventeenth century. Moreover, it suggests that the ascendancy of modern water grew incrementally as the intellectual and material consequences of seeing and relating to water hydrologically took root and spread, reaching a kind of apogee only late in the twentieth century with the advent of what might be called "global 
water". (See Chapter 7) Finally, a point that I will repeat here: Considering modern water from the perspective of the history of the hydrologic sciences suggests that the "paradigm change" was more than simply a shift from waters to water; it entailed the effective removal of water - its extrication, or abstraction - from the social relations that had given water(s) a variety of different meanings and manifestations in different places and times.

The history of hydrology is treated in greater depth in following chapters and here I want only to introduce it and suggest its contributions to modern water in the very broadest of terms. There are many definitions of hydrology, but as the eminent hydrologist, James Dooge has pointed out, they all centre on the scientific study of "the occurrence and the movement of water on our planet." (Dooge 1983:23) Scientific hydrology deals with many of the same questions, and I would argue, builds on the general approach to water found in classical natural philosophy, as opposed to the premodern attention to specific waters encountered in classical natural history. Indeed, most historians of the science have located its origins in writings that deal with the occurrence and movement of water (the nature of water) found in the works of Aristotle and other classical natural philosophers. At the same time, historians of hydrology have tended to ignore the attention paid by natural historians to the variety of waters encountered in the classical world. The reason, as I intend to show, is that modern hydrology is patently not interested in the variety of waters; its purpose might be described as reducing the world's 
waters and of the variety of hydro-social relations to an unequivocal set of mathematical abstractions.

While people had long manipulated water by artificially irrigating crops, draining marshes, redirecting streams and channelling flows through mill-races ${ }^{29}$, the demands on and for water unleashed by the growth of capitalism, the Industrial Revolution and urbanization beginning in the seventeenth century and accelerating over the next two hundred years were of an unprecedented order. (Smith 1975:150-154) ${ }^{30}$ As suggested above, these demands involved the need to know things like how much water was available for water power and for cities; to what extent did the flow of water in rivers and streams vary from one season to another; what was the relationship between the flow of rivers and the fall of rain; how might the flow of rivers and streams be augmented or reduced by changes in the landscape such as deforestation or agriculture; to what extent would the drainage of swamps increase the flow of a receiving river; how might the damming or diverting of a river effect the flow of springs... Together with the intellectual changes of the era associated with what has been called the Scientific Revolution, these needs gave rise to activities that would become the foundation of a new

\footnotetext{
${ }^{29}$ For example, thousands of water mills were built in Medieval Europe, serving purposes ranging from grinding grain, fulling cloth, sawing wood, etc. The Domesday Book, compiled in 1086 lists 5,624 mills in England alone. (Smith 1975:144)

${ }^{30}$ The ecological effects of an expanding agrarian market economy to serve the needs of growing cities included an acceleration of the process of draining of swamps and reclaiming wetlands. In Holland, for example, by the early $17 \mathrm{C}$, windmill technology was being applied on a large scale for pumping water out of inland lakes and as a source of energy for industrial production. Dutch engineers of the seventeenth century formulated comprehensive drainage plans and improved the construction of windmills, dikes, and sluices, technological expertise that was exported to other countries including Italy, France, and England. "Dutch capitalists who financed reclamation projects at home soon extended their financial backing to projects abroad." (Merchant 1980:56-57)
} 
science, the sina qua non of which was the quantification of water in measurements of the basic phases of the hydrologic cycle; evaporation, precipitation, runoff, groundwater flow, etc.

Perhaps the most significant aspect of the contribution of scientific hydrology to modern water is suggested by recognizing that the very act of measuring water abstracts it from its qualitative dimensions. "[T]he creation of a "measure" is a complex mental act;" writes Witold Kula in his social history of standards of measurement; "it demands that we abstract from a great many qualitatively different objects a single property common to them all, such as length or weight, and compare them with one another in that respect." (Kula 1986:43) Measuring water is hardly a uniquely modern practice. As Kula and others have shown, measurement is a social activity common to virtually every society of the past as well as the present. But unlike modern measures, older standards of measurement were inextricably related to their social and historical contexts.

The famous "nilometers" could be cited as an example - the oldest existing hydrometric installations on earth, their descriptions are commonly featured in general histories of hydrology and fluvial hydraulics. (e.g. Biswas 1970:3, 1417;Garbrecht 1987b:5) But what did these instruments measure? To be sure they measured the height of water, or the river stage, at various locations along the lower Nile. But rather than an abstract mathematical index, at least some of the nilometers were gauged according to the anticipated effects of different water 
levels on contemporary Egyptian society. Thus the "social calibration of nilometer readings" (Dooge 1987:63) as pointed out by Dooge:

"It is interesting to note that the first hydrological measurements were made to serve social purposes rather than to assist in the design of hydraulic works or the understanding of hydrological phenomena. Thus nilometers were installed four thousand years ago because the level of the Nile was used as a basis for taxation. In this connection it is interesting to recall that the first calibration of nilometer readings was not in terms of flow but in terms of economic and social effects as is illustrated on [Figure 3.3] which is based on the text of [Pliny the Elder]... Similarly the first recorded reference to a raingauge which dates back over a thousand years refers to it as the basis of the land tax in India." (Dooge 1987:62)

The ancient nilometers, in other words, might be described as socio-hydrometric instruments in the sense that water levels were understood and measured directly as a function of their socio-economic implications. ${ }^{31}$ (Figure 3-3)

\begin{tabular}{|l|l|}
\hline Social calibration of nilometer readings & $\begin{array}{l}\text { Equivalent } \\
\text { in ells }\end{array}$ \\
\hline & 19 \\
\hline DISASTER & 18 \\
\hline & 17 \\
\hline ABUNDANCE & 16 \\
\hline SECURITY & 15 \\
\hline HAPPINESS & 14 \\
\hline SUFFERING & 13 \\
\hline HUNGER & 12 \\
\hline & 11 \\
\hline & 10 \\
\hline
\end{tabular}

Figure 3-3 - "Social calibration of nilometer readings" (From Dooge 1987:63) (An ell is an old English measure approximately equivalent to 1.1 meters.)

\footnotetext{
31 In another article, Dooge describes the first documented reference to a rain gauge in a book written by one, Kautilya ( $400 \mathrm{BC}$ ) on topics relating to politics and administration. Dooge points out that the guage was calibrated against the land tax. (Dooge 1984:150-151)
} 
This approach to measuring water differed from that employed by the administrators of the water supply for ancient Rome (see discussion of Roman quinaria below) and again from that used to measure and control the distribution of water in traditional Balinese irrigation systems as described in the last chapter. Such idiosyncratic ways of measuring the different waters of different places (as for other things like grain, salt, etc.) were both constituted by and constitutive of the social relations through which they were practiced. (Kula 1986)

The notion that things can and should be measured in the abstract - i.e. in universal, mathematical terms that may be applied without reference to local cultural circumstances - represents a modern departure. As Alfred W. Crosby has argued: "The West's distinctive intellectual accomplishment was to bring mathematics and measurement together and to hold them to the task of making sense of a sensorially perceivable reality, which Westerners, in a flying leap of faith, assumed was temporally and spatially uniform and therefore susceptible to such examination." (Crosby 1997:17) Abstract, mathematical stock-taking of the world thus became the "measure of reality" as Crosby describes it. (Crosby 1997; see also Dear 1995) Such an accomplishment was made possible by the fusion of mathematics with natural philosophy, an intellectual feat associated with Kepler, Galileo, Descartes and others in the early seventeenth century. ${ }^{32}$ By this move, the qualitative differences that had characterized the nature of things were rendered

\footnotetext{
32

Collingwood points out that it was the Pythagoreans who had first accomplished this as early as the $5^{\text {th }}$ century BCE. (Collingwood 1945:54)
} 
mere functions of quantitative structural differences, and were made amenable to mathematical analysis. ${ }^{33}$ From a world of qualitative, often incommensurable differences, the new, mathematical natural philosophy effected "the restriction of natural reality to a complex of quantities" of which "nothing is scientifically knowable except what is measurable." (Collingwood 1945:103) In this way an uneven, heterogeneous, fundamentally qualitative world was transformed into a reality that could be expressed in common, abstract, quantitative terms. "The book of nature", as Galileo famously proclaimed, "is written in mathematical characters." (quoted in Encyclopaedia Britannica, $15^{\text {th }}$ ed.19:641) (4 $^{34}$

The mixing of mathematical analysis with natural philosophy has defined the nature of water in modern scientific practice. The philosopher of science, R.G. Collingwood, has pointed out that "when chemistry correlates the qualitative

\footnotetext{
33

Elsewhere this has been described in terms of "mixing mathematical practice and natural philosophy" (Dear 2001:55) and"the geometrization of nature" (Hall 1996:22)

34 This innovation of "mixing mathematical practice and natural philosophy" (Dear 2001:55) made an important contribution to the way space has been experienced, conceptualized and materialized in the history of the West. (Illich 1985:8-24; Kula 1986:288; Harvey 1989:Part III; Lefebvre 1991; Crosby 1997:Ch.5; Scott 1998) Once nature is understood in geometric terms, space - which may be experienced and represented of in a variety of ways - is made homogeneous, uniform, isomorphic and isometric. Space, as Lefebvre has emphasized, is always a product of history. Lefebvre distinguishes modern spatial experience and practices in terms of what he calls "abstract space", the product of a particular set of material and intellectual (historical) circumstances with roots in the classical era, and coming to flower in industrial capitalism. (Lefebvre 1991:46-50) Abstract space is space that "tends towards homogeneity, towards the elimination of existing differences or peculiarities" (ibid. :52). For Lefebvre, abstract space is isometric space, defined by its homogeneity, "a property which guarantees its social and political utility." (ibid. 285) I mention these critical assessments of (the history of) space because of what seem important parallels between modern water and abstract space. "The water that we have set out to examine", deciares Illich, "is just as difficult to grasp as is space." (1985:24) But in the sense of its having a history, its isomorphism, its indebtedness to mathematical natural philosophy and its social and political utility, modern water shares a number of important features with abstract space. Thus $\mathrm{H}_{2} \mathrm{O}$ can be cited as an example of what Lefebvre calls "the lethal use of signs" (1991:156) - 'lethal' in the sense that it kills the heterogeneity of things, destroys the unmediated experience of things in heterogeneous time and space.
} 
particularities of water with the formula ' $\mathrm{H}_{2} \mathrm{O}$ ' this is an application of the basic principle that "a thing's 'nature'.... is not what it is made of but its structure, as that structure can be described in mathematical terms." (Collingwood 1945:25) Like modern chemistry, modern hydrology also treats of water in essentially mathematical terms, although at a much larger scale than that of the water molecule. ${ }^{35}$ Indeed, in the seventeenth and eighteenth centuries, the practice approximating what is now known as scientific hydrology has been classified as a "mixed mathematical science", meaning that it combined ideas from the natural philosophy of water with mathematical abstraction (Dear 2001:55). The effect of this mixture was to produce a discipline whose overall function was to render the occurrence and distribution of water on the earth reducible to mathematical expression. $^{36}$

As we will see in the next chapter, the history of the development of scientific hydrology is strongly associated with the concept of the hydrologic cycle. For now, I simply want to sketch in the briefest of terms the West's distinctive intellectual contribution of taking water as some thing that may be measured in the abstract. When considering the discharge of water from pipes, the Romans applied a

\footnotetext{
${ }^{35}$ While chemistry treats of water at the molecular scale $\left(10^{-10} \mathrm{~m}\right)$ and hydraulics at the mesoscale $\left(10^{-2} \mathrm{~m}\right)$ Dooge points out that "the scales of interest to the hydrologist are macroscales which are about $10^{6}$ larger than the mesoscales of continuum mechanics and about $10^{12}$ larger than the microscales of physical chemistry." (1983:40-41)

${ }^{36}$ Such might be inferred from Tonini - from the International Centre of Hydrology, Padua, Italy who summed up the status of and hopes for the science in 1974: "The hydrological cycle is now being transformed into a hydrological system where the relationships between the various elements and their mutual influence and interdependence become less stochastic and more functional. Even if the results within a limited basin or a limited time interval can be considered satisfactory, a complete vision has not yet been achieved. It is however in man's nature to hope to get close, very close indeed to this goal." (Tonini 1977:135)
} 
standard measure of cross-sectional area of flow known as the quinaria. However, they found it unnecessary to measure the discharge of water itself, a measure that would have included consideration of the velocity of flow. ${ }^{37}$ Instead, their concept of the water "rate" was deemed adequate and appropriate for purposes of ensuring a just distribution of water to the citizens of Rome. ${ }^{38}$ Throughout Europe, this approach to measuring the flow of liquid water was generally applied to open channels as well as pipes until the seventeenth century. (Biswas 1970:160) The earliest efforts to produce a "scientific" understanding of the flow of water are usually associated with Leonardo de Vinci, who stressed the importance of combining measurements of wetted cross-sectional areas with the velocity of streamflow, and who conducted experiments to measure the distribution of velocities in open channels. However, Leonardo appears not to have used this data to compute actual discharge values, and in any case, his work had little

\footnotetext{
37 It is relevant to note that the Romans never calculated the amount of water serving their city. The legendary wealth of Rome's water supply is a modern preoccupation that seems to have been initiated when the American hydraulic engineer, Clemens Hershel, translated Frontinus' treatise The Two Books on the Water Supply of the City of Rome, (c. 97 AD) in 1899. After estimating losses from leakage and theft, Herchel calculated that the nine aqueducts serving the city in Frontinus' time delivered something like 38 million gallons daily to Rome's inhabitants. Based on an estimated population of 1 million at the time, this produced a per-capita figure of 38 gallons (144) litres per day - a figure that exceeded that of every city in the world when Herchel's translation was published, and indeed indicating more water per capita than is available to people in many cities today. (Britannica 26:423; see also Biswas 1970:Ch. 5; Smith 1975:Ch.7) But see Hodge (2000a:47) for the difficulty of making such calculations, and the suggestion that Rome likely received less water than is commonly believed.

${ }^{38}$ This has been interpreted by almost all modern hydrologists and most historians as a gross failure or oversight on the part of Roman science, "a startling ignorance of what is required" as Smith (1975:93) puts it, to cite but one example. However, as Blackman and Hodge point out, while the Roman "concept of 'rate' was "at very best was qualitative, certainly not quantitative" there was no perceived need for the scientific quantification of the flow of water: "What occupied them more was the administration of the distribution of water to users and of the associated licences. By modem standards a bit rough and ready, but the calices [pipes of standard sizes] ensured a stable system which apportioned what all shared in a way which was perceived to be just." $(2001: 21,24)$
} 
immediate influence on development of the hydrological sciences. (Biswas 1970; Macagno 1987)

It was not until the first half of the seventeenth century that water began to be studied systematically as a moving fluid by Galileo's students at the Academia del Cimento. (Morello 2001) One of these students, Benedetto Castelli, formalized the abstraction of the flow of water in what is now known as the "law of continuity" in his Della misura dellacque correnti, ("the measurement of currents of water") published in 1628. (Biswas 1970:170-173) In essence, this principle applies the conservation of mass to the flow of fluids, and can be expressed as $Q=A \times V$, where $Q$ represents discharge, $A$ is the cross-sectional area and $V$ is velocity. In providing a convincing proof of the law of continuity and a scientific basis for the measurement of streamflow, Castelli's work made an important contribution to the development of the hydrological sciences. (Biswas 1970:170-173) In a way that strikes me as particularly illuminating, the historian of science, Cesare S. Maffioli has described Castelli's contribution in terms of "annexing the subject of waters to the territory of the Galilean mathematical sciences" (Maffioli 1994:10, my emphasis) $)^{39}$

\footnotetext{
39 The law of continuity provides a good example of the kind of abstract thinking that was made possible by the conjoining of mathematics and natural philosophy. "In order to formulate the laws governing the movement of natural objects," Leiss points out it was "necessary to disregard the sense-qualities of things.... and to posit the existence of a uniform substance common to all objects. Since this substance or matter is assumed to be everywhere the same, the differences between things can be reduced to simple quantifiable proportions... As only relations of quantity are involved, the laws of motion could be set down entirely in mathematical and geometrical terms." (Leiss 1974:91)
} 
While Castelli's law of continuity, drawn from his experience and experimentation with the rivers of Italy, made an important contribution to the development of hydrology, it eventually followed a channel of its own and fed the (related) modern science of hydraulics. (Rouse and Ince 1957:59-61; Fasso 1987; Maccagni 1987) Meanwhile the spirit of the mathematical philosophy spread to annex the waters of other parts of Europe. It was in the mid-to late seventeenth century that water began to be measured in a scientific, systematic, fashion by natural philosophers whose work comprised the core of what modern hydrologists consider their specific field. Christopher Wren's famous rain gauges, some of which were tested on the grounds of Gresham College in the 1660s, are cited by David Livingstone as an example of the "mathematical baptism" by which "several...areas traditionally coming under the rubric of geography were beginning to experience the first flush of quantification." (1992:104) The specific "area" of which Livingstone speaks in this instance is the field of hydrology. It is no surprise therefore, that Wren, along with a coterie of other seventeenth and eighteenth century measurers and calculators of rainfall, evaporation and streamflow are championed as heroes in the conventional narrative of the development of the science of hydrology. ${ }^{40}$

As noted, in the most general of terms, hydrology deals with the occurrence and movement of water on earth. The science is based on the quantification of water, not just in liquid phase flowing in streams and rivers, but in all stages of the

\footnotetext{
${ }^{40}$ For Wren in particular, see (Biswas 1967; Biswas 1970:234-239) For others see Chapter 5 below.
} 
hydrologic cycle, including evaporation, precipitation, streamflow, groundwater flow, etc. It has also been noted that, in the context of classical natural philosophy, questions involving things like occurrence of rainfall, the relationship between evaporation from the seas and rainfall and between rainfall and the flow of rivers, the behaviour of underground water, and the origin of springs, had been of interest to natural philosophers from the earliest times. It is when the mathematical approach to water gets grafted onto such classic hydrological' questions - when water became systematically swept up in the metrological fervour engulfing Western thought through the budding science of hydrology - that modern water began to take form.

\section{Conclusion - a manifesto for modern water}

Around the time that Christopher Wren and others were measuring rainfall at Gresham College, researchers in France were conducting embryonic studies on the mathematical relationship between evaporation, rainfall and streamflow in basins tributary to the Seine River. The person considered by most modern hydrologists to be the first of their line - by virtue of his pioneering attempts to quantify these basic elements of the water balance equation in the 1760 s - was one Pierre Perrault. Until his reputation was resuscitated in the writing of hydrological history, Perrault was practically unknown, except perhaps for having lost the post of receiver-general for Paris when he was discovered helping himself 
to funds from the public treasury in $1664 .{ }^{41}$ (Larocque 1967:3) Nevertheless, it was Perrault's quantification of water rather than public funds that has stood the greater test of time. His measurements of precipitation, evaporation and streamflow in a basin at the source of the Seine were made with the ostensive aim of proving that the water of springs was derived from rainfall (precipitation) rather than from the oceans and seas via subterranean channels. More will be said of Perrault in the following two chapters, but for now I want to quote from the concluding paragraph of his famous - to hydrological historians at least - monograph, On the Origin of Springs, a statement that might be taken as a kind of manifesto for modern water:

"For me, who have undertaken to speak only about the Origin of Springs, it is sufficient to have done so, and by this means to have given them birth. Their fate is to run upon the Earth and throughout the World, I shall let them do so without taking any interest in what may happen to them, good or bad; if the ones become famous through the various good or bad qualities that have contracted in their travels, according to the lucky or unlucky meeting they may have made with favourable or unfortunate soils; if others attract the admiration and amazement of curious people by their flow and by their surprising effects, if others remain by nature mild and peaceful, as they were at birth. All this is no concern of mine, it is enough that they should be simply springs, their quality being only an accident which can happen or not happen to them without changing their essence. (Perrault 1967:144-45)

This quote suggests the main contribution of science to modern water: the disentanglement of the waters of the Earth from the chorological and cultural contexts that otherwise give them meaning to people. Here we have a founding

\footnotetext{
41 Pierre Perrault was the brother of Claude Perrault, architect of the Louvre and - most significantly in the present discussion - author of a French translation of Vitruvius' Ten Books of Architecture, published in 1673, the year before Pierre's book was published. Another Perrault brother, Charles, was controller of the department of public works under Colbert and became wellknown as an author, particularly of fairy tales. (Encyclopaedia Britannica, $11^{\text {th }}$ ed. s.v. "Perrault...")
} 
statement, at the very doorstep of the modern era and the very moment of the birth of scientific hydrology, signalling the intention to abstract water from these contexts, to establish its "essence" in terms of what can be measured, and relegate its qualities and meanings to the status of mere "accident." Here, in other words, we have a prescription for the death of the social nature of water. 


\section{The Hydrologic Cycle(s): Scientific and Sacred}

\section{Introduction}

The last chapter introduced the science of hydrology and considered its general contribution to modern water in terms of quantifying and abstracting water from the specific social relations that give it local meaning. Now, I want to begin examining this contribution in more detail, specifically through the concept of the hydrologic cycle. The hydrologic cycle is the central concept, principle, or model of scientific hydrology. But it has spilled beyond the confines of scientific, hydrological discourse and inundated the popular imagination. The hydrologic cycle's popularity is suggested by the ubiquity of its appearance - especially in diagrammatic form in academic and more popular visual discourse. There can scarcely be found a standard earth sciences or geography text that does not feature a diagram of the hydrologic cycle. A quick (Google) search for images of the "hydrologic", "hydrological" or "water" cycle on the Internet produces literally thousands of images. ${ }^{1}$ Like (modern) water itself, the hydrologic cycle is so familiar that it is usually presumed to be 'natural' - to quote a couple of eminent hydrologists, it is "one of nature's grand plans." (Langbein and Hoyt 1959:3)

The overall purpose of this and the following chapter is to present the hydrologic cycle as a hydreification that takes shape where the water process meets with the

\footnotetext{
1 On December 7, 2004, my Google search for "hydrologic cycle" produced 990 visual images; "hydrological cycle", 414 images; "water cycle", 11,500 images.
} 
practice of scientific hydrology. The hydrologic cycle is a social construction; however it represents water in a way that erases its social content. In the course of presenting the hydrologic cycle in this light, I aim to discuss the part it plays in the constitution of modern water, a theme that will be addressed more directly in Chapter 8. To anticipate the argument somewhat, the hydrologic cycle's main contribution is in fitting all the world's water within its domain - no water can possibly escape it. "All water is involved in a continuous hydrologic cycle..." as one standard reference makes quite clear. (Marsh 1985:2279) The hydrologic cycle thus provides a way of conceptualizing, representing and accounting for all water in a way that isolates it from the very social processes that make it what it is in each particular instance.

My approach will be to consider how and when the hydrologic cycle came into being, an approach that is best described as historical in the same sense that we considered the general history of modern water in the last chapter. Like every instance of (social) nature, the hydrologic cycle has a history - or rather, I should say that it has histories, for there are at least three different ways of telling the story of how it came about. In keeping with our relational-dialectical approach to things, each of the three histories presented here tells a story about something that is slightly different from the others. In each case, the observers/storytellers/historians in question see and describe a slightly different hydrologic cycle, depending on the particular practices in which they are involved. 
The first story presented below is the one told by modern hydrologists about how the scientific concept of the hydrologic cycle came into existence. This is the most common story of the origin of the hydrologic cycle. In fact, with only one exception that I'm aware of (see below), it is the only type of history that has been published; here it is referred to as the "conventional" history of the "scientific" hydrologic cycle. Moreover, because it is told mostly by scientists, for scientists (or for students of science), this is the story of what I call the "scientific" hydrologic cycle. This history presents the hydrologic cycle not as a social construction, but as something that has always existed in nature, but was imperfectly or poorly understood until relatively recently. Although the subject of much speculation in ancient and medieval times, the conventional history relates the story of how the true, or correct understanding of the hydrologic cycle was revealed, through the application of quantitative methods to the study of water, beginning in the late seventeenth century (in which the work of Pierre Perrault, the proto-hydrologist introduced at the end of Chapter 3, figures prominently). This story is commonly found in hydrology, and sometimes in other earth science, environmental science and geography, textbooks and reference books. It provides the main theme in most accounts of the history of hydrology. The type of hydrologic cycle described in the conventional history - the scientific hydrologic cycle - is the one that is most familiar today and is the one that contributes most importantly to modern water.

The second story is the exception mentioned in the paragraph above. It was told by a geographer, Yi Fu Tuan, in the late 1960s. (Tuan 1968a) Tuan describes how 
the concept of the hydrologic cycle was brought into existence by natural philosophers writing in the physico-theological (or natural theology) tradition from the seventeenth to the nineteenth centuries. ${ }^{2}$ According to Tuan's account, these natural philosophers sought to prove the existence and the providence of God by means of revealing the wonders of His creation. The concept of the hydrologic cycle that they brought into being thus bespoke the balance, harmony and generosity of the Creator as manifest in His cosmological waterworks. Because of the religious orientation and motives of its proponents, I have described this as the history of the "sacred" hydrologic cycle.

Although Tuan's history of the sacred hydrologic cycle entails occurrences that also appear in the conventional history, (and sometimes even involve the same people) the two stories very seldom overlap. They are, after all, dealing with different things. The physico-theologians were articulating a proof of the existence and the providence of God; their purpose was to present and discuss water in Christian-theological terms. Modern hydrologists on the other hand, were/are articulating a proof of the scientific rationality of water, their purpose was (and still is) to treat water in scientific-hydrologic terms. That the two stories don't overlap is partly a consequence of their drawing different lessons from water and of describing it in different (sacred vs. scientific) terms. The main reason these histories don't overlap, however, is because unlike the story told by hydrologists,

\footnotetext{
2 Physico-theology was a branch of natural philosophy/theology that sought to show evidence of God's design in the works of nature. It is described in greater detail below.
} 
Tuan does not presume that the (sacred) hydrologic cycle pre-existed its construction by the physico-theological writers. Tuan therefore does not regard the (sacred) hydrologic cycle as a natural phenomenon, i.e. as something occurring independently in nature and awaiting the application of proper method to reveal its truth. Instead, he describes it more as a concept that was invented - a product of human "ingenuity" to use his term. (Tuan 1968a:6) In Tuan's account, the social nature of the (sacred) hydrologic cycle is recognized more explicitly than in the conventional history.

While he acknowledged the constructedness of its "sacred" variant however, Tuan did not develop a critique of the hydrologic cycle itself. Throughout his study, titled The Hydrologic Cycle and the Wisdom of God, he used the term "hydrologic cycle" anachronistically, never considering that its coinage (and the specific idea that it represented) post-dated by a considerable margin the written works that he described. Had he considered this, it is possible that he would have recognized that the "hydrologic cycle" itself is the product of modem scientific discourse as much as the sacred hydrologic cycle was the product of Christian theological discourse. But Tuan insisted that there was no important difference between the modern (scientific) concept and the idea whose history he was writing. "One purpose of this essay" he wrote, "is to show that, for at least one hundred and fifty years (ca. 1700-1850), the concept of the hydrologic cycle in the 'standard' form was a handmaiden of natural theology as much as it was a child of natural philosophy." (1968:4) In the next chapter, I will show that "the concept of the 
hydrologic cycle in the 'standard' form" is actually a much more recent development than Tuan acknowledges. Here, I would argue that Tuan, like some other writers ${ }^{3}$, conflates the sacred and the scientific hydrologic cycles because he sees them both through the lens of modern water. That the two hydrologic cycles are different, that they are distilled from different discourses, and that Tuan ignored this, attests to the hegemony of the scientific hydrologic cycle, and of modern water generally.

Considering the origin of the term "hydrologic cycle" or "the hydrologic cycle in the 'standard' form", leads us to yet another history of yet another hydrologic cycle. (As the principle of potentiality, water is indeed capable of withstanding such contradictions!) This, the last history that I will impose upon the reader, tells the story of how and when the hydrologic cycle of contemporary fame (the one with which most of us are familiar today) came into being and how it managed to lay claim to all the world's water, past and present. But that is the subject of the next chapter and will make sense only after the tales of the first two hydrologic cycles have been told.

\section{Conventional History of The (Scientific) Hydrologic Cycle}

"The hydrologic cycle is the most fundamental principle of hydrology. Water evaporates from the oceans and the land surface, is carried over the earth in atmospheric circulation as water vapor, precipitates again as rain or snow, is intercepted by trees and vegetation, provides runoff on the land surface, infiltrates into soils, recharges groundwater, discharges into streams, and

${ }^{3}$ See the quote by de Villiers at the beginning of the section on the 'sacred' hydrologic cycle below. 
ultimately, flows out into the oceans from which it will eventually evaporate once again. This immense water engine, fuelled by solar energy, driven by gravity, proceeds endlessly in the presence or absence of human activity." (Maidment 1993:1.3)

"The choice of what to measure is guided by present understanding of the workings of nature." (Langbein and Hoyt 1959:5)

\begin{abstract}
Almost every standard hydrology textbook, handbook and summary article published in English ${ }^{4}$ since the 1930s begins with an affirmation of the hydrologic cycle as the central concept of hydrology. ${ }^{5}$ Textual descriptions, such the one cited directly above, are usually - and in the case of hydrology textbooks and handbooks, always - accompanied by one or more diagrams of the hydrologic cycle, a form of representation that is familiar to every high school student.
\end{abstract}

Most of these texts and standard references also feature sections of various lengths describing the history of hydrology, of which the development of the concept of the hydrologic cycle is the main theme. Hydrology is described as having origins in ancient philosophy, but is understood to have emerged as a science with the quantitative, basin-scale studies of French and English protohydrologists in the seventeenth century. With these studies, "the hydrologic cycle was firmly established, marking the beginning of scientific hydrology." (National

\footnotetext{
${ }^{4}$ And, at least with respect to hydrology textbooks, this statement may be applied to publications written in other languages too. (see Unesco 1974a; 1974b)

${ }^{5}$ With the exception of Mead's 1950 textbook (Mead 1950) - a later edition of an pre-Hortonian text (Mead 1919) - virtually all the hydrology textbooks and handbooks published in the United States after 1931 have featured prominent diagrams and descriptions of the hydrologic cycle in the introductory sections.
} 
Research Council (National Research Council) 1991:38) The following quote from the article on "Hydrology" in the Dictionary of Physical Geography, provides a typical example, placing the development of the hydrologic cycle concept squarely at the centre of the story of hydrology:

"The study of hydrology is at least as old as the ancient civilizations of Egypt, because the provision of a reliable water supply is essential to the survival of man. However, the development of plausible theories concerning the circulation of water in the hydrological cycle did not appear until the seventeenth century. These were largely based on observations of rainfall and river flow in the Seine basin by Pierre Perrault and Edme Mariotte and on the ideas of Edmond Halley who simulated evaporation from the Mediterranean and concluded that this could account for all surface drainage." (Goudie 2000b:256)

As natural scientists, it has been important for hydrologists to identify the hydrologic cycle as the representation of a natural process - something that takes place "in the presence or absence of human activity" as described by Maidment above. The conventional history of the hydrologic cycle relates the story of how, over the centuries, natural philosophers and scientists (proto-hydrologists) managed to reveal the workings of this natural process. This kind of historical narrative is typical of traditional histories of science, which assume the form of narratives of scientific progress. They are the story of the progressive unveiling of a truth that was always already present in nature, but required application of the "correct" approach or method in order to be revealed to the researcher. (Latour 1993:71-81) When written by practicing scientists, as has most often been the case for hydrology, these histories serve the purpose of authorizing and contextualizing the present practice of the science. According to Jan Golinsky, 
scientist-historians "engage in interpretation and assimilation of the past as part of their work. Practicing scientists are continually appropriating the work of their predecessors and orienting themselves in relation to it. They periodically celebrate the work of founders and pioneers of the various scientific disciplines." (Golinsky 1998:2) Most of the histories of hydrology written to date are of this type, with the main theme of illustrating the progress of hydrological knowledge. Their main purpose - as made explicit by the Committee on History and Heritage of Hydrology of the American Geophysical Union - is "to encourage the study of the classical history of hydrology in order to provide practicing scientists with a sense of continuity by knowing their professional roots." (Back 1987:ix)

Taking the subject as a whole, hydrology does not boast a large volume of work devoted to its origins and development. A handful of books and collections of articles written mostly by hydrologists and published by or for scientific or engineering associations or government agencies comprise what might be described as the bedrock of this literature, along with books written on the history of the related field of hydraulics. ${ }^{6} \mathrm{~A}$ few articles that may be described as histories of hydrology appeared in scientific journals in the 1930s in association with efforts to establish hydrology as a distinct scientific discipline in the United States. ${ }^{7}$ In the 1960s and 1970s articles began appearing in journals such as Hydrological

\footnotetext{
6 The only books available in English on the general history of hydrology are Biswas 1970; and Landa and Ince ed.1987. Standard works on the history of hydraulics - which touch on various aspects of hydrologic history include Rouse and Ince 1957; and Garbrecht. 1987a.

${ }^{7}$ Notably, Meinzer 1934; Baker and Horton 1936.
} 
Sciences Bulletin, Water International, Water Resources Research, and Journal of Hydrology that contributed to this literature ${ }^{8}$. Many of these and other contemporary publications dealing with the history of hydrology sprang from work related to the International Hydrological Decade (1965-1974) ${ }^{9}$ Among its large volume of publications, the International Association of Hydrological Sciences has published several that address directly the history of hydrology. ${ }^{10}$ Histories of hydrology of various lengths are often found in the introductory chapters of hydrology textbooks ${ }^{11}$ and handbooks ${ }^{12}$ published in English. ${ }^{13}$ In 2001, A conference was held in Dijon France on the subject of the history of hydrology. ${ }^{14}$ The Association for the History of Water, founded in 2001, has held three international conferences, at which a handful of papers has been presented on the general history of the hydrologic sciences in the West. ${ }^{15}$

\footnotetext{
${ }^{8}$ Many of these are discussed below.

${ }^{9}$ The International Hydrological Decade (IHD) took place under the aegis of Unesco. The IHD is discussed in greater detail in Chapter 7.

${ }^{10}$ For example, Rodda and Matalas 1987; Section 1

11 To cite only a few, Meinzer 1942:8-30; Eagleson 1970:1-4; Kazmann 1972:5-21; Veissman Jr. and Lewis 1996:3-5.

12 Notably, Chow 1964:1.7-1.10; and Maidment 1993:1.9-1.12

${ }^{13}$ Not quite fitting into these categories, but nevertheless contributing to the literature of the history of hydrology, are Adams (1928); Adams (1938); Jones, Walker, Harden and McDaniels 1963;

Parizek 1963; Biswas 1965; and various parts of National Research Council 1991.

14 Colloque International OH2, Dijon. 9-11 mai 2001, "Origines et histoire de l'Hydrologie". Several of the papers presented at this conference are discussed below. While recent scholarship takes a greater interest in the history of hydrology outside of the Western tradition, at this conference, most of the papers dealing with the history of hydrology in the West would fit into the "conventional" category of hydrologic history.

15 Particularly the International Water History Association Conference, 10-12 August 2001, held in Bergen, Norway.
} 
The central theme in most of the conventional histories of hydrology is the story of the hydrologic cycle: its origins and its precursors in ancient thought; the intellectual detours and absurdities of those who espoused erroneous notions about the circulation of water; the identification of the earliest proponents of the 'correct' view; and the steps leading to its completion, closing, and ongoing perfection through the exact quantification of all phases, fluxes and scales of the cycle. While conventional historians of hydrology occasionally make perfunctory reference to ideas about the circulation of water in the ancient East (e.g. Chow 1964; Biswas 1970), they locate the origins of the modern concept of the hydrologic cycle in classical, Western thought. Thus we learn that most if not all the ancient Greek and Roman philosophers commented in one way or another on the nature and behaviour of water. Some sense of its cyclical flow is suggested in the early texts, a sense that is reflected in the often-quoted passage from Ecclesiastes, thought to date from the $10^{\text {th }}$ century BC:

"All the rivers run into the sea; yet the sea is not full; unto the place from which the rivers come, thither they return again." (Ecclesiastes 1:7)

However, the question of "the place from which the rivers come" remained a subject of hot contention throughout ancient and medieval times, giving rise to what has been considered the overarching dispute in hydrologic thought until quite recently - the question of "the origin of springs." 


\section{The Origin of Springs}

According to the conventional history of hydrology, the long-standing dispute over the origin of springs had to be resolved by quantitative methods in order to pave the way for the 'correct' understanding of the hydrologic cycle. Thus the question of the origin of springs - and the methods developed by proto-hydrologists to prove that all spring waters are derived from rainfall - assumes critical importance in this history. As late as the eighteenth century, it was very widely held that rainfall could not possibly explain the origin of water found issuing from springs and flowing in rivers. Apart from the obvious - at least obvious to contemporary European observers - fact that most springs continued to flow, and rivers continued to run, during times of little or no precipitation, the greatest known river on earth, the Nile, apparently came from a place where there was almost no rain. Besides that, until the late seventeenth century, it was almost universally believed that rain water could not penetrate the ground to a depth of more than one or two metres. (Adams 1938) The question then was whether the water issuing from springs and flowing in rivers was formed by condensation underground before emerging onto the earth's surface, or whether it came from the ocean via subterranean channels through which it was desalinated. While some argued that rain and snow played at least an important part in furnishing the water flowing on the earth's surface, an astonishing number (astonishing for us) of ancient and more modern thinkers subscribed to one or another, or a combination, of the subterranean hypotheses. Indeed, for over two millennia, the "dominant theory" (Dooge 2001) was that seawater found its way into the interior of the earth, from where it was lifted by various means to immense 
reservoirs within mountains, from which it emerged to feed streams and rivers returning the water to the sea. The modern explanation, based on the argument that rainfall is adequate to provide for streamflow, slowly gained popularity from the end of the seventeenth century; however it only became universally accepted in the twentieth century. (Dooge 2001)

The subject of the dispute over the origin of springs and rivers has been treated in depth by hydrological historians and is summarized here with an emphasis on how the subject is treated in the conventional histories of hydrology. ${ }^{16}$ In his history of The Birth and Development of the Geological Sciences published in 1938, Frank Dawson Adams devoted a chapter to the "problem" of "the origin of Springs and Rivers - which was the subject of continuous speculation and controversy throughout the ages, but which may now be said to have been definitely and finally solved, in all its chief features at least. ${ }^{17}$ Because Adams' version of the "problem" has been adopted by most subsequent historians of hydrology ${ }^{18}$, it provides the main source for much of this section.

\footnotetext{
16 The more focused historical accounts of the question of the origin of springs include: Adams 1928, Meinzer 1934, Baker and Horton 1936, Adams 1938, Meinzer 1942, Krynine 1960, Biswas 1966, Biswas 1970, Nace 1974, Nace 1975; Dooge 2001.

17 Adams 1938:426. Chapter XII (pp. 426-460) is based mainly on Adams 1928, Baker and Horton 1936 and Meinzer 1934. Baker and Horton 1936 and Meinzer 1934, in turn, cite Keilhack 1912 whose work translated into English reads: "Ground-water and the hydrology of springs". Horton 1931:190 notes that Keilhack describes the history of the dispute over the origin of springs.

${ }^{18}$ Biswas 1970:139 challenges Adams' contention that Leonardo da Vinci had a 'correct' understanding of the concept of the hydrologic cycle, but the two accounts are otherwise consistent.
} 
From Adams we learn that ancient Greek philosophers such as Anaxagoras and Plato "imagined that there is within the earth an immeasurable cavern filled with water in continual motion, from which all rivers issued and to which their waters returned. ${ }^{19}$ Aristotle countered that such a subterranean reservoir, in order to accommodate all the waters flowing in the rivers, would have to be larger than the earth itself. He offered three alternative explanations for the origins of springs and rivers: First, an explanation that will be recognized by modern readers as constituting part of the hydrologic cycle: a portion of this water comes from rain, which condenses in the atmosphere, falls to earth and goes into the ground, from where it re-emerges in the form of springs. Aristotle argued that most of the water in springs and rivers, however, was formed beneath the ground; in Aristotle's words, "Is it unreasonable for anyone to refuse to admit that air becomes water in the earth for the same reason that it does above it. If the cold causes the vaporous air to condense into water above the earth, we must suppose that the cold in the earth to produce this same effect, and recognize that there not only exists in it and flows out of it, actually formed water, but that water is continually forming in it too." (quoted in Adams 1938:429) According to Adams, for Aristotle, a third source of water comes from "the condensation of vapors which 'rose' from some source which is not stated. ${ }^{20}$ In any case, instead of a subterranean reservoir, as Plato

${ }^{19}$ Adams 1938:427. Information for the remainder of this paragraph is drawn from Adams 1938:427-430.

20 Adams 1938:430. The source of this water was probably thought by Aristotle to be the earth itself. According to the Aristotelian cosmology of the four earthly elements (as described in chapter 3 ) these formed a series of concentric spheres, with those elements found contiguous to one another (earth and water; water and air; air and fire) able to engender each other. Thus air could be transformed into water in the atmosphere and below the ground, while earth was thought to 
had imagined, Aristotle held that water in the earth rose to the interiors of mountains, from which it sprang forth to aliment springs and rivers. The flow characteristics of different springs and rivers were explained by variables such as the size and temperature of the mountains.

Adams and other early historians of the earth sciences report that with one notable exception $^{21}$, the classical writers who turned their thoughts to the question of the origin of springs subscribed to the Aristotelian view that their origin was primarily a subterranean affair, with water thought to form or flow in/through the bowels of the earth and rise to the heights of land from which it sprang forth onto the earth's surface. "The Roman philosophers", writes O.E. Meinzer"22, "in general followed the Greek ideas, and did not contribute much to the Greek hypotheses except erroneous details." (1934:8) Writers like Seneca are often quoted to provide typical illustrations of how the hydrologic cycle was understood in Roman antiquity:

"You may be quite sure that it is not mere rain water that is carried down in our greatest rivers, navigable by large vessels from their very source, as is proved by the fact that the flow from the fountain-head is uniform winter and summer... So then, the earth contains moisture which it forces out...By nature, too, earth has itself the power of changing into water: this power it habitually exerts." (Seneca, quoted in Adams 1938:431).

transform itself into water in the ground. The merging of the idea of the transubstantiation of elements with the cyclical notion of water is discussed in Tuan 1968a: ch. 2.

21 This is Vitruvius, as discussed below.

22

A groundwater specialist whose work was instrumental in establishing scientific hydrology as a bona fide scientific discipline in the United States in the 1930s (See Chapter 5) 
The conventional histories describe a long hiatus after the decline of ancient Rome. "Somehow," writes Asit K. Biswas ${ }^{23}$, "after Seneca, the origin of springs was not given much thought till the latter part of the fifteenth century." (Biswas $1965: 71)^{24}$ During these Middle Ages, intellectual activity in Europe was dominated by the Christian Church, which explains why Ecclesiastes 1:7 "was quoted with tiresome reiteration, by almost every writer on this subject throughout the middle ages and even later." (Adams: 1938:432) The prevalence of the subterranean thesis combined with the doctrine that "unto the place from whence the rivers come, thither they return again" to produce widespread belief that the origin of springs and rivers was seawater that found its way under ground and was conveyed to the tops of mountains by subterranean rivers and channels. Medieval writers ascribed the removal of salt to processes of filtration and distillation, while the elevation of the water was explained by a wide variety of what today seem rather wild hypotheses. ${ }^{25}$ Faith in this explication appears to have been almost universal, as "all the philosophers and interpreters of Holy Scripture, from St.

\footnotetext{
23 Biswas is a hydrologist who wrote the first, and to date the most comprehensive general history of scientific hydrology. (Biswas 1970) The discovery of the hydrologic cycle plays a central role in this history. See also Biswas 1965

24 Given the centrality of the development of the 'true' or 'correct' understanding of the origin of springs to hydrologic identity, this period of over one thousand years merits little attention in the conventional histories. Biswas devotes a single, brief, chapter to the entire period from 200 to 1500 AD. (Biswas 1970:123-134) For the most part, the subterranean hydrologic cycle is presented as a curiosity, an example of how even great thinkers like Descartes and Kepler could entertain "fantastic notions" about the circulation of water (Biswas 1965:72) and as a cautionary tale of how far people can go wrong when they fail to employ the proper (scientific) methods. 25

These included "processes of vaporization and subsequent condensation, to rock pressure, to suction of the wind, to a vacuum produced by the flow of springs, to pressure exerted on the sea by the wind and waves, to 'the virtue of the heavens', to capillary action, and to the curvature of the surface of the sea whereby the sea was believed to stand higher than the springs and hence to furnish the necessary head." (Meinzer 1942:9)
} 
Jerome (340-420 Ad) down, taught that the springs have their origin in the sea." (Meinzer 1942:11)

Among the proponents of the subterranean thesis, Adams and others have deemed the Jesuit Athanasius Kircher, "especially worthy of mention". ${ }^{26}$ (Adams 1938:433-440) Kircher's 1664 book, Mundus Subterraneus, provides a particularly entertaining account of gaping holes in the bottom of the sea-floor, subterranean passageways, mountain reservoirs, and ingenious hypotheses for the elevation of sea waters to the tops of mountains. Adams reproduces fantastic illustrations from Kircher's book depicting the subterranean hydrologic cycle. (Figure 4.1)

26 The practice of alluding to the "fantastic" notions of Kircher and reproducing his illustrations of the subterranean hydrologic cycle was copied in subsequent historical treatments of hydrology (for example: Biswas 1965:72-73; Biswas 1970:175-180; Hanor 1987:85). 


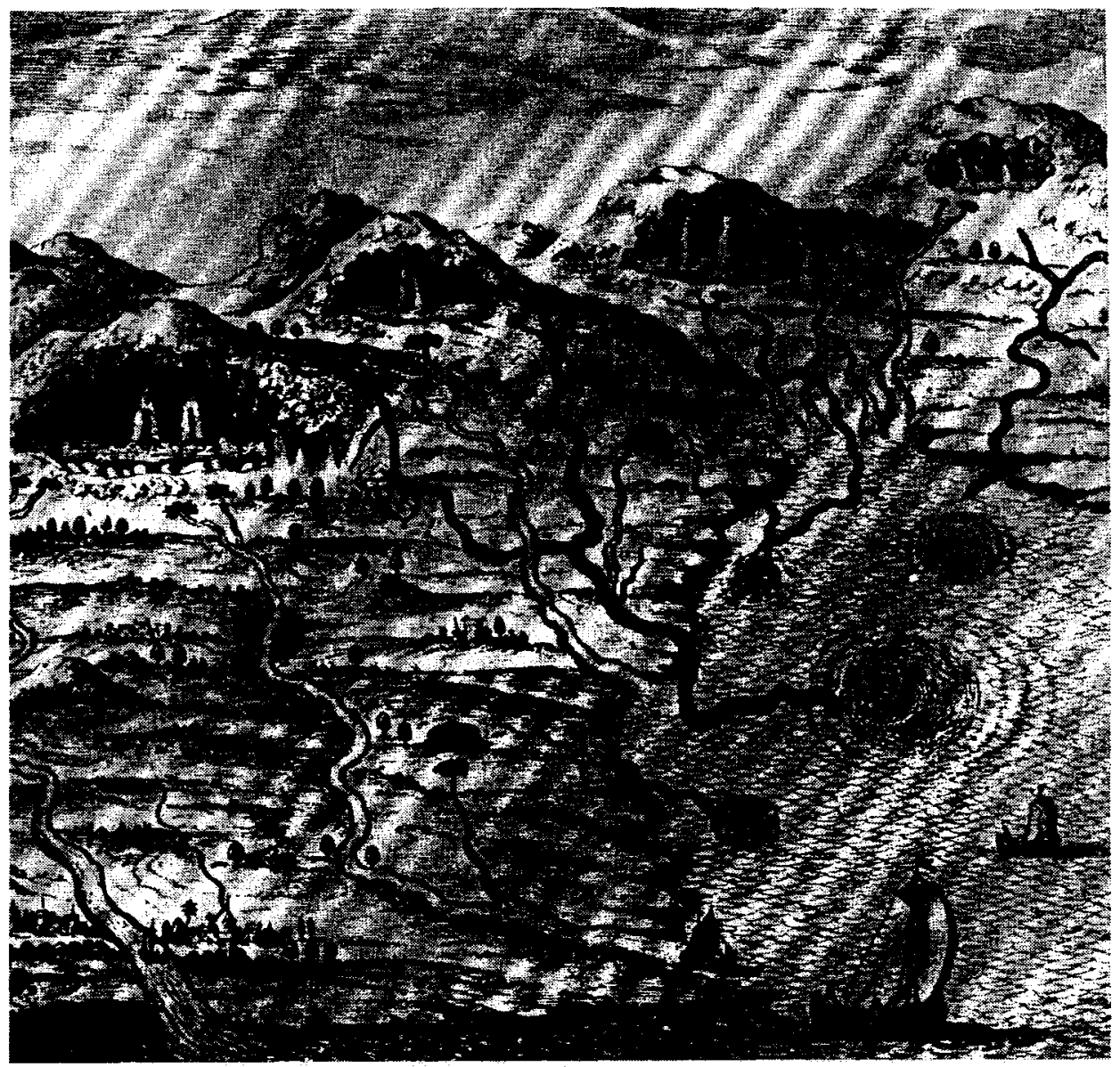

Figure 4-1- Kircher's depiction of the origin of springs and rivers, from his Mundus Subterraneus, ca.1664 (reproduced from Adams 1938:437)

"Experiments to the rescue" 27

It was not until the mid-seventeenth century and later - a time described by Biswas as "the cradle of modem science" (Biswas 1970:165) - that the subterranean theory was finally disproved and the foundations of modern, scientific hydrology

\footnotetext{
27 "Experiments to the Rescue" is a section heading in Biswas's version of the history of the hydrologic cycle. (1965:73)
} 
were laid. What are usually considered the elements of modern scientific practice were established by then in the intellectual centres of Western Europe: the formalization of experimental method; the institutionalization of scientific societies such as the Royal Society in London and the Academie Royale des Sciences in Paris; the regular publication of the results of new investigations in the journals of these societies; and - most notably for our purposes - the elevation of measurement and quantification to the status of a methodological prerequisite in all branches of scientific practice. Thus the stage was set for the investigations that have been represented by most historians of hydrology as having established the hydrologic cycle - and the science of hydrology - on a truly scientific footing. "The time had now come" writes Adams, "when close and critical observation was to replace conjecture and ingenious speculation, and when a true basis was thus to be laid for a final solution of many, if not all the problems concerning the origin of springs and rivers, with reference to which there had been such widespread differences of opinion down through the centuries." (1938:448)

As noted, the most important contribution to this "final solution" is judged by most hydrological historians to have been found in field experiments conducted by Pierre Perrault, who was introduced in the last chapter. Perrault's hydrological reputation rests entirely on the single work he had published anonymously in 1674 . Given the significance that has been attached this work (and its importance to the discussion below), Adams' description is reproduced here in full: 
"Pierre Perrault in his book entitled De l'Origine des Fontaines which was published anonymously at Paris in the year 1674 presents the results of the first serious attempt to actually measure the rainfall and determine its relation to the amount of water carried off by the rivers. Perrault selected and measured the drainage area of the Seine from its source to Aignay-le-Duc. He found this area to have a superficies of 121.50 square kilometres. He then determined by means of a rain gauge the average amount of water which fell as rain upon this area annually during the years 1668,1669 and 1670 and found it to be 520 millimetres. Taking this as $\mathbf{5 0 0}$ millimetres, if all the rain which fell upon this area during the course of a year remained in place and if no portion of it was lost by evaporation or otherwise, on the last day of the year the area would be covered with water to a depth of 50 centimetres, which would represent a volume of $60,750,000$ cubic metres. He then found the amount of water which was carried off the area by measuring the amount which passed through the Seine canal at Aignay-le-Duc each year and found it to amount to $10,000,000$ cubic metres, that is to say about one-sixth of the total rainfall." (Adams 1938:448-449)

By virtue of having quantified and correlated precipitation and river discharge in a basin, Perrault is judged by Adams, and almost all subsequent historians of the science, as the founder of modern, scientific hydrology. ${ }^{28} \mathrm{~A}$ contemporary of Perrault's, and a figure of almost equal importance, is the physician and member of l'Academie Royale des Sciences, Edme Mariotte. Several years after Perrault published his book, Mariotte made a more detailed investigation of the entire drainage basin of the Seine above Paris. Mariotte's book, Traité du mouvement des eaux et des autres corps fluids was published in 1686 and was translated into English in 1718. This work dealt for the most part with what is now known as hydraulics and hydrodynamics; however, it included sections on the origin of springs, the determination of velocities of running water and the measurement of

\footnotetext{
28

Many examples are discussed below, but here l'll note that John Rodda - who was then Director of the Hydrology and Water Resources Department of the WMO and subsequently served as President of the International Association of Hydrological Sciences - specified "the birth of scientific hydrology in 1674, following publication of 'De l'origine des fontaines' by Pierre Perrault." (Rodda 1995a:361-362)
} 
river or aqueduct discharge, which are questions that have been of special interest to hydrologists. Mariotte's more detailed and exact experimental methods of quantifying precipitation and discharge have earned for him a lasting place in the annals of hydrological history. He is understood to have "verified" (Meinzer 1934:11) or "confirmed" (Biswas 1965:73) the work of Pierre Perrault. Thus while Perrault is often identified as the first quantitative hydrologist, Mariotte is deemed "the most eminent hydrologist of the pre-eighteenth century era" (Biswas 1970:213) and even "founder of ground-water hydrology, perhaps of the entire science of hydrology." (Meinzer 1934:12)

\section{Closing the hydrologic cycle - The foundation of quantitative hydrology}

"A new epoch in the history of hydrology began in the latter part of the $17^{\text {th }}$ century through the work of Pierre Perrault (1608-1680) and Edme Mariotte (1620-1684) and other French physicists, and of the English astronomer Edmund Halley (1656-1742). These men put hydrology for the first time on a quantitative basis. " (Meinzer 1934:11)

Oscar Meinzer is the first of the hydrologist-historians to identify the beginnings of "modern" or "scientific" hydrology with the troika of Perrault, Mariotte and Halley. ${ }^{30}$ As illustrated in the quote from Andrew Goudie cited above, this interpretation of

\footnotetext{
${ }^{29}$ Meinzer appears to take this assessment from Keilhack's 1912 treatise on groundwater: Lehrbuch der Grundwasser und Quallenkunde.

30 Parizek (1963:9) identifies these three as "the founding fathers of the science of hydrology." See also: Meinzer 1942:14; Jones, Walker, Harden and McDaniels 1963:13; Biswas 1965:73; Biswas 1970:207; Nace 1974:46; Dooge 1974:280; Moser 1996:416; Veissman Jr. and Lewis 1996:4; Dooge 2001:6-7; Detay and Gaujous 2001:6-7; Mather 2004:1 (although for Mather, it was Perrault, Halley and Dalton who developed "the concept of the hydrological cycle").
} 
the hydrological past is standard in hydrologic text and reference books. The inclusion of Halley - whose interests in hydrology were peripheral to his major work in the field of astronomy - to this group is due to his quantitative studies of evaporation. An important experiment of his was reported in a paper given in 1687, with the self explanatory title, "An Estimate of the Quantity of Vapour raised out of the Sea by the Warmth of the Sun; derived from an Experiment shown before the Royal Society; at one of their late meetings: by E. Halley." (Dooge 1984:282) In a field, probably nearby Gresham College in London ${ }^{31}$, Halley measured the amount of water that was evaporated from a pan during a fixed interval of time, and extrapolated from this to estimate the volume of water that would be evaporated from the Mediterranean Sea. He then calculated the daily quantity of water flowing into the Mediterranean from its tributary rivers and found it to be "but little more than one-third of which is proved to be raised in vapour out of the Mediterranean in 12 hours time." (quoted in Dooge 1974:282) Halley thus proved that the amount of water evaporated from the Mediterranean was more than adequate to supply the flow of the rivers feeding it. Despite the obvious difficulties of extrapolating from an experiment conducted in England to estimate evaporation rates for the Mediterranean Sea, and ignoring the effects of mass atmospheric transfer, from the perspective of the history of hydrology, the major significance of Halley's contribution was in having sought quantitative

\footnotetext{
31 The experiment, carried out at a meeting of the Royal Society, is presumed to have taken place on the grounds of Gresham College.
} 
evidence for the atmospheric phase of the hydrologic cycle. Writing in 1974,

Raymond Nace points out:

"In summary, Perrault and Mariotte started with water already in the atmosphere and from there described the disposition of precipitation. Halley sought and found the source of atmospheric water vapour and attempted to show a balance in the complete cycle of water movement. Owing to the crudity of measurements and estimates, the main contribution of the three men was the concept of the cycle rather than proof by accurate measurement. The proof was delayed a hundred years until John Dalton took up the problem." (Nace 1974:46, my emphasis) ${ }^{32}$

In addition to the troika of Perrault, Mariotte and Halley, the conventional histories of hydrology often include John Dalton as a founder of the modern science. Dalton has already been mentioned (in Chapter 1) as having been first to visually represent a molecule of water. The fixity of water's essential identity as a chemical compound was strengthened by Dalton's proof that it remained fundamentally unchanged during - and despite - its transformation from one physical state to another. Moreover, Dalton's importance to hydrology is suggested in the quote by Nace given above; although Perrault, Mariotte, and Halley had contributed the concept of the hydrologic cycle, it was Dalton who gave it proof by accurate measurement.

\footnotetext{
32 The same point is made by Dooge: "Whatever one may think of the experiment it must be conceded that the result was of the right order of magnitude... Thus Halley appears to have been the first to add an estimation of the evaporation part of the cycle to the previous procedure of comparing only rainfall and runoff. Since his estimates were necessarily crude, his main contribution was in the formulation of the concept of the complete cycle rather than in the experimental verification of the water balance involved." (Dooge 1974:282, my emphasis)
} 
This proof came by means of working out what has since become known as the water balance, or hydrological balance budget equation for a specific region. In 1802, Dalton published a paper titled: "Experiments and Observations to determine whether the quantity of Rain and Dew is equal to the quantity of water carried off by the rivers and raised by evaporation, with an inquiry into the origin of springs." (Dooge 1974) With this paper, Dalton sought to settle the question of the origin of springs - which was evidently still in doubt in England at this time - by the following method: First, Dalton estimated annual rainfall in England and Wales on the basis of readings from thirty rain gauges observed over several years and added to this an estimate of the annual contribution of dew made to the region. Next, he estimated total runoff of all the rivers of England and Wales by extrapolating from work done by Halley over a century earlier on the discharge of the Thames. Subtracting this (total runoff) from the sum of rainfall and dew, he was left with a very large volume of water that had to be accounted for by evaporation in order to produce a balance. His estimate of the quantity of water raised by evaporation in England and Wales was derived from reports of other researchers and from his earlier experimentation with an atmometer. His computation proved to be out of balance to the amount of seven inches, a discrepancy that Dalton accounted for by presuming an overestimation of evaporation. ${ }^{33}$

This discrepancy aside, Dalton's place in the history of hydrology rests on his having formulated the water balance for a specific region, which has been judged

${ }^{33}$ This paragraph is summarized from Dooge (1974:288-290) 
to have finally and irrefutably proven the concept of the hydrologic cycle. His contribution was given formal recognition in 2004 when the European Geosciences Union awarded the first John Dalton Medal for distinguished research in Hydrology. The literature accompanying the medal provides a synopsis of Dalton's work, and a fitting close to this section on the conventional history of the hydrologic cycle and its contribution to modern water:

"It took well over 2000 years for a reasonable understanding of the science of hydrology to evolve. Not until the pioneering work of John Dalton in about 1800 were all the mechanisms of the large scale hydrological cycle properly determined...The correct understanding of the hydrological cycle was established and from then to now the work in hydrology has gradually grown and improved with new techniques and the availability of more data. However in this field, vital to all our lives, we still owe a great debt to Dalton and the other pioneers who helped to form a basis for our current knowledge. ${ }^{\text {"34 }}$

\section{The (Sacred) Hydrologic Cycle and the Wisdom of God}

"Water exists, then, in a closed system called the hydrosphere, and contemplating the hydrosphere and the hydrologic cycle is almost enough to make a sceptic believe in the omni-existent Gaia. The system is so intricate, so complex, so interdependent, so all-pervading, and so astonishingly stable that it seems purpose-built for regulating life." (de Villiers 1999:29)

The statement above, penned by Marq de Villiers, appeared in a best-selling book on water at the close of the twentieth century. ${ }^{35}$ It combines the modern (scientific) concept of "the hydrosphere and the hydrologic cycle" with an older idea that the

\footnotetext{
${ }^{34}$ www.copernicus.org/EGU/awards/john dalton.html (Website of the European Geosciences Union. Accessed July 4, 2005)

${ }^{35}$ de Villiers' book (de Villiers 1999) won the Governor General's Award for a non-fiction book published in 1999.
} 
circulation of water on earth is "so intricate, so complex, so interdependent..." that it could only have been designed purposefully by a divine being. While these two kinds of hydrologic cycle are sometimes presented as one, they entail separate stories and describe rather different things. The "scientific" hydrologic cycle, as described in the conventional history is essentially a mathematical concept made possible by the quantification of water as precipitation, streamflow and evaporation beginning in the seventeenth century. The conventional history of the hydrologic cycle makes little or no reference to the many (often contemporary) works that presented the idea of the circulation of water as an argument for the existence of the Christian God - a concept that I distinguish here as the "sacred hydrologic cycle." And while the scientific formulation evolved into the modern concept of the hydrologic cycle (the one with which we are familiar today), the sacred hydrologic cycle was almost completely banished from hydrological discourse by the late nineteenth century. ${ }^{36}$

Part of the story of the sacred hydrologic cycle may be found in other works (e.g. Glacken 1967), but the only effort to pull together a coherent history of this concept that I am aware of is by a geographer, Yi Fu Tuan (1968a). His study, The Hydrologic Cycle and the Wisdom of God: A Theme in Geoteleology, shows how the idea of the circulation of water was one of the most popular means by which by

\footnotetext{
${ }^{36}$ That the sacred hydrologic cycle had ceased to retain adherents by the late nineteenth century is described below. It should be noted however, that even today (and particularly with the most recent incarnation of the argument from design (usually described as "intelligent design"), the hydrologic cycle continues to provide an argument for the divine presence in the world. See for example, the April, 2002 issue of Natural History Magazine (published by The American Museum of Natural History) which features a special series of articles on "Intelligent Design."
} 
which people subscribing to the principles of natural theology argued their case. Natural theology (or physico-theology as it is also known) comprised an approach to natural philosophy that was popular especially in England from the seventeenth to the nineteenth centuries. (Glacken 1967:375-428) With roots in more ancient traditions ${ }^{37}$ and rhetorical arguments founded in scripture ${ }^{38}$, it sought to re-kindle the sacred in a world that many felt had been secularized at the hands of Cartesian mechanical philosophy. ${ }^{39}$ Against an apparently soulless, machine-like world devoid of final causes, English physico-theologians ${ }^{40}$ countered with a kind of metaphysical compromise whereby matter, which they took to be "inert and stupid of itself", was nevertheless imbued with a spiritual impulse that permitted a purposeful Christian cosmos. "This spirit of nature" as described by historian Carolyn Merchant, "was an incorporated principle that pervaded the universe, directing the parts of matter and their motions..." (Merchant 1980:244) John Ray, one of the more famous proponents of natural theology, described this impulse as originating in God and mediated by "the subordinate Ministry of some inferior

\footnotetext{
${ }^{37}$ Notably in the Judeo-Christian theologia naturalis of the early Christian era and Middle Ages, the fundamental principle of which was "the belief that one can find in the creation the handiwork of a reasonable, loving, and beneficent creator." This was opposed another, and contemporary, tradition in Judeo-Christian thought; that of "a contemptus mundi, a rejection literally of the earth as the dwelling place of man, a distaste for, and disinterest in, nature..." (Glacken 1967:162) 38

Such as the frequent citing in physico-theological writings of the passage from Psalms: "O Lord, how manifold are thy works! In wisdom hast thou made them all." (Ps. 104:24) "It is not to be wondered at that Psalm 104 has been quoted so often by thinkers sympathetic to the design argument and the physico-theological proof for the existence of God." (Glacken 1967:157) 39

As mentioned in Chapter 3, the philosophical works of Galileo, Descartes and others rendered a mechanistic view of creation by which "the universe of which the earth is a part is like a great machine and is to be understood in geometrical terms." In such a universe, "Nature owes its harmonies to an underlying mechanical order", an idea that threatened the long-standing teleological view "that the earth was a divinely designed environment, fit for the coexistence of the countless variety of beings", and humans in particular. (Glacken 1967:391)

40

Some of the better known of which included John Ray, John Keill, John Evelyn, William Derham and William Palley.
} 
Plastic Nature" (Ray 1692:39). ${ }^{41}$ Such a construction drove out all animistic powers in nature, but replaced them with the spirit of the Christian God. Moreover, with this incorporated principle pervading the universe, ancient and emerging knowledge of natural phenomena could be adduced as proof of the existence of the Creator and of his divine providence. ${ }^{42}$ To quote Ray, "There is no greater, at least no more palpable and convincing Argument for the Existence of a Deity than the admirable Art and Wisdom that discovers it self in the Make and Constitution, the Order and Disposition, the Ends and Uses of all the Parts and Members of this stately Fabrick of Heaven and Earth..." (1692:13)

For John Ray and others involved in this theo-scientific project, the apparent balance and circularity, and the usefulness to humanity that was suggested by considering the circulation of water on earth, was held to be one of the most evident proofs of the divine plan of nature. Moreover, it provided a suitable means of arguing for the rationality and purposefulness of natural features like mountains (which promoted orographic precipitation) and the size of the sea relative to that of the land (which was deemed necessary to provide adequate evaporation to produce rainfall on the continents) that were otherwise inexplicable in a teleological sense. "Until the concept of the hydrologic cycle was introduced and elaborated,"

\footnotetext{
41

By this idea of Plastic Nature, God is not immediately present in nature, directing its every activity, but has appointed, as it were his "subordinate Ministry of some inferior Plastic Nature,,, It is not decorous in respect of God, that he should... set his own hand as it were to every work, and immediately do all the meanest and triflingst things himself drudgingly, without making use of any inferior or subordinate Ministers." (Ray 1692:39)

42 As described by David Livingstone: "[I]n the wake of the Scientific Revolution of the seventeenth century, [physico-theology embraced] the idea that the correct use of natural reason, applied to the study of the world, would inexorably lead to knowledge of God." (1992:106)
} 
writes Tuan "it was difficult to argue convincingly for rationality in the pattern of land and sea, in the existence of mountains, in the occurrence of floods, etc." (Tuan 1968a:6)

Tuan's study provides numerous illustrations of "the popularity and the almost constant exploitation of the concept of the hydrologic cycle in physico-theology" from the late seventeenth to the mid-nineteenth century. (1968:122) His investigation ends with the decline in popularity of the concept the mid-nineteenth century. This decline Tuan attributes to the influence of Darwinism, by which "A new notion of fitness, dynamic and evolutionary, came into being which bore little resemblance to the older concepts of fitness and order in nature, and of divine providence." (1968:149) In the Darwinian cosmos, the wonders of nature could no longer be attributed to the arbitrariness of even the most benevolent creator-god, but had to be explained according to the internal logic of nature herself. ${ }^{43}$

In contrast to the conventional history of the (scientific) hydrologic cycle, Tuan eschews the urge to identify the origin of the concept. "Indeed" he writes, "it is not

\footnotetext{
${ }^{43}$ Darwin can perhaps be regarded as having put the last nail in the coffin of physico-theology. Its decline began with Kant's assault on the notion that "metaphysical conclusions about divine existence could... be had from the scrutiny of the sensible world." (Livingstone 1992:116) Kant thus "de-theologised the scientific study of the natural world", a move that ultimately proved fatal to physico-theology. (ibid. 115-117) it has to be acknowledged however, that the basic notion of a purposeful design in nature has continued to find expression. Glacken has suggested that in its emphasis on "living interrelationships in nature", elements of physico-theology can be found in the study of ecology (Glacken 1967:427).Moreover, in more popular discourse, the tenets of physicotheology have persisted to the present, of which the recent and growing popularity of the concept of "intelligent design" may serve as a leading example (See footnote 36 above). The quote at the beginning of this section attests to the endurance of notions of design pertaining to the circulation of water.
} 
rewarding to decide on degrees of originality when we are concerned with a concept the roots of which are multiple, deep, and entangled." (1968:7) Ideas about the circulation of water, he points out, had been expressed rather commonly since ancient times. ${ }^{44} \mathrm{~A}$ distinct concept of the hydrologic cycle emerged as these more ancient intimations of the circulation of water were re-cast through physicotheological discourse as evidence of God's design. Tuan points out that although there were many "trails and intimations" (1968:19), the (sacred) hydrologic cycle began to gel as a distinct physico-theological concept "from the seventeenth century onwards." (1968:69) Tuan centres his study on what he takes to be one of its best and most popular expressions, found (among a wealth of other evidence of intelligent design) in Ray's popular work, The Wisdom of God Manifested in the Works of the Creation, first published in 1691. By the time the third edition was published in 1701, the investigations of proto-hydrologists such as Edmond Halley had found their way into Ray's work ${ }^{45}$. These inclusions, Tuan argues, enabled Ray to assemble the main arguments comprising the hydrologic cycle. To gain a sense of how Ray conceived of this "hydrologic cycle", we might consider a relevant section that Tuan judges to be particularly significant. In response to the question put by doubters, "Where is the Wisdom of the Creator in making so much

\footnotetext{
44 "In premodern Europe the water cycle in varying degrees of completeness may be extracted from the teachings of Anaximander of Miletus, Anaxagoras, Herodotus, Plato (Critias), Aristotle, Vitruvius, Gregory of Nyssa, Theodoric of Chartres, Peter Alphonsi, William Caxton, Bartholomew Anglicus; and at the threshold of the modern age of science, from Bernard Palissy. Such a list would be much longer if we were to include water-cycle theories that later lost currency: for example, the important body of opinion that emphasized the subterranean movement of water from sea to land...." (1968:22)

${ }^{45}$ Via a monograph published in 1698 by the mathematician and natural theologian, John Keill, who in turn had drawn notably from Halley's work on evaporation (Tuan 1968a:96)
} 
useless sea, and so little dry land"? Ray replied with a lesson on the circulation of water:

"This, as most other of the Atheists Arguments, proceeds from a deep Ignorance of Natural Philosophy; for if there were but half the Sea that now is, there would be also but half the Quantity of Vapours, and consequently we could have but half so many Rivers as now there are to supply all the dry land we have at present, and half as much more; for the quantity of Vapours which are rais'd, bears a Proportion to the surface whence they are rais'd, as well as to the heat which rais'd them. The Wise Creator therefore did so prudently order it, that the Sea should be large enough to supply Vapours sufficient for all the Land, which it would not do if it were less than now it is." (Ray 170s, quoted in Tuan p. 10)

"The main elements of the hydrologic cycle", Tuan argues, "are all discernible in this paragraph: evaporation from the sea, the amount of vapour raised being proportional to the size of the evaporating surface; the transportation of the vapour to the land, its condensation over it to produce rivers... The segment of the cycle that is not explicitly given is that the rivers eventually return the water to the sea, thus maintaining its level." (1968:11) However, it might just as well be argued that while there are certain correspondences between the modern, scientific hydrologic cycle and Ray's argument, Ray has not rendered the former in this paragraph. Rather, it seems that the hydrologic cycle has been constructed in Tuan's account, even to the point of inserting the missing "segment". Many of the subsequent writers whom Tuan cites provided arguments that corresponded more or less to what we now understand as the hydrologic cycle. But again, theirs was a concept and a way of representing water that was different from that of the (scientific) hydrologic cycle with which modern readers are familiar. 
That Tuan failed to recognize his own layering of modern hydrological discourse on these works is particularly surprising in light of the very different approach he took from that of the conventional historians of hydrology. Not just the texts and quotes used, but the orientation and positioning of Tuan's study is entirely different from that of those who have written the history of the hydrologic cycle to strengthen the identity of hydrology as a scientific discipline. Rather than a timeless aspect of nature that awaited the application of correct method to be revealed to proto-hydrologists, Tuan described the hydrologic cycle as having been elaborated for a different purpose. It is, he wrote, "a concept that has been found to be eminently serviceable in explaining the harmonies of nature and the wisdom of nature's God." (Tuan 1968a:vii) Moreover, rather than a true representation of the independent reality of water, the hydrologic cycle was - for Tuan - a social construction: "For in its finer expressions the concept does honour to the ingenuity of the human mind if not indeed to the wisdom of God." (1968:6) Finally, in marked contrast to the conventional histories, Tuan acknowledges that the concept itself is of questionable scientific merit. "As commonly stated and illustrated it appears so loose and generalized as to be almost meaningless. Certainly it is of little applied use." (1968:4)

Several other particularities of Tuan's study should be taken note of: First, with the primary 'use' of the sacred hydrologic cycle serving as evidence for the manifestation of God in nature, the distinction between 'correct' and 'incorrect' explanations - which plays such an important role in the conventional histories - 
is hardly relevant. So long as the principle of circulation is seen as giving rise to a "well watered earth" by which man, animals and plants are able to thrive, it doesn't really matter whether the explanation fits the model of the 'true', scientific hydrologic cycle. Hence, the distinction that is so important to the conventional history of hydrology is almost absent from Tuan's account - he relegates the histories of the scientific hydrologic cycle to a single footnote. (1968:23) Moreover, rather than celebrate the advent of quantitative methods as the dawn of the true understanding of hydrological phenomena, Tuan points out that quantitative experiments could actually serve to 'obscure' the question of the origin of springs. ${ }^{46}$

Second, as pointed out in the preface of his work, one reason Tuan chose to study the history of the hydrologic cycle was out of his "concern for the unity of the several branches of physical geography." (Tuan 1968a:vii) As a geographer, Tuan was interested in fundamental concepts that were capable of unifying, or subsuming, a wide range of natural phenomena. In his own words, Tuan was interested in "seeing whether there exists an over-arching concept under which most of the processes studied in physical geography can find a place... and I

\footnotetext{
46

De la Hire - who in 1705 resolutely defended the hypothesis that rains were incapable of maintaining the flow of rivers, which must therefore be supplied by the sea via underground channels - relied on careful quantification and mathematical analysis as much as did Halley, against whom De la Hire directed his critique. Tuan quotes Goldsmith on this dispute: "Both sides have brought mathematics to their aid; and have shown, that long and laborious calculations can at any time be made, to obscure both sides of the question." (Goldsmith 1795, quoted in Tuan 1968a:118)
} 
found it - as had several other geographers in the idea of the hydrologic cycle" 47 (1968:viii) Tuan therefore approaches the hydrologic cycle from his interest in finding a unifying concept in contemporary geography rather than from a hydrologists' perspective of identifying the roots of what is taken to be a true or correct representation of the behaviour of water. Furthermore I would argue that from such a position, Tuan is better able to recognize the extent to which the concept is constructed in physico-theological discourse as much as it is revealed in scientific practice.

Thirdly, far from treating the hydrologic cycle as a true representation of the universal nature of water, Tuan's study provides what might be described as a critical-geographical appraisal of the biases inherent in the concept. Here, the location of the production of knowledge of the hydrologic cycle - Western Europe is recognized as having contributed in a critical way to its construction. As an idea that took shape in a certain place, the hydrologic cycle is shown to embody the biases and presuppositions characteristic of that place. ${ }^{48}$ Tuan observed that the Western imaginary of water had been (and to some extent still was, even as late as 1968) pervaded by ignorance of - or a contempt for - aridity. "We do not have to

\footnotetext{
47 I'm not sure who these others are, but Chorley and Kates (1969a) and other contributors to Chorley (1969) might be candidates.

${ }^{48}$ Tuan's critique of the hydrologic cycle anticipates - and would provide a good example for Livingstone's study of the geography of science, emphasizing its fundamentally 'local character': "Place matters in the way scientific claims come to be regarded as true, in how theories are established and justified, in the means by which science exercises the power that it does in the world. There are always stories to be told of how scientific knowledge came to be made where and when it did. The appearance of universality that science enjoys, and its capacity to travel with remarkable efficiency across the surface of the earth, do not dissolve its local character." (Livingstone 2003:14)
} 
probe deeply into the history of geographical ideas before we become aware of the very late recognition of the extent of dry lands and of aridity as a climatic fact." (1968:vii) Informed by the experience of living in a humid climate, Tuan's study shows how our long-standing ignorance and abhorrence of aridity is due in no small part to "the doctrine of the providence of God and the justification of that doctrine on the basis of the hydrologic cycle... In $18^{\text {th }}$ century England the idea of a well-watered earth was an unexamined article of faith to those who have fallen for the pervasiveness of the hydrologic cycle and to those who have allowed themselves to generalize from a very limited experience." (1968:144, italics added to emphasise confusion of tense) It was, I think, a great insight of Tuan's to recognize the sacred and scientific hydrologic cycles as "a factor that led to the slighting of the dry lands. It should also be added that scholars of northwestern Europe were helped in their delusion by the well-watered - and even drenched landscapes they saw constantly about them..." (1968:144)

\section{Conclusion}

In recognizing the European bias of the hydrologic cycle, Tuan hinted at a broader critique of the Western imaginary of water that might be described as a kind of hydrological Orientalism. The dominant (Western) apprehension and portrayal of deserts and arid lands as barren, poor, uncivilized places that must be hydraulically re-engineered in order to be made civilized has been one of the motivating forces behind the colonial and neo-colonial materialization of modern 
water on other continents. ${ }^{49}$ This materialization can be regarded as an effect of a universalizing discourse whose history can be traced, in part, in Tuan's study of the hydrologic cycle. That Tuan himself did not follow up on this lead is, I think, due to his tendency to wrap his study of the sacred hydrologic cycle within the discourse of modern water. I want to return to this question Chapter 9 , when considering the circumstances that have given rise to the present apprehension of a global water crisis. Here, in a sense, I take up from where Tuan's critique left off to consider the effects of the way water is imagined - through the hydrologic cycle and modern water generally - and how these contribute to the framing of contemporary water issues.

To conclude this chapter, I want to draw out some of the distinctions between the scientific and sacred hydrologic cycles whose histories have been summarized above. First, it should be noted that Tuan's study - which can justly be described as the most lengthy hydrologic-cycle history published in the English language, if not anywhere - has been completely ignored in the conventional histories described above and written to help establish the identity of modern hydrology. None of the post-1968 writings that comprise the conventional history of the hydrologic cycle even mention Tuan's study; nor do they attend to the physicotheological writings on the circulation of water. Unlike the scientific hydrologic cycle, the sacred hydrologic cycle was argued from first causes - that God so

\footnotetext{
${ }^{49}$ See sections of Chapter 2 dealing with the political ecology of water and post-colonialism and water.
} 
designed the earth as to make it a fit place for people to live - a line of argument that was patently not "scientific" in the sense that it did not rest on quantifiable proofs. Furthermore, in his own work, Tuan makes only passing reference to the conventional histories, attaching to them no particular significance:

"A comprehensive history of the concept of the hydrologic cycle has yet to be attempted. Short summaries are available and the facts need not be repeated here. $\left.{ }^{50}\right]$ Our main interest, moreover, is in relating the cycle to a special conception of God's providence..." (Tuan 1968a:23-24)

This is one of the few moments when the two histories overlap in Tuan's study. ${ }^{51}$

The main reason why the two histories do not overlap - and, I would add, the reason why no "comprehensive history of the concept of the hydrologic cycle" has yet been written - is because there is no single concept of the hydrologic cycle. Despite Tuan's assertions to the contrary ${ }^{52}$, the sacred hydrologic cycle was

50 Here, Tuan cites Adams 1938, Meinzer 1934, Baker and Horton 1936, Parizek 1963 and Biswas 1965. All these are cited and/or discussed in my section on the conventional history above.

51 The other main example of an overlap is Halley's quantitative studies of vapour transfer. (see below) These studies contributed to the secular as well as the scientific hydrologic cycle concept. Halley's work was "distinguished from the many vague expressions that saw print both before and after his time in being based on experiment and calculations. It was probably also the most complete statement of the cycle thus far." (Tuan 1968a:102) "Halley avoided questions of teleology, except for the almost whimsical attribution of Final Causes to the formation of mountains..." However, the physico-theologists, most notably John Keill and John Ray "exploited Halley's research for their own didactic purposes." (1968:101) 52

This assertion is best expressed in the following passage:

"One purpose of this essay is to show that, for at least one hundred and fifty years (ca. 1700-1850), the concept of the hydrologic cycle in the "standard" form was a handmaiden of natural theology as much as it was a child of natural philosophy. It is not to be presumed, however, that theologians merely took over and simplified a concept of science and used it for their own didactic purposes. In the nineteenth century this may be been true, but towards the end of the seventeenth century and in the beginning of the eighteenth such a description of the development of the concept would have been misleading. Not only was there no sharp distinction then between natural theology and science but scholars who wrote on the theme of the water cycle within the context of a physicotheological treatise actually contributed to it." (1968:4) 
unique. It certainly held "water" in the singular, as an abstract principle and substance, but in contrast to the scientific hydrologic cycle, it didn't hold water as an abstract quantity. The sacred hydrologic cycle was not defined by the measurement of water, and therefore unlike the scientific hydrologic cycle, it did not disclose water in a manner that makes it susceptible to scarcity. As we shall see, one of the distinguishing features of modern water is that by virtue of its essential quantification, the potential, if not the condition, of scarcity always inheres in it. There is, on the other hand, no possibility of scarcity with respect to the water of the sacred hydrologic cycle. By its very provident nature, the sacred hydrologic cycle denies any possibility of water's general scarcity. The undeniable occurrence of temporary, geographically-specific scarcities of water is thus explained in terms of punishments visited upon people who have failed to abide by God's laws. This form of limited, contingent, scarcity, is an exception to the general rule of God's well-watered earth.

A related distinction is that the scientific hydrologic cycle contributes to the modern disclosure of water predominantly as a resource. While this question is taken up further in Chapter 6, I want to point out here that the water of the sacred hydrologic cycle could not be reduced to a mere means or instrument to serve human ends.

I would point out that while there was certainly no sharp distinction between natural theology and science (in fact both terms came into use subsequently, with "science" being used for the first time to distinguish the modern form of natural philosophy only in the mid-nineteenth century) it is misleading to argue that "scholars who wrote on the theme of the water cycle within the context of a physico-theological treatise actually contributed to it." They undoubtedly contributed to the concept of the sacred hydrologic cycle, but it needs to be stressed that none of the physico-theological writings on the theme of the circulation of water are recognized in the conventional history as having contributed to the concept of the scientific hydrologic cycle. It is Tuan's failure to distinguish between the two concepts that, in my view, gives rise to this misunderstanding. 
This is because it was not entirely devoid of numinous qualities - the sacred hydrologic cycle held water that was still imbued with sacredness, even if in the guise of the plastik nature with which Ray and others invested it. Recalling that it was one of the purposes of natural theology to restore to nature the sacredness that it was felt had been evacuated by the mechanical philosophy of Descartes, the water of the sacred hydrologic cycle could hardly be reduced to a mere instrument to serve the needs or the pleasure of humanity. Rather it was the scientific hydrologic cycle - the true stepchild of the mechanical philosophy - that would hold the type of water that could only reveal itself as a resource.

The sacred hydrologic cycle contributed to modern water in a limited sense; namely in the sense that it did reduce all the world's water to single entity, or principle, that was divorced from the particularities of local geography or culture. But in detailing the circulation of water as a principle, the sacred hydrologic cycle was not conceived of, or represented, as a thing in itself. The history of the hydrologic cycle as such a thing is the subject of the next chapter. 


\section{Constructivist History of the (Hortonian) Hydrologic Cycle}

"Water remains a chaos until a creative story interprets its seeming equivocation..." (Illich 1985:25)

“Modern science's way of representing pursues and entraps nature as a calculable coherence." (Heidegger 1977:21)

\section{Introduction}

In addition to the "sacred" hydrologic cycle, in Chapter 4, we considered the conventional history of the "scientific" hydrologic cycle, i.e. the story of a concept that emerged through the application of "correct" (quantitative) methods to reveal the existence of something that was understood to have always already been part of nature. This latter concept is abstract in the sense that it is mathematical: the scientific hydrologic cycle conceptualizes the behaviour of water in a way that corresponds to the water balance equation. The present chapter tells the story of the scientific hydrologic cycle, but it is not the same (conventional) story as the one related above, and thus, it describes a different hydrologic cycle. The approach taken here is "constructivist" in the sense that it takes the hydrologic cycle as something that has been constructed, rather than revealed in scientific practice. The story it tells is of what I will call the "Hortonian" hydrologic cycle, after the name of author who gave it birth. ${ }^{1}$ Like the scientific hydrologic cycle, the

\footnotetext{
1 Unless otherwise stated, references to "the hydrologic cycle" below should be read as the Hortonian hydrologic cycle.
} 
Hortonian hydrologic cycle rests on the mathematical constitution of the water balance equation; but now it is identified by name - "the hydrologic cycle" - and is represented in the form of a diagram. Both the name and the diagram have made important contributions to the proliferation of modern water.

As discussed in the last chapter, Yi Fu Tuan recognized that the (sacred) hydrologic cycle emerged when ancient ideas about the circulation of water were developed in the context of physico-theological discourse, beginning in the seventeenth century. In so doing, Tuan acknowledged that the sacred hydrologic cycle was to some extent a product of human construction, a testimony to "the human imagination" as he put it. Such a construction, he pointed out, was no longer tenable after the mid-nineteenth century, when teleological cosmology was shattered by Darwin's evolutionary doctrine. But in Tuan's analysis, ancient concepts of the circulation of water, as well as the transformations they underwent under physico-theology, could be described within a single discourse of modern water, as suggested by his anachronistic use of "the hydrologic cycle". We now go a step further and submit the hydrologic cycle itself to critical analysis. By this account, the hydrologic cycle - as distinct from earlier references to the circulation of water - is of much more recent origin, coincident with the emergence of hydrology as a separate scientific discipline in the United States in the first half of the twentieth century. While the sacred hydrologic cycle served the purpose of assembling an argument for the wisdom of God, Hortonian hydrologic cycle was initially put forward for the purpose of constituting the discipline of "scientific 
hydrology." From the signal moment of this constitution - specifically, a paper read by the American hydrologist Robert E. Horton in 1931 - this hydrologic cycle has been carried forward in the hydrological and more popular literature, and projected backward in the process of writing (conventional) hydrological history. Through this process of carrying the hydrologic cycle forward and projecting it backward, as well as by the invocation of nature at the moment of its birth, the origin of this hydrologic cycle has been obscured, making it appear timeless and authorless.

Finally, to put the emergence of the Hortonian hydrologic cycle in relationaldialectical terms, it may be described as a hydreification that occurs where the constitutive process of water - approximately the "circulation of water" as described by proponents of the sacred hydrologic cycle" - meets with the modern practice of scientific hydrology. The specific location of this particular meeting occurred, remarkably enough, in a place called Voorheesville, New York.

\section{Constructivist History of Science}

In contrast to the histories of the scientific and the sacred hydrologic cycles discussed in the chapter above, here I will employ an historical approach consistent with what historian of science, Jan Golinsky (1998) describes as "constructivist history of science."

2 The reassessment of the history of hydrology that follows is not unlike David Livingstone's critique of conventional histories of geography and his assertion that a "new historical consciousness" particularly drawn from recent approaches to the history of science compels us to revisit the standard histories. (Livingstone 1992: Ch. 1) 
"By a 'constructivist' outlook, I mean that which regards scientific knowledge primarily as a human product, made with locally situated cultural and material resources, rather than as simply the revelation of a pre-given order of nature. This view of science has attained widespread currency in recent years..." (Golinsky 1998:ix)

The epistemological problems associated with the application of "social constructivism" (or "constructionism") to the production of scientific knowledge and the history of science have been the subject of a great deal of scholarly debate. ${ }^{3}$ My position is that by adopting a relational-dialectical view, things like water may be approached from a constructivist position that nevertheless acknowledges water's reality. This position is elaborated fully in the concluding chapter. For now, I want to repeat that from a relational-dialectical perspective, scientists do not construct water as such; instead, instantiations, reifications or representations of water get constructed as events that occur where the water process meets with scientific practice. I am therefore in agreement with Golinsky, for whom "'Constructivism' is more like a methodological orientation than a set of philosophical principles; it directs attention systematically to the role of human beings, as social actors, in the making of scientific knowledge." $(1998: 6)^{4}$ Golinsky

${ }^{3}$ For good examples of the thought that has been given this matter see Livingstone 1992:12-23; Hacking 1999; Demeritt 2001a, Demeritt 2001b; Demeritt 2002; Soule and Lease 1995; Soper 1995; Eden 2001; Cronon 1995a,b, and c, among many others.

${ }^{4}$ With this rather loose formulation Golinsky, is able to subsume under the term "constructivist history of science" the approaches of researchers such as Latour, Hacking and others, who have disagreed with aspects of the construction metaphor (Hacking 1999) or who have argued that the social construction of (scientific) knowledge "implies that the initiative of action always comes from the human sphere, the world itself doing little more than offering a sort of playground for human ingenuity...." (Latour 1999:114; see also Latour 2004:ch. 1) For Latour, there is no question that scientists are involved in the production of facts and representations of nature, but in his view these are co-productions or co-constructions between human (scientists) and non-human (laboratory instruments, technologies etc.) actants. Thus: "Construction and fabrication... have to be 
draws from the work of researchers in various fields, including the sociology of scientific knowledge, philosophy of science and history of science, to formulate this methodological orientation, a few aspects of which are particularly relevant to the discussion below:

First, a constructivist history of science attends to the establishment and maintenance of separate scientific disciplines as influencing the production of knowledge. Scientific knowledge is thus understood and analyzed in the context of specific scientific disciplines - the main social structures within which modern scientific practices take place. Moreover scientific disciplines "cannot be observed and described as natural organisms existing in their own right. Rather, they are the result of deliberate activities oriented toward order and specific purposes." (Stichweh 1992:5) When considering hydrology as a discipline, the efforts of hydrologists to establish its scope and its purpose can thus be seen as having had a bearing on the kind of knowledge produced in hydrological discourse. As argued below, the establishment of the Hortonian hydrologic cycle is intimately related to the establishment of hydrology as a distinct scientific discipline and the identification of its field and scope.

Second, constructivist history attends to the stabilization of a scientific representation as the outcome of subsequent practice. As Latour has put it, "the status of a statement depends on later statements...[T]he fate of what we say and 
make is in later users' hands." (Latour 1987:27) Latour advocates a method of observing "science in action" that traces the stabilization of scientific facts through their incorporation in subsequent texts, emphasizing: "To survive or be turned into fact, a statement needs the next generation of papers..." (1987:38) Eventually, as a fact gets incorporated into the body of a scientific literature, its origins become obscure. To give a most relevant example, Latour asks, "Who refers to Lavoisier's paper when writing the formula $\mathrm{H}_{2} \mathrm{O}$ for water?" The stabilized fact - in this case, $\mathrm{H}_{2} \mathrm{O}$ - thus becomes "incorporated into tacit knowledge with no mark of its having been produced by anyone". (1987:43) As shown below, from its point of origin, the hydrologic cycle has been carried forward in subsequent hydrological literature while simultaneously being projected backwards into the past through the writing of hydrologic history.

Finally, Golinsky calls attention to the process by which scientific facts are generated in particular epistemological circumstances, and are then translated into universal truths: "As facts are translated from the language in which they are represented among specialists to language appropriate to a lay audience, they become consolidated as knowledge. As experts describe their findings to nonexperts, facts are simplified and rendered more dramatic, and the sureness with which they are held is strengthened, even among the experts themselves." (Golinsky 1998:34) The scientific hydrologic cycle, as argued below, can be understood as a fact generated in a particular scientific practice and universalized in popular literature by rendering it's representation more 'simple' and 'dramatic.' 
In Chapter 4, I endeavoured to show in what sense the sacred and the scientific hydrologic cycles differ. As a first step towards my constructivist history of yet another hydrologic cycle, I want to point out some of the main ways the Hortonian hydrologic cycle differs from those already described. As shown in the conventional histories as well as in Tuan's work, notions about the circulation of water had been put forward since ancient times, providing a variety of explanations for the origin of springs. However, none of the ancient thinkers whose work is cited in the conventional histories posited the existence of "the hydrologic cycle" as a distinct part of nature or a way of representing water. Even the claim that ancient and medieval writers advanced ideas about the "circulation of water" is probably anachronistic. ${ }^{5}$ Tuan did point out that the hydrologic cycle "in varying degrees of completeness may be extracted from the teachings" of numerous thinkers of the past (Tuan 1968a:22, my emphasis), but none of these thinkers put forward a cogent argument for the hydrologic cycle as a distinct entity, with the name and the visual form of representation that is so prevalent today.

Insofar as it posited a fundamental qualitative distinction between what we now see as water's three phases (solid, liquid and gas), the tenacity of the (Aristotelian) doctrine of the elements would have precluded a sense of the hydrologic cycle as

5 Ivan Illich contends that prior to the seventeenth century, "the connection between 'waters' and what we call circulation had not been made." (1985:40) Harvey first applied the idea of circulation to the flow of blood in the human body in the 1620s. "After blood and ideas," writes Illich, "water began to circulate; electricity 'circulated' after 1865." (1985:43, my emphasis) (see also Sennett 1994; Swyngedouw 2004:31) 
a distinct, unified natural process. ${ }^{6}$ Furthermore, Tuan himself recognizes that for classical philosophy, the circle as symbol and metaphor for the perfection of nature could only be applied to the realm of heaven; the sublunary cosmos on the other hand, "was the region of change and irregularity. The sublunar elements - fire, air, water, and earth - lacked not only the permanence of celestial bodies but also their orderliness of motion." (Tuan 1968a:36) The metaphor of the circle of perfection was indeed brought down to earth during the Renaissance, when it became a symbol for the perfection and wisdom of God. But even then - and afterwards, as for the writers Tuan studied - ideas about the circulation of water were rather different from what we now understand as "the hydrologic cycle." John Ray, for example, who supplies Tuan's main example of the sacred hydrologic cycle, subscribed to the Aristotelian account of the elements. (Hamlin 2000:316317) Furthermore, Ray clearly supports the subterranean thesis when arguing "That Springs should break forth on the sides of Mountains most remote from the Sea." (Ray 1692:75)

Tuan's description of the hydrologic cycle as presented by Sir Walter Raleigh provides a good illustration of the problem of confusing its sacred and scientific variants: "In Sir Walter Raleigh's The History of the World" writes Tuan, "....he uses the hydrologic cycle as a process in nature that illustrates God's power.

${ }^{6}$ Here I am in disagreement with Tuan, who recognized that the Aristotelian theory of transmutation of the elements was commonly held well into the seventeenth century, but who insisted that this was understood as being compatible with, and indeed dovetailed with, the concept of the hydrologic cycle. (Tuan 1968a: 36-37; 47) 
Without the exercise of that power nature would become 'silent, virtueless, and dead.' [and quoting Raleigh]:

For as it is God's infinite power and every-where presence... that giveth to the sun power to draw up vapours, to vapours to be made clouds; clouds to contain rain, and rain to fall: so all second and instrumental causes together with nature itself, without that operative faculty which God gave them, would become altogether silent, virtueless, and dead: of all which excellently Orpheus, Per te virescunt omnia; 'all things by thee springs forth in youthful green.' (Tuan 1968a:38)

Here is an illustration of the physico-theological discourse in water was made to circulate, as well as an example of Tuan's tendency to extract "the hydrologic cycle" from writings that describe something of a different sort altogether: In this case, Raleigh is actually describing the transmutation of elements - from water to air and back into water again. ${ }^{7}$ Moreover, this is hardly the "hydrologic cycle" as we know it, in that it leaves out the landward parts, including infiltration, runoff, streamflow, etc.. ${ }^{8}$

Nor did the early founders of scientific hydrology conceive of the hydrologic cycle in anything like its modern form. Pierre Perrault, for example believed that water from rivers entered the earth and was converted to "vapours", which then rose to the tops of mountains to feed springs. He resorts to Aristotle, claiming that "all

\footnotetext{
${ }^{7}$ Tuan points this out himself on p. 37.

8 Likewise, two seventeenth century visual representations of the circulation of water, which Tuan reproduces (one of which is on the book's cover) bear but little resemblance to the modern hydrologic cycle; the first being Thomas Robinson's diagram illustrating "the common notion of how water circulates both above and below the earth's surface" (1968:33) and the other, Thomas Burnet's "fantastic system of air and vapour circulation over the primitive earth" (1968:91)
} 
Philosophy, ancient and modem is with me" to buttress his argument that "just as vapours on the outside of the Earth rise in the air and are there converted to water, so also those inside, caused by rain water that rivers cause to enter into it, can rise to the top of mountains and produce water there." (Perrault 1967:108) ${ }^{9}$ Ironically, it has to be concluded that Perrault was quite wrong on the question of the origin of springs! His reputation as the founder of modern, scientific hydrology is based less on his having 'correctly' understood the hydrologic cycle than on having merely measured a small portion of it. Likewise, Halley was an ardent subscriber to the view that most of the vapours that rose from the sea did not precipitate from the atmosphere, but were diffused and condensed "in the caverns of the hills" to supply water for springs and rivers. (quoted in Dooge 1974:283-4) ${ }^{10}$ Even Dalton, who no doubt had what is now considered the 'correct' understanding of the hydrologic cycle, did not use the term, nor did he present the concept in its modern form. For him, "the unceasing circulation of a fluid so essentially necessary to the very being of the animal and vegetable kingdoms" was presented in the context of his wider aim of proving that "the rain that falls is sufficient to supply the demands

\footnotetext{
${ }^{9}$ Perrault thought that some water from rivers went into the ground but steadfastly refused to accept that rainwater was capable of doing the same: "Whatever a spring may be, either strong or weak, it cannot flow continuously if it has no other origin than the penetration of the ground by waters from rain and snow melted from Winter, and even granting that this penetration takes place, as I have agreed it does in one particular case, and because of special arrangement of the soil in places: this penetration happens more rarely and in much fewer places, than there are true springs that I mention." (Perrault 1967:144)

${ }^{10}$ Here we have another putative founder of modern hydrology, who actually subscribes to the view that the condensation of water in the interior of mountains makes an important contribution to the flow of springs. The willingness of the hydrological historians to overlook these shortcomings in order to locate the origins of hydrology in quantitative experimental studies is illustrated by Dooge: Commenting on Halley, he points out: "In spite of his adherence to the subterranean condensation theory, Halley's contribution to the hydrological cycle is undisputable because of his emphasis on the importance of a quantitative estimate of evaporation for the analysis of the hydrological cycle and for the formulation of a proper water balance." (Dooge 1974:285)
} 
of springs and rivers" (Dalton 1802, quoted in Tuan 1968a:130 and Dooge 1974:289).

The hydrologic cycle with which we are familiar, on the other hand, gives the water process a definite form. This is perhaps its main distinction from the vague concept of the circulation of water: the hydrologic cycle provides a formal means of representing the morphology of water. In its modern guise, the hydrologic cycle clearly owes a great deal to the ancient and modern natural philosophers and the proto-hydrological scientists who discoursed on the circulation of water and the origin of springs; but as a formal representation of what water is and what it does, the hydrologic cycle's origins are of more recent vintage.

\section{Horton 1931}

The first time that the "hydrologic cycle" appeared as a formal means of describing the nature of water occurred in 1931, and for an entirely different purpose than as a proof of the existence of God. It was in this year that the American hydrologist, Robert E. Horton read a paper titled "The Field, Scope, and Status of the Science of Hydrology", a paper that was signed from Voorheesville, New York, and published in Transactions of the American Geophysical Union the same year. 
(Horton 1931) This paper introduced English-speaking readers to "the hydrologic cycle" and provided the first diagram to illustrate it. (Figure 5.1) ${ }^{11}$

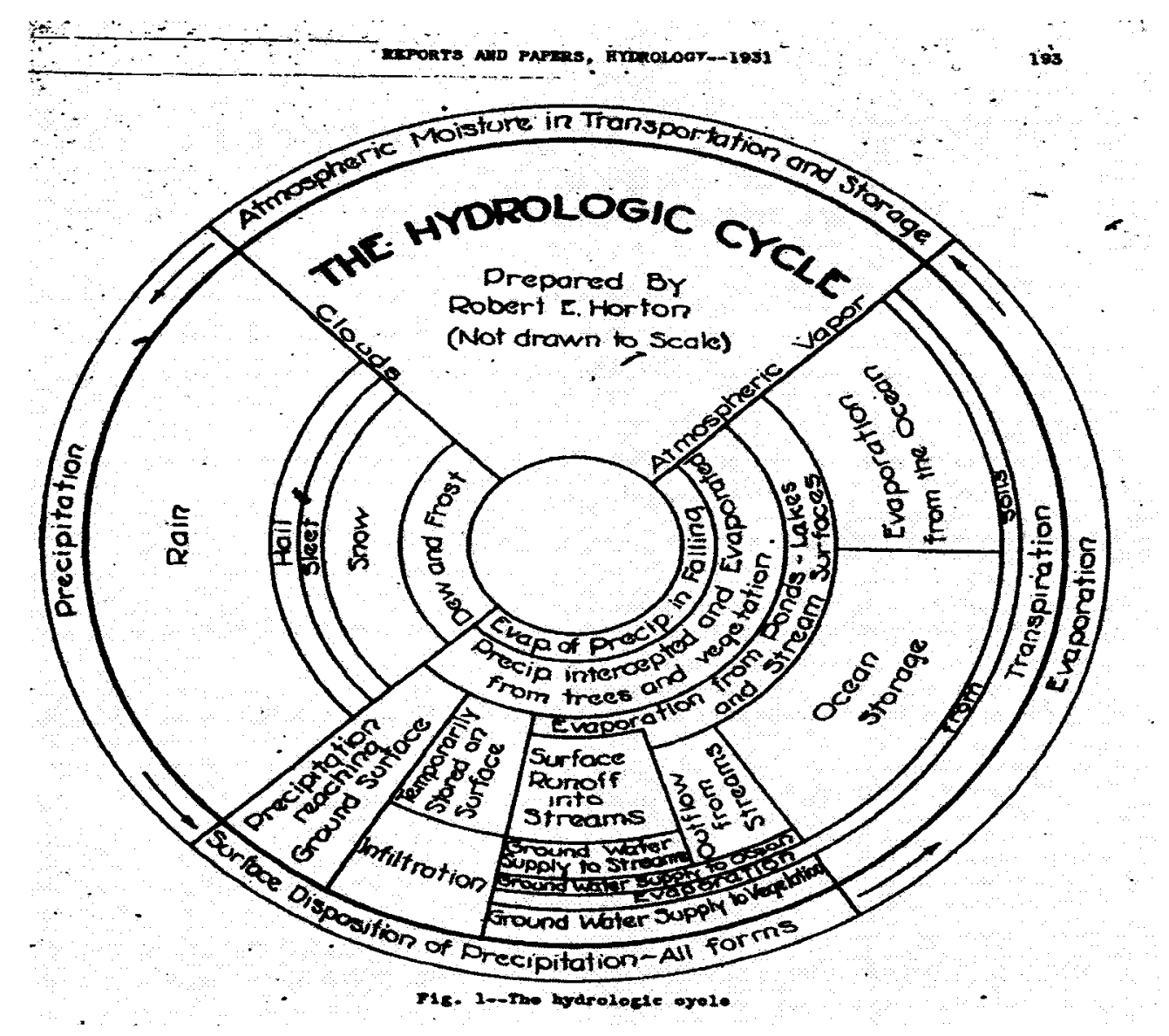

\section{Figure 5-1 - Horton's illustration of the hydrologic cycle (reproduced from Horton 1931:193)}

\footnotetext{
11 Although the general focus of this project is on the development of hydrological thought in the English-speaking world, the question of whether an equivalent term and form of representation (equivalent to the Hortonian hydrologic cycle) had been used previously in the hydrological literature of another language is of obvious interest. Horton refers to several works (now very obscure) published in German and French that might have included it. Also, it should be pointed out that the Russian concept of "the circulation of water" - which L'vovich (1979) describes as the closest approximation in Russian to - but not exactly the same as - the concept of the hydrologic cycle - had been used as a basis for the calculation of global water balances by Russian hydrologists since the late nineteenth century. (See Chapter 7, footnote 10) In any case, it seems that the Soviet hydrologists readily took to the American mode of representing the circulation of water/hydrologic cycle. Kalinin's 1971 (originally published in 1968) Global Hydrology, for example, illustrates the hydrologic cycle with a diagram that is almost identical to the one appearing in the frontispiece of Meinzer's 1942 textbook. (Kalinin 1971) Here it is obvious that Kalinin has copied the illustration from Meinzer's text. One may surmise that had the scientific hydrologic cycle been indigenous to Russian/Soviet hydrology, Kalinin's book would have featured a different, presumably Russian/Soviet representation.
} 
It is important to understand the institutional context in which Horton's paper was written to gain an appreciation of the significance of his hydrologic cycle. By the late 1920s, hydrology had attained something of the status of a distinct and bona fide science internationally. In 1922, the Rome Assembly of the International Union of Geodesy and Geophysics had accepted a proposal to establish a separate International Section for Scientific Hydrology. (Littlehales 1931:189) The following year, in 1923, the International Association of Scientific Hydrology was established, with the adjective "scientific" being added to distinguish it from the enterprise to promote various mineral waters and thermal springs and "from the many charlatans and people misled by them who, with the help of all kinds of divining rods, undertook to find water, these people called themselves hydrologists; the point was to be disassociated from them." (Nemec 1976 334; Volker 1983:52 $)^{12}$ Nevertheless, hydrology's identity as a science remained rather precarious. In some places, the term "hydrology" was still commonly associated with "the treatment of disease by the internal and external application of natural mineralized waters of reputed value...". (Gordon and Thompson 1930:24) Even among engineers and geologists, "hydrology" was often considered to apply only to "underground-water phenomena" well into the twentieth century. (Horton 1931:190) Those who considered themselves scientific hydrologists thus felt a need to: First, distinguish hydrology from its associations with mineral water

\footnotetext{
12 The name was changed to "International Association of Hydrological Sciences" in 1971, reflecting "a step towards breaking down the boundaries between hydrology and sciences in the diverse field of water resources development and management" and the abiding desire "to conserve the word 'science' in its title." (Nemec 1976:334)
} 
enthusiasts, water diviners and the like in order that it might properly be considered a 'science'; and second, set boundaries around its field and scope and to maintain these so that hydrology might be distinguished from the other geosciences.

The matter of distinguishing hydrology as a separate and bona fide science was addressed by the International Section of Hydrology in 1924 in the following way:

La nouvelle Section aurait le but de contribuer au développement des recherches scientifiques des phénomènes géophysiques lies aux fleuves, aux lacs, aux glaciers et aux eaux souterraines, qui forment le sujet de l'Hydrographie continentale ou de l'Hydrologie scientifique, nom peut-être préférable, afin d'éviter l'éventuelle confusion avec d'autres branches de la géophysique. (Section Internationale d'Hydrologie Scientifique 1924:6-7)

For the purposes of our study, perhaps the most significant aspect of this definition of the field of l'Hydrologie scientifique is that it is comprised of only the surface and sub-surface portions of what we now call the hydrologic cycle - none of the atmospheric hydrological processes are included $!^{13}$ The identification of hydrology as the science that treats of water through all phases and fluxes of what we now call the hydrologic cycle is an American invention. In the United States, proposals to establish a separate hydrology section of the American Geophysical Union (AGU) had been rejected by the leadership of the Union on the basis that "active

\footnotetext{
${ }^{13}$ This would have served the purpose of distinguishing hydrology from meteorology, a distinction that was particularly important in light of a suggestion, offered by the president of the International Union of Geodesy and Geophysics, that the Section on Hydrology be fused with the Section on Meteorology. (Section Internationale d'Hydrologie Scientifique 1924:9)
} 
scientific interest in the United States did not justify a separate section of scientific hydrology within the AGU." (National Research Council 1991:40) Finally, when the AGU was transformed from a committee of the National Research Council into an independent society in 1930, approval for a section on hydrology was given and the Section on Hydrology came into existence, with O.E. Meinzer as chairman and R.E. Horton as vice-chairman. At the 1931 meeting of the American Geophysical Union, Horton's paper on the "field, scope and status of the science of hydrology" was presented. With this paper, Horton introduced the hydrologic cycle, the main purpose of which was to provide a framework by which the new discipline of hydrology might become established and distinguished from the other geosciences:

"Defining science as correlated knowledge, it is true that a statement of the field, scope, and status of hydrology at the present time may be little more than a birthcertificate. Nevertheless, there is scattered through scientific and engineering literature a mass of quantitative results adequate to make a most respectable body of science, wanting only to be coordinated...

In one sense the field of hydrology is the Earth and so is co-terminous with other geo-sciences. More specifically, the field of hydrology, treated as a pure science, is to trace out and account for the phenomena of the hydrologic cycle...

... Again, hydrology may be regarded as charged with the duty of tracing and explaining the processes and phenomena of the hydrologic cycle, or the course of natural circulation of water in, on, and over the Earth's surface. This definition has the advantage that it clearly outlines the field of hydrologic science." (Horton 1931:190, 192, my emphasis)

The hydrologic cycle thus has to be seen in the context of contemporary efforts to establish hydrology as a separate scientific discipline in the United States. Prior to Horton's 1931 intervention, the elements of the hydrologic cycle had been studied 
and were understood by American hydrologists, among others, to fit together in a 'logical' way. Thus without actually using the term, Meyer's (1917 and 1928) text, The Elements of Hydrology, was arranged in a way that corresponds to the sequence of components later given form in Horton's hydrologic cycle: "In developing the subject" Meyer notes, "the author has followed what from his viewpoint, acquired through about fifteen years of experience with the practical problems of hydraulic engineering, appeared a logical sequence..." (Meyer 1917:6), namely chapters on water in the atmosphere, followed by the condensation of water, precipitation, evaporation from water surfaces and land areas, transpiration, groundwater flow, runoff, stream flow, stream-flow data and finally, modification of stream flow by artificial storage. In another early American hydrology text Mead (1919:1) associated hydrology with the "circulation of water above, on and within the earth's crust," noting that this "is as important and necessary in geological change and development as is the circulation of blood in the animal body or the circulation of sap to vegetable life." Horton's main contribution was to give a particular form and substance to this "circulation of water" which to others merely "appeared a logical sequence."14

As the main social structures within which modern scientific practices take place, scientific disciplines do not just appear as reflections or manifestations of nature. As argued by Stichweh (1992:5), "they are the result of deliberate activities

\footnotetext{
${ }^{14}$ Horton probably owes some measure of debt for his idea of the hydrologic cycle to the American geographer, William Morris Davis. Davis' elaboration of the cycle of erosion, which he called the "geographical cycle" was first presented in 1899 and rapidly gained currency in the geosciences. (James 1972:354-355)
} 
oriented toward order and specific purposes." Prior to 1931, hydrology in the United States had been developed as an adjunct of civil engineering. Beginning around the turn of the century, the subject had been introduced as a separate technical study in several American engineering schools,(Mead 1919:v) and the first American texts on hydrology, such as those by Mead and Meyer, were written by engineers. Horton's paper - although written by someone who identified himself as a "consulting engineer" - represented a deliberate effort to raise hydrology from the status of a merely practical or applied field of study to a bona fide scientific discipline. Horton's 1931 paper has thus been deemed the signal document in hydrology's "struggle for scientific recognition" in the United States. (National Research Council 1991:40)

Horton's hydrologic cycle constituted the field and scope of scientific hydrology. But the relationship between hydrology and the hydrologic cycle was more complex. There was, as Horton noted "scattered through scientific and engineering literature a mass of quantitative results adequate to make a most respectable body of science, wanting only to be coordinated..." For decades, (and even longer if we consider the work of the proto-scientific hydrologists in the late seventeenthcentury), scientists and engineers had been measuring precipitation, infiltration, groundwater flows, runoff, streamflow and evaporation. From the conventional histories, we learn that it was by virtue of these measurements that it became possible to think of the hydrologic cycle as an integrated system. Beginning with Perrault, Mariotte and Halley, and culminating in Dalton's computation of a balance 
between precipitation, streamflow and evaporation, the hydrologic cycle emerged as a scientific concept. This, together with the subsequent work of hydrologists in measuring flows of water gave rise to a body of "quantitative results" that was crystallized in the form of Horton's hydrologic cycle. In this sense, the practice of hydrology has constituted the scientific hydrologic cycle while, since the time of Horton, the hydrologic cycle has constituted the practice of hydrology - a mutually constitutive relationship.

Horton's formulation of the hydrologic cycle accomplishes two requisite tasks associated with the establishment of scientific hydrology. First, it constitutes hydrology as "a pure science" in Horton's terms, because it represents the (abstract, objective) nature of water. The hydrologic cycle, as Horton defined it, is "the course of natural circulation of water in, on and over the Earth's surface." (Horton 1931:192, my emphasis) By positioning the hydrologic cycle in the realm of nature, Horton effectively applied what Bruno Latour has described as "the modern constitution" - the epistemological constitution dividing the world of nature from the world of society - to water. For Latour, this constitutional division is what allows science to represent and speak for nature. (Latour 1993:ch. 2; Latour 2004:13-15) More will be said of this "modern constitution" as it applies to water in Chapter 8. For now, I want to stress that it was by asserting the hydrologic cycle as a part or aspect of "nature", that Horton was able to make a claim for hydrology as a "pure science": "As a pure science, hydrology deals with the natural occurrence, 
distribution, and circulation of water on, in, and over the surface of the Earth." (Horton 1931:190, my emphasis)

Second, having charged hydrology "with the duty of tracing and explaining the processes and phenomena of the hydrologic cycle" Horton was able to establish definite boundaries around the field and scope of the new science while orienting its work toward a specific purpose. The business of marking boundaries is always political, and Horton's intervention was no exception. By claiming the hydrologic cycle for hydrology, Horton was, in effect, intruding on the territory of another discipline. Prior to 1931, the atmospheric and other portions of the hydrologic cycle were seen to fall squarely within "the domain of meteorology" in the United States. (Marvin 1923:54) Meteorologists were involved in "evaporation and run-off investigations", "river and flood work" and "mountain snowfall and water supply investigations"; and these were even considered to be among the "most valuable and important activities" of meterologists. (Marvin 1920:566-567) The early hydrologists were sensitive to the intrusive character of their enterprise. On the occasion of the establishment of the Section of Hydrology of the AGU, its chairman, O.E. Meinzer, suggested that it's work should be restricted to the nether portions of the hydrologic cycle: "The scope of the Section's activities" he suggested, "will not necessarily include everything that might be included within the science of hydrology. As the Union includes a Section of meteorology and a Section of Oceanography, it would seem that the work of the Section of Hydrology should relate chiefly to the study of the natural waters from their precipitation upon 
the land to their discharge into the ocean." (Meinzer 1931:228) But the integrity of the hydrologic cycle concept established a framework that proved difficult to break up and distribute among the different geo-sciences. By 1942, Meinzer was claiming the entire hydrologic cycle as the domain of hydrology, albeit with an emphasis on its landward phases. (Meinzer 1942:1-2) ${ }^{15}$

In addition to establishing the hydrologic cycle as an entity that could be represented in linguistic and diagrammatic form, Horton's paper gave it a simple mathematical expression. "There is", he asserted, "a simple basic fact involved in the hydrologic cycle: Rainfall = Evaporation + Runoff." (1931:190) (Figure 5.2)

\section{Thero 10 almplo baslo paot lavolrod in the hydrologic oyelo Ralnfall $=$ Evaporat1on + Runoft}

Figure 5-2- The hydrologic cycle as an expression of the basic water balance equation (text reproduced from Horton 1931:190)

The mathematical expression of the hydrologic cycle, i.e. the basic water balance equation, ${ }^{16}$ validated the hydrologic cycle as a "fact" of nature while setting

\footnotetext{
15 The meteorologists responded in the mid-1930s by, literally, re-drawing the hydrologic cycle to account for atmospheric phenomena that they felt the hydrologists had left out of their representations. (see Thornwaite 1937-38; Leighly 1938; Jenkins 1940) This episode, it could be said, amounted to something of a turf-war between the two sections, with different versions of the hydrologic cycle serving as the means of claiming portions of the hydrosphere for the respective sub-disciplines.

${ }^{16}$ Rainfall = Evaporation + Runoff (or $P=E+R$, where $P$ represents precipitation, $E$ represents evaporation and $R$ represents Runoff) is the basic water balance equation for river basins, often
} 
scientific hydrology on the path of elaborating this fact by mathematical, quantitative methods. "The central problem" of hydrology, Horton asserts, "is that of determining the physical process and principles and the quantitative relations involved in the hydrologic cycle..." (1931:199) While recognizing that "Much remains to be done to bring hydrology fully into the domain of quantitative science" (1931:196) the intended direction of scientific hydrology was unmistakable. ${ }^{17}$ Since 1931 , the hydrologic cycle has been reproduced by hydrologists and others in the United States and elsewhere who have carried it forward in scientific and popular literature. In this process of carrying the hydrologic cycle fonward, Horton's original contribution of naming and picturing it has disappeared from view. Today, the invisibility of Horton's handiwork allows the hydrologic cycle to be understood as part nature instead of something with an origin and an author. At the same time, beginning around 1931, the historical roots of the concept of the hydrologic cycle began to be projected far into the past, further blurring its modern origin and

known as the Penck-Oppokov equation, after the Austrian and Russian scientists who developed it around the turn of the twentieth century. (Unesco 1971:12-14; but see Chapter 7, footnote 10 for an alternative view of things) This equation, as with the continuity equation noted above, can be described as a hydrological expression of the conservation of mass. A slightly more comprehensive version of the Penck-Oppokov equation - and the one most frequently cited - is expressed as $R=P$ $-E+/$ change in storage, "This states that for any arbitrary volume and during any period of time, the difference between total input and output will be balanced by the change of water storage within the volume." (Unesco 1971:12)

17 Horton's 1931 paper can be seen as initiating a process by which the hydrologic cycle has become established as a scientific fact. Here, the term "fact" may be considered in the sense in which Ludwig Fleck elaborated it in his 1935 book, Genesis and Development of a Scientific Fact. Fleck is recognized as a pioneer in the sociology of science who insisted that the production of scientific knowledge should be understood as a social enterprise. (Golinsky 1998:32) For Fleck, the social character of scientific facts is revealed by attending to the circumstances of their production within a specific scientific community: "A fact always occurs in the context of the history of thought and is always the result of a definite thought style." (quoted in Golinsky 1998:33) Horton's hydrologic cycle may thus be understood as having been produced in the context of an interactive community (practitioners of hydrology) for whom evaporation, precipitation, runoff and stream-flow had been reduced to mathematical relations that could be expressed as a simple formula: Rainfall = Evaporation + Runoff. The hydrologic cycle and its mathematical expression as the water balance equation now constituted a fact that could be readily represented and duplicated. 
enhancing its apparent timelessness. This simultaneous process of carrying the hydrologic cycle forward into the future and projecting it backward into the past is discussed in the next two sections.

\section{Carrying the Hydrologic Cycle Forward from 1931}

\section{Consolidating Hydrological Identity}

Within the hydrologic literature, the Hortonian hydrologic cycle has been carried forward since 1931 primarily as a means of identifying the field and scope of scientific hydrology and providing "a conceptual framework for hydrological studies" (Goudie 2000c:256). As already noted ${ }^{18}$, the hydrologic cycle is represented diagrammatically and described as the 'central concept' or 'fundamental principle' in practically every textbook, handbook and general article on hydrology published in the United States since $1931 .{ }^{19}$ Even the very structure of many hydrology textbooks has been deliberately arranged so as to follow the apparent route of water through the major phases of the standard hydrologic cycle, beginning with precipitation, followed by interception, evaporation, runoff, groundwater movement, streamflow, and so on. (e.g. Meinzer 1942; Kazmann 1965, 1972; Eagleson 1970; Maidment 1993:Part 1; Ward and Robinson 2000)

\footnotetext{
18 See Chapter 4, footnote 5 .

19 The geographic focus here is on the United States. It should be pointed out that - partly as a result of the translation of American hydrology texts into other languages and partly as a result of the diffusion of the idea via other forms of literature - the hydrologic cycle has been taught as the central concept of hydrology in most countries since the Second World War. (unesco 1974a and 1974b)
} 
Carrying the hydrologic cycle forward has been instrumental in upholding the identity of scientific hydrology. By most appearances, this identity has been relatively stable. Recall that Horton's 1931 paper asserted the field and scope of hydrology in the following terms: "As a pure science, hydrology deals with the natural occurrence, distribution, and circulation of water on, in, and over the surface of the Earth." (Horton 1931:190) In 1962, the Ad Hoc Panel on Hydrology of the U.S. Federal Council for Science and Technology asserted: "Hydrology is the science that treats of the waters of the Earth, their occurrence, circulation, and distribution, their chemical and physical properties, and their reaction with their environment, including their relation to living things... Hydrology is the scientific examination and appraisal of the whole continuum of the water cycle conceived as a circle made up of numerous arcs, some of which traverse the domains of other related earth sciences." (United States 1962:2-3)

Sixty years after the publication of Horton's paper, a major stock-taking exercise by the U.S. National Research Council identified hydrology in remarkably similar terms: "Hydrologic science deals with the occurrence, distribution, circulation, and properties of water on the earth...Water moves through the earth system in an endless cycle that forms the framework of hydrologic science." (National Research Council 1991:ix)

Nevertheless, over the same period of time, hydrologists themselves have recognized the ambiguous status of their practice, an ambiguity that arises from 
the perceived conflict between hydrology as a 'pure' natural science and the practical, utilitarian, "applied" purposes that have tended to orient hydrologic research. ${ }^{20}$ In 1937 Horton called attention to "The fact that hydrology has largely grown up in the families of sister sciences, and the tremendous pressure for hydrologic research created by recent activities in soil and water conservation, have created a situation which seems to call for some pertinent discussion of the objectives and methodology of hydrologic research." (Horton 1937:527) Horton's abiding concern for wresting hydrology from its status as an applied, "engineering" science has persisted among many hydrologists in the United States and elsewhere until at least the recent past. "[T]he present sorry state of hydrological science", declared V. Klemes in 1988 (1988:11), has arisen because hydrologists have allowed their discipline to be guided by practical and technical demands relating to water management rather than by the more pure, disinterested pursuit of knowledge about the behaviour of water. "The main reason is that, after all, many hydrologists do not have strong feelings about the science of hydrology and are only too easily seduced into performing the technological pirouettes required of them..." (Klemes 1988:4) ${ }^{21}$ According to Klemes, hydrology still had not succeeded "to establish itself as a science." (ibid.) Around the same time, other hydrologists perceived that " $[\mathrm{t}]$ he cultivation of hydrology as a pure science per se has not

\footnotetext{
20 Hydrology has been qualified as "an applied science" (American Society of Civil Engineers:1949:viii), and "an observational science." (Maidment 1993:1.1-1.2)

21 The quote continues rather caustically, "because... most of them are themselves technologists in their hearts." (!) For expressions of similar concern around this time see Sutcliffe 1972; Dooge 1986; Bras and Eagleson 1987; Dooge 1988.
} 
occurred". (Bras and Eagleson 1987:227) In 1991, the National Research Council reported...

"increasing concern among scientific hydrologists about the future and long-term vitality of their field...owing, somewhat paradoxically, to the fact that throughout the history of this field applications have preceded science...Because of the pervasive role of water in human affairs, the development of hydrologic science has followed rather than led the applications - primarily water supply and hazard reduction - under the leadership of civil and agricultural engineers."(National Research Council 1991:vii)

"[H]ydrologists", as one hydrologist has put it, "agonise over the status of their subject and seek, as they appear to have done for the last seventy years at least, the status implied by the term scientific." (Nash 1992:192) For a scientific discipline that has, at least until recently $y^{22}$, exhibited something of an identity problem, the importance of the hydrologic cycle in upholding hydrology as a "pure science", as Horton put it, can hardly be overstated. Thus, in addition to its value as "a conceptual framework for the hydrological studies" the hydrologic cycle has been carried forward within the hydrologic literature as an affirmation of the unity and the scientific status of the discipline, a kind of talisman for hydrology's continual "struggle for scientific recognition." (National Research Council 1991:40). This

\footnotetext{
22 22 The heightening of expressions of concern from within discipline in the 1980s may be explained in part by the critique from outside the discipline, particularly from environmentalists "for alleged narrowness of outlook and for our inability, or at least our failure, to assess the consequences of our interferences in the watery environment." (Nash 1992:192) In any case, as we know, the 1980s marked a period of erosion of popular faith in the "engineering" solution to water problems, as manifest in growing opposition to large dams around the world. (see Chapter 2) That these developments outside the discipline would give rise to a heightened degree of introspective activity within is not surprising. In any case, the identity crisis seems to have passed in recent years. The growing popularity of global hydrology in the context of concerns about climate change, and the popularity of hydrology in an era of increasing general interest in water issues has invigorated many hydrologists with a sense of purpose that appears to have been lacking in the 1980 s and early 1990s. (Sean Carey, personal correspondence)
} 
significance of the hydrologic cycle is most obvious when it is insisted that the "mission" of hydrology needs to be "seen as improving the understanding of the water cycle" (Klemes 1988:6) or, as put in slightly more mathematical terms by Dooge, "The business of hydrology is to solve the water balance equation." (Dooge quoted in Klemes 1988:19)

This constitutive function of the hydrologic cycle is particularly evident when hydrologists acknowledge, as they occasionally do, that it of little or no use in the actual practice of hydrology. ${ }^{23}$ Such acknowledgement appears to be offered more readily by hydrologists outside the United States. (e.g. Ward and Robinson 2000:8) With the possible exception of research in global hydrology, the hydrologic cycle can hardly be said to have been instrumental in the day-to-day practice of hydrologists, which tends to involve detailed investigations of different phases of the hydrologic cycle on the scale of the river basin. That it has been carried forward within the discipline and reaffirmed as hydrology's central concept reflects its continuing importance as a means of holding the discipline together. ${ }^{24}$ The hydrologic cycle then, still serves Horton's original purpose as a means of framing and demarcating hydrologic science and establishing a distinctive hydrological identity. Perhaps the best recent illustration of this utility comes from the report of

23 As noted in the last chapter, Tuan recognized the uselessness/irrelevance of the hydrologic cycle to the practical work of most hydrologists. (1968:4)

24

Given the recognition by hydrologists that water exhibits extremely complex, non-linear responses "resulting from the effects of spatial variability in rainfall, vegetation canopy, soil structure, and topography" it may be regarded as somewhat surprising that they have not offered more explicit criticism of a concept as simplistic and linear as the hydrologic cycle, particularly when calling for such things as a "New Paradigm" in the hydrologic sciences. (Beven 1987:400) 
an important study by the Committee on Opportunities in the Hydrologic Sciences of the National Research Council, the explicit purpose of which was "[t]o establish an identity for hydrologic science as a separate geoscience." (National Research Council 1991:xii) Here the hydrologic cycle is still the central concept of hydrology and "the framework of hydrologic science." (National Research Council 1991:35) Indeed, the hydrologic cycle has now quite graphically become the very identity of hydrology itself. As represented in the illustration on the frontispiece of the book; the hydrologic cycle and hydrologic science are literally one and the same. (Figure 5.3)

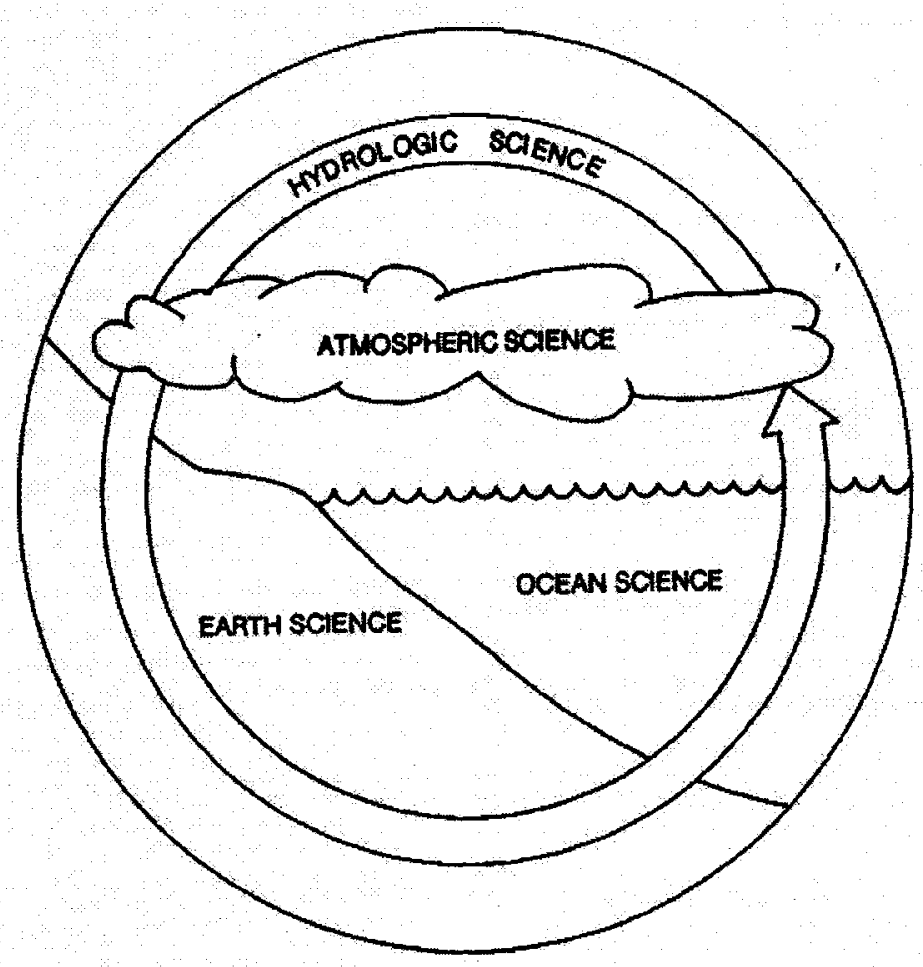

Figure 5-3 - Hydrologic Science $=$ The Hydrologic Cycle (diagram reproduced from title page of National Research Council 1991) 


\section{Picturing the Hydrologic Cycle}

Perhaps the most obvious means by which the hydrologic cycle has been carried forward since 1931, has been through reproduction of Horton's original idea of depicting it in diagrammatic form. As a diagram, the hydrologic cycle has become a very prolific image in scientific and popular discourse, such that it is often coeval with the concept of the hydrologic cycle itself. An early hydrologist, Thorndike Saville, put it like this: "The generalized picture of the movements of water as it relates to the earth is called the hydrologic cycle." (Saville $1937: 1)^{25} \mathrm{~A}$ brief discussion of the scientific diagram as a form of visual discourse is therefore in order.

Historian of science, Bert Hall has written that since the seventeenth century, visual images (naturalistic representations as well as diagrams) have gained authority in scientific practice as a consequence of having been accepted as "bearers of authentic information." (Hall 1996:4) The authority of scientific images rests on structures of scientific discourse that are intimately associated with specific disciplines, or 'thought communities':

"As a rule, we expect images that appear in the company of texts to explicate the material covered in the text in some fashion or other. Behind this lies the further assumption that both words and images are related to an external reality,

\footnotetext{
${ }^{25}$ Thornewaite similarly conflates the concept and the diagram in a paper describing the need to re-examine the hydrologic cycle in light of meteorological considerations: "The consideration of the hydrologic cycle from the standpoint of air masses reveals an important omission from all existing diagrams illustrating its operation." (Thornwaite 1937-38:90)
} 
a world 'out there' whose description is one of the principal tasks of the scientistwriter whose texts we are reading. Yet it should be obvious by now that drawings cannot play so seemingly simple a role without an elaborate structure of institutional authority and personal credibility on the part of the author..." (Hall 1996:21)

The various parts of Horton's hydrologic cycle corresponded with different kinds of investigations that were underway in 1931, and were, in his words "wanting only to be coordinated." Moreover, a scientific discourse in which the occurrence and movement of water - as water vapour, precipitation, groundwater, runoff, streamflow, etc. - could be accounted for quantitatively was clearly in place by 1931 . There was, as Horton asserted, "scattered through scientific and engineering literature a mass of quantitative results adequate to make a most respectable body of science." In other words, the readers of Horton's paper shared a language and set of rules that permitted a certain kind of hydrological discourse. This common discourse, together with Horton's immense personal credibility ${ }^{26}$ and the institutional circumstances in which his paper was presented, made the hydrologic cycle and the diagram used to depict it intelligible and credible.

The immense popularity that has been achieved by the hydrologic cycle diagram as a form of visual discourse is due largely to this scientific credibility. At the same time, there is an aesthetic quality in the idea and in the visual form of a cycle that, like many other didactic images, acquires the power to convince by its very elegance. The persuasive power of such forms of representation is suggested by 
Hall, who although describing technical illustrations of imaginative machinery in the Renaissance, offers an insight into the discursive effect of the visual depiction of the hydrologic cycle. Such images, he points out,

"persuade entirely through their effect on the viewer. The image ... seeks to reveal the hidden, inner workings of the machine to the viewer. The imagined machine will seem to work, and it well be seen to work by the viewer. In this way, the image draws the viewer into a process of verification that establishes the image's plausibility, and it creates its own authority thereby." (Hall 1996:37)

There are important differences between the hydrologic cycle diagram and fifteenth-century images of imaginative machinery. For one thing, we may go outside and feel the rain or dip a hand into a flowing stream, thus apparently corroborating parts of what we see in the picture with our personal experience. We can also measure these things, thus corroborating parts of what we see in the picture with scientific evidence. But to the extent that the hydrologic cycle is represented as a kind of machine - an "immense water engine, fuelled by solar energy, driven by gravity" as Maidment puts it in his Handbook of Hydrology - to see it is, in a sense, to believe it. (Maidment 1993:1.3) Seeing the hydrologic cycle, moreover, is hardly an intellectual challenge. As first depicted by Horton, and certainly more so as the diagram became simplified (and as naturalistic features have been added to facilitate visualization), the hydrologic cycle is easy to comprehend. As we know, the intellectual labour that preceded the crystallization of the Hortonian hydrologic cycle in 1931 was anything but simple. Moreover, each part, or phase, of the hydrologic cycle is astonishingly complex. In view of this complexity, the fact that a popular writer in the year 2001 could declare that "the 
hydrological system is simple to grasp" (de Villiers 2000:52) shows the brilliance (and ultimate success) of Horton's notion to represent it as a diagram seventy years earlier.

A few general observations may be noted respecting the process by which the hydrologic cycle diagram was carried forward in the hydrological and other literatures after 1931: First, acknowledgement of Horton's authorship of the concept, the term, and the diagram, attenuated rapidly as a variety of depictions and descriptions of the hydrologic cycle proliferated. Second, without reference to Horton and the context in which he presented it, the hydrologic cycle is shown to be entirely natural; even within the discipline, it is often presumed to represent an intrinsic part of nature rather than a construction deliberately formulated on the occasion of the issuing of hydrology's "birth certificate." Thirdly, subsequent descriptions and diagrams, especially when presented outside of scientific hydrological discourse - i.e. in more popular writings - have been far less complex than Horton's original.

Horton's description of the way his diagram of the hydrologic cycle is to be read suggests a concept that is far more complex than one finds in more recent versions:

"Beginning at the top and reading counter clock-wise the path of the water in the course through the hydrologic cycle may readily be traced. Figure [5.1] is, however, little more than a suggestive picture from which a wealth of detail is necessarily omitted. For example, on the diagram but little space is devoted to evaporation from the soil. This, however, is a very complex process. It involves the flow of vapor from the air into the soil, from the soil into the air, temperature 
differences between the soil and air, the diurnal and annual heat-waves flowing into the soil, evaporation from the water-table, and also evaporation from capillary films in the non-saturated zone... As a further illustration, the little segment labelled "Temporarily stored on the surface" includes water some of which goes into the soil as infiltration. In that case the detention or storage is often but a surface-film or thin layers in tiny pools. Temporary surface-storage ranges from such transitional phenomena to the extended and long-continued storage of water in lakes, swamps, marshes, as accumulated snow-layers in winter, as glaciers and polar ice-caps. Other details might be similarly amplified." (Horton 1931:192-3, my emphasis)

Few of the subsequent descriptions and diagrams were as detailed and suggestive of the complexity that is hidden by representing water in the form of the hydrologic cycle. Nevertheless, so long as it was confined to texts and reference books circulating among professional hydrologists and students of hydrology, the hydrologic cycle remained relatively complex, and the difficulty of representing something as complicated as the behaviour of water by means of a single diagram or descriptive text was more or less acknowledged. For example, Meinzer's Hydrology (1942) - the first English-language hydrology textbook to be published in the United States following the appearance of Horton's paper - featured an illustration of the hydrologic cycle in the frontispiece that provided considerable detail, particulariy in the sub-surface phases, and included only the barest hint of naturalistic features (Figure 5.4). 


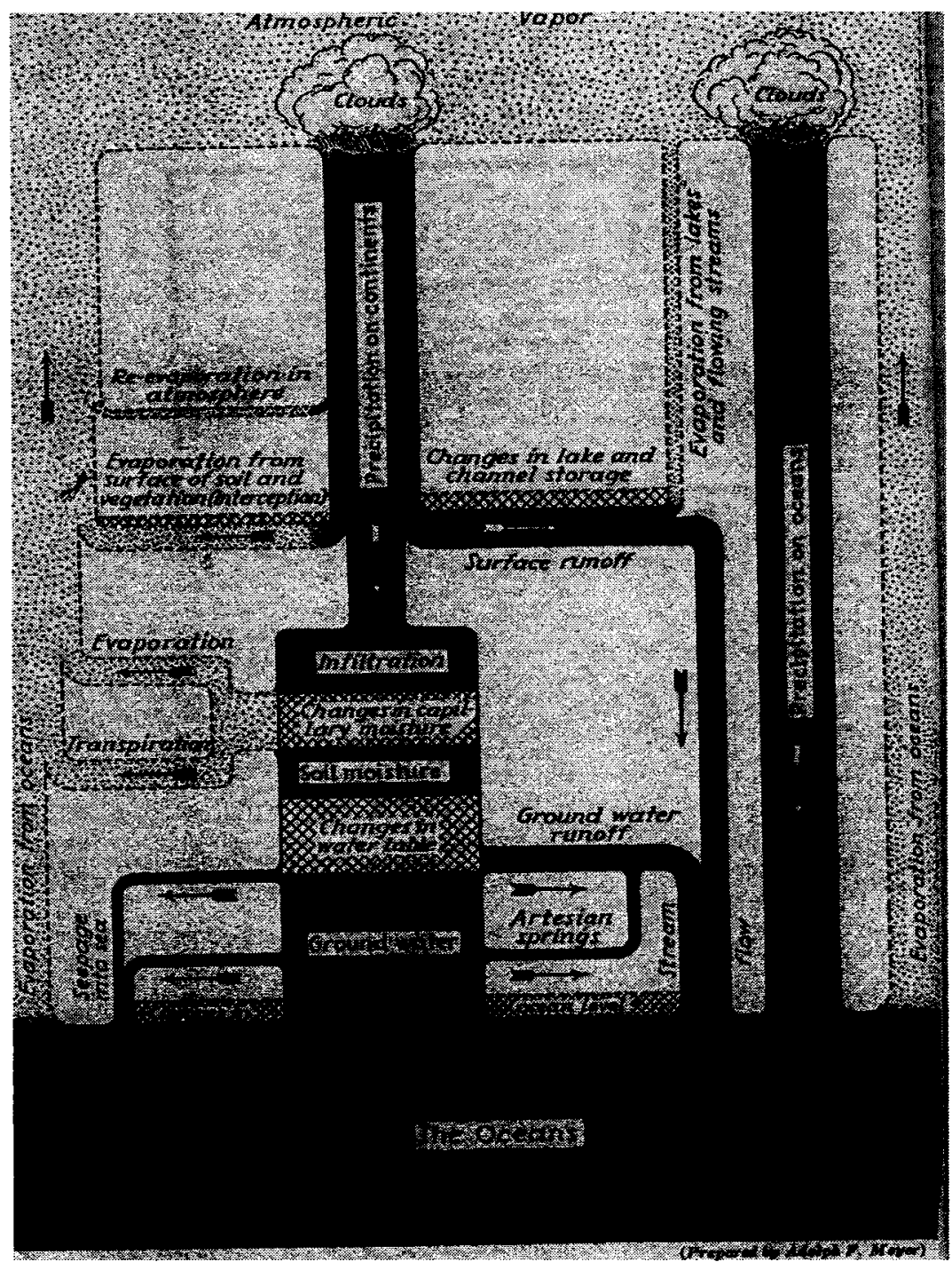

Figure 5-4 - "The Hydrologic Cycle" (diagram reproduced from frontispiece of Meinzer 1942)

Meinzer's textual description, appearing on the very first page, begins as follows:

"The central concept in the science of hydrology is the so-called hydrologic cycle - a convenient term to denote the circulation of the water from the sea, through the atmosphere, to the land; and thence, with numerous delays, back to the sea by overland and subterranean routes, and in part, by way of the atmosphere; also the many short circuits of the water that is returned to the atmosphere without reaching the sea." (Meinzer 1942:1-2) 
By referring to "numerous delays back to the sea" and "the many short circuits of the water that is returned to the atmosphere without reaching the sea", Meinzer's description represents something more convoluted than a simple cycle. Other, especially earlier, descriptions of the hydrologic cycle appearing in the hydrology literature have done likewise. In Chow's 1964 Handbook of Applied Hydrology, it is stressed: "The hydrologic cycle is by no means a simple link but a group of numerous arcs which represent the different paths through which the water in nature circulates and is transformed." (Chow 1964:1-2) Most of the more recent descriptions of the hydrologic cycle within the scientific literature have suggested less complexity. For example, compare Chow's qualifications with the description of the hydrologic cycle found in Maidment's more recent Handbook of Hydrology, cited at the beginning of the second section above.

Further, Meinzer's description of the "so called hydrologic cycle" as "a convenient term" has the effect of showing its constructedness. A similar acknowledgement is made in some of the other earlier texts and articles by means of placing "the hydrologic cycle" in quotation marks or in italics. (e.g. Jenkins 1940:309; American Society of Civil Engineers 1949:1; Wisler and Brater 1949:3) However, in none of these is Horton's authorship - either of the term "hydrologic cycle" or the diagram acknowledged, and even his role in having first identified hydrology as the science that treats of the hydrologic cycle is ignored. ${ }^{27}$ In time, acknowledgement of the

\footnotetext{
27 Following Meinzer's 1942 textbook, Wisler and Brater's Hydrology (1949) affirms hydrology "is the science that treats of the various phases of the hydrologic cycle" and "the hydrologic cycle... provides the groundwork upon which the science of hydrology is constructed." (Wisler and
} 
hydrologic cycle as a concept or term with a definite history disappears entirely.

The hydrologic cycle thus looses its inverted commas and becomes "the natural pattern of circulation of water" (Thomas 1956:544), "one of nature's grand plans", (Langbein and Hoyt 1959:3) and "a great natural system". (Chorley and Kates $1969 a ; b: 3)^{28}$

The 1949 Hydrology Handbook published by the American Society of Civil Engineering (American Society of Civil Engineers) acknowledged Horton's illustration in noting, "A comprehensive diagrammatic representation of [the hydrologic cycle] was published in 1931." (American Society of Civil Engineers 1949:1) However, the illustration presented in the American Society of Civil Engineers Handbook is far less complex than Horton's original and is described as "A somewhat less complete but perhaps more readily visualized diagram". (Figure 5.5)

Brater 1949:3) However, while dedicating the book to the memory of Robert Horton, "whose untiring efforts throughout more than a quarter of a century contributed immeasurably toward the development of the science of hydrology", the only specific contributions of his that they cite are with respect to the theory of infiltration capacity (1949:5). Horton's major feat of issuing the "birth certificate" and identifying the hydrologic cycle as the midwife is invisible. They include a hydrologic cycle diagram that is evidently based on Horton's original (1949:2), but again neglect to acknowledge that it was, in essence, Horton's diagram that they reproduced. The only reference that I can find to Horton as having identified hydrology as the science whose purpose is "to trace out and account for the phenomena of the hydrologic cycle" is National Research Council 1991:40. 28

${ }^{8}$ Other examples could be provided to show that the hydrologic cycle is understood to be a natural thing or process. As already noted, Maidment describes the hydrologic cycle as an "immense water engine, fuelled by solar energy, driven by gravity..." (Maidment 1993:1.3) Another example is in Veissman and Lewis's Introduction to Hydrology. "The hydrologic cycle is a continuous process by which water is transported from the oceans to the atmosphere to the land and back to the sea." (1996:5) Examples from more popular literature might include Hunt's Thirsty Planet: Strategies for Sustainable Water Management - "The water cycle is the combination of natural physical, chemical and biological processes that constantly recycle water, ensuring a steady supply to support life on Earth." (2004:1) Or de Villiers, (1999:29) who describes the hydrologic cycle as "a self-regulating quasi steady-state chemical system that transfers water from one "reservoir" to another in complex cycles." 


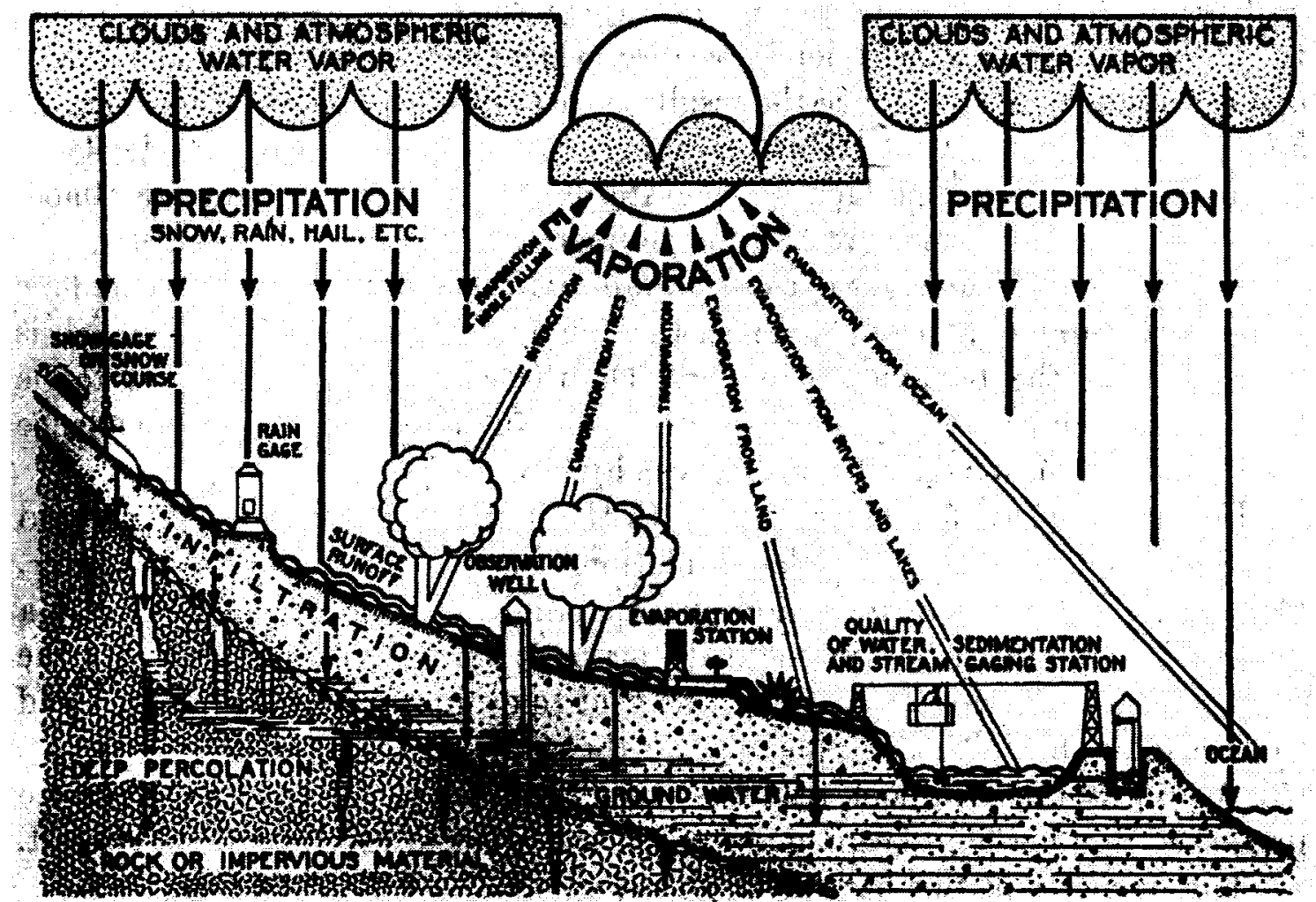

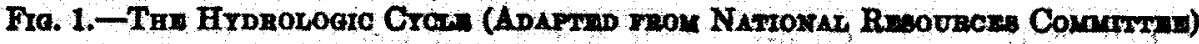

Figure 5-5 - "The Hydrologic Cycle" (diagram reproduced from American Society of Civil Engineers 1949:2)

A discussion of this particular diagram is in order, for it is this type of simplified illustration that has served as the most common vehicle for disseminating the hydrologic cycle in popular discourse. Here the hydrologic cycle is presented as the interchange of water between the ocean and a (continental) landmass, and employs a number of naturalistic features that make the concept more easily recognizable than in Horton's diagram. With only minor modifications, the 1949 illustration was reproduced from a paper titled "Basic Principles of Water Behaviour" presented at a 1936 conference organized by the US Soil Conservation 
Service. (Saville 1937) Its author ${ }^{29}$, in turn, had reproduced (again, with minor modifications) a slightly earlier diagram that had been prepared for a 1934 US Federal Government report on the need to rationalize the collection of hydrologic data on a national scale. (See Figure 6.1)

The significance of the relationship between the hydrologic cycle and the development of water resources in the modern state is discussed in the next chapter. Here, I want to stress a couple of important points about this "descriptive" ${ }^{30}$ style of diagram. By virtue of its relative simplicity, its inclusion of stylized images of recognizable landscape features and the ease with which it could be read and understood, this type of diagram gained immediate popularity within and outside of hydrological literature, such that it could be described as "the hydrologic cycle...as conventionally drawn" as early as 1938 (Leighly 1938:335) and "the usual form" by 1940. (Jenkins 1940:309) And so it remains today; on perusing any standard earth sciences or geography textbook, or publication (academic or otherwise) dealing with water in general, one is likely to encounter a similar diagram. ${ }^{31}$ There is,

\footnotetext{
${ }^{29}$ Saville, notes, "The most comprehensive diagrammatic representation of [the hydrologic cycle] was published by Horton in 1931 ..." and points out that "A somewhat less comprehensive but perhaps more readily visualized diagram is presented herein..." (Saville 1937:1) Unlike most of the subsequent representations, Saville stresses that while hydrological phenomena "may appear an obvious and simple cycle of natural events, especially as pictured in figure 1", they are in fact extremely complex. (Saville 1937:5) 30

Chow's 1964 Handbook of Applied Hydrology identifies three types of hydrologic cycle diagram: "Many diagrams have been designed to illustrate the hydrologic cycle; some are qualitative, some descriptive, and some quantitative." A variation of Horton's 1931 diagram is given as an example of a "qualitative" diagram. (Chow 1964:1-3) Although Horton's authorship of the diagram is acknowledged, there is nothing to indicate that it was the first. A diagram much like Saville's is given as an example of a "descriptive diagram".

31 landmass to the left of an ocean. This is consistent with the (1934) prototype. As a matter of
} 
however, an important difference between the earlier illustrations and the "descriptive" diagrams that circulate today; examples cited in this and the following chapter are notable for their inclusion of the placement of hydrologic instruments snow gage, rain gage, observation well, evaporation station and stream gauging station - at their corresponding places, or phases, within the cycle. Some of these earlier diagrams even bore the title: "How the Water Cycle is Measured." (Figure 6.2) By featuring the instruments by which the hydrologic cycle is measured, the mutually constitutive relationship between the practice of hydrology and the hydrologic cycle is rather apparent. It may be recalled that it was by virtue of the use of stream gauging techniques, measurements of evaporation and rain gauges that proto-hydrologists such as Perrault, Halley and Dalton were able to provide the data that are understood to have proven its existence.

As the science of hydrology became established as a bona fide discipline in the United States, Robert Horton has often been identified as the "father of American hydrology" (Hall 1987; National Research Council 1991:41; Reuss 2001a:275), the foremost "leader" of the science (Leopold 1987:27) or "the dean of American hydrologists." (Nace 1978:23) But the reasons given for Horton's fatherly status are not what one might expect from the reading intended here. Rather, it is his elaboration of a quantitative relationship between the infiltration capacity of soils to the generation of floods by surface runoff that is most often cited as his major

speculation, such a proclivity suggests the American (as opposed to the European) origin of this way of representing the hydrologic cycle, as most American hydrologists of the era, including Horton (who was from New York state) were based in the eastern part of the United States, and would likely have visualized an ocean lying to the east. 
contribution to hydrology, especially his 1945 paper outlining a "hydrophysical approach to quantitative geomorphology." (Horton 1945) ${ }^{32}$ What is perhaps his major contribution - to materialize the hydrologic cycle concept, to establish the "hydrologic cycle" as a distinct entity, to represent it in diagrammatic form, and identify it with the discipline of hydrology - goes entirely unrecognized. Perhaps this should not be surprising. Hydrology, as a natural science that locates its roots in classical philosophy, is unlikely to proclaim its origins in a paper written in 1931 from Voorheesville, New York.

\section{Projecting the Hydrologic Cycle Backward from 1931}

Having been given birth in 1931, the hydrologic cycle could now be developed in the practice of writing history. The hydrologic cycle was thus projected backwards into the works of ancient philosophers, seventeenth century natural philosophers, and modern scientists alike. This project has already been described in some length in the last chapter, in terms of the "conventional" history. Here, it remains only to highlight several key aspects of this history and to reconstruct the main sequence of events by which it was put together.

There was a notable surge of historical interest in the controversy over the origin of springs around the time Horton wrote his 1931 paper. It has already been noted that despite the work of the seventeenth and eighteenth-century proto-

\footnotetext{
${ }^{32}$ For assessments of the significance of this paper, and Horton's reputation in the science, see (National Research Council 1991:41; Dooge 1986:52s)
} 
hydrologists, notions about the subterranean cycling of water remained popular, even among some scientists in the 1800 s, and that these were only finally discredited to everyone's satisfaction within the last 100 years. (Meinzer 1934: Dooge 2001) Now that the matter had been "definitely and finally solved in all its chief features at least", wrote Adams in 1928, it became "of interest to see where the observers of the past centuries strayed away from the path which would have led to the true explanation which they sought, and especially to determine what causes led them into error." (Adams 1928:3) Adams might have added that it now became possible to see where the observers of the past strayed from the path of truth. Adams' "The Origin of Springs and Rivers: An Historical Review", published in 1928, appears to have been first publication in English that deals with the controversy as a matter of historical interest. (Adams 1928) It was followed by Meinzer's "The history and development of ground-water hydrology" (Meinzer 1934), Baker and Horton's "Historical development of ideas regarding the origin of springs and groundwater" (Baker and Horton 1936) and Adams' chapter on the "problem" of "the origin of Springs and Rivers" in his book, The Birth and Development of the Geological Sciences. (Adams 1938)

Following Horton's 1931 paper, as the hydrologic cycle was carried forward in hydrologic discourse, the salient historical question was framed less in terms of the debate concerning the origin of springs and more in terms of the development of the concept of the hydrologic cycle. In Meinzer's 1934 account of the history of groundwater hydrology, he described its development in relation to the ancient 
dispute over the origin of springs (and never mentions the hydrologic cycle) (Meinzer 1934). By 1942 however, Meinzer's historical analysis was centred entirely on "the hydrologic cycle", which he introduced by noting: "The concept of the hydrologic cycle has become so generally accepted that it is difficult to appreciate the long history that lies back of its development and demonstration." (1942:8) To cite another example, writing in 1938, Adams identified Bernard Palissy as "the first writer to recognize and insist that rain and the melting snows on the earth's surface were not one but the only source from which spring and rivers derived their waters" (1938:446). Thirty years later, describing the same thinker, Biswas asserts; "up to the time of Palissy very few persons had a correct understanding of the hydrologic cycle." (1970:151, my emphasis) In general, after 1940, the main players - Aristotle, Vitruvius, Leonardo da Vinci; Palissy, Perrault, Mariotte, Halley, etc. - whose work had been featured in the history of the dispute over the origin of springs in the late 1920s and 1930s, were recast in the new story of the "General evolution of the concept of the hydrological cycle." (Nace 1974; see also Krynine 1960; Jones, Walker et al. 1963; Parizek 1963; Biswas 1965; Larocque 1967; Tixeront 1974; Dooge 2001, among others)

Interest in the history of the concept of the hydrologic cycle appears to have peaked in 1974, the year that Unesco sponsored a conference "on the occasion of the celebration of the Tercentenary of Scientific Hydrology." (Unesco-WMO-IAHS 1974) The significance of the date may be noted, as it marked exactly 300 years since the publication of Perrault's monograph, l'Origine des Fontaines. However, it 
was not the origin of springs whose history was written in the papers presented at this conference; as stated in the foreword to the published conference proceedings: "Among the basic concepts of hydrology, the concept of the hydrological cycle may be considered as central. Obvious as this cycle may seem nowadays, it took a very long time to understand the mechanism correctly..." (Unesco-WMO-IAHS 1974:11)

A common trait in the process of writing the conventional history of the hydrologic cycle has been to locate its origin by identifying the first person to have the true, or correct understanding of the modern concept. Reference has already been made to Bernard Palissy in this respect. Others have cited different writers: Meinzer points out that Book 21 of Homer's lliad contained a statement which "suggests the concept of the hydrologic cycle" and that the "theory now generally accepted... was briefly but clearly stated by Marcus Vitruvius." $(1942: 9,12)$ Meinzer identifies, Leonardo da Vinci as the first to have "a correct understanding of the hydrologic cycle." (1942: 13) For Biswas, "It can be said, with some justification, that Theophrastus [a student of Aristotle] was the first man to have a correct understanding of the hydrologic cycle, and that the Roman architect Vitruvius later restates his ideas." (Biswas 1970:74) Garbrecht opines that "The first advocate of the atmospheric interpretation of the hydrological cycle was Xenophanes of Colophon (570-475 BC)..." however, "Before Xenophenes, Anaximander of Miletus (610-545 BC) had described the cause and the process of evaporation and thus discovered one of the main elements of the water cycle." (Garbrecht 1987b:14) 
Various other sages have been credited with being the first to describe the 'correct'

hydrologic cycle, ranging from the relatively renowned, such as the pre-Socratic

Greek philosopher Anaxagoras of Clazomenae (Encyclopaedia Britannica, $15^{\text {th }}$ ed.

$20: 770 ; 17: 573)$ to the rather more obscure nineteenth century English

hydrogeologist and expert on the thermal springs at Bath, one Edward Jorden.

(Edmunds 2004:194) With respect to the variety of these attributions, it may be

suggested that projecting the hydrologic cycle backwards into the writings of

people for whom it did not exist is bound to be a somewhat haphazard affair. ${ }^{33}$

33 The anachronism with which the hydrologic cycle is inserted into earlier literature is also evident in recalling that none of the ancient and more modern writers to whom the hydrologic cycle concept is attributed ever actually discussed it as such. And yet, in order to make the claim that the origins of the modern science of hydrology may be associated with great thinkers of the past, it has sometimes been necessary to make it appear as though they did. A couple of the more reconstructive examples from the conventional history may be cited: Although they were interested in the "Historical development of ideas regarding the origin of springs and groundwater", and not directly the hydrologic cycle, the problem is illustrated in Baker and Horton's 1936 article "Historical development of ideas regarding the origin of springs and groundwater" After describing what the likes of Thales, Pythagoras, Aristotle, and Lucretius had to say about hydrological processes, Baker and Horton note "The first engineer to describe the origin of springs was the Roman, Vitruvius." (Baker and Horton 1936:398) Their exegesis of Vitruvius text proceeds as follows:

"Vitruvius was treating primarily of sources and quality of water-supplies. Taking out and arranging in logical order what he wrote on evaporation and condensation, precipitation and springs, we have the following:

[Evaporation and condensation] That vapor and mists and humidity come from the Earth, seems due to the reason that it contains burning heat, mighty currents of air, and a great quantity of water. So soon as the Earth, which has cooled off during he night, is struck by the rays of the Sun, and the winds begin to blow while it is yet quite dark, mists begin to rise upward from damp places...

[Precipitation] Whenever the winds carry the vapor which rolls in masses from springs, rivers, and marshes and the sea it is brought together by the heat of the Sun, drawn off, and carried upward in the form of clouds. Then the clouds are supported by the current of air until they come to the mountains where they are broken up from the shock of collision and the gales, turn into water on account of their fullness and weight and in that form are dispersed upon the Earth (as rain)..

[Springs] The valleys among the mountains receive the rain most abundantly, and on account of the thick woods, the snow is kept in them longer by the hade of trees and mountains.

Afterwards, in melting, it filters throughout he fissures in the ground and thus reaches the very foot of the mountains, from which gushing springs come belching out..." (Baker and Horton 1936:398, my emphasis)

What Baker and Horton have done here is re-organize Vitruvius' writing so as to make it fit a certain "logical order", specifically "evaporation and condensation", followed by "precipitation" and then "springs". Although presented in a different sequence, this account corresponds to what Horton had 


\title{
Conclusion - the Fate of Perrault
}

\author{
Perhaps the most interesting illustration of the projection of the hydrologic cycle
}

backwards into history is the identification by twentieth century hydrologists of

Pierre Perrault as the founder of the hydrological sciences. The legacy of Perrault

offers a particularly good example of Latour's observation that "the fate of what we

say and make is in later users' hands." (1987:27) Beginning in 1938 with Adams,

the historical writings of modern hydrologists have almost unanimously identified

Perrault as the foremost trailblazer of modern, scientific hydrology. ${ }^{34}$ At a recent

identified in his 1931 paper as the "three phases" of the hydrologic cycle, "namely rainfall, runoff, evaporation". (1931:192) The reconstruction of Vitruvius writings here and elsewhere (e.g. Biswas $1970: 83-84$ ) to produce a site onto which the scientific hydrologic cycle is projected into antiquity is ironic, given that the same writings have been used elsewhere to provide an example of premodern, heterogeneous, multiform waters. (see Hamlin 2000:317-318)

Another example of forging the hydrological present by projecting elements of modern hydrology into the past is found in Dooge's "The development of hydrological concepts in Britain and Ireland between 1674 and 1874." (Dooge 1974) Here the work of Edmond Halley is repositioned with respect to the "hydrologic cycle": "It is probable that when writing [his 1687] paper Halley was aware of the comparison of rainfall and runoff made by Perrault and Mariotte and that he attempted to close the cycle by estimating the amount of evaporation and comparing this with the amount of rainfall and runoff. Since his estimates were necessarily crude, his main contribution was in the formulation of the concept of the complete cycle rather than in the experimental verification of the water balance involved." (Dooge 1974:287, my emphasis)

To be sure, Halley's paper was taken as proof that evaporation provided a quantity of water sufficient to account for the source of springs and rivers. But to say that he "attempted to close" and "formulated the concept of the complete cycle" attributes something to Halley that wasn't quite there. For one thing, it isn't at all certain that Halley was aware of the work of Perrault and Mariotte when he wrote his paper in 1687. (This is shown by Dooge himself; 1974:286-7). In any case, it is obvious that Halley never mentioned Perrault or Mariotte in his 1687 paper. He could not then have been attempting to "close" or formulate the hydrologic cycle concept, as such a concept would have required acknowledgement of their work on precipitation and streamflow for its completion. Only from the perspective of the present - when we can position the work of Perrault, Mariotte and Halley in relation to the modern, scientific hydrologic cycle - can Halley be seen to have done such a thing. To speak of Halley as having 'attempted to close the cycle' makes sense only if we presume that the cycle existed in Halley's time. This may be an acceptable presumption for Dooge and other writers of hydrological history who treat the hydrologic cycle as a part of nature that has always existed. But from a constructivist point of view, Halley could not have attempted to 'close' or 'formulate' a concept that did not materialize until centuries later.

34

In addition to the many references to Perrault found in the historical introductions of hydrology textbooks see for example: Adams 1938:448; Meinzer 1942:14; Jones, Walker et al. 1963; Parizek 
conference on the history of the discipline, a reproduction of Perrault's 1674 monograph, De l'origine des fontaines, was provided to every participant. (Perrault 2001). Larocque perhaps best summarizes the way Perrault's contribution is understood by stating, "Without Perrault's discoveries on springs and rivers, the entire concept of the hydrologic cycle would never have been developed." (Larocque 1967:1)

Prior to the establishment of the hydrologic cycle in 1931, however, Perrault was more likely to have been ignored or even ridiculed than elevated to the status of the founder of a discipline. There is very little, if any reference to his work by English or American hydrologists in the nineteenth century. For example, Beardmore's text, Manual of Hydrology, considered the first textbook on hydrology published in English (Chow 1964:1-16; Biswas 1970:315) makes no reference to Perrault. (Beardmore 1862) T.H. Huxley's Physiography, which presents perhaps the closest contemporary approximation to the modern concept of the hydrologic cycle (Huxley 1907[1877]:74) makes no mention of Perrault. And as late as 1926, A. Hallays, who wrote a history of the Perrault family ${ }^{35}$, rather contemptuously dismissed Pierre's scientific efforts. (Larocque 1967:3)

Twelve years after Hallays dismissed his work, Perrault was judged to be the key figure in laying the "true basis for a final solution of many, if not all the problems

1963:9; Biswas 1965; LaRocque 1967; Biswas 1970; Unesco-WMO-IAHS 1974; Nace 1974; Nace 1975; Dooge 1974; Dooge 1984:156: Dooge 2001; Carbonnel 2001.

35 For a modicum of background information on the Perrault family, see Chapter 3 , footnote 41. 
concerning the origin of springs and rivers" (Adams 1938:448) and - two years after that - he was the person to "put hydrology for the first time on a quantitative basis" (Meinzer 1940:14), a position that he has held more or less ever since. What accounts for this extraordinary improvement in Perrault's reputation? The fate of Perrault and that of the hydrologic cycle, it seems, are closely related. The birth of the hydrologic cycle in 1931 as the foundation of hydrologic science has had a marked influence on the way hydrologists have interpreted the past, including the significance of an otherwise obscure administrator of the l'Ancienne Régime who was dismissed by Colbert for dipping into the receipts he had collected on behalf of the King. 


\section{Reading the Resource: Modern Water, the Hydrologic Cycle and the State}

\section{Introduction}

Having seen how the hydrologic cycle took form in scientific practice in the United States, we may now consider how it helped effect the rationalization of water by the state. Adoption of the hydrologic cycle by state planning agencies in the 1930 s is just a small detail of a much larger process in which modern water and the state have mutually strengthened and prospered: Essentially, modern water has been strengthened as an effect of hydrological discourses by which the state has gained capacity to survey and control the nation's water resources; and by the same token, the accounting for, and harnessing of, water resources has greatly strengthened the apparatus of the state. The aim of this chapter is to summarize the key historical events constituting this process as they occurred in the United States. It may be suggested that the mutual strengthening of modern water and the state could be traced in many different countries, and in relation to the proliferation of hydrological discourse. ${ }^{1}$

The identification of water as a "resource" is of central importance to the story of how the state came to exercise control and management of the nation's rivers.

1 For example, Erik Swyngedouw's study of the twentieth century hydrological modernization of Spain could be regarded as an account of the same basic dialectical process that $I$ investigate below with respect to the United States (Swyngedouw 1999). 
Water's resourcefulness, of course, has always been evident to people, as people have always exploited it in myriad ways. A distinction of modern water, however, is in formally associating this resourcefulness with the imperative need to quantify and account for water in a systematic manner. That the state has the potential to do so is suggestive of the internal relation between modern water and the modern state. The naming of water as a "resource" in the early part of the twentieth century is thus a pivotal moment in the history of modern water as well as in the history of the state. This moment occurred in the context of the early Conservation Movement in the United States, and it is to this era that we will devote our attention in the first part of the chapter. The realization of state domination of water began in earnest some two decades later - at the time of the New Deal - and this will be the subject of the latter part.

\section{Water Becomes a "Resource"}

We can begin with a quote from a paper published in 1909 by W.J. McGee, a leading light of the early Conservation Movement and Theodore Roosevelt's main confidante and spokesperson for matters pertaining to exploitation of the nation's waters. ${ }^{2}$ Here McGee represents the cutting edge of progressive American

\footnotetext{
2 McGee has been identified as "the chief theorist of the conservation movement." (Hays1959:102) $\mathrm{He}$ "emerged as the prophet of the new world which conscious purpose, science, and human reason could create out of the chaos of a laissez-faire economy where short-run individual interest provided no thought for the morrow. McGee was a key figure in disseminating the expanding concepts of the conservation movement..." (ibid.:124) A self-made scientist and author of many articles in fields ranging from anthropology to hydrology, McGee was instrumental in establishing the National Geographic Society, the American Anthropological Society (both of which he served as president) and the Geological Society of America. In 1909 he was head of the Inland Waterways
} 
thought about the correct way to dispose of the nation's water. The title of his

paper is, "Water as a Resource":

"No more significant advance has been made in our history than that of the last year or two in which our waters have come to be considered as a resource - one definitely limited in quantity, yet susceptible of conservation and of increased beneficence through wise utilization. The conquest of nature, which began with progressive control of the soil and its products and passed to the minerals, is now extending to the waters on, above and beneath the surface. The conquest will not be complete until these waters are brought under complete control." (McGee 1909:522-523, my emphasis)

Why is McGee making this statement now ${ }^{3}$ While advances in hydro-electrical techniques around this time are no doubt part of the answer ${ }^{4}$, the deliberate

Commission, which had been established - at McGee's own urging - by Roosevelt in 1907 . The IWC epitomized the conservation movement as it applied to water, promoting the view of rivers as integrated hydrological systems providing multiple benefits to society, the rational exploitation of which required coordinated, centralized control of entire river basins. (ibid.:102-109).

${ }^{3}$ After all, water had been used extensively for purposes of navigation, irrigation, and power for thousands of years. McGee knew this. He was aware that prehistoric peoples of North American had constructed "elaborate systems of irrigation" upon which complex agricultural societies had been built (McGee 1895:372-3) and no doubt he knew of the great ancient hydraulic societies of Mesopotamia, China, India, and Egypt. In his own country, water had powered the American industrial revolution in the East. The Erie Canal had been constructed some seven decades earlier, providing a transportation resource between the Hudson and Great Lakes-St. Lawrence drainage basins. Moreover, the Bureau of Reclamation had been established 7 years earlier, had completed or initiated dozens of projects (including the construction of numerous large dams west of the Mississippi) by the time McGee wrote. (See also McGee 1907) So why is water suddenly a "resource" in 1909?

4 The relatively recent advent of hydroelectric power contributed to the "advance" McGee alludes to. Improvements in the design of turbines and the invention of the dynamo and alternating current in the latter part of the nineteenth century had made it possible for people to recognize a new kind of resourcefulness in water by the early twentieth century. Hydro-electricity was seen as one of the hallmarks of a new era, one that Lewis Mumford would later (and famously) describe as "the neotechnic revolution". (1934) There was tremendous excitement as "the mysticism of hydro development" gripped an entire continent and the prospects of exploiting hydro-electrical potential on a large scale, fired the imagination of politicians, industrialists and engineers alike. (Nelles 1974:215-275) This potential was uppermost in the minds of McGee and his colleagues in the conservation movement. (McGee 1911; Leighton 1909; Newell 1920) Nevertheless, water had been famous for generating power (albeit in direct form) for at least a thousand years. (Smith 1975) The growth of hydro-electricity alone, therefore, is unlikely to account for this newfound recognition of "water as a resource." 
naming of water as a resource needs to be seen in the broader context of scientific, economic and political developments that comprise the Conservation Movement in the United States during the first two decades of the twentieth century. It was in this context that water became known to the state in a way that made it an object of calculation and subject to a particular kind of accounting and manipulation, which for McGee and his contemporaries was signalled by declaring water a "resource."

Many accounts of the conservation movement stress its democratic ideal - often expressed as a "crusade" - of serving the interests of the "people" over the interests of the corporations, its "trust-busting" rhetoric, its tempering of the doctrine of laissez-faire etc. However Samuel P. Hays has argued persuasively that the populist rhetoric of the movement belied its main significance. "Conservation, above all," he argues, "was a scientific movement, and its role in history arises from the implications of science and technology in modern society... The essence [of the movement] was rational planning to promote efficient development and use of all natural resources." (Hays 1959:2) Rather than the question of "resource ownership", Hays stresses, the conservation movement was mainly concerned with promoting a rational, efficient regime of "resource use." (1959:262) McGee's proclamation of water as a resource in 1909 can thus be regarded as a proclamation of the need for the scientific management of the nation's waterways, a need that could only be satisfied by the state. 
The single most important prerequisite for achieving scientific water management was to procure a quantitative account of the nation's water. Realizing the "complete control" of water required a capacity to survey the national field, to account for the stocks and flows of available water, and to represent these accounts in a way that was conducive to rational management. James $C$. Scott uses the term "legibility" to describe the means and apparatus by which the state has been able to take command of a vastly complex field and reduce it to a framework and to terms that are actionable by government agencies so as to bring things under control: ${ }^{5}$

"Certain forms of knowledge and control require a narrowing of vision. The great advantage of such tunnel vision is that it brings into sharp focus certain limited aspects of an otherwise far more complex and unwieldy reality. This very simplification, in turn, makes the phenomenon at the centre of the field of vision more legible and hence more susceptible to careful measurement and calculation. Combined with similar observations, an overall, aggregate, synoptic view of a selective reality is achieved, making possible a high degree of schematic knowledge, control and manipulation." (Scott 1998:11)

5 For Scott, "legibility" is "the central problem of statecraft." (1998:2) While his examination of the state and natural resources is directed mainly toward forestry, his analysis could just as well be applied to hydrology and the control of water, particularly in the United States in the twentieth century. (In fact, an earlier draft of Scott's book included a study of the TVA, which unfortunately, is unavailable.) Scott stresses how the "precise measurements of forests" was an elementary aspect of scientific forestry, which emerged in the later half of the eighteenth century in the context of "the centralized state-making initiatives of the period." (1998:14) "The fact is that forest science and geometry, backed by state power, had the capacity to transform the real, diverse, and chaotic oldgrowth forest into a new, more uniform forest that closely resembled the administrative grid of its techniques." (1998:15) The same may be said of the combination of the hydrologic sciences and state power, and the transformation of myriad waters into the uniform stuff impounded in reservoirs and flowing through turbines and irrigation ditches to supply the electrical and agricultural grids of twentieth century America. Moreover, Scott's analysis of the social and ecological implications of scientific forestry applied by the state have parallels in the social and ecological effects of large dams: Monocropped forests were a "disaster" (1998:19) for the people who had been dependent on the ecology of mixed forests, just as drainage projects and the building of reservoirs has often been disastrous for people inhabiting the affected regions; and the ecological degradation of scientifically managed forests, in terms of loss of biological diversity (1998:20-21) is not unlike that of aquatic (particularly riverine) ecosystems subject to hydrologic regulation. 
Scott describes how thoroughly the physical environment has been represented and refashioned by what he calls "state maps of legibility" - models of nature that "rather like abridged maps... represented only that slice of [reality] that interested the official observer." (1998:4) Borrowing Scott's term, in order for water to be brought under control - it had to be made "legible". The usefulness of the hydrologic cycle for this purpose was, as we shall see, exploited after 1931. In the mean time, knowing and representing "precisely how much water was running through the land" became a project to which the federal government devoted considerable attention. (Worster 1985:135) In 1888, Congress authorized the United States Geological Survey (USGS) to undertake the first investigation of water in the West. As head of the Survey, John Wesley Powell took it upon himself to coordinate a massive program of water measurement and accounting. ${ }^{6}$ Powell appointed Frederick H. Newell - known to American hydrologists as "the father of systematic stream gauging" (Nace 1978:22) ${ }^{7}$ - to the task.

Newell's assignment marked the beginning of the Hydrographic Branch of the Geological Survey, which rapidly evolved into a nation-wide program dedicated to

\footnotetext{
6 A quote by Worster (1985:135) offers a good illustration of how this program made water legible to the state, and how this in turn was tied in to an even more ambitious program of social engineering: Its purpose was:

"to identify all lands in the public domain that would be suitable for reservoirs, ditches, canals, or irrigated agriculture... By 9 December, Powell had a corps of young engineering-school graduates learning the art of stream gauging under Frederick Newell's direction... That was the hydrographic branch of the survey. Another group traveled by horse and rail, looking for reservoir sites while compiling a series of topographic maps of every western river basin, beginning with those in Colorado, Nevada, Montana, and New Mexico. First the grand map of the West, Powell decided, with statistics on precisely how much water was running through the land. Then could come the grander scheme, the mapping of a new society."

Also described by Hays as "one of the architects of water policy and of the entire conservation movement" (1959:7)
} 
producing and disseminating data enumerating the country's water resources (Hays 1959:6). "The information thus obtained and widely diffused", Newell subsequently wrote, "laid the foundations for a presentation of the needs and opportunities of water conservation and furnished the facts for action by Congress..."(Newell 1920:149). In other words, on the basis of the hydrological data that was produced, government agencies - particularly the Bureau of Reclamation (of which Newell was named the first director) and later the Army Corps of Engineers - were able to plan and execute their large-scale water development projects.

By 1911, McGee thought it reasonable and expedient to declare:

"Under the federal legislation and administrative operations, water is not only measured more accurately than in any other country but is steadily passing under control in the public interest... The advance in this direction during the last decade has been especially rapid; and though apparently little noted, it is among the most significant in our entire history with respect to knowledge, use and administration of the natural waters." (McGee 1911:822)

The relationship between the hydrographic needs of the state and the development of water science is suggested in noting the contemporary progress in hydrological discipline in the country's universities. In 1904 the first course on hydrology was taught at an American university and the first "textbook" was

${ }^{8}$ The US Army Corps of Engineers had been involved in gathering hydrographic data since 1824. Given the Corps' exclusive focus on navigation at this time however, its work was limited to measurements of low flow and the Corps undertook no responsibility for collecting a wider range of hydrological data pertaining to such things as floods, the availability of water for irrigation and power, the effects of drainage and deforestation on streamflow, etc. "Until the advent of the Geological Survey these wider uses of water remained uninvestigated." (Hays 1959:7) 
prepared to assist in the university instruction of hydrology. ${ }^{9}$ (Reuss 2001a:275) In the first decade of the twentieth century, considerable advancements were thus made in the systematic production of hydrological data, pushed by the emerging science of hydrology in the country's universities and pulled by the growing demands of the state for reliable hydrometric information. Moreover, it is important to stress the specific nature of this data. Like the resources of the land - mainly forests, soils and crops - water was now becoming available to central planners as a quantum. McGee captured this moment in the instant of proclaiming water as a resource:

"Our growth in knowledge of that definite character called science is notable particularly in its ever-multiplying applications... It is in harmony with the general development that the quantitative method is now applied not only to soil production in forests and crops, and to mine production and minerals in the ground, but finally to the rains and rivers which render the land habitable and the ground waters which render it fruitful." (McGee 1909:522, my emphasis)

McGee stressed that thinking of water in fundamentally quantitative terms marked a radical change: "The quantitative view of water, except in smaller measures" he pointed out, "is so new to thought that familiar units are lacking." (1909:523) ${ }^{10}$ Prior to this, water "has been viewed vaguely as a prime necessity, yet merely as a

\footnotetext{
${ }^{9}$ The text referred to was a compendium of course notes compiled by Mead in 1904, which served as the basis for his 1919 text on hydrology, discussed in Chapter 5. (Mead 1919)

${ }^{10}$ McGee's devotion to the quantification of things included his very person. He and his friend and colleague John Wesley Powell, made an extraordinary wager that involved having scientists at the Smithsonian Institution in Washington remove the brains from their skulls and weigh them, posthumously of course. Powell won. Powell's brain can still be found on a shelf at the Smithsonian Institution, where it "rests in a preservative." (Miller 1994:114 and see Figure 1.1). I don't know where McGee's brain is; but recalling our discussion of Descartes in Chapter 1, perhaps it is floating in a vat of water!
} 
natural incident or providential blessing. In its assumed plentitude the idea of quantity has seldom arisen..." (McGee 1909:532) We know that the quantitative approach to water had been a defining feature of scientific (hydrologic) practice for some time. McGee's statement declaring water a resource might then be interpreted as defining the moment when the scientific mode of knowing (modern) water became "official", in the sense of its adoption by the state. The main thrust of his argument was that the state had to adopt a modern, hydrological perspective, so as to adequately read and exploit the resource. Approximately from this time onward, it became one of the primary preoccupations of the USGS and other relevant federal agencies to standardize hydrologic methods, instruments and measures while expanding the scope of investigation to encompass the full range of hydrological phenomena - from precipitation to infiltration, groundwater flow, runoff, streamflow and evaporation. (Langbein and Hoyt 1959:ch. 1)

In the meantime, McGee managed to come up with a unit of measurement that he felt was suitable ${ }^{11}$, and he used it to present a description of "Our Stock of Water" on both the national and the global scales. (524-526) ${ }^{12}$ Representing the "stock of

\footnotetext{
11 The "kilostere", which equals one-thousand cubic metres.

12 Actually, he provides data on flows: "The World Supply", in terms of mean annual global precipitation is reported as 125 billion kilosteres. "The National Supply" totals six billion kilosteres of annual precipitation, which he breaks down regionally between the "more humid two-fifths of the country east of the ninety-fifth meridian", the "semi-arid fifth ... between the ninety-fifth and hundred and third meridians" and "the western two-fifths of the country, including our arid lands..." The total volume of annual national precipitation is reported as being disposed of in the following manner: "Of the total rainfall, over half is evaporated; about a third flows into the sea; the remaining sixth is either consumed or absorbed." (1909:40-41) It isn't clear what the sources for this data are. They are the same data found in the Report of the National Conservation Commission published in the same year, and in which McGee played a leading role. (National Conservation Commission 1909: $21-23 ; 39-45$ ) It would appear as though the figures for "the world supply" are derived from
} 
water" suggests another important reason that water is now considered a "resource": Because water now has a definite "supply", it is now recognized as having a definite limit. Water, in other words, is now susceptible to scarcity, which makes it imperative that it be managed efficiently. So long as we can assume its "plentitude" and regard it as a "natural incident or providential blessing", the idea of scarcity can hardly apply to water, as was ever the case for proponents of the sacred hydrologic cycle. Now considering water in quantitative terms, McGee is compelled to warn, "Our growth in population and industries is seriously retarded by dearth and misuse of water." (1909:532) The "quantitative view of water" therefore renders it naturally scarce. Hence, water has to be "considered as a resource - one definitely limited in quantity, yet susceptible of conservation and of increased beneficence through wise utilization." (McGee1909:522-523)

\section{The Hydrologic Cycle and the "Complete Control" of Water Resources}

The general principles of the scientific management of the nation's waterways were worked out during the time of the Conservation Movement in the early part of the century. However, despite the best efforts of Roosevelt and his conservationist allies, political circumstances were not yet conducive to bringing the nation's waters under central control. Agency rivalry in Washington, political bickering and

Brickner's (1905) calculation of the global water balance. (See Chapter 7, footnote 10) The data for the "national supply" appear to come from a variety of US federal sources, including the Bureau of Reclamation, the Hydrographic Branch of the USGS, and the US Weather Bureau. 
outright hostility to conservationist policies in Congress prevented the Conservation Movement from achieving much in the way of actual policy change with respect to the development of water resources. With some notable exceptions ${ }^{13}$, a backlash against conservationism during the years of Republican control of the White House from 1921 to 1933 held federally-sponsored river basin planning and development in check. (Rogers 1996:50)

It was not until the mid-1930s, under F.D. Roosevelt's New Deal programs, that these projects were put into effect on a large scale, thereby realizing McGee's vision of "complete control" of the nation's waters in several of the country's largest river systems. The Great Depression provided the social circumstances in which significant progress was made in expanding of the role of the state to manage the national economy. Perhaps the single most defining feature the New Deal era was the federal project to take command of the nation's waterways. Harkening back to the vision of the early conservation movement, the resource economist and geographer Erich Zimmermann describes these developments in terms of a "revolutionary change" in attitudes...

... attitudes which imperceptibly emerge from the womb of social philosophy and take on tangible form in rewritten and reinterpreted laws and in revised public policies. In the United States these new attitudes with their tangible aftermath are largely identified with the New Deal. But that is not quite accurate. The roots of the new movement, the origin of the new way of viewing our natural and national endowment of basic assets, reach further back in time, to the conservationists of Theodore Roosevelt's day...

\footnotetext{
${ }^{13}$ Such as the Boulder (later to be named the Hoover) Dam, begun in 1931.
} 
"The crux of the new philosophy is the realization that, in the long run, the magnificent achievements made under private capitalistic enterprise are endangered by inadequate regard for the durable basic assets, natural and cultural, on which all economic life depends, and for the conditions, forces, and processes of nature which underlie all human endeavor...

"In [this] scheme of things, water plays a vital part. If properly cared for, water is the bringer of life; if neglected, it can be the cause of disaster. And it has been neglected by the market-conscious leaders of our economy..."(1951:571-572)

Given this neglect, the central role of the state in developing water resources now became irresistible:

"Here was a vast field in which governments - local, state and federal - could perform prodigious feats without stepping on the toes of private business. If government had not done this long before, it was due partly to incomplete realization on the part of both experts and laymen of this vital necessity, partly to the failure of penny-wise and pound-foolish Congressmen to appropriate the necessary funds. But now all this changed. Business was unable - in the Depression - to take care of the livelihood of large portions of the population. The government had to step in. Here was the golden opportunity to make up for decades, perhaps a century of neglect... (Zimmermann 1951:571-572)

The most comprehensive and ambitious thrust of federal resource strategy was to promote "a unified plan of water control" for the entire nation, based on the philosophy of multi-purpose water planning and integrated development of the nation's river basins. (National Resources Committee 1938:7; Maass 1970:100101) A series of agencies established by the President to coordinate national resource conservation and development - the National Resources Board,19341935; National Resources Committee, 1935-1939; and National Resources 
Planning Board, 1940-1943 - devoted enormous efforts to this undertaking. ${ }^{14}$

"[T]here must be", declared the National Resources Board in 1934,

"national control of all the running waters of the United States, from the desert trickle that may make an acre or two productive to the rushing flood waters of the Mississippi... There is no stream, no rivulet, not even one of those tiny rills which cause 'finger erosion' in the wheat fields of the Corn Belt, that is not a matter of some concern to all the people of the United States." (National Resources Board 1934:255)

It is in the context of the need to account for and control the nation's water resources in the New Deal era that the hydrologic cycle was insinuated in public policy discourse. Following Horton's 1931 paper, a diagram depicting the hydrologic cycle appeared in a 1934 report of the National Resources Board that dealt with the need to rationalize and centralize water planning. (Figure 6.1) "The key to the beneficial control and use of the waters of the country is to be found in recognition of four unities..." the report declares; "Unity of Physical Factors... Unity of Man's Interests... Unity of Responsibility...Unity of Action." (National Resources Board 1934:260-263) Literally in the midst of these declarations of unity - unifying all these principles, as it were - appears the diagram of the hydrologic cycle. Here, the hydrologic cycle is described as a means of conceptualizing "the extremely complex and diverse phenomena producing and affecting the water resources of the country." (1934:292) Recalling the three types of diagram discussed in the last chapter (qualitative, descriptive and quantitative), this appears to be the first

\footnotetext{
14 According to Zimmermann, these agencies, "regardless of trivial changes in name, constituted a single force aimed at developing a policy to safeguard our national resources" and to "plan for the common good." (Zimmermann 1951:6)
} 
example of a "descriptive" hydrologic cycle diagram produced.$^{15}$ As this type has become the most common way of depicting the hydrologic cycle, this might be considered the prototype for what has emerged as a foundational means of representing modern water in popular discourse.

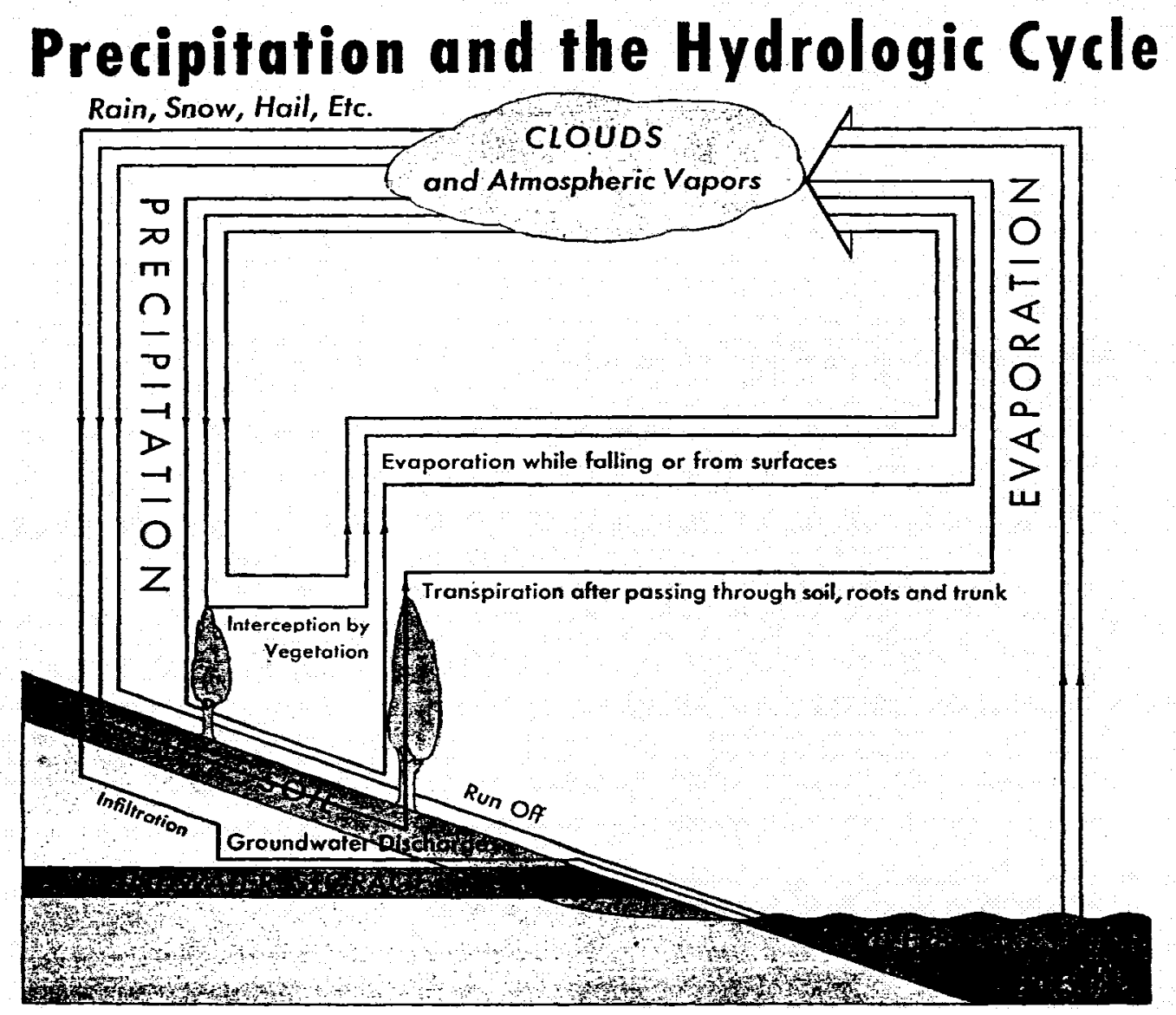

Figure 6-1- "Precipitation and the Hydrologic Cycle" (diagram reproduced from National Resources Board 1934:262)

As a means of making water legible for the administrative purposes of the state, the hydrologic cycle was an ideal concept; it structured an understanding of water for which large-scale engineering solutions to water problems could be seen

${ }^{15}$ See Chapter 5 , footnote 31. 
(literally) as the norm. It also provided a means of visualizing the nation's water in a way that could be used as both a model and an argument for the need to collect comprehensive and integrated hydrometric data. In order to gain "national control of all the running waters of the United States" it was felt by the central planning agencies that the necessary first step was to correct the "Deficiencies in Basic Hydrologic Data" that were felt to pertain throughout the country. (National Resources Committee 1937) ${ }^{16}$ To correct for these perceived deficiencies, the National Resources Committee initiated a program for the nation-wide coordination and standardization of hydrological data gathering. The hydrologic cycle was brought onto this scene as a means of pulling together a vision of what was needed: "Water-conservation measures in the past" declared the Committee, "have been hampered by lack of basic data concerning the hydrologic cycle." (1937:v) Development of water resources depends on "exact knowledge of such factors as rainfall, snowfall, the flow of streams, the level at which water stands in the ground, the rate at which it evaporates or at which it transpires from trees and other vegetation, and the chemicals, suspended matter, or impurities which are found in it." More succinctly, "What we need to Know" is identified precisely as "The Hydrologic Cycle." $(1937: 1,2)$ The diagram accompanying this particular report was titled "How The Water Cycle is Measured." (Figure 6.2)

\footnotetext{
${ }^{16}$ I should point out that this has ever been the case. The state's apparent requirements for hydrological data always manage to exceed - by considerable margin - the quantity and quality of data available. The best example, and discussion, of this shortfall is found throughout Langbein and Hoyt 1959. See also National Research Council 2001.
} 


\section{HOW THE WATER CYCLE IS MEASURED}

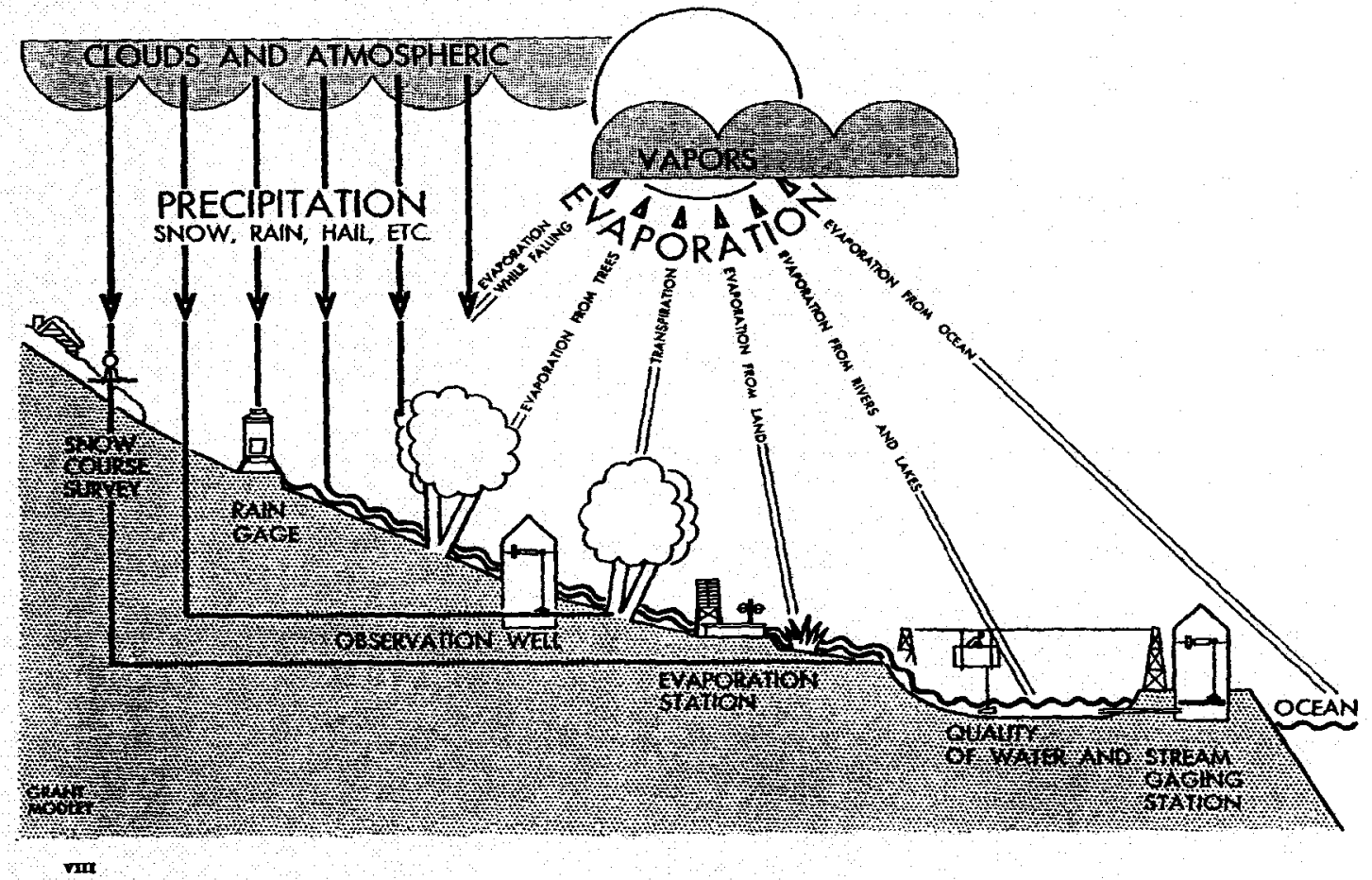

Figure 6-2 - "How the Water Cycle is Measured" (diagram reproduced from National Resources Committee 1937:viii)

As we noted in the last chapter, a slightly altered version of this diagram was reproduced subsequently in the Hydrology Handbook of the American Society of Civil Engineers. (Figure 5.5) The propagation of the hydrologic cycle in the United States can thus be regarded in part as a function of the way it has been traded back and forth between scientific hydrologists and state planners. As already noted above with respect to the teaching of hydrology in the universities, the development of American water resources has been characterized by a very tight relationship between the practice of hydrology and the knowledge requirements of the state. The adoption of the scientific hydrologic cycle by the state, its 
propagation through public policy discourse and its re-entry into scientific

hydrology, provides a good illustration of the dialectical process relating

bureaucratic interests with scientific practice. "Over time," writes V.K. Saberwal,

"one observes a two way process, whereby bureaucracies may use science to

inform a particular rhetoric; at the same time, bureaucratic rhetoric comes to

influence the scientific discourse itself, and, thereby, the very nature of science...."

(Saberwal 1997:311)

\section{Conclusion: Modern Water and the State}

"In the first few decades of the twentieth century," writes Donald Worster, "the command over rivers in the West could hardly be said to have commenced." (1985:194) It began in eamest in the mid-1930s. Given the "revolutionary change" in social attitudes mentioned above, the full potential of water could now be made to serve the people of the United States. The newfound role of the state meant that the enormous multiple-purpose water projects dreamt of by McGee and his colleagues were now feasible. ${ }^{17}$ The water that he and Newell had lamented was

\footnotetext{
17 By the mid-1930s, the use of water to generate electricity became most compelling, and it was this use that financed the large multi-purpose dam projects of the era. There were several reasons for this compulsion: improvements in the design of turbines in the 1920s had significantly increased the hydraulic head at which they could operate efficiently, greatly increasing the potential of hydrogeneration; (McCully 1996:15) improvements in the efficiency of long-distance transmission of electricity (through stepped-up voltage) made hydro-electricity - for which there is usually no choice but to transmit power over long distances - more economical; and increases in the cost of fuels in the 1920s raised the price of hydro's competitors in thermal power generation. (Zimmermann 1951:570) These factors contributed to substantial growth in installed hydroelectric capacity during the 1920s in the U.S. and elsewhere in the industrialized world. It was largely on this basis that, in his seminal treatise on the functional theory of resources published in 1933, Zimmermann devoted an entire chapter to "The New Era of Water Power" (Zimmermann 1933:542-558). In
} 
going to "waste" was finally tractable; with a more active federal state, improvements in technology and legislation permitting the revenues from power generation to amortize the costs of project construction, this water could now be managed for the benefit of the nation.

Beginning in the 1930's, there followed several major water projects intended to engineer the fluvial topography of the United States: the great dams of the Tennessee Valley Authority; the Colorado River Projects; the Columbia River Basin Project; the California water projects (including the Central Valley Project, the Imperial Valley Irrigation District and the California State Water Project). In addition to these projects, flood control became a huge priority and almost exclusively a function of the federal government with the passing of the Flood Control Act of $1936 .{ }^{18}$ With the additional responsibility of flood control, the federal government's authority to contain and command the nation's rivers was exercised in the form of dams and levees thrown up - mainly by the US Army Corps of Engineers - all across the country. ${ }^{19}$ But the most impressive monuments to the state-sponsored hydromania of the era were the series of mammoth dams beginning with the Hoover Dam, completed in 1935 - sewn up and down the

Zimmermann's functional terms: "One of the most valuable byproducts of the development of the electrical industry is the new significance which has been given to water power." (1933:542) 18

Congressional support for the Act came as a result of the need for a political response to the severe storms that had recently hit the Northeast as well as the requirement for public works during the Great Depression. (Reuss 2001b; Langbein and Hoyt 1959:160-161)

19 The Bureau of Reclamation was also a major dam-builder, in respect of its responsibility for federal irrigation projects. But by the time of the New Deal, the mandate of the Corps had expanded from improving navigation to include flood control and river development for purposes other than navigation, such as hydroelectric generation. This wide mandate meant that the Corps usually took the lead role in building the large multipurpose projects of the 1930s and beyond. (Marcus and Segal 1989:255-266) 
Colorado and the Columbia Rivers. (Worster 1985:202-250; Reisner 1986; White 1995) The project of "completing the West's hydraulic regime" was continued in the 1940s, and in terms of total expenditures and the size of structures built, the "Big Dam Era" ${ }^{20}$ reached its zenith in the two decades after the Second World War. Marc Reisner writes, with only a tinge of hyperbole, "In that astonishingly brief twenty-eight year period between the first preparations for Hoover Dam [in 1928] and the passage of the Colorado River Storage Project Act [1956], the most fateful transformation that has ever been visited on any landscape, anywhere, was wrought." (Reisner 1986:172)

The Big Dam Era can be regarded as the zeinith of modern water in the United States. The hegemony of modern water was both a cause and an effect of what Worster terms the "immense ballooning of the state" associated with the production of a twentieth century "modern hydraulic society" in the Western U.S. $(1985: 279,7)^{21}$ After the Second World War, the enlargement of state apparatus associated with building dams and harnessing rivers was rationalized by the apparent need to "secure for the entire country an enhanced international power" in the all-out drive to fight communism. (1985:265) The state, in other words, materialized modern water, while modern water helped build the state in a kind of reciprocal ratchetting process that helped make America the world's greatest

\footnotetext{
20 The term is from Reuss $2001 \mathrm{~b}$.

21 The Bureau of Reclamation, to illustrate the increase in size of the American hydrocracy, mushroomed from two or three thousand to "an elephantine bureaucracy" of nearly twenty thousand employees between 1930 and the late 1940s." (Reisner 1986:152-3)
} 
economic and military power. The Columbia River, to cite a particularly cogent example, was set to providing electricity for the production of aluminium in federal (Defense Plant Corporation) factories used to build warplanes for the Second World War. (White 1995:72-73) The River's contribution to the war effort was immense; "It is safe to say that the war would have been seriously prolonged at the least without the dams." (Reisner 1986:168) And by 1943, the Columbia - which was by far the largest source of electricity in the world at the time - fed the reactors at the Hanford complex as well as cooling them in order to produce the plutonium to fuel the early American nuclear weapons program. (Reisner 1986:170; White 1995:82)

The Big Dam Era also occasioned the more prosaic growth of state apparatus, simply in terms of the vast public resources that became tied up in hydraulic infrastructure. By the 1940s, Americans were boasting of "managing" water more effectively than any other part of the planet. (Worster 1985: 59) By the late 1950s, it was estimated that ten percent of the county's entire national wealth was tied up in "capital structures designed to alter the hydrologic cycle: to collect, divert and store about a quarter of the available surface water, distribute it where needed, cleanse it, carry it away and return it to the natural system." (Chorley and Kates 1969a;b:3) Worster's description of the plumbing of the North American continent is worth citing as a description of the production of modern water on a national scale: 
"It drips endlessly from the roof of North America, from the cordillera of the Rockies, down from its eves and gables and ridges... Put a barrel where it drips, and a second next to that one, and so on until the yard is full. [He then lists dozens of large dams in the American West] Barrel after barrel, each with a colourful name but all looking alike, quickly becoming an industry in their manufacture, with industrial sameness in their idea and use...Everywhere barrels filling in the spring, barrels emptying out again in the dry season. Plink, plink, save, save. It would have been a crime simply to stand by and watch it drip and run away." (Worster 1985:266-7)

By 1980 , virtually every potential site for a large dam in the continental United

States had been developed. (Wescoat and White 2001:161) McGee's vision of the "complete control" of water had been realized by the state, and in the process of its realization, modern water had completely engulfed the nation. In the next chapter, we will consider one way that modern water has been made to engulf the entire globe. 


\section{Culmination: Global Water}

"The water cycle is a global phenomenon. Therefore, water resources are a global problem with local roots." (Nace 1967:551)

"The specific need for international collaboration in hydrology stems from the very nature of the hydrologic cycle." (Nemec 1976:333)

"[l]nternationalism in science, insofar as it really does exist, must be considered a social achievement, not the inevitable consequence of some inherent scientific essence. It has to be worked at." (Livingstone 2003:89)

\section{Introduction}

Part I of this essay is concluded with a discussion of what might be considered the culmination of modern water: the abstraction of the world's water as a quantitative essence that can be described in terms of "global water." The globalization of modern water is an effect of multiple processes and could be approached from many different perspectives. In the last chapter, we considered the mutually beneficial relationship between modern water and the state, and how, in the process of expanding state control of waterways in the United States, modern water was made to engulf the nation. In his environmental history of hydraulic society in the western U.S., Donald Worster described this process as an effect of the America's interior imperial expansion, thus producing "Rivers of Empire." (Worster 1985) As already noted, to the extent that American and other Western powers have been responsible for developing the world's waterways, the globalization of modern water might be approached in similar terms, namely as an 
effect of hydrological imperialism. ${ }^{1}$ However, investigating modern water more specifically as an effect of scientific discourse, requires that a different approach be used here.

In this chapter we will consider global water as having been produced by scientific assessments of the world's stocks and flows of water. These assessments are represented and disseminated in tables, charts and diagrams (see Figures 1.2 and 1.3), and contained on and between the covers of books (e.g. Gleick 1998; 2000; $2002 ; 2004)$ in a way that makes global water seem the natural way of conceptualizing the world's water. From this epistemological perspective, "global water" is, literally, what results when the scientific hydrologic cycle is projected onto the globe. (Figure 7.1) In all its various appearances, global water is a pure abstraction, a universal expression of fixed quantity or quantified flow. The overall importance of global water to my argument is only partly explained by saying that it represents the culmination of modern water; for the impossibility of containing global water within hydrological discourse has resulted in its having mixed with society at large, a mixture that presents a critical problem, as we shall see in Chapter 9.

${ }^{1}$ See sections of Chapter 2 dealing with post-colonial studies of water. 


\section{I. The World Hydrological Cycle}

R. G. BARRY

Institute of Arctic and Alpine Research, University of Colorado

\section{r. Global water and the components of the hydrological cycle}

We begin our consideration of water in the global context with some figures to illustrate the storage capacity of the earth-atmosphere system. The oceans, with a mean depth of $3.8 \mathrm{~km}$ and covering $71 \%$ of the earth's surface, hold $97 \%$ of all the earth's water $\left(1.31 \times 10^{24} \mathbf{c m}^{3}\right) .75 \%$ of the total fresh water is locked up in glaciers and ice sheets, while almost all of the remainder is ground water. It is an astonishing fact that at any instant rivers and lakes hold only $0.33 \%$ of all fresh water and the atmosphere a mere $0.035 \%$ (about $12 \times 10^{18} \mathrm{~cm}^{3}$ ).

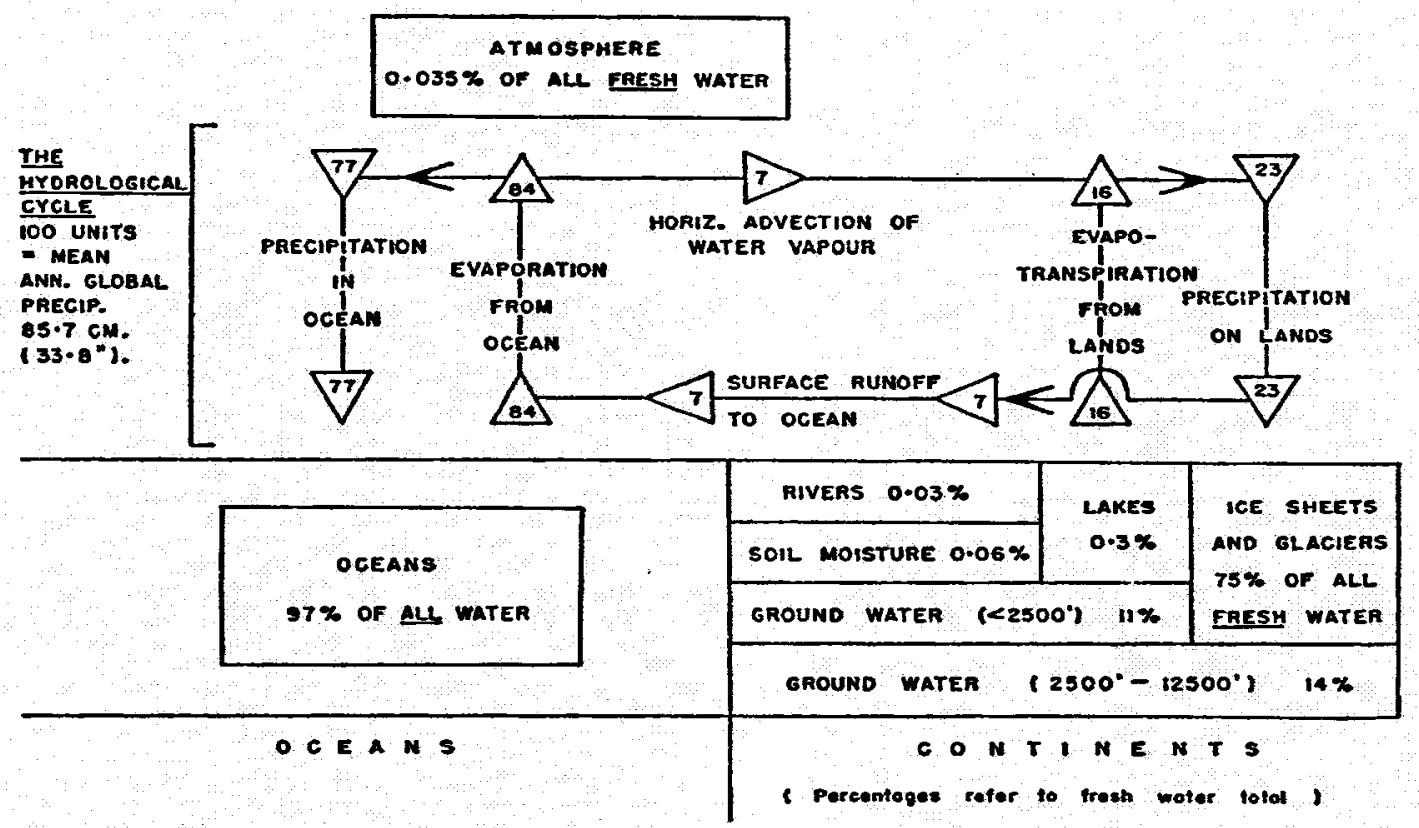

Fig. 1.1.1 The global hydrological cycle and water storage.

The exchanges in the cycle are referred to 100 units which equal the mean annual global precipitation of $85.7 \mathrm{~cm}(33.8 \mathrm{in}$.). The storage figures for atmospheric and continental water are percentages of all fresh water. The saline oceans make up $97 \%$ of all water (From More, 1967). Figure 7-1 - The Hydrologic cycle and the production of global water (page
reproduced from Barry 1969:8) (Note the identification of "global water" in heading I.) 
Where does global water come from? To put the matter into relational-dialectical terms, it is wrung from the application of modern hydrologic practice to the water process on the global scale. Recalling Horton's formulation of a framework for the science of hydrology, the hydrologic cycle accounts for all water, and because it may be expressed in quantitative terms, the hydrologic cycle serves as the fundamental model for calculating global water.

"Any natural exposed surface may be considered as a unit area on which the hydrologic cycle operates. This includes, for example, an isolated tree, even a single leaf or twig of a growing plant, the roof of a building, the drainage-basin of a river-system or any of its tributaries, an undrained glacial depression, a swamp, a glacier, a polar ice-cap, a group of sand-dunes, a desert playa, a lake, an ocean, or the Earth as a whole." (Horton 1931:192)

Global water is produced in its most sophisticated, scientific form when hydrologists address themselves to considering the operation of the hydrologic cycle on "the Earth as a whole." In historical terms, it emerged in a compelling, rather sophisticated form in the second half of the twentieth century, at the confluence of the water process and a concerted effort to promote international collaboration among hydrologists. By the 1990s, "Water of the World" (Nace 1964), "Water as a World Resource" (Chow 1979) "World Water Resources" (Shiklomanov and Rodda 2003), "World Water" (Rodda 1995b) and simply "The World's Water" (Gleick 1998; 2000; 2002; 2004) had become part of our language.

While a product of hydrologic practice, it needs to be added that global water is also an effect of understanding water as a "resource". It is significant that in the 
course of declaring the resourcefulness of water in 1909, McGee offered one of the earliest assessments of "The World Water Supply" in Anglo-American literature:

"The water of the world (or hydrosphere) is about $1 / 600$ of the globe, or some $410,000,000$ cubic miles. Nearly three quarters occupies depressions in the earth-crust as seas; about a quarter, or some 100,000,000 cubic miles, permeates earth and rocks as ground water; the remaining small fraction is gathered in fresh-water lakes and channels, accumulated in snow and ice, or distributed in the atmosphere as aqueous vapor." (1909:524)

It is not just a coincidence that McGee introduced readers to (albeit a rather unscientific rendition of) global water in the same article where he introduced the idea of water as a resource. The idea of scarcity is built-in to all natural resources, and scarcity always implies limits. As the resource geographer Judith Rees has declared, "Once a substance has been defined as a resource, the question inevitably arises as to how much is available for use by man." (1990:17) Defining how much water was available for use by "man" became something of a preoccupation among a number of hydrologists, state planners and international bureaucrats by the 1970s. The more attention was focused on the resourcefulness of water, the greater the interest in assessing the quantity of global water resources. At the same time, the very calculation of global water has actually helped entrench the idea of water as a scarce resource.

\section{From Modern Water to Global Water}

Modern water always contained the seeds of global water. When the early, mathematically inclined geographers, natural philosophers and proto-hydrologists 
addressed themselves to questions of water in general (as opposed to the myriad waters of antiquity), global water was ever a sparkle in their beholding eye. Thus in the late seventeenth century Varenius suggested a method "To compute what Quantity of Water the Earth containeth, and what Quantity of Land" (Varenius 1693:142) $)^{2}$ Several years later, the mathematician and physico-theologian John Keill, attempted to calculate the amount of water the ocean received from the world's rivers in what amounted to an early effort to compute a major component of the global water balance. (Tuan 1968a:99) ${ }^{3}$ Another early attempt to quantify total river discharge into the oceans was made by Count Buffon in the mid-eighteenth century. (Unesco 1971:14)

For the most part however, hydrological phenomena on the global scale were of little interest to the proto-hydrologists, who measured flows for purposes of calculating the water balance of specific drainage basins. Indeed, consideration of global water made its entry into scientific hydrological discourse - especially in the English-speaking countries - only quite recently. In 1923, one of the better-known American hydrologists of the day admitted, "The position occupied by water in the

2 His proposed method is as follows: "For finding out the accurate and true quantity of water and land, first we ought to know both the whole Superficies of the water, as also its depth in divers parts of the Sea: also the subterraneous heaps of water ought to be examined. All which, feeling that we cannot find out by any method, therefore we cannot find out the accurate quantity of water..." Hypothesizing that the superficies of the water is half that of the earth, and the profundity to be a quarter or half a mile, Varenius suggests that it may nevertheless be possible to compute the quantity of water. Unfortunately, he doesn't follow through, admitting too many uncertainties, and also that it is impossible to judge the volume of the "subterraneous heaps of water." (1693:142) In any case, it could not have provided any estimate of freshwater volumes.

${ }^{3}$ This, I must admit, is an exception to the general observation made earlier that the proponents of the sacred hydrologic cycle were not interested in quantifying flows of water. Perhaps such an exception can be granted for Keill, as he was, after all, a mathematician...(!) 
economy of Nature is most remarkable. Everywhere natural conditions are influenced and molded by its wonderful properties, and yet it is nowhere told how much water there is in the world." (Littlehales 1923:69-70) ${ }^{4}$ Even as late as the mid-1980s "the science was strongly dedicated to the river basin, with few hydrologists able to acknowledge that hydrology extends beyond the individual watershed towards a global dimension." (Rodda 1997)

Nevertheless, a "global dimension" of hydrology, and "global thinking" among hydrologists had been maturing in some quarters since around the turn of the twentieth century. McGee's data ${ }^{6}$, for example, presents an estimate of static - as opposed to flow - quantities of ocean and fresh water at the global scale. Earth scientists had made similar estimates since the late nineteenth century. ${ }^{7}$ Because people generally have been less interested in the resourcefulness of ocean water than freshwater, and because freshwater is always in circulation, the static

\footnotetext{
${ }^{4}$ Littlehales indicates a volume of $324,000,000$ cubic miles in the global ocean, but is either unaware, or incredulous of any efforts to calculate global water balance. 5 ut see Chapter 5, footnote 22.

${ }^{6}$ McGee gives no indication where this data comes from.

7

There are two basic ways of measuring, or accounting for global water. The second, by means of global water balance studies is described in the text below. The first, and simplest, is to estimate the total volume of water existing at any one time in the hydrosphere. Given the overwhelming preponderance of ocean water comprising the hydrosphere (about $97 \%$ ), the amount of water on earth is closely approximated to this value. As already noted, as long ago as the late seventeenth century, a method for estimating the total volume of the world ocean was proposed - although not implemented - by Varenius. Interest in calculating the relative volumes of ocean water and fresh water grew in the late nineteenth century, as evidenced for example in McGee's 1909 article. With the advent of echo-sounding surveys of ocean depths in the 1920s, calculations of ocean water became reasonably accurate. By the 1970s, a "highly reliable determination of the volume of the oceans" was considered to apply, largely abetted by a degree of coordinated international hydrological study that had taken place by this time. (L'vovich 1979:14) Also by this time, many hydrologists were satisfied that determination of the combined mass of glaciers and the volume of lake water on earth had reached a reliable stage (1979:15-17), although the volume of groundwater was, and remains, relatively unknown.
} 
approach has long been thought to provide an inadequate account of the water resources available to society (L'vovich 1979:22) A more useful method takes into account the dynamic processes occurring in the hydrosphere that have the effect of constantly renewing water resources. The water balance - the mathematical expression of the hydrologic cycle - has thus provided the concept used by most scientific hydrologists for estimating available water resources in a given region. This was the case from the late-seventeenth-century investigations of Mariotte to determine the size of basin necessary to supply the waterworks at Versailles. (Soullard 2001) And this instrumentality was built-into the nascent science of hydrology; "The central problem" of hydrology, Horton declared in 1931, "is that of determining the physical process and principles and the quantitative relations involved in the hydrologic cycle..." (Horton 1931:199) Not surprisingly, when hydrologists turned their attention to quantifying global water resources, it was the concept of the global water balance to which they turned.

In scientific terms, the calculation of global water began in earnest around about a century ago; the Russian hydrologist E. Ya. Brickner, published the first scientific estimate of world water balance in 1905 (Lvovitch 1972:402; Unesco 1971:14; Baumgartner and Reichel 1972:585) Considering the example of McGee, it is reasonable to surmise that hydrologists' interest in the water balance grew with increasing awareness of the value of water as power-generating resource, 
particularly in an era of growing international geopolitical and economic rivalry. ${ }^{8}$ In any case, following Brickner's work, some 34 global water balance studies by

Russian, German and other hydrologists in the years between 1906 and 1970

have been cited. (Baumgartner and Reichel 1972:585) The most sophisticated of

these was made by Russian (later Soviet) hydrologists. Several reasons may be

given for Russian/Soviet leadership in this field. ${ }^{9}{ }^{10}$ In any case, it was the work of

${ }^{8}$ In a companion piece to McGee's article, M.O, Leighton, Chief Hydrographer of the USGS, argues for the need to develop American hydro-power potential, warning that "The menace to American industrial leadership is already on the horizon" with the construction of hydro facilities in other countries. Future world power, he points out, will depend to a large extent on exploitation of hydro potential: "If we are to place ourselves in an economic position in which we may finally prevail as a world power, our point of view regarding fuel and water power must be changed, and our policies must be altered so that we may wisely prepare to use the vast power resource which we are now neglecting." (Leighton 1909:59, 81)

9

The Russians took an early interest in putting the water balance concept to work in practical terms. L'vovitch points out that the Russian term that translates as "circulation of water" corresponds - albeit not identically - to the Anglo-American "water cycle" or "hydrological cycle", and that it was on the basis of considering the quantitative aspect of this "great process" that early Russian hydrologists worked out calculations for regional and global water balances.(Lvovitch 1972:402) According to a Unesco report, a number of outstanding Russian scientists took a strong interest in the water balance concept in the nineteenth century in their efforts to find the cause of endorheic drainage of the Caspian Sea . (Unesco 1971:14) In any case, it appears that Russian hydrologists were the first to apply, if not develop the water balance equation. The development of the basic equation for river basins $(P=R+E)$ around the turn of the twentieth century was instrumental in the calculation of the global water balance (1972:405-8). Usually known as the Penck-Oppokov equation, after the Austrian and Russian hydrologists credited with its invention, L'vovitch argues that it was rather Brickner than Penck who deserves credit for its invention in the last decade of the nineteenth century: "That is why justice would demand the major formula of water balance to be named [the all-Russian] Brickner-Oppokov's equation." (1972:408) In any case, it is widely acknowledged that, "First to present a general scheme of the global hydrological cycle was Bruckner [sic]." (Unesco 1971:14)

The influence of V.I. Vernadsky's pioneering work in global systems is likely to have sparked further development of global hydrology in the early years of the Soviet Union. (Bassin 1997) It was building on the foundation of earlier Russian and Soviet hydrological investigations that hydrologists such as Kalinin, Budyko, and Korzun as well as L'vovich produced the world's most sophisticated and accurate methods of assessing the global water balance. According to L'vovich, researchers working in the hydrology division of the Geography Institute of the Soviet Academy of Sciences developed methods that yielded hydrological information in circumstances where "hydrological data were very scanty." (L'vovich 1979:v) The production of this information was made necessary by the demands of the Soviet system of central economic planning. As L'vovich and other Soviet hydrologists improved their techniques for producing information on the hydrology of the vast territory of the Soviet Union, they began to apply their methods on a global scale. Writing in 1974, L'vovich explained: "Because information available about sizable parts of the earth is less complete than the information available about other parts..." the Soviet "kind of approach... has to be taken 
Soviet hydrologists, including Kalinin (1971) and Korzun et al. (1978), but especially L'vovich (e.g.1979), that set the standard for global water balance studies when these began to attain scientific credibility among Western hydrologists the 1960s and afterwards. (Nace 1979:iv; Dooge 1984:156-7; Rogers 1985:260; Rogers 1990:234; Gleick 2001) L'vovich himself sums up the history of the development of global water balance concept from the time of the protohydrologists to the recent present as follows (managing to insinuate the importance of his own method):

"The forerunners of the methods that provide modern knowledge of water resources of the world's continents... appeared at the beginning of our 300-year period. In subsequent years, a general view of the water cycle as atmospheric precipitation equaling the sum of evaporation and river runoff was elaborated and refined. By the middle of the twentieth century, a six-component method represented a new stage in water balance studies. It interprets the process of the water cycle in a broader and deeper framework. At first, this method was used for studying and evaluating the anthropogenic transformation of water balance, and, later on, for making global water balance maps." (L'Vovitch et al. 1990:236)

to hydrological studies of the earth's water balance and water resources." (L'vovich 1979:v; see also Korzun et al. 1978:7-9) Notwithstanding an early U.S. study of the global water balance (van Hylckama 1956), American hydrologists who took an interest in global water in the 1960s relied for the most part on Soviet sources for methods and data. (Barry 1969:17)

10

in calculating the global water balance may be associated with the entrenchment of the idea of water as a resource in the Soviet Union. While I have focused attention (in Chapter 6) on the emerging resourcefulness of water in the United States in the twentieth century, water was formally conceptualized, intellectually abstracted and materially developed as an economic resource in the Soviet Union to an extent that is widely recognized as having done extensive ecological damage, with the dehydration of the Aral Sea being perhaps the most infamous example. An ideological emphasis on the resourcefulness/instrumentality of nature was reflected in Russian and Soviet science. Vernadsky, for example "envisioned humankind as having the potential through science and technology to control even the biogeochemical cycles, albeit within the limits set by the biosphere." (Kates et al. 1990:2) 


\section{Global Water Goes West: The International Hydrological Decade 1964-1975.}

"If the International Hydrological Decade has done no more than force the countries of the world to look at their water on the world scale as a commodity they must inevitably share, and it has done much more than this, it will have justified the effort that has been made." (Sutcliffe 1972)

Prior to the 1970s, American and English hydrologists showed little interest in the global water balance. ${ }^{11}$ This began to change with the work of an American hydrologist, Raymond L. Nace, whose reading of a 1945 paper by L'vovich sparked a life-long personal interest in global hydrology. (Nace 1979:iv) Nace, a staff hydrologist employed by the US Geological Survey, who happened to read Russian, became a leading interpreter and proponent of global hydrology in the West. He authored numerous scientific and popular articles as well as government reports that built on the work of L'vovich and other Soviet hydrologists to present a picture of the availability of world water resources to English-speaking readers. (especially Nace 1964a, 1964b, 1967; 1968; 1969; 1972; 1978; 1979) Nace's work came to fruition in the International Hydrologic Decade (IHD), an international scientific programme that Nace himself was instrumental in founding. ${ }^{12}$ Through

\footnotetext{
11 An exception is found in the work of van Hyickama (1956), the first American effort to calculate the water balance for the earth's continental areas.

12 Along with fellow American hydrologist Walter Langbein and L.J. Tison, head of the IASH. Nace put a proposal for the IHD forward in 1962 in his capacity as special advisor to the ad hoc Panel on Hydrology of the Federal Council of Science and Technology. (United States 1962:24-37; see also Nace 1967:554) Nace's summary of the program's purpose is worth citing: "The purpose of the proposed international program is to strengthen the whole science, to broaden the base of world water facts, and to advance understanding of hydrologic processes, all leading to improved ability to bend the forces of nature to the benefit of man." (United States 1962:27) (See Nace 1972 for a kind of interim report )
} 
this international collaborative effort, global water gained a measure of credibility in Anglo-American scientific circles that had been lacking earlier.

Systematic efforts to coordinate hydrologic practice on an international basis had already begun in the 1920s and helped provide an institutional foundation for the more refined collaborative exercises of the post-war era. From its inception, the International Association of Scientific Hydrology (IASH), founded in 1923, was dedicated to the international standardization of methods, measures and instruments used to measure water in the hydrosphere. (Section Internationale d'Hydrologie Scientifique 1924) Such coordination was hardly unique to hydrology; IASH was formed as a subsidiary association to the International Union of Geodesy and Geophysics, which had been established in 1919 to promote coordination of physical, chemical and mathematical studies of Earth and its environment in space. ${ }^{13}$ Historians of science have identified such coordinating and standardizing activities as characteristic of the practice of "gathering the world together", a practice that has given scientists "the power to shape the way the world was put together, not least by their role in condensing the earth to the scale of a chart or an index or a catalog." (Livingstone 2003:171-177; see also Latour 1987:224-5; Golinsky 172-182) While the production of charts, indices and catalogues of world water would not become routine until decades later, this early

\footnotetext{
${ }^{13}$ Website of International Union of Geodesy and Geophysics (IUGG) http://www.iugg.org/eoverview.html - accessed August 23, 2005.
} 
work of the IASH helped lay the groundwork for the scientific calculation of global water in the post-war years.

After the Second World War, Nace authored a proposal that was adopted by the IASH, and which eventually resulted in the International Hydrological Decade (IHD), a ten-year programme of international scientific hydrological study that came under the aegis of Unesco. ${ }^{14}$ While a scientific exercise in the sense that it sought to improve the capacity to produce objective, scientific assessments of world water, the nature of the water that inspired these proposals was expressly that of a "resource", and one that was definitely limited in quantity: "These proposals" wrote an important proponent of global hydrology, "undoubtedly corresponded to a specific need - in many countries the public and hence the governments were becoming aware of the scarcity of water and the difficulties of developing new sources of supply." (Nemec 1976:335) Or, as put by another of the leading hydrologists of the late twentieth century, the purpose of the IHD was "to promote international cooperation in the field of hydrological research and education as a means for achieving a full assessment of the world's water resources and a more rational use of them." (Dooge 1984:154) Or, as put by another, the IHD was "man's first concerted attempt to take stock of his diminishing available resources of water in face [sic] of expanding population and rising

\footnotetext{
14 Mention can also be made of the International Geophysical Year (1957-8), a program of scientific cooperation among $\mathbf{4 0}$ of the more developed countries, during which some of the gaps in global water information were identified. (Nace 1967:552)
} 
standard of living and to coordinate world-wide research on ways of making better use of these resources." (Chow 1979:3)

The International Hydrological Decade facilitated dialogue among hydrologists from different countries and between international agencies with an interest in hydrology, advanced a measure of international coordination of hydrological education and standardization of methods, and identified important gaps in hydrological knowledge, particularly in developing countries. But most notable for our purposes was that it advanced international study of the global water balance, described by Nace as "an inventory of the total amount of water in the Earth system and its movement through the global hydrological cycle." (Nace 1967:555) In particular, it brought the latest global water research of Soviet hydrologists to the attention of the international hydrological community and advanced discussion of how the latest computer and remote sensing techniques could be applied to produce improved global hydrological data.

The global water studies and data produced under the auspices of the IHD were published so as to reach the widest possible audience among professional hydrologists and water experts worldwide. The most significant accounting of global water to emerge during this time was "World Water Balance and Water Resources of the Earth" prepared by the USSR Committee for the International Hydrological Decade in 1974 and published in English by Unesco a few years later. (Korzun et al. 1978) Drawing from the global water balance investigations of L'vovich and other Soviet hydrologists, this was arguably the definitive statement 
of world water, and remained so into the 1990s. (Dooge 1984:156; Maidment 1993:1.3-1.6; Jones 1997:ch.2) Other global water resource assessments published in English around this time, which the IHD was critical in helping inspire and disseminate, include (Nace 1969; Kalinin 1971; Baumgartner and Reichel 1972; and L'vovich 1979.

Despite these developments, the global dimension of hydrological thought was slow to pervade the science. Writing in 1983, one hydrologist, J.T. Houghton, observed:

"It is only recently that hydrologists have begun to think in global terms, largely because it is only recently that meteorological information with global coverage has become available and that theoretical models of global extent have been developed. This global thinking is at an early stage. Greatly improved data and much better formulations of physical processes are required before further progress can be made." (Houghton 1983:2)

It was not until the 1990s that the concept of global hydrology had become much more widely accepted among the community of western hydrologists. In his preface to a 1997 textbook on "global hydrology" - the first of its kind - John C. Rodda, President of the International Association of Hydrological Sciences wrote:

"Of course, a text entitled Global Hydrology would have been impossible to publish twenty or even ten years ago. Then the science was strongly dedicated to the river basin, with few hydrologists able to acknowledge that hydrology extends beyond the individual watershed towards a global dimension. But for a number of reasons this has all changed during the last decade and the science has 'gone global'." (Rodda 1997:xi) 
Although Rodda does not elaborate, part of the reason for hydrology "going global" is no doubt due to improvements in the quality and quantity of data on parameters such as groundwater and surface streamflow, evapotranspiration and precipitation in different parts of the world. Another factor behind the globalization of hydrological discourse was the growth of an international network of water professionals and experts that promoted a common discourse for accounting and governance of the world's water. Taking root in the 1970s (towards the end of the International Hydrologic Decade), this network gained momentum in the 1980s, partly through the International Hydrologic Programme, coordinated by UNESCO, which followed the IHD and had the general mandate of continuing the international collaboration among hydrologists that had begun under that earlier program. Other key developments were the establishment of the International Water Resources Association (IWRA), a membership organization for water professionals founded in 1972, the "routinization of global water conferences, world congresses, and international meetings of experts" by the 1980s, and the establishment of professional water publications such as Water International (published by IWRA beginning in 1975), World Water in 1978, International Journal of Water Resources Development in 1983, and Water Policy in 1998. (Conca 2006:132, 135-7) As Ken Conca has noted, a proliferation of "professional membership organizations, specialized publications, professional journals, international congresses, technical meetings and issue-oriented global summits on 
water" in the 1980s and 1990s gave rise to a new discourse of "global water governance". (2006:131) $)^{15}$

Thus by the early 1990s, global hydrology was no longer an oxymoron in the West. Global hydrology and study of the hydrologic cycle on the global scale became a key component of the coordinated international scientific enterprise associated with the study of climate change. Moreover, it was on the verge of being taken up and repackaged for lay English-speaking audiences by writers who were increasingly concerned with the specter of a looming worldwide water crisis.

\section{Conclusion}

When the landmark publication, Man's Role in Changing the Face of the Earth, appeared in 1956, the section dealing with water included nothing on the global water balance, on quantities of global water resources or on the impending danger of water scarcity facing humanity. (Thomas et al.1956) Thirty-five years later, its sequel, The Earth as Transformed by Human Action presented the latest global water data in the context of a general discussion of the "Scarcity of Water" (Rogers 1990:234-237) as well as an article (with L'Vovitch as lead author) that approached

\footnotetext{
15 In addition to these factors, there is another possible explanation for the popularity of global water in the 1990s: the geopolitical sea-change that had occurred during the years intervening between Houghton and Rodda's observations might have had an influence on how global water circulated. The collapse of the Soviet Union and the end of the Cold War had had the effect of freeing a number of Soviet hydrologists - who practiced hydrology in the tradition and with the methods of L'vovich and his contemporaries - to work in the west for the United Nations and other agencies. As a matter of speculation, these geopolitical changes might also have had the effect of freeing the inhibitions of scientists working in places like the United States and England who might formerly have been disinclined to accept Soviet methods.
} 
the "Use and Transformation of Terrestrial Water Systems" using the framework of the global water balance. (L'Vovitch et al. 1990) As I have attempted to show, the proliferation of global water in the intervening period can be explained in large part by the deliberate coordination of hydrological practice on an international scale beginning in the early part of the century and given a substantial push in the late 1960s and early 1970s with the International Hydrological Decade.

"[l]nternationalism in science..." to repeat the quote from Livingstone in the epigram at the top of this chapter, "must be considered a social achievement, not the inevitable consequence of some inherent scientific essence. It has to be worked at." (Livingstone 2003:89) But bringing global water to the attention of the public was not just a matter of the work of hydrologists; it also required, and was inspired by, growing concerns about the scarcity of global water resources that rose to prominence in the later part of the century. By the late 1990s, the work of hydrologists had become fused with these concerns to present the image of a mounting global problem:

"There is a growing concern over the future of the world's water resources. A series of world water assessments, starting with the classic work of L'vovich (1979) and the fundamental work by Falkenmark ... onwards to the latest freshwater assessments ... have convincingly shown that humankind is, through increased pressure on finite water resources, heading towards a water resources scarcity." (Rockstrom 2003:70)

We will return to this concern of "heading towards a water resources scarcity", a concern that has been expressed very widely in terms of a "global water crisis", in Chapter 9. But first, before dealing with this crisis in more historical terms, we 
need to review the nature of modern water - this time from a more philosophical perspective. This will help explain why global water - and modem water generally - is so potently capable of producing a crisis. 


\section{Part II - The Constitutional Crisis of Modern Water}




\section{The Constitution of Modern Water}

"We are so used to taking it for granted that we find it difficult to develop clear and specific ideas on the nature of water" (Zimmermann 1933:102)

"Indeed, we have become so accustomed to the presence of water in our daily life that it has been a long time since we have questioned its existence." (Goubert 1986:21)

"Invisibility is indeed the height of conquest" (Goubert, from The Conquest of Water 1986:26)

\section{Introduction}

So far, we have explored various aspects of what I have presented as a history of modern water. In Chapter 2, we interpreted a diverse body of research as suggesting the need to consider the modern, Western mode of relating to water much as historians, ethnologists, cultural ecologists and others have considered the place of water in other cultures. In Chapter 3, we initiated an investigation of the social nature of modern water by considering its specific history; we surveyed a variety of premodern waters and examined how these were reduced to "the essential idea of water itself" through modern scientific practice, focusing particularly on modern chemistry and hydrology. In Chapters 4 through 6, we explored the concept of the hydrologic cycle from a variety of historical perspectives in an effort to show its contribution to modern water. The essence of this relation can be described by saying that the hydrologic cycle helps constitute the way modern water is represented while at the same time, the production of 
modern water as a "resource" to be managed by the state both relies upon and reinforces the hydrologic cycle as a way of representing and realizing the nature of (modern) water. Finally, in Chapter 7, we considered modern water's culminating act in the form of "global water", an abstraction - or hydreification - that internalizes the practice of global hydrology.

Here, we shift from modern water's history to a more philosophical examination of what I will call its "Constitution." The articulation of modern water with people - the way modern water relates to people - now becomes a particularly important part of my argument. I want to explore why, although it was certainly produced in relation to social (particularly scientific) practice, modern water is nevertheless taken to be independent of social relations; this fictional independence is at the core of its Constitution. The Constitution holds together only so long as the fictional independence of modern water is upheld in hydrological and popular discourse. The increasing difficulty of maintaining this fiction is now manifest in what can be seen as a worldwide movement against the hegemony of this discourse. It is in this sense that (modern) water may be considered to be in "crisis": the Constitution is breaking down under the strain of having to acknowledge that water and society inevitably bleed into one another.

I won't lose sight here of the relational-dialectical approach to water that I have employed throughout the essay. However, in addition, I will introduce the concept of hybridity, drawn mainly from the sociologist of science, Bruno Latour. Hybridity 
suggests a concept and a metaphor that is helpful when trying to conceptualize things as neither and both natural nor/and social. Several difficulties are involved in combining dialectics with Latour's method, and this is a question to which I shall return in the concluding chapter. (In brief, while it is most useful for understanding how it is that we have come to accept some things as natural and other things as social, Latour's approach does not provide us with a very practical means of changing either.) For the purpose of this chapter however - which is to gain an understanding of the epistemological commitments that are necessary to sustain modern water - I will frequently employ the concept/metaphor of hydrosocial hydbrid in place of hydreification.

Something of a precedent for blending relational-dialectical and Latourean hybridity to elaborate the social nature of water is found in the work of the economic geographer, Eric Swyngedouw. Swyngedouw's studies of the modernization of hydraulic society in Spain (Swyngedouw 1999) and the urbanization of the hydrologic cycle in urban waterworks (Swyngedouw 1996; $1997 ; 2004)$ are underlain by an approach that combines dialectical reasoning with hybridity to produce a view of water that is at once social and natural.

Swyngedouw's combined approach is represented in the following passage from his most recent book on the urbanization of water:

"The production process of socio-nature embodies both material processes and the proliferating discursive and symbolic representations of nature. Therefore, if we maintain a view of dialectics as internal relations as opposed to external recursive relationships [which forces us to] transcend the binary formations of 
nature and society and develop a new language that maintains the dialectical unity of the process of change as embodied in the thing itself. 'Things' are hybrids or quasi-objects (subjects and objects, material and discursive, natural and social) from the very beginning. By this I mean that the 'world' is a process of perpetual metabolism in which social and natural processes combine in a historical geographical production process of socio-nature, whose outcome (historical nature) embodies chemical, physical, social, economic, political and cultural processes in highly contradictory but inseparable manners." (2004:21)

Like much of Swyngedouw's writing, this passage is as difficult to comprehend as it is insightful. In the discussion that follows, I hope to remedy the former quality while not sacrificing the latter.

\section{The Modern Constitution}

"Water has been critical to the making of human history..." stresses Donald Worster: "To write history without putting any water in it is to leave out a large part of the story. Human experience has not been so dry as that." (1985:19) The point that I wish to make here is very similar; I too want to stress the futility, or the misapprehension of separating water from human history, although I would like to alter Worster's terms somewhat: Human history, I would say, has (also) been critical to the nature of water; to talk about water without including its social and historical ingredients is to leave out a large part of the story. Water is never so pure as that.

A useful means of exploring water's essential impurity is though the philosophy of Bruno Latour. Latour's work is well known outside the field of the sociology of scientific knowledge, or "science studies" as he calls it, particularly for his 
elaboration (with others) of ideas that have helped give rise to actor-network theory (ANT). (Hubbard et al. 2002:193) Here I don't want to engage with ANT, but am rather interested in Latour's diagnosis of the modern predicament. In his essay, We Have Never Been Modern, (Latour 1993) Latour identifies a set of rules by which humanity/society and nature have been separated in modern thought and held apart from one another conceptually and discursively. ${ }^{1}$ Under what he calls the "Modern Constitution", this separation is upheld in a philosophical and discursive sense, but is nevertheless belied by the proliferation of real entities that combine the two - Latour calls them hybrids - that increasingly pervade the modern world. It is upon recognition of the hybridity of the (by)products of modernity, Latour argues, that a kind of crisis ensues.

In the broadest terms, Latour wants to transcend what he sees as the current intellectual impasse, a "crisis" arising from the inability of either natural science, social science or poststructural criticism to adequately recognize/analyse/comprehend and respond to a host of contemporary (modern) problems and circumstances. Examples of such problems include the hole in the ozone layer; the simultaneous global spread of the AIDS virus and the efforts by officials, chemists, biologists, patients and industrialists to respond to it; the moral dilemma of keeping "frozen embryos" for later use; and the loss of forest biodiversity. (Latour 1993:1-2) These problems and circumstances combine

\footnotetext{
1 To illustrate the conceptual separation of people and nature in modern discourse, it might be useful to note that many (especially aboriginal, i.e. non-European) languages do not have a word "that translates even roughly into our 'nature'." (Scarce 2000:3) Nature has become an important category only in modern Western thought: "Non-Western cultures", Latour points out, "have never been interested in nature; they have never adopted it as a category; they have never found a use for it." (Latour 2004:43)
} 
nature, society and discourse in ways that elude the conceptual grasp of any one of these three traditional approaches; they are, as Latour argues, "simultaneously real, like nature, narrated, like discourse, and collective, like society." (1993:6) In order to develop a stance from which it is possible to analyse these problems in their full complexity, Latour argues is necessary to put modern society (he calls it "nature-culture") under the microscope, much as anthropologists have studied other, premodern nature-cultures. (1993:7) Only once we have reflected on the fundamental epistemological commitments of modern society can we consider what it might mean to get beyond the dilemma that we find ourselves in.

Latour thus sets out to investigate "what does it mean to be modern?" (Latour 1993:8) "Being modern", he argues, means subscribing to a particular Constitutional formulation of the relationship between nature and society. First, this Constitution posits a radical separation between these two categories. "Nature and Society" under the Modern Constitution, "must remain absolutely distinct." (1993:32) There is nothing particularly novel about this observation. ${ }^{2}$ A common

\footnotetext{
2 This characteristic of modernity has been stressed by many others, writing from different perspectives, and it may be taken as something of a critique of Latour that he does not acknowledge this: I'll just cite four examples: First, Glacken's (1967) history of ideas of nature devotes considerable attention to how, beginning in the seventeenth century, increasing awareness of the damages inflicted by human agency in the physical environment led to the sense that "man was going his own separate way" from nature - and how this marked a departure from the prevalent notion of mankind and the changes wrought by mankind in the physical environment as irreducibly part of nature. (Glacken 1967:particularly Chapters 3, 7, 10, 14) Second, Smith's (1984) Marxian-inspired analysis of bourgeois representations of nature - which he calls "the ideology of nature" that has made it appear, as Castree and Braun have pointed out, "resolutely external to society." (1998:7) Third, environmental historians, to make a rather gross but nonetheless valid generalization, have shown how nature is far more a product of human history not only in a physical sense, but also in a conceptual and discursive sense, than has been acknowledged. To quote one of its leading figures,
} 
theme in social theory is to distinguish "the modern secular and rational social universe" by its disembeddedness from nature and from the lifeworld. (Lansing 1991:8). But perhaps because he is more interested in the events that he sees undermining the modern social universe, Latour goes much further, arguing that this separation has been false from the beginning: In effect, while we moderns insist that nature and society are radically pure, or distinct (a process that he calls "purification"), we constitute both nature and society by combining the two (a process that he calls "mediation", or "translation"). Thus nature "has always existed and has always already been there", yet at the same time, the modes by which we discover its secrets and laws are "fabricated" in scientific practice: "Despite their artificial construction...(such is the phase of mediation or translation), the facts completely escape all human fabrication (such is the phase of purification.)" (Latour 1993:30,31) As for the other (social) half of the contradiction, "human beings, and only human beings, are the ones who construct society and freely determine their own destiny" as demonstrated by the work of purification. (1993:30) But "despite its human construction [society] infinitely surpasses the humans who created it, for in its pores, its vessels, its tissues, it mobilizes the

\footnotetext{
"'nature' is not nearly so natural as it seems. Instead, it is a profoundly human construction. This is not to say the nonhuman world is somehow unreal or a mere figment of our imaginations - far from it. But the way we describe and understand that world is so entangled with our own values and assumptions that the two can never be fully separated. What we mean when we use the word 'nature' says as much about ourselves as about the things we label with that word." (Cronon 1995b:25)

Fourth, drawing largely from the work of Michel Foucault, poststructuralist accounts of the construction and the effects of discourses of nature have drawn attention to how "discursive relations infuse our relation with nature at every turn, including even at the micro-level of knowledge and practice." (Castree and Braun:1998;17) Latour may perhaps be distinguished from all of these in illustrating that/how the world refuses to behave in the manner decreed by the Modern Constitution, as evidenced in the proliferation of hybrids.
} 
countless goods and objects that give it consistency and durability...as demonstrated by the work of mediation." (1993:31)

As Latour points out, these ways of formulating the relationship between nature and society "are contradictory, not only mutually but internally, since each plays simultaneously on transcendence and immanence."(Latour 1993:31) This double contradiction of the Modern Constitution enables the moderns to, in effect, get away with the impossible: "They are going to be able to make Nature intervene at every point in the fabrication of their societies while they go right on attributing to Nature its radical transcendence; they are going to be able to become the only actors in their own political destiny, while they go right on making their society hold together by mobilizing Nature." (1993:32) The Modern Constitution, in other words, gives us license to transgress the boundaries between nature and society while insisting that they (we) are not doing so; as Latour puts it, the Constitution "makes it possible to do everything without being limited by anything." (1993:32)

The result of this transgression is the proliferation of things, problems, circumstances, that combine nature and culture: "hybrids." But because of the Constitutional imperative that "Nature and Society must remain absolutely distinct", we fail to - indeed we cannot - recognize these hybrids as such. "The essential point of this modern Constitution is that it renders the work of mediation that assembles hybrids invisible, unthinkable, unrepresentable... the modern 
Constitution allows the expanded proliferation of the hybrids whose existence, whose very possibility it denies." (Latour 1993:34)

To bring this brief description of Latour's Modern Constitution around to a conclusion, it is the very proliferation of hybrids that has now reached the point where the Constitution itself is threatened, precipitating an intellectual "crisis." For a time, they "posed no problem because they did not exist publicly and because their monstrous consequences remained untraceable." (Latour 1993:42) But the Constitution has been in force for so long, and has permitted such a profusion of hybrids, that the situation is no longer tenable: The modern Constitution" Latour argues, "has collapsed under its own weight, submerged by the mixtures ...The diagnosis of the crisis with which [he began his] essay is now quite clear: the proliferation of hybrids has saturated the Constitutional framework of the moderns." $(1993: 49 ; 50-51)^{3}$

\section{Adding Water to the Modern Constitution}

Having outlined Latour's Modern Constitution, I want to consider how it might it be applied to formulating a Constitution for modern water. The con-temporality of the

${ }^{3}$ Swyngedouw's gloss of Latour offers a slightly different interpretation:

"The separation [of nature and society under the modern constitution] worked at the epistemological level, that is as a way of understanding the world, and as such has indeed managed to produce knowledge. The problem with this epistemological perspective, once it became hegemonic, is that it eventually turned from a dominant epistemology to a dominant ontology, that is a strong belief that the world was actually ontologically split into things natural and things social. This translocation of epistemology into ontology was not of course without profound social, political, and cultural implications... As Latour argues, the proliferation of 'hybrids' permits (and even necessitates) everyone (including scientists) to see the impossibility of an ontological basis for such a separation. Their very existence is proof of the flaw of such an argument." (2004:14) 
Modern Constitution and modern water is auspicious: Latour locates the historical origins of the Modern Constitution in the mid-seventeenth century, specifically in the outcome of an intellectual dispute between Robert Boyle (known mainly as a key figure of the so-called Scientific Revolution) and Thomas Hobbes (known mainly as a political philosopher who made an important contribution to the idea of the modern state). ${ }^{4}$ The chronology here is worth noting, as it corresponds closely to the period when proto-hydrologists (such as Perrault and Mariotte) began the work of purifying modern water - i.e. of eradicating the social nature of water and divesting it of its cultural content.

Latour's Modern Constitution effects a radical distinction between what it is to be modern and what it is to be premodern, a distinction that Latour characterizes in terms of the "Great Divide." (Latour 1993:198-99) By this distinction, premodernity (including all contemporary non-western or non-modern cultures) tends to be regarded by moderns as failing to subscribe to the fundamental Constitutional separation of nature and culture. Thus, in our anthropological and historical investigations of other cultures, we recognize a seamless coextension of society and the lifeworld, between nature and culture, that can hardly be applied to the investigation our own (modern) society. "[]]t is impossible to do with our own culture - or should I say nature-culture? - what can be done elsewhere with others. Why? Because we are modern. Our fabric is no longer seamless... For traditional anthropologists there is not - there cannot be, there should not be - an

\footnotetext{
4 In locating the origin of the modern constitution in this dispute, Latour draws from a study by science studies scholars Steven Shapin and Simon Schaffer (1985).
} 
anthropology of the modern world." (1993:7) Of course, writing "an anthropology of the modern world" is more or less what Latour is up to. By revealing the contradictions (one might say the sleight of hand) of the Modern Constitution, this very distinction by which moderns hold themselves to be different from others, is shown to be false, suggesting that we might indeed apply the same kind of critique to ourselves as we apply to them. The significance of this conclusion for our purposes is to suggest that while it may appear to have been rendered asocial, modern water is as deeply embedded in the social fabric of modern western culture as the tanks of southern India or the subaks of Bali are embedded in those cultures, and that modern water may be analysed as such.

We can begin by considering in what sense modern water is (dis)embedded from/in the social fabric and what are the implications of this paradox. In the representations of modern water considered so far - including $\mathrm{H}_{2} \mathrm{O}$, the world water system, the water tables and the hydrologic cycle - there is no evidence of people, including the people who made it possible to represent water in such an abstract manner. Following Latour's formulation, however, we know that the absence of people is only apparent - while it appears to be entirely natural, modern water is nevertheless thoroughly imbued with human intention. Latour's elaboration of the Modern Constitution illustrates this paradox by revealing how the scientific practices in which the 'facts' of nature are fabricated (the work of translation) insist on the asocial, ahistorical nature of these 'facts' (the work of purification). As Latour puts it "even though we construct Nature; Nature is as if we did not construct it." (1993:32) A formulation such as this allows "Water Facts" to speak 
volumes "For the Nation's Future", to quote from the title of an important assessment of the hydrological sciences in the United States. (Langbein and Hoyt 1959) Since the facts are construed as having been revealed scientifically as objective statements, they can safely be put to work without fear of disrupting the hydrosocial conditions in which they were produced.

The Constitution thus allows us to do anything with water, and imagine that we can get away with it, intact. This fallacy is belied by a host of hybrids that blend water with people in ways that are now recognized as unhealthy, or "unsustainable". Perhaps the most easily recognized among these hybrids are the myriad forms of anthropogenic water pollution extant; but they would also include the dams, diversions and other structural fixes that have come under increasing political pressure as much for their social and human costs as for their environmental impacts. (See Chapter 2) Despite the implicit challenges that these more obviously harmful hybrids pose to modern water itself, the prevailing response has been to separate waste at the source, to adopt a "new water paradigm", to wage campaigns of "water use efficiency," and develop technical programs to extract "more crop per drop" - measures that if anything, tend to reinforce the fixture of modern water by prevailing on people to use it with greater mathematical efficiency instead of addressing the social relations that produce specific cases of pollution and waste in the first place. Also, as with attempts to fix the water pollution and supply problems by technical means, efforts to reconstitute water as a commodity or as an economic good, are presumed to solve a host of water efficiency and 
availability problems without necessarily debouching a flood of disruptive social consequences.

To conclude this section, I want to take the various strands of the discussion above to set out several epistemological commitments entailed in the Constitution of Modern Water, commitments that I will put in terms of four clauses. The Constitution, I might add, begins to unravel as soon as any of the following commitments - especially the first - comes under criticism:

Clause 1 -Water and society are separate and must remain absolutely distinct.

Clause $2 a-$ People make water what it is while maintaining that it is as if water were natural. Social practice, in other words, is dissolved in water, the modes by which we discover its secrets and represent its essence are fabricated in scientific practice (examples are $\mathrm{H}_{2} \mathrm{O}$ and the hydrologic cycle).

Clause $2 b-$ In making water what it is, human society is affected, while maintaining that it is as if society were independent of hydro-social relations. Water, in other words is dissolved in society - "human history is wet" (to paraphrase Worster), human society, "in its pores, its vessels, its tissues, it mobilizes" water, to quote Latour again (Latour 1993:31).

Clause 3 - This double contradiction "makes it possible to do everything [with water] without being limited by anything." (1993:32) In other words, society can do 
what it will with water while maintaining the (mis)apprehension that society itself remains unaffected.

Clause 4 - The result of this transgression is the proliferation of water hybrids, but because of the first clause, "Water] and Society must remain absolutely distinct", these are not recognized as such. Water resources, water-as-commodity, water scarcity combine social and hydrological reality, but are seen and treated as though they corresponded to the nature of water.

\section{The Constitution and the Hydrologic Cycle}

"Man and the hydrological cycle' is a story in itself..." (Nace 1964:18)

Having specified modern water's Constitution will prove useful in the next chapter, when it comes to describing the crisis that it has gotten itself into. For the time being, I want to show how this Constitution relates to some of the earlier arguments of this essay - particularly those that identified modern water as having been constituted in scientific practice and modes of representation. To illustrate the relevance of modern water's Constitution to the science of water, I will consider how it relates to the hydrologic cycle. ${ }^{5}$

5 Swyngedouw (2004) uses the term "hydrosocial cycle" to describe the social nature of water circulation in urban environments and more generally, he uses the term to indicate the hybridity of water. This section perhaps provides something of an elaboration of the meaning of such a term. 
The hydrologic cycle is constituted by two moves that correspond to the Constitution of Modern Water:

First, the hydrologic cycle effects the banishment of people so as to produce an objective representation of nature. The hydrologic cycle, as Horton defined it, is "the course of natural circulation of water in, on and over the Earth's surface." (Horton 1931:192) As already discussed, such a move was necessary to establish hydrology's credentials as a natural science: "As a pure science, hydrology deals with the natural occurrence, distribution, and circulation of water on, in, and over the surface of the Earth." (Horton 1931:190) The hydrologic cycle could thus be seen as consistent with the first clause of the Constitution, dividing the world of nature from the world of society, a constitution that enables science to represent and speak for nature. (Latour 1993:Ch. 2; Latour 2004:13-15)

However, while the hydrologic cycle was thus constituted as "a great natural system" (Chorley and Kates 1969a;b:3), it was in fact adulterated by the presence of humans from the very start, a move that corresponds to clause 2a of the Constitution. Humans can be found lurking in even the most ostensibly uncontaminated sections of Horton's paper, defiling the purity of the water balance equation (See Figure 5.2):

"There is a simple basic fact involved in the hydrologic cycle:

Rainfall $=$ Evaporation + Runoff

(Inasmuch as most persons think of evaporation in a more restricted sense, it is better to define runoff as equal to rainfall minus water losses. Water-losses are of 
three kinds, all evaporative in their nature: (a) Interception; (b) transpiration; (c) direct evaporation from soils and water-surfaces.)" (Horton 1931:190)

Horton's use of the term "losses" to describe various kinds of evaporation is important. Evaporation is not a "loss" to the hydrosphere, to non-human nature or to the hydrologic cycle. It may be considered a "loss" only by those for whom the available water flowing in rivers, stored in lakes or held in aquifers is what really counts - in other words, those for whom water is seen as a resource. ${ }^{6}$ The use of the term "losses" to describe those phases of the hydrologic cycle perceived as being of no immediate use to humans has been very common in hydrological discourse. (Klemes 1988:20) "Losses" reveals the central contradiction of the hydrologic cycle - it is purported to be something entirely natural that is nevertheless suffused with human intention. This contradiction is at the root of hydrology's occasional, if not perennial, identity crisis ${ }^{7}$ occasioned by a science inspired by a pure vision of the nature of water that nevertheless has a hard time extricating itself from the practical interests and affairs of the state. ${ }^{8}$ The hybridity

\footnotetext{
${ }^{6}$ Newell's Water Resources: Present and Future Uses gives a particularly good illustration of this attitude. His chapter on "Evaporation" begins as follows: "A force is at work day and night, summer and winter, steadily robbing water from lakes, streams, trees, animals, and all objects that contain it...Man's ability to use water in all of its varied forms and applications is confined largely to that portion of it which is left after evaporation has taken its full share." (Newell 1920:65)

7 This is discussed in Chapter 5 above.

${ }^{8}$ The extrication effort is manifest in statements like that of Dooge (quoted in Klemes 1988) that "The business of hydrology is to solve the water balance equation." But given the implication of people in the hydrologic cycle, this may be an impossible proposition. Railing against what he sees as the practical orientation of hydrology and struggling for an explanation for its failure to develop along the lines of a pure science, Klemes opines that "hydrologists have not been brought up to be motivated by curiosity and so solve nature's puzzles." (Klemes 1988:20) However the problem is perhaps less the lack of imagination among hydrologists than that 'nature's puzzle' is produced in human discourse.
} 
of the hydrologic cycle cannot but give rise to a certain amount of confusion among those for whom the natural and the social must remain categorically distinct.

The hydrologic cycle is perfectly legal under the Constitution of Modern Water in the sense that it internalizes both the water process and hydrologic practice. Thus, "hydrology" is defined in a classic hydrology textbook as "the science that treats of the various phases of the hydrologic cycle." (Wisler and Brater 1959:3) Here the hydrologic cycle exists independently in nature, as something that scientific hydrologists can thus "treat of" objectively. But, on the very next page, we find that the "hydrologic cycle...provides the groundwork upon which the science of hydrology is constructed." (1959:4)The circularity of this formulation - the hydrologic cycle providing both the groundwork on which the science of hydrology is constructed as well as the object of its investigations - illustrates its simultaneous transcendence and immanence, the basic contradiction of modern water.

As intimated by research that was reviewed in Chapter 2, the ghostly presence of people in the hydrologic cycle is now becoming manifest in a way that makes it more and more difficult to maintain the Constitution. In Horton's time, however, and until quite recently, this separation authorized all manner of human intervention in the hydrologic cycle without presenting a constitutional challenge. Thus, the hydrologic cycle served as a framework in which "man" could safely situate his interventions without fear of producing radical socio-ecological dislocation. (To 
paraphrase Latour, it 'made it possible to do everything with water without being limited by anything.') As the overarching framework and principle of scientific hydrology, the hydrologic cycle constituted a group of experts formally schooled in the abstraction and accounting of water. These experts were instrumental in the "improvement" of rivers, the impoundment of runoff, and all other hydrologic manipulations contributing to the monumental twentieth century project of altering "the natural circulation of water". So long as this intervention could be seen as a matter of "improving" something that remained external to society, the project could proceed without risk to water, people or the Constitution that held them apart.

The sense of this risk-free manipulation of water is reflected in Harold E. Thomas' ${ }^{\prime 9}$ contribution to the 1955 symposium on "Man's Role in Changing the Face of the Earth":

"[F]or the hydrologist, there is a need to know as accurately as possible the modifications that man makes in the hydrologic cycle - past, present, and future - in the hope that man can progressively increase his ability to modify the hydrologic cycle to his advantage. By working with nature, adapting his needs to the natural cycle or adapting that cycle to his needs, man can obtain the greatest beneficial use of the water resources." (Thomas 1956:556) ${ }^{10}$

\footnotetext{
9 A groundwater hydrologist working with the USGS

${ }^{10}$ As noted above, a little over a decade later, it was estimated that fully "ten percent of the national wealth of the United States is found in capital structures designed to alter the hydrologic cycle: to collect, divert and store about a quarter of the available surface water, distribute it where needed, cleanse it, carry it away and return it to the natural system." (Chorley and Kates 1969 a and b:3)
} 
In effect, what Thomas does is situate "man" both outside, and inside, "this natural circulation of water" (1956:544), the only (im)possible position from which he is able to make "modifications in the hydrologic cycle" without having to worry about changing the nature of water or himself. (See Figure 8.1)

With its simultaneous presence and absence of people, it is no problem to depict the hydrologic cycle in a way that features structural works such as reservoirs, water treatment plants, etc., without raising potentially dangerous questions about the overlapping of the world of water and the world of society. Even the instruments that hydrologists have used to measure precipitation, streamflow, evaporation etc. can be shown (Figure 5.5) without having to acknowledge that it is by virtue of such instruments and the disciplined coordination of the measurements they record that the hydrologic cycle has been constructed in the first place; the recording of such measurements is understood merely as a matter of observing the nature of water. Because the hydrologic cycle is regarded as "one of nature's grand plans", as Langbein and Hoyt proclaim, "there is clearly enormous profit in knowing as much about it as possible" (Langbein and Hoyt 1959:3) without having to acknowledge that such knowledge actually reflects human interests and intentions rather than the nature of water itself. 


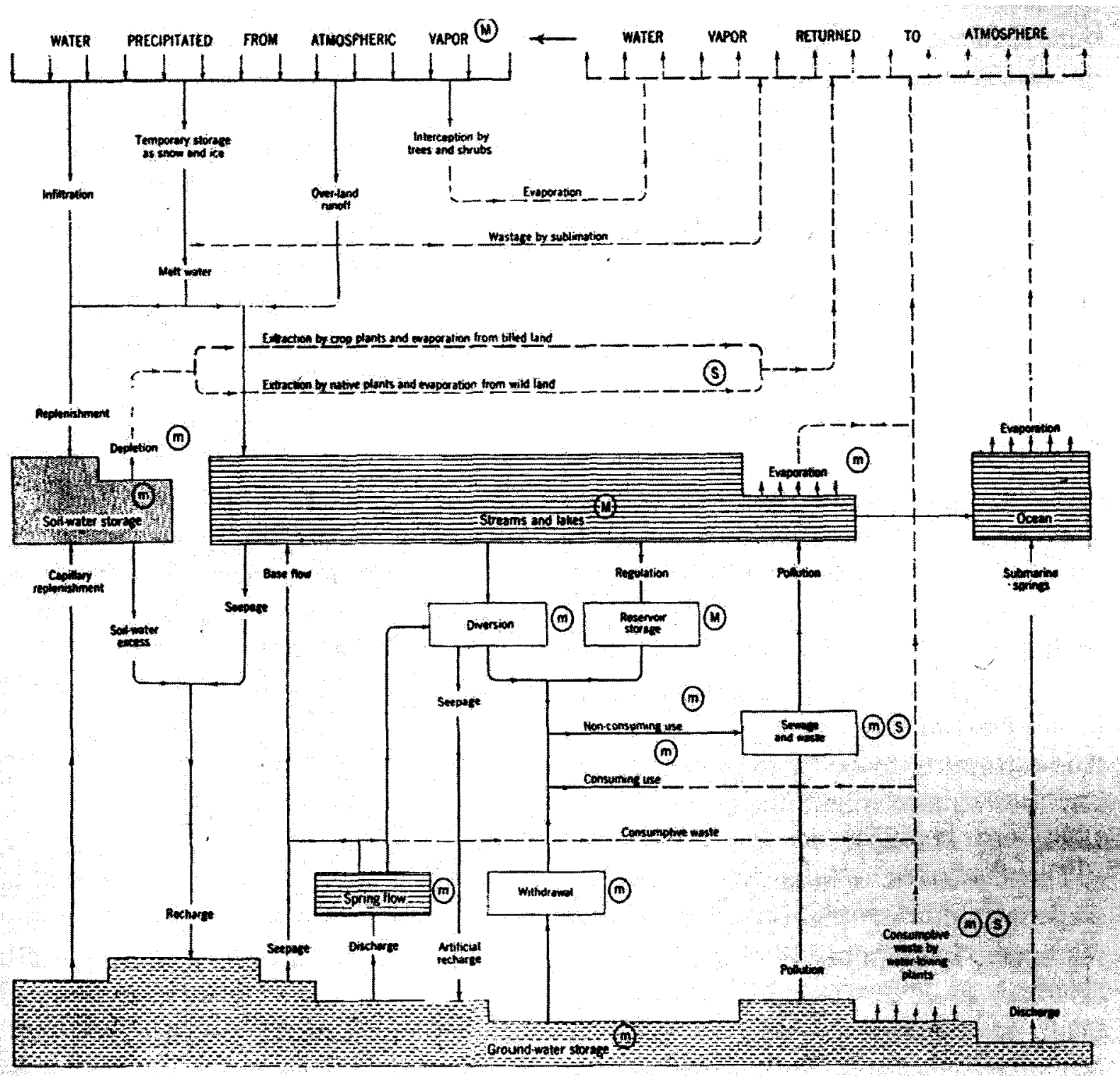

Fic. 111.-Water's complex pattern of circulation

Figure 8-1-Can you find the people in this picture? ("Water's complex pattern of circulation", reproduced from Thomas 1956:545).

By the 1970s, awareness of the unintended consequences of human impact on the physical environment produce a change in the way people and the hydrologic cycle came together. For the most part (and as suggested in the quote by Thomas 
above), this relationship had been seen as benevolent; it was humanity's natural task to "improve" waterways and promote "the rational management of water resources." (Jiaqu 1987) Now however, the agency of "man" was increasingly regarded as being harmful. Thus the growing attention that was paid to "Man's Impact on the Hydrologic Cycle" and "Man's Influence on the Hydrologic Cycle." 11 While the appearance of environmental problems (as hybrids) might then have forced reform of the basic Constitution, this wasn't the case. Despite what might have been regarded as a challenge to the integrity of modern water, the environmental changes perceived in the 1970 s only strengthened its Constitution, as evidenced by the hydrologic cycle's remarkable resilience in the face of our depredations.

Even today, the hydrologic cycle retains its robustness. Its identity as something that may be modified and improved with impunity is definitely a thing of the past. However, rather than challenge the hydrologic cycle itself, the strength of modern water's Constitution is such that it has, if anything, become naturalized to an even

\footnotetext{
${ }^{11}$ By the mid-1970s, "man" had begun to find his situation in the hydrologic cycle rather uncomfortable. He therefore began to define the relation in a slightly different way. Instead of merely improving it to his advantage he now saw himself as "impacting" it and "influencing" it. The shift was perceptible by the latter part of the International Hydrological Decade. "The Influence of Man on the Hydrological Cycle" was the title chosen by the Coordinating Committee of the IHD for an leading study in 1972. (Pereira 1972) A key symposium organized in 1974 by IAHS-UnescoWMO was titled "Effects of Man on the Interface of the Hydrological Cycle with the Physical Environment" (Fournier 1974:v) And see also Dooge et al. (1973). It could be added that eventually, the situation became so unbearable that "man" even changed his identity and became "humans", or "human society". Describing the growing "human impact on the hydrologic cycle" the National Research Council in 1991 suggested that "It was the dramatic color photographs of the earth in space...that crystallized active interest in the interconnectedness of nature and in the changes being wrought by humans. This realization has found its way into contemporary views of the interactive role of man in the hydrologic cycle." (NATIONAL RESEARCH COUNCIL 1991:45) My main point however, is that throughout it all, the basic integrity of "man" "humanity" or "human society" and the waterproofness of the hydrologic cycle have remained fundamentally intact.
} 
greater extent. Today, the objective is no longer to modify and improve the hydrologic cycle as it was in 1956, but to maintain its "integrity":

"A working definition of sustainable water use... is the use of water that supports the ability of human society to endure and flourish into the indefinite future without undermining the integrity of the hydrological cycle or the ecological systems that depend on it." (Gleick 2000a:131)

"The thesis conveyed by these pages is simple. Nature is the source of water; therefore our ability to support additional human lives on planet Earth depends upon the protection of nature and the continued operation of the water cycle." (Hunt 2004:1)

In respect of the analysis made above, it might be said that maintaining the integrity, and continuing the operation, of an abstraction such as the hydrologic cycle is bound to present serious constitutional problems - problems almost as serious as those arising from our efforts to modify it to our advantage.

\section{Conclusion}

The project of modifying the hydrologic cycle has everywhere given rise to social and ecological problems that were unforeseen by those for whom water was taken to be separate and distinct from society, in accordance with the Clause 1 of modern water's Constitution. Because we have made water what it is while maintaining that it is natural (Clause 2), we have imagined it possible to do anything with water without being limited by anything (Clause 3 ). The proliferation of hydrosocial hybrids like water pollution, canalization of rivers, salination of soils, countless examples aquatic ecosystem degradation, groundwater depletion, 
alteration of the hydrologic regime and river diversions - all made possible under the pretension of the risk-free exploitation of modern water (and the hydrologic cycle) - has come back to haunt us in various unexpected ways (Clause 4). But because of the first clause, "Water] and Society must remain absolutely distinct", these hybrids are not recognized as such. The urge to purify the realm of water and that of society is reflected in the most recent, and inevitably futile, calls to respect, protect and sustain the integrity of the hydrologic cycle.

Like nature itself, the hydrologic cycle has always served to bolster someone's social and political agenda. Whether as an argument in support of the providence of a Christian God, a means of constituting an exclusive body of knowledge workers, a framework for legitimizing and coordinating state intervention in the nation's rivers, or an argument for the universal application of techniques of efficiency in a post-industrial world, the hydrologic cycle has served as a powerful ally. But the effectiveness of such an ally is ensured only so long as its Constitution holds. As an acolyte of modern water, the hydrologic cycle functions only if it is seen as categorically separate from and independent of the ambitions of those who variously seek to define, measure, modify or protect it. Upon the first clause of modern water's Constitution rests its legitimacy and its utility.

In the next chapter, we will consider the possibility that this Constitution has begun to unravel and that it can no longer be upheld. The "scandalous" (to use Latour's term) problems to which it has given rise - the effects of translation and mediation 
that it has so long authorized - are proliferating and becoming obvious in a way that make it no longer tenable. 


\section{Modern Water in Crisis}

"When it comes to water, nature has dealt a difficult hand." (Postel 1999:3)

'Where 'global thinking' is concerned [environmentalists] have come up with nothing better than nature already composed, already totalized, already instituted to neutralize politics." (Latour 2004:3)

\section{Introduction}

For the purpose of establishing a date, the publication of Peter Gleick's Water in Crisis: A Guide to the World's Fresh Water Resources in 1993, marks the moment when a certain wave swept ashore, flooding the popular imagination as well as the academy with a conviction that something was fundamentally wrong with respect to the world's water. (Gleick 1993a) This wave had been building at sea for some time; much of what I have written so far is an effort to describe its morphology, its birth, its incubation and the process by which it was made to swell within scientific and more popular discourse. As with many storm surges, most people were unprepared for its landing. Some - especially those living in North America - might have recalled a similar cataclysm in the 1960 s, and there were periodic repercussions that occurred thereafter. But few were prepared for the water crisis of the 1990s, a crisis that shows no sign of abating:

The water crisis is real. If action isn't taken, millions of people will be condemned to a premature death. According to the World Water Development Report, a [major] UN survey... population growth, pollution and climate change are conspiring to exacerbate the situation. Over the next two decades, the average supply of water per person will drop by a third. Heightened hunger and disease will follow. Humanity's demands for water also threaten natural ecosystems, and 
may bring nations into conflicts that - although they may not lead to war - will test diplomats' skills to the limit. (Aldhous 2003:251)

"MAKE NO MISTAKE: THE WORLD WATER SUPPLY IS IN CRISIS, and things are getting worse, not better. In spite of the many grandiose plans made by the United Nations and other international bodies since the 1970s, the basic issues have yet to be tackled in practical terms. The situation will continue to worsen until effective action is taken on a worldwide basis." (Clarke and King 2004:19)

It is a widely known fact that the world has plunged itself into an ever deepening "water crisis". The term is now commonly used in academic and popular discourse. The most recent edition of the Fontana Dictionary of Modern Thought includes an entry under "water crisis". (Goudie 2000a:916) In this chapter, we will consider this crisis as it was presented in the early 1990s. We will also consider an important historical antecedent, a conviction held by many in the 1960 s, especially in the United States, that a general condition of water scarcity loomed on the horizon of America's future. This precedent is important because the "global" water crisis of the 1990s emerged mainly from the pens of American writers, and was founded on the same presuppositions and discourses of the earlier crisis.

I should make it clear that the purpose of this analysis of the water crisis hardly to argue that there is no crisis; what I want to do is suggest a different way of framing it. The water crisis, as it has been presented in academic and popular discourse, presumes the naturalness of modern water. Making this presumption, we are bound to interpret things like "the average supply of water per person" in terms of an inviolable external relation that inevitably gives rise to a critical situation. In this sense, I will argue that modern water has itself created the conditions of its own 
crisis, and rather than a water crisis, what we are facing is the crisis of modern water. Framing the crisis in this way suggests that we need to change the way we think about water, which is the subject of the following chapter. Here, my main purpose to identify the unmarked presence of modern water in the conventional crisis discourse. At the risk of repeating myself, this critique is not meant to denigrate the important and thoughtful work that has drawn the world's attention to a wide variety of real and growing water problems. ${ }^{1}$ These problems are real, but they may be framed in alternative ways. With a few exceptions ${ }^{2}$, there has been very little critical examination of the water crisis. While the social dimensions of other environmental issues appearing on the global scale - including climate change, desertification, deforestation and

1 Any critical approach to water problems must be constrained by the fact that, as one hydrologist succinctly puts it, "Water is the most fundamental ingredient of all life on Earth; it is more universally necessary even than free oxygen." (Jones 1997:2) Or to put it in a slightly different way, water is one of "the features of the world which we can not afford to ignore." (Soper 1996:23) That a great many people lack access to sufficient quantities of low-cost, clean water; that millions of children die every year from preventable water-borne diseases and that many more millions live in conditions whereby 'natural' disasters involving water (e.g. droughts and floods) transmogrify into instances of immense social trauma and personal tragedy. According to the World Health Organization, about 1.7 million deaths are caused annually by contaminated water, most of which are accounted for by children who die as a result of dehydration from diarrhoea caused by ingestion of faecal bacteria. A 1997 report published by the United Nations claimed that between 5 and 10 million deaths annually are attributable to contaminated water, and that half of all people in developing countries suffer at any given time from disease caused by drinking foul water or eating contaminated food. (Clarke and King 2004:12) These are hydrosocial realities demanding responsive and innovative action at all scales of political activity. Hence the many well-intentioned and at least partly successful coordinated efforts to address such problems, the most recent of which is the United Nations' "Water for Life" Decade for Action launched in March 2005. (United Nations, Secretariat of UN-Water 2005) My point isn't to denigrate these efforts, but to suggest that the habits of thought and the fixed discourses engendered by and reflected in modern water actually constrain the breadth of possible and desirable responses that might otherwise be considered.

2

Stott and Sullivan (2000), Biro (2002), and Conca (2006) might be cited as exceptions. 
biodiversity loss - have been examined from critical perspectives ${ }^{3}$, the water crisis has been largely taken for granted as an inevitable and obvious consequence of growing human populations, increasing affluence and limited physical water supplies. One explanation for this lack of critical attention is the hegemony of modern water, because modern water is so natural for us, it is difficult to make out the extent to which it is responsible.

\section{For an instant crisis, just mix people and water}

The root of the notion that the world is facing a crisis of modern water is the recognition that modern water does not mix well with people, especially in their abstract, statistical guise as 'population.' Modern water, as I hope to have shown when elaborating its Constitution, may be considered a hydrosocial hybrid that nevertheless purports to have nothing whatsoever to do with people. Modern water would not present much of a problem if only it could be contained on the remote side of the levee separating water from society. But as is so typical of our contemporary predicament, the levee is full of holes, and water has got mixed with people in ways that make modern water difficult to sustain. After having spent 300 years incubating as a rarefied, socially disembedded concept, when re-introduced

${ }^{3}$ Some of these have already been discussed in Chapter 2, particularly in the section dealing with the political ecology of water. See Forsyth $\mathbf{2 0 0 3}$ for a good summary critical assessments of these issues in the political ecology tradition. In addition, for critical sociological analyses of global environmental issues see Taylor and Buttel 1992; Buttel and Taylor 1994;Wynne 1994; Yearly 1996. A very good indication of what I mean by an examination of the social dimensions of global environmental problems is reflected by Buttel and Taylor who have argued that "the 'global construction' of environmental issues is as much a matter of the social construction and politics of knowledge production as it is a straightforward reflection of biophysical reality." (Buttel and Taylor 1994:232) 
to society, especially in its culmination as global water, a kind of constitutional crisis ensues ${ }^{4}$ And as a constitutional crisis, the problem can only be resolved by reconstituting water.

All that is required for a crisis is to recombine modern water with people. An article aptly titled "Troubled Waters" appearing in the Observer Magazine in 1993 provides an illustration of what I mean:

"All land-bound life has to share one ten-thousandth of the planet's water. Less than three percent of the world's water is fresh, and more than three-quarters of that is frozen, mainly at the poles. Ninety eight percent of the rest lies deep underground.

The tiny fraction that remains should still, in theory, be more than enough. Every year about 27,000 cubic miles of rainfall on the continents, enough to submerge them under two and a half feet of water. But nearly two-thirds of it evaporates again, and two-thirds of what is left runs off in floods. Even the remaining 3,400 cubic miles of rainfall could still sustain more than double the world's present population - if only it would fall evenly where people live. But while Iceland gets enough rain every year to fill a small reservoir for each of its quarter of a million inhabitants, Kuwait, with seven times as many people, scarcely gets a single drop to share between all of them.

In all, 26 of the world's countries - including many of those in Africa and the Middle East - get less water than they need. Over the next 30 years another 40 nations are expected to join them, as their populations outstrip rainfall. The number of people affected is expected to grow tenfold from the present 300

\footnotetext{
4 I want to acknowledge my debt to Latour, who sees ecological crises as manifestations of a general "crisis of objectivity". Environmental crises, he points out, "are never presented in the form of 'crises of nature.' They appear rather as crises of objectivity, as if the new objects that we produce collectively have not managed to fit into the Procrustean bed of the two-house politics, as if the 'smooth' objects of tradition were henceforth contrasted with 'fuzzy' or tangled objects that the militant movements disperse in their wake. We need this incongruous metaphor to emphasize to what extent the crisis bears on all objects, not just on those on which the label 'natural' has been conferred - this label is as contentious, moreover, as those of appellations d'origine controlee. [The environmental movement] thus does not reveal itself owing to a crisis of ecological objects, but thorough a generalized constitutional crisis that bears upon all objects." (Latour 2004:20)
} 
million to three billion - one-third of the projected population of the planet." (quoted in Yearly 1996:50)

Here we have modern, global water presented (in the first paragraph), which actually appears to constitute a very serious problem all by itself! Such is the inevitable outcome of what has been described in Malthusian terms as "the gloomy arithmetic of water" when presented as a tiny fraction of a fraction of a fixed quantity. (Figuertes, Rockstrom and Tortajada 2003:229) It has already been pointed out (in Chapter 6) that merely by virtue of its quantification, modern water is distinguished by a general susceptibility to scarcity. The ability to quantify the amount of the world's freshwater in relation to the total amount of water on the planet yields a ratio that ineluctably produces a rather startling picture:

"Quantitative studies of the distribution of water", we read in the latest edition of Encyclopaedia Britannica, "have revealed that an astonishingly small part of the Earth's water is contained in lakes and rivers. Ninety-seven percent of all the water is in the oceans; and, of the fresh water constituting the remainder, three-fourths is locked up in glacial ice and most of the rest is in the ground." $\left(15^{\text {th }}\right.$ ed. $17: 580, \mathrm{my}$ emphasis) Thus the mere quantification of the world's water establishes the possibility in which scarcity becomes manifest. I want to describe this as the latent scarcity of modern water. Modern water cannot help but be latently scarce, a condition that is repeated frequently in representations of the world's water. (Figure 9.1; see also Figure 1.1) 
It is this latent scarcity that lends greater credibility to the statement by environmental writer and water expert Sandra Postel cited above, that "When it comes to water, nature has dealt a difficult hand." (Postel 1999:3) Such a statement, it might be pointed out, is the antithesis of the idea of the "well-watered earth" propounded by the adherents of the sacred hydrologic cycle. But neither the natural, latent scarcity of water nor the concept of the well-watered earth reflects water's reality so much as the way different nature(s) and water(s) may be invoked to support different arguments or points of view. ${ }^{5}$ The point in making water out to be naturally scarce is to drive home the argument that the hydrosocial predicament facing mankind is deadly serious, just as the point in stressing its timeless circulation is to argue for the providence of the Creator. Both of these arguments are equally valid.

${ }^{5}$ Alluding to the modern constitution of "a two-house politics in which one house is called politics and the other, under the name of nature, renders the first one powerless", Latour puts this point more strongly: "From now on, whenever people talk to us about nature, whether to defend it, control it, attack it, protect it, or ignore it, we will know that they are thereby designating the second house of a public life they wish to paralyze." (2004:18-19) 


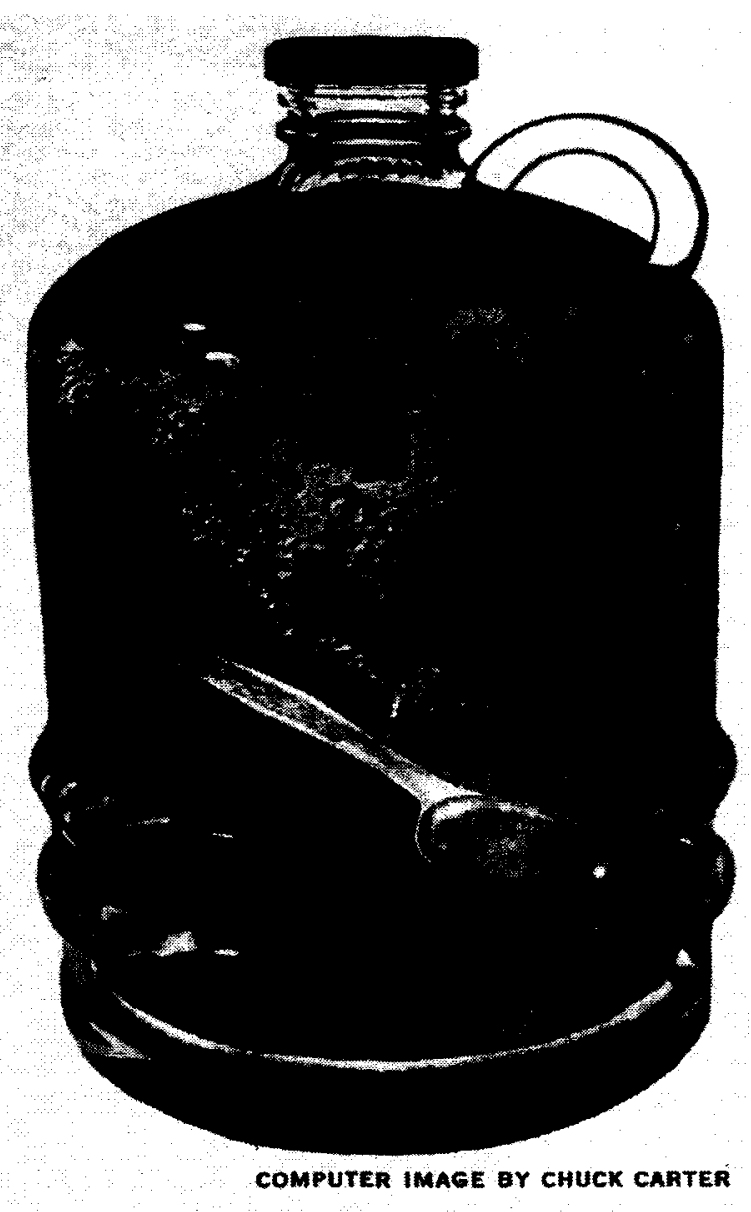

The world's water supply

If all earth's water fit in a gallon jug, available fresh water would equal just over a tablespoonless than half of one percent of the total. About 97 percent of the planet's water is seawater; another 2 percent is locked in icecaps and glaciers. Vast reserves of fresh water underlie earth's surface, but much of it is too deep to economically tap.

Figure 9-1 - "The World's Water Supply" (reproduced from Parfit 1993:24) 
The latent scarcity of water, however, is not sufficient grounds for declaring a crisis; the crisis requires that we add people to the equation: When it comes to water, nature has dealt a difficult hand - to people - and to some people more than others. Returning to the "Troubled Waters" described above, it is when we add these people to the equation - particularly those of the 26 countries today, and the 40 nations that are expected to join them soon - that a full-blown crisis takes shape. In all, as we are told, "the number of people affected" is expected to grow to some three billion. Modern water therefore does not constitute a crisis all by itself; it requires modern people. Just as the water presented here remains a fixed, abstract quantity stripped of its native potentiality, so too do the people involved. For here, they are as just as inert as the water against which they are juxtaposed. (Figures 9.2 and 9.3) Neither the water nor the people involved in this juxtaposition are alive because they relate to each other only in an external sense and not in the (internal) sense by which people and water may be understood to affect each other in process of mutual becoming.

The people of the water crisis are a $21^{\text {st }}$ century version of Malthusian Man - one dimensional, consuming, procreating, biological units - whose relation with water is as fixed and determinate as the statistical methods by which they are produced. 


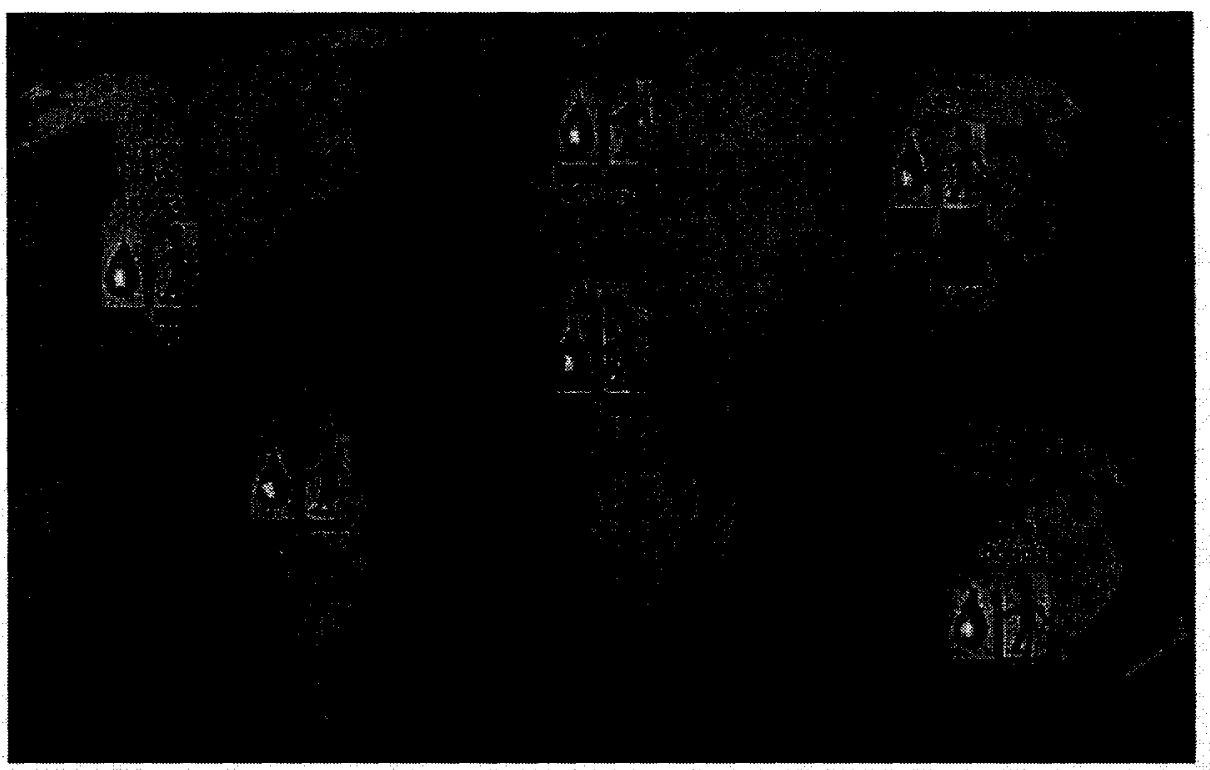

Figure 9-2 - Juxtaposition of two abstractions: "Water Supply vs. Population" (reproduced from Unesco 2003:9).

The map shown above provides a somewhat crude illustration of the juxtaposition very commonly drawn in the water literature. Here, The figures shown indicate proportions of the world total. More commonly, this juxtaposition is shown as the availability of water per capita, per country, as shown below:

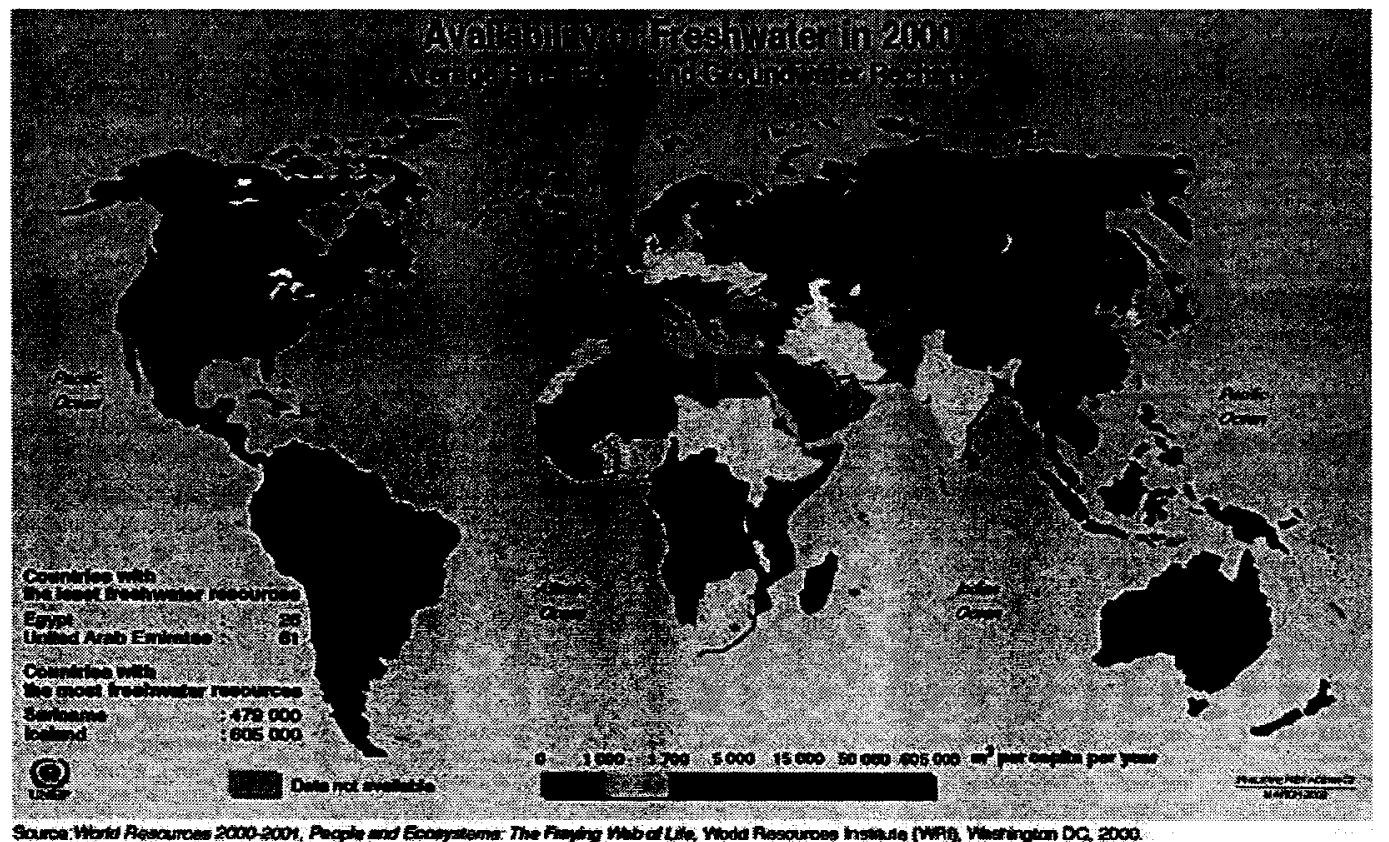

Figure 9-3 - "Availability of Freshwater in 2000" (reproduced from United Nations Environment Programme 2002) 
Modern water needs to be juxtaposed alongside Malthusian Man in order for its latent scarcity to be revealed as part of its nature. ${ }^{6}$ (This juxtaposition cannot help but produce a water crisis. ${ }^{7}$ (Figures 9-2 and 9-3) As described succinctly by the Lester Brown and others at the Worldwatch Institute: "Wherever population is growing, the supply of fresh water per person is declining." (Brown et al. 1998:16)

${ }^{6}$ Perhaps a more analytical term than Malthusian Man in this context is homo economicus, the particular brand of human nature that is universalized and formalized in modern economics. Illich attributes the origin of the term to the anthropologist, Louis Dumont, (lllich 1981) Homo economicus is presumed always to act in order to obtain the highest possible well being for itself given available information about opportunities and other constraints on its ability to achieve its predetermined goals. Its wants are presumed to be limitless. Scarcity can thus be seen to reside in the juxtaposition of homo economicus and resources, which are presumed to be limited. Such a juxtaposition constitutes resources as naturally scarce. In his history of the concept of scarcity, Xenos has shown how the idea of scarcity as a generalized human condition is a "modern invention" that originated in classical economic discourse beginning in the eighteenth century. Prior to the modern era, as Xenos points out, there were localized "scarcities" - specific, historical shortages of commodities or resources in particular places and times. But was not until the economic theorizing of Smith, Malthus, Ricardo and Hume that scarcity became understood "as a universal condition of the human species" (Xenos 1989:2) (Malthus' contribution to this idea of homo economicus as an abstract population comprising "a perpetually reproducing scarcity situation" was critical in giving it a kind of scientific legitimacy. (Xenos 1989:38-9; see also Harvey 1974) A good illustration of how homo economicus gives rise to the universal condition of scarcity can be shown by citing my undergraduate economics text: "For all practical purposes, ${ }^{n}$ it says, "human wants may be regarded as limitless. An occasional individual may have everything he [sic] wants, but people's capacity to generate new wants as fast as they satisfy old ones is well-known to psychologists. For the overwhelming preponderance of the world's [six] billion human beings, scarcity is real and ever present. In relation to the desires of individuals...the existing supply of resources is woefully inadequate; it is sufficient to produce only a small fraction of the goods and services that people desire." (Lipsey, Sparks and Steiner 1976:6-7)

This credo, of course, is fundamental to the doctrine of the market, which is posited as the most efficient means of allocating (naturally scarce) resources in a society presumed to be comprised of competitive individuals (another feature of homo economicus). But what interests us here is the effect of conjoining the limitless wants of homo economicus with the limitations of modern water: the combination of the concept of a humanity for whom "the existing supply of resources is woefully inadequate" with the concept of water as a resource, one moreover that is "definitely limited in quantity" - to hearken back to McGee (1909:422) - cannot but produce a problem.

7 scarcity in the face of population growth. The origins of this critique are found in Marx's response to Malthus. Using the logical-empirical approach (and drawing heavily on demographic data provided by Humboldt) Malthus had posited the inevitability of poverty and scarcity, and used this position to justify a politically conservative policy. Marx responded with the argument that poverty is not the inevitable outcome of natural processes (as Malthus had argued) but rather was the product of the capitalist law of accumulation. As described by David Harvey:

"[Marx] replaces the inevitability of the "pressure of population on the means of subsistence"... by an historically specific and necessary pressure of labor supply on the means of employment produced internally within the capitalist mode of production. Marx's distinctive method permitted this 
Before describing its history, it should be stressed that the water crisis isn't simply a matter dwindling supplies. As populations have grown, as industry has expanded, and as humans have concentrated themselves in urban regions, water pollution is understood to have greatly exacerbated the dismal arithmetic of the population-water equation. Water pollution, of course, is a real problem that is responsible for untold human mortality, morbidity and diminished quality of life. (See footnote 1 above) But the particular way that we understand water pollution like the way we understand the water crisis generally - is conditioned by modern water: The rather explosive mixture of modern water and modern people has produced myriad hybrids of water pollution and water scarcity, which automatically get placed on water's side of the constitutional divide. Thus, water pollution tends to be regarded as a "water problem" rather than a social problem, and the crisis to which it contributes is "the water crisis" rather than the crisis of modern water.

\section{From Problem to Crisis}

"Today, man is losing his race with the growing need for water." (President Lyndon B. Johnson, 1967:10)

Modern water contains the seeds of an apparently insoluble dilemma. Virtually everywhere modern water - especially in its culmination as global water - has been mixed with people, a paradox ensues. Professor Raymond Furon of the

reformulation of the population-resources problem, and put him in a position from which he could envisage a transformation of society that would eliminate poverty and misery rather than accept its inevitability." (Harvey 1974:269) 
Faculte des Sciences in Paris described this paradox rather bluntly in a 1963 study, perfectly titled The Problem of Water.

"There are only $20,000 \mathrm{cu}$. Km of fresh water available each year on the Earth's surface, which would imply that a world population in excess of 20,000 million could not be supported; this is the future foreseen for the year 2100. It is not my intention to predict how coming generations will die, but to show that we are on the threshold of a world water shortage, and that in the year 2000 we shall have only the sea to drink. The problem affects the entire world." (Furon 1967:3)

Furon's deliberately shocking assessment can be taken as a prescient warning of the global water crisis. His pioneering application of global water as a means of establishing the epistemological basis of a global-scale water problem was to be taken up most convincingly by North American water experts a generation later. Meanwhile, "the problem of water" was recognized by some of Furon's contemporaries, especially in North America, who looked ahead and saw the collision of modern water and Malthusian Man on more limited geographical scale.

The dilemma can be traced as far back as the early twentieth century in North America. W.J. McGee, who it will be recalled, offered American readers an introduction to "the quantitative view of water" in 1909, was compelled by the same token to warn that the nation's "growth in population and industries is seriously retarded" by its "dearth", a situation which called for extraordinary measures to bring it under "complete control". (1909:523) Little more than two decades later, as it was about to embark on a program to do just that, the U.S. Department of the Interior stressed, "The western third of the United States grapples always with one 
stern fact... Out west there is a shortage of water." (quoted in Zimmermann 1933:103) ${ }^{8}$ The idea of a generalized, "dearth" or "shortage of water" makes no sense unless we acknowledge the unmarked presence of people who are constitutionally incapable of being satisfied with what is available to them. ${ }^{9}$ Like "losses" in the hydrologic cycle, the idea of such a general dearth or shortage reveals the presence of such people in what is otherwise presented as a fact of nature. Thus the presence of Malthusian Man is naturalized in every statement asserting or predicting a general dearth of water, water shortage, water scarcity or water famine.

Concerns about a general shortage of water in the United States were put off somewhat by the Great Depression and by the stupendous measures taken to realize "total control" of the country's rivers. Faith in man's ability to manipulate the hydrologic cycle - by such means as artificially inducing precipitation and retarding evaporation in reservoirs by means of covering their surface with a monomolecular film - also may have dampened the worst fears of water famine. ${ }^{10}$ But so long as the underlying conditions - modern water and Malthusian Man - prevailed, concerns about water shortages were sure to reappear. They were indeed very apparent shortly after the Second World War, when there "evolved a nationwide

\footnotetext{
${ }^{8}$ For a contemporary assessment of potential water shortages affecting the entire country see (Brown 1933).

9 See the discussion of homo economicus in footnote 6 above.

10 According to one climatologist, about half of the US West was under contract to rain makers ("pluviculturists") in the early 1950 s, at charges ranging from one to ten cents an acre. ("Meigs 195_:358)
} 
concern for water as such." (Nikolaieff 1967b:9) By the late 1950s, the country's most senior hydrologists were warning, "Every estimate indicates that this country's need for water in the next several decades is bound to grow enormously... It is no wonder then that strains on water resources are already showing up, and that these stresses are certain to grow." (Langbein and Hoyt 1959:ix, 3) A national report on the state of the hydrological sciences in 1962 found, "There is a continual appeal for water studies, bolstered by recurrent grim warnings about water problems by 1980 , by 2000 , and so on." (United States 1962:24)

By the mid-1960s, as the data from these very studies became more widely available, as the post-war economy boomed, as the major basins in the continental US approached full regulation, as water pollution became a matter of national concern, and as an exceptionally protracted drought struck the north-eastern states, concerns about water scarcity reached new heights of rhetoric: "The United States of America, the richest and most powerful nation in the world, is running out of its most indispensable commodity...” wrote US Congressman Jim Wright in The Coming Water Famine, published in 1966. "...That commodity is clear, usable water." (Wright 1966:15) In another popular book, The Water Crisis, published the following year, Senator Frank Moss reflected, "There is general agreement that the nation is in the midst of a perilous water crisis." (Moss 1967:276 and see also Nikolaieff 1967a) Indeed, by the late 1960s, many Americans had worked 
themselves into a fit of anxiety over water scarcity. ${ }^{11}$ As the Canadian author and environmentalist Richard Bocking observed (with understandable alarm), "[A] stream of books, magazine and newspaper articles, and political pronouncements have proclaimed 'The Water Crisis' one of the most serious problems to be faced by Americans in the very near future." (Bocking 1972:1)

11 There were important exceptions. Gilbert White, for one, stressed a more flexible approach to predicting future demands for water, one that admitted of alternative possibilities depending on prospective management strategies. In denying the proclamation of a "water crisis" he recognized that the US was in a "situation [where] there are major opportunities to improve public management of water by making it less rigid and more responsive to accelerating technological change. The methods of allocating resources can be fashioned so as to increase efficiency by national standards as well as to be more sensitive to human needs for spiritual and aesthetic expression. The most menacing aspect of the prophecy that the United States is running out of water is that it may become self-fulfilling. For the view that water will be in short supply and requires augmentation sets in motion forces that in time worsen the situation. It is more likely that human welfare in the United States will be impaired through degradation of water quality or through inept management than from a physical scarcity of water." (White 1969:2) In what could be interpreted as a rather dialectical statement, White concludes: "A vast arena for water management of other types remains available to man on the North American continent." (1969:5) It might also be noted that White responded in a similar fashion to the rather dire warnings of a generalized water crisis projected a decade later in the Global 2000 Report to the President. (White 1984) A relevant section of this response is worth citing in light of the present critique of the global water crisis:

"To learn how adequate the water resource is for a present or future society it is necessary to look into how the physically available waters are being used and what physical, social, economic and political constraints apply to further use. In some places the physical limits are severe, and changes in technology, as with central pivot irrigation, can alter the estimates drastically. More frequently, the crucial factors are social, economic and political. The capacity of a society to manage demand, to assure continuity in management policy, and to place values on environmental effects and the maintenance of the quality of surface and ground waters is more likely to influence the course of development. (White 1984:263, my emphasis to highlight White's use of "waters")

Besides White, there were those who decried the water crisis on the basis of their faith in prospective technological fixes. "Though some of the recent writing leaves one with a feeling of impending disaster, through desertification, flood destruction, or soil loss, a dispassionate appraisal indicates that the basic situation is hopeful." Writes the climatologist, Peveril Meigs in The Geographical Review. (Meigs 195_:346) Meigs places his 'hope' in such things as: artificial inducement of precipitation ("pluviculture") (357-8), the building of bigger reservoirs, more extensive and efficient regulation of runoff (359), "extensive" and "comprehensive" control of water at the large-basin scale on the model of the Tennessee Valley Authority projects (365), inter-basin water diversions (360), desalination and water re-use (360), artificial groundwater recharge and "the destruction of phreatophytes - plants whose roots penetrate to the moist capillary fringe overlying ground water." (361, 362) 
In projecting this "crisis", the gloomy arithmetic of the water resources available to the nation was set against an equally gloomy prognosis of future demand for water, predicated on the assumption of a rock-solid correlation between population growth, increasing living standards and growing water demands. The prevailing assumption was that the water resources of the United States could support a maximum population of some $\mathbf{2 3 0}$ million, beyond which "our standard of living starts to suffer." (Bradley 1967:24) It is important to point out that after the Second World War, in addition to providing the usual data on the availability of water resources, hydrologists in the United States became more and more involved in compiling and publishing data on water-use. (Langbein and Hoyt 1959:36-7,ch. 4) Because the available trend data showed a positive correlation between growth in GDP and increases in water withdrawals and consumption, the presumption was made that rising living standards led inevitably to proportionate per-capita demands for water. That hydrologists, of all people, would be called upon to give predictions of future water demands may seem mistaken in light of the need to consider water's social nature. But recalling the hegemony of modern water and its constitutional divorce from society, it is perhaps not surprising that those deemed expert in its quantification would naturally be presumed the most qualified to give projections of its future use. ${ }^{12}$

\footnotetext{
${ }^{12}$ As producers of modern water, hydrologists may be expected to presume a particular social relation to water that is expressed in terms of measured quantities of water withdrawn and consumed. The point I want to make is that because of their particular expertise, hydrologists may be expected to naturalize modern hydrosocial relations. Thus, their projections of future water demand have tended to be extrapolations of current (contemporary) use. The hegemony of modern water has perhaps led to a presumption that hydrologists are the most appropriate, qualified experts to make this sort of projection. Consideration of water as a hydrosocial phenomenon, by
} 
These projections were, of course, invariably wrong - something that I want to return to below. For now, I want to stress that the spectre of general water scarcity was - and remains - underwritten by the presumption that with respect to their hydrological needs, modern people are as inflexible as modern water. Senator Moss relied largely on the work of Raymond Nace for the gross hydrological data underpinning The Water Crisis. (1967:29-41) He also relied on Nace to substantiate the correlation (vital to Moss's argument) between population, living standards and the need for greater supplies of water: "Water need per individual in industrial societies is greater than has been supposed, by nearly ten times," he quotes Nace as saying, "and the population that can be supported with acceptable living standards undoubtedly is much smaller than some writers have calculated." (Nace quoted in Moss 1967:41) The conclusion was obvious, at least for Moss and most of his contemporaries: "A rising standard of living is not possible without increasing water use." (Moss 1967:36) ${ }^{13}$ Nor, it might be added, despite solid evidence to the contrary ${ }^{14}$, has this view of a rigid correlation between water demands and living standards changed much, at least in some quarters. "[I]ncreasing affluence" declared a popular report in 2005, "inevitably means more water consumption: from needing clean fresh water 24 hours a day, 7 days a week

contrast, is likely to stress other forms of expertise and give rise to very different sorts of projections.

${ }^{13}$ Joseph L. Myler, a popular American environmental writer and author of the memorably-titled book, The Dirty Animal - Man (Myler 1970), also draws heavily from Nace's expert commentary to present "The Crisis on the Horizon". (1970:118) Here, the same fixed relation between water use and standard of living is unequivocal: "The high standard of living in the United States and other affluent nations of the modern world depends on fresh water - lots of it." (Myler 1970:117) 14 The evidence is found in statistics showing reduced water use intensity in several wealthy, industrialized countries (particularly the United States) since the early 1980s. (see Gleick 1998c) 
and basic sanitation service, to demanding water for gardens and car washing, to wanting Jacuzzis or private swimming pools." (Fry 2005:11) Such is the strength of modern water.

As with earlier expressions of concern about water dearth and shortage, the American water "crisis" of the 1960s was fuelled by the ambitions of the state, allied with politicians and corporate leaders, all of which stood to aggrandize themselves by manipulating water supplies to address the perceived imbalance between supply and demand. Thus politicians like Wright and Moss provided moral support for the hydraulic engineering agencies of the federal government in calling for redoubled efforts (and expenditures) to control and exploit the rivers of the continental United States. The wave of hydrological hysteria that seized Americans in the 1960s attracted attention to even more distant supplies, and it was thus that the notion of diverting rivers from Canada to slake the growing American thirst became a matter of earnest speculation in US political circles. (Wright 1966; Moss 1967; Bocking 1972) Thus the amalgam of modern water, Malthusian Man, and US water politics gave rise to the remarkably enduring trepidation shared by many Canadians that it was only a matter of time before the U.S. came after Canada's water resources. But that is another story.

The American water crisis ebbed somewhat by the late 1970 s. Then, a series of relatively wet years, economic recession, deindustrialization associated with globalization, and initial improvements in water-use efficiency - improvements that 
would produce a significant reduction in the water-intensity of the US economy by the late 1980 s - combined to dampen the most excessive water worries. But lingering concerns remained, a circumstance that made Americans particularly well prepared to take on concerns about a 'global water crisis' in the 1990s. Moreover, the habit of juxtaposing modern water with Malthusian Man to produce a collision of two abstractions remained a central feature of hydrological prognostication, which made recurrences of the crisis virtually inevitable.

\section{The Global Water Crisis of the 1990s}

At the outset of this chapter, I cited Peter Gleick's publication, Water in Crisis as marking the beginning of the global water crisis of the 1990s. (Gleick 1993a) One might just as well have cited Sandra Postel's Last Oasis: Facing Water Scarcity as the signal publication. (Postel 1992) Both these books drew from the same basic hydrological data and presented the same fundamental contradiction of limited water supplies and growing demands for water to produce a water crisis of global proportions looming on the horizon. But one might also have gone back ten years, to 1981 , when the United States Department of Agriculture Yearbook proclaimed "The energy crisis of the 1970 s will take a back seat to the water crisis of the 1980s and 1990s." (cited in Clarke 1991:19) Or perhaps a decade before that, to 1972, when the Club of Rome's Limits to Growth study warned that among constraints to food production, "second in importance only to land, is the availability of fresh water" and cautioned, "the approach of the increasing demand curve for water to the constant average supply" would be reached in some places 
"long before the land limit becomes apparent." (Meadows et al. 1972:62-63) Or one might have gone back yet another decade to Furon's dire warnings in The Problem of Water cited at the beginning of the last section. (Furon 1967) For as long as modern water had gone global, the spectre of global water crisis was only a matter of combining it with the world's (growing) population.

That this combination was not widely presented before the 1990 s is due perhaps to diversion of the world's attention to other matters. The late 1980s marked a general shift in public concern toward environmental problems operating on a global scale. ${ }^{15}$ The 1987 Report of the World Commission on Environment and Development (The Brundtland Commission) popularized a decade or more of scientific research and environmental thought that had treated of the entire planet as a single system and as the most relevant scale for the investigation of a growing number of environmental issues. (World Commission on Environment and Development 1987) With environmental problems now defined as global in nature, the Brundtland Commission and other opinion leaders seized on the need to coordinate environmental management on the same scale. A special issue of

\footnotetext{
15 It is useful to contrast two monumental studies of the human-nature relationship: "Man's Role in Changing the Face of the Earth" (Thomas et al. 1956) and "The Earth as Transformed by Human Action" (Turner et al. 1990). In the introduction of the more recent study, Kates et al. distinguish between it and the earlier study in emphasizing "transformations of the biosphere at a global scale", noting that "the capability now exists...to estimate their trajectories over the past several centuries with some degree of confidence; to identify some of the broad, direct processes underlying them; and to understand the interactions of these processes at the regional scale." The epistemological foundation of contemporary global environmental concern is also noted: "In formulating the study we have drawn upon three significant, indeed profound, developments of science - developments that have gained prominence since the Man's Role effort: 1) new ways to conceptualize the unity of the biosphere, symbolized by the wide currency of the term itself; 2) new ways and collective efforts to acquire data and analyze their detail and complexity; and 3) reassessment of some of the avenues that link social behavior with environmental transformations." (Kates et al. $1990: 2$ )
} 
Scientific American appearing in 1989, titled: "Managing Planet Earth", was something of a landmark indicating the global reorientation of scientific and managerial discourse. ${ }^{16}$ (Scientific American 1989)

The globalization of environmental concern was galvanized around several issues of systemic and cumulative global change, especially global warming, depletion of the stratospheric ozone layer, deforestation, and losses of biological diversity. Water remained a relatively minor concern in the 1980 s. Around the time of the Brundtland Commission Report, the eminent Swedish hydrologist, Malin Falkenmark, complained bitterly that the international environmental and policy community was failing to acknowledge a looming water catastrophe: "[l]t is highly alarming to note" she stressed in an article titled The Massive Water Scarcity Now Threatening Africa, "that endemic water scarcity seems to be a hidden international issue." (Falkenmark 1989:114) The Brundtland Commission, she pointed out, had paid practically no attention to water, while elevating climate change, deforestation and biodiversity loss to the top of the international environmental agenda. This oversight was repeated, albeit to a lesser degree ${ }^{17}$, at the United Nations Conference on Environment and Development in 1992, where a failure to give adequate recognition to the water problems of poor countries was

\footnotetext{
16 "It is as a global species that we are transforming the planet. It is only as a global species pooling our knowledge, coordinating our actions and sharing what the planet has to offer - that we may have any prospect for managing the planet's transformation along the pathways of sustainable development. Self-conscious, intelligent management of the earth is one of the great challenges facing humanity as it approaches the $21^{\text {st }}$ century." (Scientific American 1989)

17 The "Action Plan" produced at UNCED contained a chapter on water issues. (Agenda 21, Chapter 18)
} 
described scathingly by Falkenmark in terms of the "water blindness" of the world's decision makers. (Falkenmark 1996; see also Biswas 1998) ${ }^{18}$

The Western world was to be cured of its "water blindness", although not entirely in a manner that Falkenmark would approve of. By the mid-1990s, no one in the international environmental community could possibly have been unaware that the world was embroiled in a water crisis. What was described in 1992 as a "sleeper of problem" by Sandra Postel (Postel 1992:7-8), rose to become widely recognized a few years later in terms reflected in the title of a contemporary academic paper: "Global water crisis: the major issue of the $21^{\text {st }}$ century, a growing and explosive

18 Falkenmark postulated three related causes for this "water blindness", a discussion of which is useful in clarifying some of the arguments below: First was the world's - or rather the international environmental elites' - preoccupation with what were perceived as global issues. For Falkenmark, water scarcity was (and remains) a problem specifically "endemic" to certain parts of the world, and was/is not a global issue. The places particularly affected, she argued, were regions of the developing world (particularly sub-Saharan Africa) where poverty prevented the adoption of techniques that would otherwise enable people to overcome "the environmental constraints of hydroclimatically-induced water scarcity and the considerable interannual fluctuations which characterize the natural freshwater supply." (Falkenmark 1989:112; 1996b) Here, it might be noted, she takes aim at "Northern scientists and professionals", and in presenting her views on the water crisis, completely ignores the global water balance data, as well as the global crisis literature of Gleick, Postel, Shiklomanov, etc..

Second, Falkenmark argued that the world community of environmental experts failed to see endemic water scarcity as a problem because their thinking was conditioned by experience in wealthy temperate regions, where "water scarcity is generally no serious problem, and supply of water tends to be seen as a technological issue." (1989:118) Third, the water blindness of the Northern environmental and policy community was abetted by a deference to problems that either appeared not to affect them directly or called for measures that were unlikely to provide them with much political or economic benefit. The appropriate means of addressing the water needs of people in poor countries, Falkenmark had long argued, was to apply "a modified approach" that consisted of exploiting the pre-runoff portion of the hydrologic cycle instead of concentrating on conserving the runoff portion - i.e. building large dams - which was the favoured - i.e. most capital-intensive Western approach. (Falkenmark 1986) In addition to being of no benefit to the construction and engineering consortiums of the industrialized world, Falkenmark's "modified approach" eschewed the economically-inspired solutions that were increasingly in vogue among water resource planners, economists and policy experts influenced by contemporary American perspectives: "The view held by influential water engineers and economists - biased by the present conditions in the southwest USA and claiming that the water-related future of arid lands is just a problem of setting the right price on water... " was particularly singled out for criticism. (1986:192) By the mid-1990s, when this view had become a global creed, she pointed out that the "current emphasis on water economics in the general debate" has diverted attention from the "human dimensions of the water crisis" particularly on conditions in low-income countries (Falkenmark 1996:216) 
problem." (Saeijs and van Berkel 1995) By the end of the decade, the United Nations Environment Programme reported that a survey of leading environmental scientists had identified water shortage as one of the two most worrying problems facing the world in the new millennium. (BBC News 2000) ${ }^{19}$ That same year, the cover story of an issue of Harper's Magazine was titled, "Running Dry: What happens when the world no longer has enough freshwater?" (Leslie 2000) What accounted for this rather rapid shift from water blindness (or somnolescence) to "the major issue of the $21^{\text {st }}$ century"? Certainly an important factor was that the problem was now made out to be "global" in nature, and thereby touched the sensitivity - and the interests - of people in the wealthy industrialized world in a way that Falkenmark's presentation of water problems as endemic to poor countries could not. By presenting it as a global issue in the 1990s, water was poured into the mold of global environmental concern that had been forged in the previous decade.

As noted at the beginning of this section, a few "key documents" ${ }^{20}$ brought the matter of global water scarcity to the attention of decision makers and the general - particularly Anglo-American - public. One of the first, and most influential of these was Postel's book, Last Oasis: Facing Water Scarcity, published by the Washington-based Worldwatch Institute in 1992. (Postel 1992) Another was Water

\footnotetext{
19 The other was global warming.

20 In "Environmental Refugees, the origins of a construct", Patricia Saunders traces the history of the concept of "environmental refugees" through 30 "key documents" that "emerged from a wideranging examination of the literature." (Saunders 2000:219) I use the term in a similar fashion to trace the origins of the global water crisis of the 1990s.
} 
in Crisis: A Guide to the World's Fresh Water Resources, edited by Peter Gleick and published by the California-based Pacific Institute for Studies in Development, Environment, and Security the following year (Gleick 1993a) These studies published the essential data and established the discursive space in which a host of others could elaborate the problem in academic journals, through the mass media and in forums such as the World Water Council. Because it appeared first and articulated the basic construction of a global water crisis, the remainder of this section is devoted mainly to an examination of Postel's book.

\section{"The Last Oasis"}

The thesis of Last Oasis: Facing Water Scarcity is that the world has entered "a new water era", one that is marked by "water scarcity." (Postel 1992:ch. 1) At the core of this new era is the realization that we can no longer presume that our water problems can be resolved by means of engineering more and improved water supplies: there are fewer and fewer unexploited supplies available, and the water remaining is needed to sustain aquatic ecosystem health. Securing enhanced water supplies has, Postel argues, had the effect of hiding, or masking the scarcity that characterizes water: "In a sense, masking scarcity is a principal aim of water development, the collection of engineering projects and technologies that give people access to and control over nature's supply." (1992:18) With the option of developing new supplies rapidly diminishing, our "last oasis" is to be found in improving the efficiency with which available water supplies are used. Much of the 
book (parts II and III) outlines strategies for improving water-use efficiency, stressing the need for "major changes in the way water is valued, allocated, and managed..." (1992:166) How this presentation of the problem and its solutions complements an effort to promote the market as the most efficient and appropriate means of allocating (scarce) water resources is discussed below. Here, I am mainly interested in how the problem was made known.

The cover of The Last Oasis features a composite photographic image of an anonymous, dessicated lake-bed with a windswept sand dune in the middle range and an utterly barren mountainscape in the background. Postel begins the textual construction of global water scarcity by conjuring the image of our "strikingly blue planet" from space. It is "hard to believe" she points out, that "scarcities could arise in the midst of such amazing water wealth...

"The total volume of water, some 1,360,000,000 cubic kilometers would cover the globe to a height of 2.7 kilometers if spread evenly over its surface. But more than 97 percent is seawater, 2 percent is locked in icecaps and glaciers, and a large proportion of the remaining 1 percent lies too far underground to exploit." (Postel 1992:27)

Of the 500,000 cubic kilometres of precipitation that falls on the earth every year, she points out that most of this falls into the oceans. After these reductions, we are left with only 40,000 cubic kilometres as "the world's renewable freshwater supply." Furthermore, fully two thirds of this amount "runs off in floods, leaving about 14,000 cubic kilometres as a relatively stable source of supply." (Postel 1992:28) 
Presented in this way, it has to be admitted that fourteen thousand cubic

kilometres of water seems like a very small amount indeed.

The global water data on which Postel constructs the world water predicament is derived principally from the work of the Soviet hydrological studies already discussed in Chapter 7, on "global water. ${ }^{21}$ The Last Oasis can thus be seen as a means of disseminating global water in a popular format. In addition, data on regional water balances derived from L'vovich and other Soviet scientists, together with demographic data permits the construction of the important concepts of "water stress" and "water scarcity:"22

"One of the clearest signs of water scarcity is the increasing number of countries in which population has surpassed the level that can be sustained comfortably by the water available. As a rule of thumb, hydrologists designate water-stressed countries as those with annual supplies of $1,000-2,000$ cubic meters per person. When the figure drops below 1,000 cubic meters (2,740 liters per person a day), nations are considered water-scarce - that is, lack of water becomes a severe constraint on food production, economic development, and protection of natural systems." (Postel 1992:28-29)

${ }^{21}$ Specifically, her information on the total volumes of saltwater and freshwater on earth is from Nace, as cited in van der Leeden et al. (1990). As discussed above, Nace's work drew from Soviet sources, and was inspired by the global-hydrological approach of L'vovich. Postel's data on the amount of renewable fresh water flowing through the global hydrologic cycle is from L'vovich (1979). The data on global runoff are from the Institute of Geography, National Academy of Sciences of the Soviet Union as published in World Resources Institute (1992). And the "14,000 cubic kilometers as a relatively stable source of supply" is from L'vovich (1979). (Postel 1992:194) Other measures of global water in The Last Oasis are taken indirectly from mainly Soviet sources via other secondary sources e.g. Todd 1970; van der Leeden 1975; Spidel and Agnew 1988; L'vovich et al. 1990; van der Leeden et al. 1990.

22 Postel and others attribute the origin of these indexes to Falkenmark (1989). Falkenmark, in turn, relies on L'vovich (1979) for the regional water balance data with which to construct them.

(Falkenmark 1989) 
"Today," writes Postel, "26 countries, home to 232 million people, fall into the water-scarce category." (Postel 1992:29) A variety of methods of calculating water stress and water scarcity have been presented in the water crisis literature. ${ }^{23}$ They all abstract human populations and available streamflow and present these as a ratio over a specific territorial unit - most commonly, the territorial state. As fixed indices (ratios of water supplies per capita), water stress and water scarcity presume a rigid set of hydrosocial relations, rooted in what Postel identifies as the "population-water equation". (1992:29) Here is an important feature of the conventional water crisis: In this formulation, both water and people (population) are reduced to their most essential bio-physical characteristics, a form of reduction that gives scientific legitimacy to the "population-water equation" and makes it a compelling argument for proclaiming a state of crisis. The equation cannot be contradicted, a certainty that produces a crisis as the natural, inevitable

\footnotetext{
${ }^{23}$ For example, the World Water Council (Cosgrove and Rijsberman 2000) points out that the Falkenmark indicator does not account for the temporal variability in water availability or for water use. Instead, they use what is called "the criticality ratio of withdrawals for human use to renewable resources." It ranges between $20 \%$ for basins with highly variable runoff and $60 \%$ for temperate zone basins. The WWC report uses a threshold of $40 \%$ to indicate "high water stress." (2000:26) I want to point out that the use of this indicator has several interesting implications. First, by adding water use to the equation, the number of countries suffering from water stress is increased. Second, by using the figure of $40 \%$ threshold to indicate "high water stress", the indicator is weighted in a fashion that defines more temperate countries as suffering from "high water stress." Because the more temperate regions tend to have denser human populations, they can conclude: "Under the business as usual scenario, by 2025 about 4 billion people - half the world's population - will live in countries with high water stress." (28). Third, the indicator is neutral on the question of water use, so countries that use high volumes of water per capita (relatively more wealthy countries) are more likely to be considered "highly water stressed." The overall effect is to expand the occurrence of "water stress" to areas in temperate regions that otherwise would not be considered. They then use a map projection and colour coding that gives a strong impression that water stress affects places like the United States.
} 
consequence of the (latently scarce) nature of water when combined with growing human populations. $^{24}$

Indices of water stress and water scarcity are constructed on the presumption that "available water supplies" derive from the runoff or streamflow portion of the hydrologic cycle. This focus on liquid water flowing in rivers or streams as the basis for assessing water resources is arguably a bias conditioned by modern water, particularly by thinking (or seeing) water through the lens of the hydrologic cycle.

24 ${ }^{24}$ Although the population-water equation provides a compelling rationale for declaring a crisis, it may nevertheless be criticized as an inadequate index of the kind and severity of water problems in a given region or for a given population. Indices like water stress and water scarcity territorialize water problems on the spatial basis of the state. (For an exception to the territorial-state based calculation of water stress see the World Resource Institute et al. PAGE (Pilot Analysis for Global Ecosystems) Assessment published in 2000. World Resources Institute et al. 2000:107) Thus, an entire country may be assigned to the category of water stress or water scarcity regardless of the heterogeneity of hydrosocial relations that may pertain between different regions and classes of people within each country. More generally, Yearly (1996) has elaborated on how the science of global change typically promotes an understanding of environmental problems as universal generalizations applicable to all locations, without regard to how they may be interpreted and managed by people locally. Similarly, Taylor and Buttel (1992) have pointed out how global environmental change science presumes similar ecological relations for everyone and how "global" environmental risks and crises imply a uniform threat for everyone. These critiques underscore how, in discourses of global change, the biophysical is privileged over social relations. In other words, scientifically grounded global change discourse - of which the water crisis serves as one example - has promoted an "emphasis on biophysical changes as a key guide to environmental problems, rather than social contextualization and vulnerability to changes..." (Forsyth 2003:174) This universalizing tendency has the effect of downplaying the fact that the implications of biophysical changes - real though they may be - are always "mediated locally through social, economic and political factors influencing the exposure of societies to such changes, and their ability to adapt." (2003:176) As noted by Bradnock and Saunders: "In the contemporary world of social science intense interest in the search for universal laws and global processes has often reduced the level of interest in the specific and the regional. Yet it is in the complex interlocking of variables within particular places with their own unique combinations of environmental and human systems that the real world of environmental change is being played out." (Bradnock and Saunders $2000: 85$ ) In light of these observations, a concept as abstract and universal as the populationwater equation should be recognized as inadequate for understanding the complexities of hydrosocial relations. However, the habit of thought induced by modern water, helps produce and sustain such abstraction. 
As Falkenmark makes clear ${ }^{25}$, such indices focus attention on what she calls "blue water" (liquid, flowing water) which constitutes "only one third of the overall water resource" and excludes naturally infiltrated soil moisture, which she calls "green water":

"The green water in the soil is the main water resource involved in rain fed crop production and in biomass production in natural terrestrial ecosystems. Therefore, one urgent shift in thinking is to move from seeing only blue water as the economic resource to also seeing green water as a resource... A remarkable window of opportunity exists in semiarid rain fed agriculture. The perceptional [sic] change from blue water only to blue and green water together therefore offers a foundation for considerable hydro-optimism as compared to the past blue - and largely technical - perspective focusing on a vanishing resource." (Falkenmark 2005:9-10)

It is worth pointing out here that "green water" corresponds to a portion of the hydrologic cycle traditionally has been considered by hydrologists in terms of "losses." What might be called the 'blue bias' inherent in modern water has produced a way of seeing that focuses on this "vanishing resource." Concepts like water stress and water scarcity have been hugely influential in producing an understanding of the scale and depth as well as the territoriality of the water crisis. The Last Oasis was one of the first popular books to present the idea that entire countries suffer from water stress and water scarcity, and that many more, comprising billions of people, are bound to this fate at some point in the near future. Such conclusions and projections have been applied very frequently in the

\footnotetext{
25 It is ironic that Falkenmark has emphasized this distinction between blue and green water resources, given that most hydrologists, water experts and writers have adopted her measures of water stress and water scarcity, which are based exclusively on blue water. (de Villiers 1999:99)
} 
water literature ever since. ${ }^{26}$ To cite but one authoritative source, the

Comprehensive Assessment of the Freshwater Resources of the World, published

by the United Nations in 1997 concluded that "as much as two-thirds of the world population in 2025 may be subject to moderate-to-high water stress and almost half the world could have clear difficulties in coping owing to inadequate financial resources." (quoted in Conca 2006:399)

Because most indices of water stress and water scarcity are calculated on the basis of the territorial state, many researchers in the field of environmental security have found it convenient to make use of them. ${ }^{27}$ For example, a forecast of countries likely to face "water stress" by 2015 made by Postel and Aaron Wolf yields the following conclusion:

"By 2015 , nearly 3 billion people -40 percent of the projected world population are expected to live in countries that find it difficult or impossible to mobilize enough water to satisfy the food, industrial and domestic needs of their citizens. This scarcity will translate into heightened competition for water between cities and farms, between neighboring states and provinces, and at times between nations." (Postel and Wolf 2001:61)

26

The concept of "water stress" has become so pervasive in the international water literature that it often used without reference to its hydrological origins. For example, Aaron Wolf, one of the foremost authorities on water and international conflict has written: "The scarcity of water for human and ecosystem uses leads to intense political pressures, often referred to as "water stress." As a consequence, competition for water resources has contributed to tensions around the globe..." (Wolf 2001)

27 Although the water crisis usually presents the global South as more needy than dangerous or threatening to Northern security, it makes a contribution to what critical scholars of environmental security have elaborated as an "environmental geopolitics of fear." (Dalby 2002) This fear is derived from the concerns that international and intra-national competition for water in regions of the global South might destabilize international trade in oil and other raw materials important to countries of the North, and contribute to the spectre of environmental refugees seeking shelter in wealthier countries. 
Postel's book was significant in revitalizing the sense of crisis among the (particularly Anglo-American) public in the wealthy, industrialized world, by effectively globalizing "endemic" water scarcities. ${ }^{28}$ Unlike Falkenmark's "massive water scarcity now threatening Africa" (Falkenmark 1989), the "new water era" is universal in scale and the lessons of The Last Oasis pertain, more or less, to everyone. While this has served the important purpose of alerting citizens of the developed world to the urgency of the water problems faced by people especially in the global South, it has come at the expense of generalizing the water crisis in a way that occludes its social specificity. Falkenmark and others who have subscribed to her analysis (e.g. Clarke 1991; Biswas 1998) have emphasized instead that regional water problems must be addressed in accordance with local hydrological and social circumstances. Their analysis of the problem demands a very limited role for western techniques and capital. "In fact," writes Robin Clark, "few developed countries have anything to offer developing countries in terms of improved water management." ${ }^{29}$ (1991:87) Postel's book was categorical in

\footnotetext{
${ }^{28}$ The Last Oasis can be contrasted with Robin Clarke's Water: The International Crisis, published a year earlier. (Clarke 1991) While the two books are alike, and Clarke does proclaim the water crisis to affect not merely African countries, "the international crisis" that he presents is different from the one presented by Postel. (See footnote 19 above) 29

Clarke (1991:82) draws heavily from Falkenmark to describe "water blindness" or "water paralysis" which might be described as a blindness to anything but modern water. For Clarke, "water blindness" is caused by "a poor understanding of the importance of the water cycle to security and well-being in the tropics on the part of the donors and experts... They [most donors and water experts] live in water-rich societies. Where their plans and projects embrace areas where water is scarce, they tend to think in terms of the technological fix: how to make available the water needed fro a new village, an urban centre, an irrigation project... Unhappily, these basic attitudes are often instilled into the hydrologists and hydraulic engineers from developing countries - many of whom, of course, must train in industrial regions for lack of appropriate courses at home..."

" $[T]$ he industrialized regions have developed their own particular solutions to water management issues. They mostly involve technical fixes and gargantuan developments... They are expensive, involve difficult technologies and are conceived in regions where rainfall is high and barely
} 
declaring that traditional, Western methods of solving water problems by largescale engineering techniques had been discredited. But in universalizing "the new water era", The Last Oasis reinforced the tendency, inherent in modern water, to look to a universal solution, namely increasing the efficiency with which water is used.

\section{"Water in Crisis"}

Turning briefly to the monumental collection edited by Peter Gleick, Water in Crisis (1993), it should be noted that this publication was considered by many in the 1990s as an essential, if not the definitive statement of the condition of freshwater resources on the planet. ${ }^{30}$ Its authoritativeness has since given rise to a series of influential bi-annual reports titled, The World's Water, also produced by Gleick and the Pacific Institute. (Gleick 1998; 2000; 2002; 2004) On the cover of Water in Crisis is a photograph of the dry bed of Russia's Aral Sea, with the rusting remains of several ships in the foreground. The first page of Gleick's introductory chapter describes the latent scarcity of modern water; it cites a famous line from "The Rime of the Ancient Mariner" by Samuel Taylor Coleridge, who,

seasonal, and where rainfall is high and where evaporation rates are low. Extrapolating such schemes to tropical countries where evaporation rates are high, and rainfall is either scant or excessive for three months and then negligible for the rest of the year, has proved more than difficult; in many cases, it has proved disastrous. In fact, few developed countries have anything to offer developing countries in terms of improved water management." (Clarke 1991:87)

30

Its significance is suggested by Gilbert White's foreword to the publication, which White describes as "a solid, discriminating array of data on the spatial and temporal distribution of the worid's fresh water resources. The tables selected for this collection encompass more completely than any other effort to date the basic statistical information available." This work is cited with great frequency in the water literature of the 1990s and more recently. See for example, among numerous others; Patrick 1994; Ohlsson 1995; de Villiers 1999; Buckley 2001; Unesco 2003. 
"effectively described the principal characteristic of the earth's water resources when he wrote, 'Water, water everywhere, nor any drop to drink.' Ninety-seven percent of all the water on earth is salt water - unsuitable for drinking or growing crops. The remaining $3 \%$ is fresh water, comprising a total volume of about 35 million $\mathrm{km} 3$. If this water were spread out evenly over the surface of the earth it would make a layer $70 \mathrm{~m}$ thick. Yet almost all of this fresh water is effectively locked away in the ice caps of Antarctica and Greenland and in deep underground aquifers, which remain technologically or economically beyond our reach. Less than $100,000 \mathrm{~km} 3$ - just $0.3 \%$ of total fresh water reserves on earth - is found in the rivers and lakes that constitute the bulk of our usable supply." (Gleick 1993b:3)

The first substantive article in Water in Crisis is "World fresh water resources" by Igor A. Shiklomanov. Shiklomanov, who was then based at the State Hydrological Institute in St. Petersburg, seemed to have inherited Marc L'vovich's informal title as "the dean of Soviet hydrology." ${ }^{31}$ In a world where popular concern about water issues has given at least some hydrologists an unprecedented measure of prominence, it may be said that Shiklomanov is world-famous. Chosen by the United Nations to lead the massive collaborative inventory of global water known as the Comprehensive Assessment of the Freshwater Resources of the World (United Nations Commission on Sustainable Development 1997), his work is citied in the vast majority of studies dealing with global water issues in the past decade. In the award-winning book Water, Canadian author Marq de Villiers describes Shiklomanov as "a formidable figure in the water world" and even "the central figure in the water universe." (de Villiers 1999:30, 364)

${ }^{31}$ L'vovich was named thus by Nace. (Nace 1979:iv) 
The global water data presented in Shiklomanov's chapter ${ }^{32}$ provides the essential numbers that allow Gleick to declare that water is "in crisis." ${ }^{33}$ As with Postel's book, these numbers suggest an obvious problem: the available water resources available just don't add up to the projected demands, especially in the developing world. Gleick notes that the rate of population growth in developing countries is such that "almost all new births will be in regions where access to clean water and sanitation services" are already severely lacking. (1993:105) Stressing that the number of countries with inadequate water resources per capita will grow to unacceptable levels unless extraordinary measures are taken, he concludes that "The world's population cannot continue to grow indefinitely. It must be stabilized as quickly as possible...The problem of population must be tackled directly..." (1993:106) This prescription, in addition to other solutions put forward in the concluding chapter - mainly improving water use efficiency and applying economic

32 iklomanov's tables depicting global water resources and global water balances are, respectively, based on data "collected by Soviet scientists" and "based on research conducted by Soviet scientists." (Shiklomanov 1993:13,15) Moreover, the data he used in 1993 were not new they were from sources originally published in the 1960s and 1970s, during the International Hydrologic Decade. (Shiklomanov 1993:24) ${ }^{32}$ (For an illustration of these tables depicting global water see Figure 1-3) 33

One aspect in which Water in Crisis differs from Last Oasis is in emphasizing that these numbers should be read with caution. In his article, Shiklomanov warns: "It should be noted that the data on the amount of water on earth (as the authors of the cited monograph themselves note) should not be considered very accurate; they are only approximations of the actual values." (Shiklomanov 1993:14) He urges that while "[c] considerable advances have been made in the study of global water balance and water resources... the imperfection and inadequacy of our knowledge of water resources become increasingly apparent." (23) In a section prefacing the tabular data at the back of the book, Gleick repeats these cautions, noting, "There are likely to be errors in these data, either inadvertently propagated from errors in the original sources, or introduced in transcriptions and conversion." (Gleick 1993a:117) There are, he points out, "many problems and pitfalls with...computed data", difficulties with "uneven regional data coverage and uneven data quality" and issues associated with "verifiability, uncertainty and illusory precision and accuracy." (117-118) In particular, information on water resources, by country, "should be viewed with healthy scepticism." (128) Moreover, data that "differ substantially" from the water balance information presented by Shiklomanov are given in tables in Part II of the book. 
instruments to the allocation of water and water services - is based on the assumption of a rather rigid correlation between population, living standards and demands for water built into Shiklomanov's method for projecting future water needs. $^{34}$

To conclude this section, it should be noted that more recently, Gleick himself has pointed out that every one of the "projections and estimates of future freshwater demands...made over the past half century... [including those of Shiklomanov that Gleick himself used in 1993] have invariably tumed out to be wrong." (Gleick $2000 \mathrm{~b}: 39)$ Around the same time that he made this admission, Gleick appears to have begun refraining from using the term "crisis" to describe the basic condition of the world's water. ${ }^{35}$ These projections, he admits, "routinely, and significantly, overestimated future water demands because of their dependence on relatively straightforward extrapolation of existing trends." Gleick ascribes this overestimation partly to the inadequacy of water supplies to meet needs in some places, but it is mainly due to the failure of forecasters to factor in the "major improvements in the efficiency with which water is used in all sectors." (2000b:58) These improvements in efficiency, it will be recalled from the discussion in Chapter

\section{4} According to Shiklomanov's method, 'The values of water use in various large regions of the earth are determined by three main factors: the level of economic development, population, and the geophysical (especially climatic) particularities of the territory in question." (Shiklomanov 1993:19) Estimates for future water demands are based on extrapolation from past trends, but also took into account expected improvements in water use efficiency in irrigation processes. Overall however: "In considering the dynamics of water use throughout the world, we should note that a continual increase in water withdrawals during this century has been characteristic of all regions, the largest growth occurring in the 1950s and 1960s. A significant increase in water requirements over 1980 levels is also expected through the turn of the century, with the largest increases expected to occur in South America and Africa ( $95 \%$ and $70 \%)$. Decreases are possible in many major industrialized countries." (ibid.) 35 Gleick was still describing "water in crisis" in 1998. (Gleick 1998a) But he has abjured use of the term in all of The World's Water series so far. I should stress that many, many others have not. 
2, constitute what Gleick calls "the changing water paradigm". (Gleick 1998c)

While this new paradigm of water efficiency still holds great promise, there is a sense in which it is not all that new: By merely changing the mathematical ratios by which people are juxtaposed with - or the rates at which people use - water, the new paradigm is still made of modern water. In this sense, it could be argued that instead of negating the water crisis, the paradigm of efficiency only postpones it. The possibility of going beyond efficiency to consider the more basic question of how people relate to water requires a different sort of paradigm change. In the following section, I want to argue that the possibility of a more fundamental paradigm change for water is, ironically, jeopardized by the conventional response to the water crisis.

\section{Sustaining Modern Water - The New "Global Water Regime"}

"We are not witnessing the emergence of questions about nature in political debates, but the progressive transformation of all matters of facts into disputed states of affair, which nothing can limit any longer to the natural world alone which nothing, precisely, can naturalize any longer." (Latour 2004:25)

The immanent denaturalization that hovers over every water problem today reflects the critical state of modern water. However, plunging water into a disputed state of affair hardly seems an expedient or practical response to what is universally recognized as a serious and pressing suite of urgent problems. Moreover, denaturalizing modern water would place the various professional and expert discourses that it sustains - and that sustain it - in jeopardy; it would risk undoing the authority that has been conferred on the expert groups of water 
managers, water resource economists, academics and researchers whom we have authorized to speak for water in the modern world. Therefore, despite the challenge that the water crisis poses for modern water, the urge to naturalize water as a modern abstraction retains a powerful hold. Instead of thinking in terms of reconstituting hydrosocial relations, the predominant response to the water crisis has been to find new ways to sustain them.

In this section, I want to describe a coordinated project to salvage modern water that is being led by a coalition of actors comprising what critic, Riccardo Petrella, describes as "a kind of global high command for water." (Petrella 2000) ${ }^{36}$ The main player in this "global high command" is a quasi-non-governmental organization known as the World Water Council (WWC). Established in 1996, the WWC is an elite international body established by the World Bank, the United Nations Development Programme, the water services industry, professional water associations and water policy experts. In 1997, the WWC gave itself the mandate to develop a World Water Vision, the purpose of which was to "offer relevant policy and ... recommendations for action to be taken by the world's leaders to meet the needs of future generations." (Cosgrove and Rijsberman 2000:68) The panoptical gaze of this Vision has been extended and widened through an ongoing series of high-level meetings known as the World Water Forum. The Vision and a companion document, World Water Security: A Framework for Action, were presented at the Second World Water Forum held in 2000:

36

Elsewhere he describes this group as the new “international water cartel”. (Petrella 1998) 
The first report, the World Water Vision, framed the global water challenge as a case of inadequate supply in the face of greatly increasing demand. Without dramatic technological innovations, institutional change, and substantial new investment, the world in $\mathbf{2 0 2 5}$ was projected to face an even more sizable 'water gap' than that of today, when an estimated 1.3 billion people lack access to safe drinking water and 2.6 billion lack access to adequate sanitation.

The second report, World Water Security: A Framework for Action, presented a blueprint for achieving that vision. The Framework called for dramatically expanded investment in water supply infrastructure, primarily by mobilizing the private sector through incentives such as privatization and full-cost pricing of water. The Framework also called for more effective water governance based on a paradigm of Integrated Water Resources Management." (Conca 2006:1-2)

In these reports, water is framed as a scarce resource and an economic good that must be managed in an "integrated" fashion. Together with the machinery by which they are diffused, these doctrines constitute what Ken Conca has called a new "global water regime ... a set of norms - prescriptive rules and standards of appropriate behavior meant to govern water-related actions on a global scale". (Conca 2006:2) Conca's critique of this "global water regime" is most relevant to my argument for the need to overcome the limitations imposed by modern water when addressing the crisis. So long as we remain beholden to modern water, the possibility of entertaining a simultaneous variety of waters is practically nil:

"Attempts to create a broadly cooperative international approach to managing water - to govern water globally, so to speak - seem doomed to founder on more fundamentally contested questions. Should it be the privatized, supply-oriented vision of the [World Water] Forum? Or the grassroots, watershed-scale vision of the Forum's most ardent critics? Or an updated version of the state-led model of infrastructure expansion and water as a public good that so many governments have historically favored?" (Conca 2006:4)

Putting this problem in terms of the present analysis, it might be said that modern water cannot withstand being subjected to these "more fundamentally contested 
questions." Ultimately, what is being questioned - and what therefore makes the new global water regime "doomed to founder" - is the presumption of modern water that it is built on.

Our conventional understanding of the water crisis reinforces the presumption of modern water and thus gives greater credibility to the "global water regime." "In recent years", we learn from the preface of the World Water Vision, "it has become evident that there is a chronic, pernicious crisis in the world's water resources." (2000: xii) "The world", as is proclaimed on the back cover, "is experiencing a water crisis". The term "water crisis" is used fourteen times in the foreword, preface and executive summary of the Vision. And we are informed by its President:

"From its inception the World Water Council has understood the dimensions of the world water crisis. As the world population increased and urbanisation and industrialisation took hold, the demand for water kept rising while the quality continued to deteriorate. Water scarcity afflicted many more nations, and access to clean drinking water and sanitation remained poor. A decline in public financing and a rise in transboundary water conflicts made these problems worse. But awareness of the problems was limited to the few on the "inside," in the water sector. We start the new century with a water crisis on all accounts. A concerted effort and extraordinary measures are needed to face the challenges head on." (Mahmoud A. Abu-Zeid, Egyptian Minister of Water Resources and President of the World Water Council, in foreword to Cosgrove and Rijsberman 2000:iv)

The only possible solution to such a crisis "is the development of a shared vision on world water for the long term..." (Cosgrove and Rijsberman 2000:iv) Let's now consider the two basic ideas upheld in this shared vision to show how they reinforce modern water. 


\section{Water as a Scarce Resource and an Economic Good}

Central to the new "global water regime" is the idea of maximizing water-use efficiency and abstracting water as an "economic good." Given the fixed constitutional relationship between modern water and people, and with the political difficulties entailed in promoting the stabilization of world population, only two possible solutions to the water crisis remain available without jettisoning modern water altogether. The first is to augment supplies of water in the face of greatly increasing demands, particularly in rapidly growing urban regions of the developing world. This, in turn, calls for vast increases in infrastructure investment, which at a time of recognized state failure in the water sector (Bakker 2003a; 2003b) translates into the need for substantial new private investment. The other solution is to increase the efficiency and productivity with which available water resources are used. The latter notion in particular, as already noted, is the gist of the "changing water paradigm" (Gleick 1998c) and "the last oasis" (Postel 1992) to which humanity must turn in this era of growing water scarcity. ${ }^{37}$ Thus increasing private investment in water supply and improving the economic productivity of water, have become the twin hydrological hopes of state planners, water experts,

\footnotetext{
37 There's no question that it works. As noted above, over the past 20 years or more, certain countries have experienced increased population and economic growth while reducing their total annual volume of water withdrawals. In the United States, to cite the best-documented example, total annual water withdrawals rose by a factor of ten between 1900 and 1980, and then fell by ten percent between 1980 and 2000. Considering the increase in population from 1980 to 2000, per capita water withdrawals in the United States actually fell by 25 percent from their peak in 1980 . (Gleick et al. 2004:313) At the same time, since the late 1970s, the economic productivity of water the ratio of annual economic output (GDP) to annual water withdrawals - has risen substantially in all sectors of the US economy. (2004:317, 320) Similar patterns of reduced water use combined with increases in population and economic growth "are emerging around the world." (Wolff and Gleick 2002:23)
} 
and corporate leaders alike. Both presume a slightly different, more flexible, set of relations between people and water than pertained in the old statist paradigm, but they are nevertheless modern in the sense that the fundamental relation is unchanged - water is still a resource (and increasingly an economic good) to be supplied and consumed or used in the most rational, economical fashion possible. Moreover, both solutions - increasing private investments to augment water supplies and economizing water use - complement the framing of water as an economic good. And in accordance with the end-of-history ideology of the day, ${ }^{38}$ the only possible means of economizing water is presumed to be through the market.

The economisation and privatization of water and water services have, of course, occasioned a great deal of debate, as mentioned in Chapter 2. The point that I want to stress here is that the single most powerful response to the crisis of modern water - i.e. the response proffered by the most powerful actors in the water policy world - has been to attempt to salvage it by means of deliberately rendering water an economic abstraction built on the principle of naturally scarce water supplies. The formula for sustaining modern water in the face of crisis has thus been to move from conceiving and treating of water as a common resource and a public good to conceiving and treating of water as an "economic good." ${ }^{39}$

\footnotetext{
${ }^{38}$ The reference is to Francis Fukayama's famous essay, "The End of History", in which he proclaimed the post-Cold-War culmination of history in the triumph of capitalism over socialism. (Fukuyama 1992)

39 good example. In it, she describes how the provision of water was reconstituted in the later part of
} 
The identification of water as an economic good sustains modern water in the face of growing evidence of the unsustainability of water as a public good; merely substituting one of the "things" that it makes possible for another only sustains modern water's essence. ${ }^{40}$

Although they were manifest in the World Water Vision, concerted efforts by the World Bank, regional Development Banks, governments and the water industry to promote a new, global hydro-economics ${ }^{41}$ predate the publication of that document by well over a decade. (Petrella 1998:22) Perhaps the signal historical moment of the re-branding of water as an economic good can be identified with the International Conference on Water and the Environment held in Dublin Ireland in January 1992. This conference has been described as "a seminal frame-shifting event" (Conca 2006:140) and has been of critical importance in setting the agenda for subsequent international discourse and policy on water. (Young, Dooge and

the twentieth century from an earlier era of perceived market failure to a period of perceived state failure, so as to produce "a discursive rescripting of water as a commodity rather than a public good, and of users as individual consumers rather than a collective of citizens." (Bakker 2003b:39) "Over the past two decades, the concept of state failure has gradually displaced the concept of 'market failure' which formerly underpinned arguments in favour of public ownership and management of water." (Bakker 2003b:41)

40

Modern water is prerequisite to pricing water and making it into an economic good. The creation of markets for buying and selling water requires that water be reduced to the commodity form - that it be reduced to that which can be compared in terms of price. By the same token, the commodification of water strengthens modern water by fixing hydrosocial relations in terms of water-consuming subjects and water-commodity objects.

41 The term "hydro-economics" was used by Frederick Newell to describe a programme for rationalizing the use of water in the early conservation era. For Newell, the term conveyed "the conception of [water's] efficient employment, of utility or of thrift." (Newell 1920:31) In contrast with the ideal of the World Water Vision, Newell's might be considered the old "hydro-economics, wherein water was regarded as a national, public good rather than a commodity. 
Rodda 1994:26-41; Rodda 1995b; Gleick et al. 2002a;) The Conference adopted the following principle:

"Water has an economic value in all its competing uses and should be recognized as an economic good." (quoted in Gleick et al. 2002a:37)

This has been by far the most frequently cited and controversial of the four socalled Dublin principles. ${ }^{42}$ It could be argued that not since McGee's declaration of water as a "resource" in 1909 had water been so deliberately framed in terms of an abstract concept. (McGee 1909) The timing of this statement - virtually at the moment of the emergence of the global water crisis - suggests how the crisis helped produce the circumstances in which the economisation of water became most compelling. ${ }^{43}$

Integrated Water Resources Management

Promoting water as an economic good was not the only blanket solution to the water crisis that was proposed by water experts in the 1990s. The idea of getting

\footnotetext{
42 The other three are given below.

43 In Postel's Last Oasis, the obvious - one might say the natural - alternative to engineering new water supplies is the procurement of market-based solutions to promote greater water-use efficiency. "Moving toward more efficient, ecologically sound, sustainable patterns of water use", she argues, "requires major changes in the way water is valued, allocated, and managed. Appropriate pricing, the creation of markets for buying and selling water, and other economic inducements for wise water use hardly exist in most places. They have a central role to play in the transition to an era of scarcity." (Postel 1992:166) And Gleick, in Water in Crisis, signals a transition from water as resource to economic good by emphasizing: "Water is a scarce resource in many parts of the world, yet it is still often treated as a free good, available at no charge to whoever can pump it from the ground or remove it from a river or lake... Until water is priced at its true value, there will be few incentives for wise and efficient water use." (Gleick 1993a:110)
} 
the price of water right for the sake of economic efficiency "has long been a central theme", but only one theme comprising Integrated Water Resources Management (IWRM), an overarching prescription for global water governance that gained international currency in the 1990s. (Conca 2006:154) As Conca observes, Integrated Water Resources Management "has become the discursive framework of international water policy - the reference point to which all other arguments end up appealing." (Conca 2006:126; see also Allan 2003) IWRM is a concept with a long and controversial history (Young, Dooge and Rodda 1994; Biswas 2004; Conca 2006:ch. 5) Moreover it is an extremely difficult concept to pin down. Typically, IWRM stresses several requirements: the need to recognize the cultural, economic and ecological values of water; the need to integrate various sectoral water applications (such as in agricultural, industrial, and municipal uses), the need to integrate management of water at multiple scales (local, national, transnational); and the need to include or involve the participation of all relevant stakeholders in managing water. (Conca 2006:124) There are two points that I want to emphasize here: First, as with the idea of water as an economic good, IWRM floats in modern water - modern water is the unmarked, presumed, naturalized essence of what water is that makes IWRM possible, and that makes it possible to imagine that such a concept may be applied to the world's water and the world's people as a whole. However - and this is the second point that I want to emphasize - by its own logic, modern water also dooms IWRM to failure. 
The most often-cited short definition of Integrated Water Resources Management is found in the aforementioned report, World Water Security: A Framework for Action: "IWRM" it declares, "is a process which promotes the coordinated development and management of water, land and related resources in order to maximize the resultant economic and social welfare in an equitable manner without compromising the sustainability of vital ecosystems." (Global Water Partnership 2000) The presence of modem water in this formulation is perhaps best indicated where IWRM is identified as "a process that promotes the coordinated development and management of water." (my emphasis) But the urge to formulate a single, coordinated process for developing and managing the world's water has produced what must be recognized as a completely unworkable concept. Asit Biswas, ${ }^{44}$ has recently critiqued IWRM as a "vague, indefinable and unimplementable concept" that has nevertheless achieved widespread popularity in the past ten years because water professionals required a "paradigm for management, which will solve the existing and the foreseeable water problems all over the world." (Biswas 2004:3, my emphasis) The problem, as Biswas points out, is that a paradigm with such universal ambition suffers a critical breakdown when brought to bear on specific water issues. "Not surprisingly, even though the rhetoric of integrated water resources development has been very strong in the various international fora during the past decade, its actual use (irrespective of what it means) has been minimal, even indiscernible in the field." (Biswas 2004:6)

\footnotetext{
${ }^{44}$ Whose History of Hydrolgy appears prominently in the standard history of the hydrologic cycle as described in Chapter 5. (Biswas 1970)
} 
The problem that Biswas identifies is perhaps best illustrated by quoting from one of the foundational expressions of IWRM: "Integrated water resources management" declares Agenda 21, "is based on the perception of water as an integral part of the ecosystem, a natural resource, and a social and economic good." (quoted in Gleick et al. 2002:38) Consistent with the constitution of modern water, each of these ways of perceiving discloses water as one thing. But by the same token, (modern) water can hardly be all of these things at once. This difficulty is apparent when considering all four of the principles adopted at the 1992 International Conference on Water and the Environment (the Dublin principles) together:

1. "Fresh water is a finite and vulnerable resource, essential to sustaining life, development, and the environment.

2. Water development and management should be based on a participatory approach, involving users, planners, and policy makers at all levels.

3. Women play a central part in the provision, management, and safeguarding of water.

4. Water has an economic value in all its competing uses and should be recognized as an economic good." (quoted in Conca 2006:141)

It has to be admitted that these principles comprise numerous contradictions. How can recognizing water as an "economic good" be reconciled with its essential function of sustaining life? Does adopting "a participatory approach involving users, planners, and policy makers at all levels ${ }^{n}$ not create a formula for protracted conflict? Does Principle 3 mean that the needs and views of women should trump those of men in matters regarding "the provision, management, and safeguarding of water"? Of course, in every instance, water (like everything else) internalizes 
contradictions that imbue it with a tremendous capacity for change. These Dublin principles - like the IWRM concept generally - might therefore have served as a means of transcending modern water by underscoring its heterogeneous social nature. However, modern water's presence in these formulations is betrayed by the insistence that water is and should be considered fundamentally as one thing; a betrayal that inevitably constrains the practical success of these formulations.

Because it retains modern water, the declension of an unresolvable global debate over the question of what water is under the new global regime has characterized water politics over the past decade. If water "has an economic value in all its competing uses and should be recognized as an economic good", as declared in the fourth Dublin principle, how can this be reconciled with the perception of water as a "social good" or as "an integral part of the ecosystem" as declared in Agenda 21 ? Is water a natural substance to which all people are entitled as a function of their fundamental human rights, or a product that may be priced and traded? Is it a national resource, to be conserved and safeguarded by the territorial state, a global commons to which all of humanity has some claim, or a transnational commodity to be disposed of in accordance with market principles? Is it the lifeblood of ecosystems or a resource in the functional sense? As Conca has argued, the global water regime, grounded as it is on such ambivalence, is "doomed to founder" on these fundamental questions: "[F]ar from generating more workable, consensual norms [IWRM] has instead become embroiled in chronic conflict and controversy... 
For some, IWRM represents the death of the idea of rivers as resources and substitutes an imperative for comprehensive planning to balance economic, ecological, and social considerations. For others, it constitutes an effort to perfect rather than abandon the rivers-as-resources idea - to shift river development projects and water itself from a state-supplied public good to a private economic good, subject to the disciplining rule and valuation techniques of the market. As a result, the IWRM arena has been marked by struggles over public versus private authority, conflict over market versus nonmarket bases for resource valuation and allocation, and tensions between the territorially fixed character of the state and the transnationally fluid character of contemporary global capitalism." (Conca 2006:127-8)

\section{Conclusion}

It is telling that all sides engaged in the politics of water have used "the water crisis" as a rationale for advancing their respective views. The World Water Council's parlaying of crisis into its particular Vision has been described above. ${ }^{45}$ Meanwhile, Maude Barlow, a Canadian-based activist and leading figure in the transnational campaign against privatizing and marketizing water, is equally adamant about the seriousness of the water crisis. In a seminal polemic titled The Global Water Crisis and the Commodification of the World's Water Supply, she declares, "There is simply no way to overstate the water crisis of the planet today." (Barlow 2001:9) The same could be said for, and has been said by, others who are primarily concerned with protecting the health of freshwater ecosystems in the face of a growing suite of anthropogenic assaults: "This water crisis" reports the International Rivers Network on the occasion of its tenth anniversary, "has

\footnotetext{
45 The commitment to the market and to private sector solutions that is entailed its Vision is perhaps best indicated by its subtitle - Making Water Everybody's Business.
} 
significant ramifications for the world's river systems and all who depend upon them." (Lamers 1999)

The political debate itself attests to the strength of modern water's constitution. Instead of a crisis of modern water, the water crisis has been interpreted by most as a set of circumstances that demands that modern water be strengthened! The irony is that modern water can hardly be sustained in this climate of competing claims. Water - or rather modern water - cannot be an economic good, a resource, a public good and the lifeblood of rivers at once. By channelling all these various waters through "the water crisis" we produce a stunning paradox. No wonder, as Ken Conca has observed, "We seem, therefore, to be at an impasse." (2006:4) Chapter 10 describes a relational-dialectical practice that transcends the paradox, and gets us beyond the impasse. The aim here will be to proceed on the basis of recognizing "internal" relations of water and society, and thus to emphasize the potential for their mutual transformation. 


\section{Part III - In the Wake of Modern Water}

"[T]he task of critical analysis is not, surely, to prove the impossibility of foundational beliefs (or truths), but to find a more plausible and adequate basis for the foundational beliefs that make interpretations and political action meaningful, creative, and possible." (Harvey 1996:2) 


\section{Hydrolectics}

"Water is not about water. Water is about building people's institutions and power to take control over decisions." (Sunita Narain, head of the Centre for Science and Environment, on the occasion of accepting the 2005 Stockholm Water Prize, August 25, 2005.) $)^{1}$

"Let me put it bluntly: political ecology has nothing to do with nature." (Latour 2004:5)

\section{Introduction}

As I write this, many Canadians are learning (or being reminded) of the appalling water conditions that pertain in many of the country's remote native communities. In late October of 2005, it came to light that the water treatment and distribution system of the Kashechewan reserve on the shore of James Bay was contaminated with potentially deadly Escheria coli bacteria. Most of the community's 1,200 residents were evacuated to cities in central and southern Ontario pending a solution to the problem. In the ensuing media coverage of the event, it was reported that for over two years prior to this outbreak, people in Kashechewan had been advised by federal government officials to boil their tap water before using it. Now, in the wake of an infamous $E$. coli outbreak in 1999 that had killed seven people in Walkerton, Ontario, the discovery of $E$. coli in Kashechewan was felt as a disgrace to all Canadians.

\footnotetext{
${ }^{1}$ World Water Week in Stockholm Webpage. Accessed August 26, 2005 http://www.worldwaterweek.org/press/050826.asp
} 
The plight of the residents of Kashechewan, although certainly acute, was hardly unique. At the time the incident was reported, there were 38 other native communities in Ontario that were under official "Boiling Water Advisories"; and for Canada as a whole, the number was over one hundred. ${ }^{2}$ It thus came to light that the residents of native communities all across the country were compelled to use bottled water, or water imported from hundreds if not thousands of kilometres away. (Globe and Mail 2005a, 2005b) Nor was this regretful situation only a recent occurrence. In 1988, the Science Council of Canada had reported that fully onehalf of all on-reserve homes in Canada had no piped water. And in 1994, an outbreak of water-borne hepatitis B. in the community of Pukatawagan in northern Manitoba galvanized the county's attention when a group of its residents began to walk south to the provincial capital to protest the deplorable water conditions in their community. (Linton 1997:108) As with the revelation of $E$. coli in Kashechewan, the Pukatawagan story drew national attention to the water crisis facing Canada's native communities. Then as now, Canadians expressed their shock and disgust, and politicians promised to fix the problem.

The irony of the water crisis in Canada's northern native communities is striking. Although a couple of the reserves involved are located in the southern, more densely populated part of the country ${ }^{3}$, almost all are in more remote northern

\footnotetext{
${ }^{2}$ A 2003 survey had found that of 740 First Nations community water systems assessed in Canada, "about 29 percent (218) posed a potential high risk that could negatively impact water quality." (Indian Affairs and Northern Affairs Canada 2003a:i-ii)

${ }^{3}$ At the time of the Kashechewan incident, it was reported that the Mohawks of the Bay of Quinte, near Belleville, had been dealing with boil-water advisories since at least 2003.
} 
regions. There is perhaps no place on Earth world where 'natural' water resources are more plentiful and of better quality than in northern Canada. Even when including the more heavily populated parts of the country, Canada boasts a per capita supply of river runoff greater than almost every other country (Gleick 1993b:18), and our share of the world's lake water is second to none. ${ }^{4}$ With its vast hydrological resources and relatively miniscule human population, there could not be more unlikely place for severe water problems than northern Canada. And yet, it has to be acknowledged that these problems are of a magnitude equal to those facing communities in parts of the world that have been designated as "highly water stressed" when measured in terms of water resources per capita. ${ }^{5}$

The stories of Kashechewan and Pukatawagan illustrate how the water crisis has less to do with water than it may appear. As the Indian socioenvironmental activist Sunita Narain has declared, "Water is not about water." This assertion strikes us as paradoxical - like a water crisis in northern Canada! - because we regard "water" in the first instance as some-thing that we act upon. In the way of thinking conditioned by modern water, water can always only be "about water." That water is, or may be, about something entirely different from that to which we have

\footnotetext{
${ }^{4}$ Canada has about 9 percent of the total (global) volume of runoff. About 20 percent of the world's water stored in lakes is found in Canada, and a slightly larger percentage of the world's wetlands. (Pearce et al.:1985) When set against the less-than-0.5 percent of the world's human population, Canada's water resources may be considered extremely abundant.

5

${ }^{5}$ One useful way of thinking about such problems is to distinguish between first and second order scarcities. (Ohlsson and Turton 1999) First order scarcity describes a shortage of naturally occurring water as say measured in terms of water availability (streamflow) per capita. Second order scarcity can be considered the incapacity of a society to either manage first order scarcity or to translate natural water supplies into useful water services. (Brooks 2003:53-54) The water problems in Canada's north would be a prime example of second order scarcity in the midst of water plenty.
} 
become accustomed is suggested in the second part of Nairain's statement: "Water is about building people's institutions and power to take control over decisions."

Taking "control over decisions" is relevant to the water crisis in Canada's north. Of all Canadian communities, the residents of northern reserves have been among the least likely to have a say in the water systems on which their collective and individual health depends. Although First Nations Band Councils have primary responsibility for the construction, operation and maintenance of water systems on reserves, these systems are designed, built and operated in accordance with federal (or in some cases provincial) government standards and they use technologies that have been developed in industrialized, urban environments. The choice of technologies, as well as the construction, operation and maintenance of these systems, is largely a matter of remote control from Ottawa, governed by what can only be described as foreign knowledge and expertise. ${ }^{6}$ The result is a product so alien to people in these communities that many residents have come not to trust it for drinking, or even for bathing. The irony of people living in northern Canada who feel that they must use bottled water for their daily needs suggests a fundamental, and tragic, disconnect in hydrosocial relations. It also suggests that until these people gain a greater measure of "power" and "control" over the manner

\footnotetext{
${ }^{6}$ The difficulty entailed in transferring this knowledge and expertise from places where these technologies were developed to northern communities is manifest. A study conducted by the federal Department of Indian and Northern Affairs in 2003 found that only about ten percent of the operators working in First Nations water and wastewater treatment facilities were trained to meet industry certification requirements. (Indian and Northern Affairs Canada 2003a:9) The importance of embedding water technologies into the fabric of local culture is the main theme of Brooks 2002.
} 
in which they relate to water, the basic problem will remain, no matter how much money the federal government allocates to infrastructure development for these communities. $^{7}$

Water isn't about water - it can't be about water, because as I have sought to argue throughout this thesis, water is no one thing. So long as we accept uncritically the notion that water is about water, we acquiesce to fixing its nature in a particular web of knowledge, management, and material infrastructure. In so doing, water is effectively removed from the more immediate ecological and social contexts in which people find it and give it meaning. Such an act of removal, or abstraction, renders different waters susceptible to technical discourses of water management, but occludes their particular social natures. As the blanket application of modern water management comes under critical scrutiny in more and more places, the idea of water's social nature, and of is specificity in relation to different social circumstances, becomes more compelling.

In a summary of recent scholarship on water issues, Malin Falkenmark has noted that water "is recognized increasingly as an essential component in the dynamics of poverty; poor water management can indeed create and perpetuate poverty. Not only is secured access to water essential for poverty alleviation, but water

${ }^{7}$ For a recent federal government assessment of the nature and scope of the problem, as well as recommendations on how to address it, see (Indian and Northern Affairs Canada 2003a). Note that in the spring of 2003, the federal government announced $\$ 600$ million in new funding targeted towards improving the quality of water and wastewater treatment in First Nations communities across Canada. (Indian and Northern Affairs Canada 2003b) 
development is closely linked to food production and hunger alleviation, and to energy development." (Falkenmark 2005:5) Similarly, the resource economist David Brooks has stressed how, over the past dozen years, development professionals "have come to recognize that, if efforts to improve the quantity and quality of water supply are to be successful, not only must they be technically sound and economically feasible, they must also deal directly with poverty alleviation, local empowerment and ecological protection." (Brooks 2002:xi-xii) Such statements as these indicate that despite the efforts of the "global water regime" as discussed in the last chapter, a growing cadre of water experts are beginning to operate on the presumptions that water is not merely about water. This growing recognition of the importance hydrosocial relations suggests the need for a method of approaching water that formalizes its social nature. The rudiments of such an approach are offered here under the term "hydrolectics." Hydrolectics is as a relational-dialectical approach to water that I have more or less applied throughout the foregoing critique of modern water. What I hope to do here is suggest how this approach might be applied in more practical, or constructive, sense.

My thesis is that modern water - the scientific abstraction of water from social relations - frames water problems in such a way that water itself is made the problem. Accordingly, addressing water problems is a matter of "water management", i.e. performing some kind of operation on water (traditionally by engineering new supplies, and more recently by devising ways to allocate 
available supplies more efficiently and to treat water as an economic good).

Instead of conceptualizing water as something to be manipulated and governed by remote control and the hidden hand, hydrolectics begins with the premise that waters are diverse and are made known through different modes of engagement. This approach suggests an alternative kind of hydrological science, one that fits the philosopher Catherine Hayles' description of "a science understood to flow from historically specific interactions":

"By separating subject from object, objectivism helped to constitute the belief that one could act upon the world without oneself being acted upon. The Baconian vision of human domination of the planet through science could thus be put forward as an enterprise that would not necessarily also affect those who dominated. Extrapolated to the environment, this attitude implies that rainforests can be cut without affecting those doing the cutting; rivers polluted without poisoning those polluting; flourohydrocarbons released without affecting those doing the releasing. By contrast, a science understood to flow from historically specific interactions implies that we know the world because we are involved with it and because it impacts upon us. While such an understanding of the scientific enterprise does not guarantee respect for the environment, it provides a conceptual framework that fosters perceptions of interactivity rather than alienation." (Hayles 1995:56, my emphasis)

As discussed in Chapter 9, the "crisis" that has garnered such attention in the last fifteen years can productively be considered as a crisis in the way water is understood to be as well as a crisis involving water's scarcity or availability. In this view, the question of its scarcity - as well as the question of the efficiency with which it is used - is understood not so much as a hydrological fact, but as a condition of the interaction between people and the water process. By the same token, problems like poverty and economic development in many cases may be 
understood as conditions that flow from particular hydrosocial relations, conditions moreover, that might be changed through hydrolectic practice.

As a final point of introduction, it might added that hydrolectics offers an approach that dampens the impulse - conditioned by modern water - to establish universal rules, criteria, or principles for how humanity ought to relate to water to in order to promote sustainable water management. I mention this because such universal rules, criteria, or principles, whatever their merits, have the effect of sustaining the hydrosocial relations that comprise modern water - in other words, they tend to sustain modern water in the face of the constitutional challenges that might otherwise cause people to question it. "Understanding the stocks and flows of water through the world's hydrologic cycle", Gleick asserts, "is essential to any discussion about the world's water problems." (Gleick 2000b:19) This may be so, but the point that I want to stress is that such an understanding conditions "any discussion about the world's water problems" in such a way that the discussion is framed by the possibilities of modern water. ${ }^{8}$

\footnotetext{
${ }^{8}$ Modern water thus conditions a response that calls for "a sustainable vision", a vision that sustains modern water itself. Gleick defines "sustainable water use" as: "the use of water that supports the ability of human society to endure and flourish into the indefinite future without undermining the integrity of the hydrological cycle or the ecological systems that depend on it." (Gleick 1998a:574) Elaborating on a set of "sustainability criteria for water planning", he puts forward a set of rules for water governance that are presumed to apply universally. (1998a:574578) (Gleick 1998b:ch. 7)
} 


\section{Principles of Hydrolectics}

The core idea of hydrolectics is that water becomes what it is through engagement with social processes. Hydrolectics thus provides a relational-dialectical means of realizing the social nature of water. The objective of a hydrolectic approach is to consider how and why water becomes what it is at any given place and time, and how it might become something different. Because it situates water at the confluence of non-human and social processes, hydrolectics posits an extremely fluid and transformative notion of the nature of water, of society, and of the potential for hydrosocial relations. Here are several principles from which a hydrolectic approach might proceed:

1. Water, in the first instance, is not a thing; it is a process. ${ }^{9}$ The water process may be regarded as an example of what Harvey (1996) calls an "underlying generative process" that gives rise to a rich diversity of potential things. ${ }^{10}$ The water process itself, however, cannot be described or represented in an objective way, because it shows up for us only in relation to the social processes that engage it. ${ }^{11}$ Thus, the water process may occur as the hydrologic cycle when engaged with the practice of scientific hydrology; it may occur as (thermodynamic)

\footnotetext{
9 Harvey uses capital as his prime example of a generative process: "Capital is directly conceptualized, therefore, as a process or as a relation rather than as a "thing." It is viewed, in its simplest incarnation, as a flow which at one "moment" assumes for "form" of money, and at another assumes the "form" of commodities or the "form" of productive activity." (Harvey 1996:63) The analogy between water and capital is suggestive, especially considering that the idea of "the economy" as constituted by the circulation of capital, became current (sorry!) at approximately the same time that the (scientific) hydrologic cycle appeared. (For invention of "the economy" as a discursive object see Mitchell 1998)

${ }^{10}$ This statement is considered more carefully in the concluding chapter. 11

Something of this idea is captured in llich's notion of "...this ineffable stuff called water..." (1985:8)
} 
energy when engaged with the practice of sub-atomic physics; as a river when engaged with the process of Heraclitan philosophy; as an arena when engaged in the process of playing hockey; as an energy resource when engaged with the process of hydro-electric generation; as a solvent when engaged in the process of private bathing; as a medium of social interaction and conviviality when engaged in the process of public bathing, or public skating; a factor of production when engaged in the process of agriculture; as time, change, striving, desire or life itself when engaged with the process of writing poetry.

2. Water then, is a process that may get hydreified in a variety of ways in relation to social processes. It follows that the usefulness of water to people (its resourcefulness) is extremely fluid and may be recognized and defined differently, relative to particular hydrological and social circumstances. Modern water has the effect of fixing water resources in a particular way, one that sustains some hydrosocial relations while denying the legitimacy of others. ${ }^{12}$ Hydrolectics offers a means of helping bring entrenched sets of hydrosocial relations to light, thus

\footnotetext{
12 The similarities between hydrolectics and Zimmermann's functional appraisal of resources are readily apparent. (Zimmermann 1933; 1951) Hydrolectics, however, differs from the functional approach in at least one fundamental respect: Zimmermann is quite unable to accept the implications of his own relational view of resources. In order to protect the functional approach from charges of wonton relativism, he combines it with the doctrine of progress. Thus, in the event of a contradiction of appraisals, Zimmermann allows for the legitimacy of that appraisal that corresponds to what he regards as the more developed society. For example, in the event of a First Nations group appraising a river as a spiritual resource - an appraisal that is inimical to the kind of resourcefulness disclosed by the same river to a provincial hydro-electrical utility - Zimmermann's functional approach holds that the utility's appraisal of the river must be regarded as prior, or more legitimate, than that of the First Nations group. (For elaboration of this argument, see Linton 2006) The implicit conservativism of the functional approach can thus be contrasted with a more transformative hydrolectics.
} 
providing a means of contesting them and defining water's resourcefulness in alternative ways.

3. Just as "water is not about water", in most cases it is not "water" that people need, but the various services that water may provide. (Brooks 2003) Due to the remarkable fluidity of the water process, these potential services are practically limitless, and as a result, water has come to be regarded as an 'essential resource' for myriad purposes ranging from agriculture, to industrial production, to sewage disposal. Hydrolectics offers an approach that facilitates a freeing-up of this 'essential resourcefulness' of water - a basis for realizing the potential inherent in the notion that it is not water that people need, but the services that water may provide. "By looking at water as a bundle of services rather than a natural resource or commodity," writes resource economist, David Brooks, "many more options can be conceived to satisfy demands..." (Brooks 2003:11) ${ }^{13}$

4. As noted in the conclusion of Chapter 3, from approximately the time of Pierre Perrault, the "fate" of various waters is no longer a legitimate subject of scientific inquiry. Following Perrault, although these waters may...

\footnotetext{
${ }^{13}$ This idea is from one of Brooks' recent studies on 'soft water paths.' Water soft paths describes an approach that is at the cutting edge of thought in the water management community, based on earlier work by Amory Lovins on energy. (Lovins 1977) Among other ingredients, it attends to the potential efficiencies that can be realized by matching the quality of water supplies with the requirements of water demands, and - as suggested - satisfying social ends by alternative means that may not require the use of water at all. (See Brooks 2003; Brooks 2005; Brandes and Brooks 2005; Gleick 2003) These aspects of water soft paths are entirely consistent with hydrolectics, particularly insofar as they suggest a radical alternative to modern water. Not entirely consistent with hydrolectics, however, is the presumption of managerial expertise required to ensure that they be followed correctly.
} 
"...run upon the Earth and throughout the World, I shall let them do so without taking any interest in what may happen to them, good or bad; if the ones become famous through the various good or bad qualities that have contracted in their travels, according to the lucky or unlucky meeting they may have made with favourable or unfortunate soils; if others attract the admiration and amazement of curious people by their flow and by their surprising effects, if others remain by nature mild and peaceful, as they were at birth. All this is no concern of mine, it is enough that they should be simply springs, their quality being only an accident which can happen or not happen to them without changing their essence. (Perrault 1967:144-45)

The point of hydrolectics is to invert Perrault's formulation; it is to give particular consideration to the fates of waters (not water's fate) in relation to the places and the peoples through which they flow. Hydrolectics promotes an epistemology that shifts attention from water's "essence" to its "accidents." To foster knowledge of waters in relation to the circumstances in which they appear is to assume a kind of local and social responsibility that has been permitted to lapse in the era of modern water. (Ward 1997)

5. Water may be understood in fundamentally different ways, depending on the circumstances. The circumstances may be described as social and historical, but they also include the scale at which water is made known. This hydrolectic principle is actually derived from modern scientific practice: James Dooge writes of the "differences in the concepts of water and of models used in the physical sciences to simulate water" and "how these depend greatly on the question of scale":

"There is no single meaning of water and no universal model for water even in the physical sciences. To the physical chemist, water is a polar molecule and 
therefore non-isotropic... To the scientist interested in continuum mechanics, water is considered as an isotropic fluid without memory whose constitutive equation can be assumed to be linear and consequently whose motion can be described by the Navier-Stokes equations [for fluid dynamics, or hydrodynamics]. To the expert in hydraulics, water is an incompressible fluid of turbulent behaviour for which the Navier-Stokes equations may still be valid at a point but which are no longer useful because of the complexity of the flow pattern. To the geomorphologist, water is an agent of denudation whose action has moulded the landscape and determined the drainage pattern whether permanent or ephemeral. At the global scale, water to the geochemist is a reactive transporter in the various geochemical cycles of carbon, nitrogen, phosphorus and sulphur. To the geophysicist, it is a climate modifier whose anomalously high latent heat of vaporization enables large quantities of energy to be transported from the tropics to the polar regions through the general circulation of the atmosphere.

It is becoming increasingly clear that the differences in the concepts of water and of the models used in the physical sciences to simulate water depend greatly on the question of scale." (Dooge 1983:40)

Dooge makes it very clear that the concept of what water is changes in relation to the type and scale of scientific investigation undertaken. Water is one thing to a chemist, another thing to hydraulician, and yet another to a geomorphologist. The relational-dialectical assertion that water becomes what it is relative to the (social) context is, as l've been trying to show throughout, conspicuous outside of the physical sciences. We say that water is one thing to the parent who has her child baptized, and another thing to the bather, the gardener, the thirsty traveller, the sailor, the entrepreneur, the desert dweller, the skier, the drowning person.... In each of these instances, water is a different thing. This notion contradicts modern water to its very core. But the prejudice induced by habituation to modern water, the sort of water blindness that insists that all of these waters can ultimately be reduced to the same thing scientifically is, as Dooge points out, belied by the very practices of the different sciences themselves. 
6. Hydrolectics attends to the way a given hydreification internalizes multiple contradictions, giving rise to the possibility of transformation. "A...consequence of the heterogeneity of all objects", write Levins and Lewontin, "is that it directs us toward the explanation of change in terms of the opposing processes united within that object. Heterogeneity is not merely diversity: the parts or processes confront each other as opposites, conditional on the whole of which they are parts." (Levins and Lewontin 1985:278) Even something that appears to be as simple and straightforward as a glass of water can be understood hydrolecticly as internalizing multiple contradictions. Swyngedouw's meditations on a glass of water drawn from a typical urban water supply system provides a good illustration of this complexity:

"If I were to capture some urban water in a glass, retrace the networks that brought it there and follow Ariadne's thread through the water, [quoting Latour] 'I would pass with continuity from the local to the global, from the human to the non-human'. These flows would narrate many interrelated tales: of social and political actors and the powerful socio-ecological processes that produce urban and regional spaces; of participation and exclusion; of rates and bankers; of water-borne disease and speculation in water industry related futures and options; of chemical, physical and biological reactions and transformations; of the global hydrological cycle and global warming; of uneven geographical development; of the political lobbying and investment strategies of dam builders; of urban land developers; of the knowledge of engineers; of the passage from river to urban reservoir. In sum, my glass of water entails multiple tales of the 'city as a hybrid'. The rhizome of underground and surface water flows, of streams, pipes and networks is a powerful metaphor for processes that are both social and ecological. Water is a 'hybrid' thing that captures and embodies processes that are simultaneously material, discursive and symbolic."

(Swyngedouw 2004:28)

In this passage, Swyngedouw presents a glass of water as something that has to be understood in relation to the hydrologic and social processes that have made it what it is. The numerous contradictions internalized in such a glass of water 
suggest the possibility of transformation at every node of the "networks" that produce it. Water is thus understood as a "hybrid thing" with enormous social potential.

\section{Practicing Hydrolectics}

In this section, we will consider how hydrolectics may be applied practically and analytically. The distinction is somewhat arbitrary as the way we analyse a problem or thing is internally related to the way we relate and respond to it, and visa versa. Moreover, as we shall see, analytical and practical hydrolectics overlap in many ways; nevertheless, by considering them separately, different aspects of the practice might be better explained. To offer a rough approximation, practical hydrolectics can be described as the business of changing waters and the social relations that sustain them while analytical hydrolectics can be described as the study of such relations and changes:

Practical hydrolectics means getting ourselves into the water, not only by becoming involved in decisions about water but by actively becoming mixed up in the solution that produces what water is and what it might be. Getting into the water in this fashion may have the effect of transforming modern water into alternative hydreifications.

Analytical hydrolectics means identifying the particular structure of water's hydreification(s) in any given situation. That water is different things to different 
people depending on their respective modes of engagement is the main principle behind this mode of analysing problems and issues involving water. After discussing practical hydrolectics, I want to propose a very rudimentary method for this kind of analysis.

\section{Practical Hydrolectics}

"[T]echnocratic discourse and argumentation help to obfuscate the issues of power and control and to formulate the water problem as one that is determined by the power over nature rather than by the power of one social group over another." (Swyngedouw 2004:176)

Practical hydrolectics reorients our response to water problems so that instead of striving to master a presumed water nature, we strive to change water's (social) nature in order to promote alternative hydrosocial relations. An inkling of this reorientation can be found in Integrated Water Resources Management. Recall the second and third principles adopted at the 1992 International Conference on Water and the Environment (the Dublin Conference): "Water development and management should be based on a participatory approach, involving users, planners, and policy makers at all levels." And "Women play a central part in the provision, management, and safeguarding of water." However, the fact that there may be fundamental differences between the waters of users, planners and policy makers (including women in each of these roles) is not recognized. ${ }^{14}$ The modern-

\footnotetext{
${ }^{14}$ For an excellent study of the disenfranchisement of women from control of water via discourses and techniques of modern water management see Strang 2004.
} 
water bias of IWRM thus makes it difficult to put these excellent principles into practice. As Conca has pointed out:

"Not surprisingly an approach grounded in expert knowledge, scientific rationality, and increasingly bureaucratic organization has often reinforced a limited, huband-spoke notion of participation. Helpful information about uses, preferences, behavior, and effects flow in from society to expert centers; scientific truths as guides to social action flow out." (Conca 2006:158)

Practicing hydrolectics might be considered a means of allowing IWRM to live up to its participatory potential. But it suggests a different kind of participation, one that begins by recognizing that water may show up in a variety of different ways to different people, depending on how they are involved. A practical hydrolectics starts with the proposition that any forum that brings together "users, planners and policy makers at all levels" inevitably entails a discussion of different hydro-social relations and different modes of knowing what water is. ${ }^{15}$ Of particular importance is that the waters of those whose hydrosocial relations are not represented in discourses of modern water management are given equal time. Stressing the reality and the legitimacy of subaltern waters is thus an important aspect of practical hydrolectics.

\footnotetext{
15 Something of what I mean for water has been suggested by Bruce Braun with respect to the forest: Critiquing efforts to bring together various "stakeholders" to identify a single consensus on the disposition of a British Columbia forest, Braun observes: "What was needed [instead] was a sustained examination and appreciation of the multiple ways that the forest was invested with meaning and value. What was required was an examination of our passionate attachments to these forests, attachments whose histories were not merely personal, but political, not merely local, but carried from afar... Where once I imagined that consensus could be reached by stripping away ideological preconceptions, I now realize that if any consensus is to be reached, it will have to be something built rather than found, provisional rather than final, always open to examining its own constitutive exclusions." (Braun 2002:5-6)
} 
I want to give a couple of examples where practical hydrolectics might be regarded as effecting reconstitution of water and people in ways that deliberately challenge modern water. In both these examples, modern water might be seen as an obstacle to achieving sustainable and salutary hydro-social relations; the people most affected are directly engaged in dismantling this obstacle and are in the business of defining and managing new relations with water. The first example has been described as "people-oriented water solutions" that are being developed in urban environments in both the global north and south. The second example is drawn from the consolidation of decades of experience in water-related research and in developing regions.

\section{"People-oriented water solutions"}

Balanya et al. (2005a) have recently edited a compendium of case studies where the citizens of urban regions are taking control of water in a way that patently bucks the modern trend of statist, technocratic water management. The basic principle of these "people oriented water solutions" (Balanya et al. 2005b:247) is that local citizens must be involved in all matters pertaining to water management. But it is also patent that when they are so involved, communities of people identify water and assert its social nature in ways that differ markedly from modern water.

As with so many other aspects of water management, the 1980 s marked something of a paradigm change with respect to urban water services, especially 
notable in the developing world. The International Drinking Water Supply and Sanitation Decade (1980-1990) was occasioned by a shift in approach to urban water supply and wastewater treatment that emphasized a diversity of techniques; flexibility in adapting techniques to local hydrological and social circumstances rather than uniformity; and more fluid modes of water management than had been permitted by the bureaucratic rigidity characterizing modern urban water management structures. As such, it has been argued that the 1980s "formed part of a widespread contemporary critique of modernisation" (Bell 1992:83) and "came to bear many hallmarks of a post-modern age." (1992:84) Among these hallmarks was the swelling wave of marketization and privatization of water infrastructure encouraged, in part, by the structural adjustment policies of the World Bank:

"During the course of the Decade, the World Bank, taking its lead from the new Right, led the way in ensuring that the concept of basic needs, codified internationally as legal rights, was narrowed down and its meaning altered by a succession of additional labels including affordability, cost recovery and hence replicability. In effect, basic services as an essential part of collective consumption were transformed from human rights to commodities subject to the rigours of the market." (Bell 1992:85)

It is against this codification of water as commodity that water activists and many academics have more recently asserted alternative identities of water as a public good and a human right. (e.g. Shiva 2002; Barlow and Clarke 2002; Bond 2001). The shift - especially marked in the 1990s - towards privatizing water service infrastructure may have had the salutary effect of breaking up some of the least responsive statist water regimes, however many examples of privatization are now judged to have failed, especially in improving services for the poor. (Hall 2005) In 
the wake of these failures, it is recognized that the source of many urban water problems is not the public sector per se, but "a lack of democratic process in the public sector..." (Hall 2005:20) State-owned and managed water systems (especially when highly centralized and concentrated) have proven to be socially as well as financially unsustainable, with many having been entirely unresponsive to public concerns, including the need to provide the less affluent residents of cities with adequate water and wastewater services. When reconstituted in more democratic, responsive fashion, the general result has been the "reclamation of public water", manifested in myriad ways through different organizational structures responding to particular social and hydrological circumstances. The Balanya compendium shows...

"how significant improvements in access to clean water and sanitation have been achieved by diverse forms of public water management. These people-centred public water solutions have occurred under a variety of socio-economic, cultural and political circumstances. ... In [most of these cases], citizen and user participation in various forms is an essential factor behind the improvements in effectiveness, responsiveness and social achievements of the water utility. ... While it should not be considered a panacea to be implemented in every situation, and in some circumstances may not be feasible, participation and democratization in its multiple forms can be a powerful tool for positive change in most circumstances. (Balanya et al. 2005b:247,249,254)

Especially relevant in the context of this discussion, is that in order to gain access to and control of water on their own terms, the players involved in these "peopleoriented water solutions" have insisted on identifying water in their own terms, i.e. as a public good, but one to which the state has no prior claim. 


\section{Local water management}

What seems to be emerging at the progressive edge of urban water governance combines the rejection of state structures and rigid techniques, with a renewed emphasis on democratic participation in decision making to produce a plethora of what we might call post-modern public waters. The principle of local involvement in water discourses and governance is also an important lesson that has been gained by international development agencies involved in water in recent decades. "Local water management" writes resource economist David Brooks,

"permits a democratizing decentralization of decision making and accountability. Well done, it empowers people (particularly the poor and otherwise disadvantaged) to take part in the decisions that define their own futures. And it encourages the integration of traditional knowledge with innovative science to promote fair and efficient supply management." (Brooks 2002:5-6)

The overriding principle of "local water management" as described by Brooks, is that people "need to be engaged in the decisions affecting their lives" (Brooks 2002:7) While this may seem an obvious prerequisite for success, it nevertheless poses a serious challenge to modern water and to the expert discourses by which modern water is sustained. Adhering to such a principle means paying attention to the particular hydrosocial relations and the different waters that inhere in specific social contexts. Further, it often means recognizing the legitimacy of, and adapting, relatively simple techniques that embody traditional, or local knowledges of water. In many cases, these knowledges and techniques have been shown to be more 
successful and sustainable than complex, exogenous technologies, no matter how brilliant the latter may appear to their progenitors. (Brooks 2002:17)

The adaptation of traditional waters to $21^{\text {st }}$-century circumstances has already been discussed (in Chapter 2) above, for example with respect to the tank system in southern India and other techniques of rainwater harvesting. These examples are suggestive of hydrolectic practice in that they begin with understandings of, and relations with, water that are indigenous to particular peoples and places. Exogenous techniques may be adapted to such circumstances - indeed they often must be so in order for traditional waters to meet today's needs - but in these cases, there is no imposition of modern water.

A kind of counter-example is provided in cases where an inattentiveness to local waters has resulted in the failure of what otherwise appear to be ideally appropriate technologies. Among the many illustrations that may be cited are technologies for harvesting water from fog that were developed with funding from the International Development Research Centre and UNESCO in the 1980s. The construction of "fog catching" apparatus (nets) on the highlands, and water conduits leading to communities in the rain shadow of the Andes Mountains in Chile, materialized an ingenious solution to the problem of water scarcity in these communities. Prior to being introduced to this novel source of water supply, these communities had relied almost entirely on very expensive water trucked over long distances. By the early 1990s, one installation of fog catchers was providing 
people of the local village with 11,000 litres of clean water daily, enough to furnish 33 litres for every person in the village at very low operating costs - this was more than twice the per capita supply that the community was paying to have delivered by truck.

Despite their technical elegance and initial functional success, the fog catchers in Chile ultimately failed, partly because of higher-than-expected costs and because they required more coordinated maintenance of the nets for harvesting fog and pipes for transporting it than the community was able to sustain. More significantly, the failure for a reason that their designers hadn't considered beforehand: the water from fog catchers was deemed inferior - or "second class" - to water supplied via "modern" supply systems such as municipal distribution networks, or even trucks! The perceived inferiority of the water provided by the new technology made this technology unsustainable in this particular social context. (Brooks 2002:10-12) While it may have been regarded by outside observers as far superior to more expensive truck-delivered water, the production of fog-water could only be sustained within a set of social relations, attitudes and expectations that were then foreign to the target community.

\section{Analytical Hydrolectics}

By analytical hydrolectics I mean simply applying a relational-dialectical approach to the study of people and water. This thesis could be considered a lengthy 
exercise in analytical hydrolectics. Here, I want to suggest something of a framework for hydrolectical analysis of specific water issues. The value of such a framework might be suggested by recognizing that the water "users, planners and policy makers" invoked in the third principle enunciated at the Dublin Conference in 1992 each has a different relation to, and understanding of, water. The need to consider these different waters is perhaps implied in various calls to involve all "stakeholders", or "participants" in water decisions. For the most part however, the very language of stakeholding and participation belies the homogenizing effects of the process: IWRM, and related prescriptions for reforming water management generally call for the involvement of all stakeholders and participants, but with the underlying notion that all have a stake in, and can participate in a discussion about, the same thing. ${ }^{16}$ By making such a presumption, these discourses have the effect of naturalizing modern water, which in turn, disciplines the discussion and constrains the potential outcomes. Although it does perhaps Integrate the interests of different stakeholders, IWRM is still Water Resources Management. Stakeholders and participants are thereby consulted, but not so as to elicit how different players may relate to water in ways other than as resource whose natural disposition is to be managed.

A framework for analytical hydrolectics might be suggested in order to provide an approach to ensure that the different waters of different actors are considered when analysing water issues and problems. This framework would involve two

${ }^{16}$ See footnote 14 above. 
complementary moves: to identify the different actors involved; and to associate different actors with different waters. The example that I will use builds on a recent article dealing with the question of how to best manage scarce water resources in Israel. Over half the freshwater used west of the Jordan River in Israel comes from groundwater, which makes this an extremely important source of water for Israelis. Although the social and hydrologic circumstances presented in this article are unique to modern Israel, the approach that I want to suggest here could be applied to a wide variety of places, peoples and waters.

In "Political Economy of Groundwater Exploitation: The Israeli Case", Eran Feitelson observes that despite possessing adequate knowledge, expertise and power, the office of the state Water Commissioner nevertheless oversees a regime of unsustainable aquifer exploitation, allowing water to be withdrawn by farmers during droughts at a rate the exceeds the rate of natural recharge. Here, all the "steps and measures" that would need to be put in place in order to regulate aquifers sustainably are known to the Water Commissioner, an agency that moreover "has more power than almost any other water manager in the world." (418) "The question that needs to be asked, therefore, is why have the best measures advanced not been used?" (Feitelson 2005:413)

To analyse this problem, Feitelson identifies a number of actors in the in the "political game" of water allocations from aquifers. First, there are the farmers (the "pumpers"), who use the water. Second, are the "water managers", namely the 
hydrologists and water resource experts who possess the knowledge and skills required to manage aquifers sustainably. Third, are the "decision-makers" who have ultimate responsibility for weighing various hydrological, ecological, political and economic considerations relevant to the question of the level of abstractions that are to be permitted. Both "water managers" and "decision-makers", it should be noted, are represented within the office of the state Water Commissioner. Fourth, is the general "electorate", whose interests in water are far more diffuse and attenuated than those of the water users themselves and therefore have less political clout than the farmers who use the water directly. Feitelson points out that because decision-makers are certain to lose the support of farmers if they cut back on abstractions, they are only acting reasonably when they allow over-pumping against the advice of water managers and the disinterest of the electorate.

"As the extent of abstractions is of little importance to most of the electorate, organized pumpers who focus on this issue and can monitor decisions regarding it are likely to be highly effective. Actually, the only group likely to oppose the pumpers are water managers as they seek to minimize the probability of overdraft who which they may be criticized or held accountable. The political game that ensures, therefore, is one in which users strain to increase abstractions, mainly by using political leverages, while water managers strive to constrain them, often using legal means or administrative authority. The conflict between these two parties is likely to come to a head in drought situations when both the shadow value [The value of water that would most likely pertain should there be a free market for water, i.e. if water were not a subsidized commodity] of water and the threats to the aquifers rise.

"The risk posed to aquifers from over-draft in droughts is a function of the attributes of the aquifer, the extremity of the drought and the extent of overpumping. In most cases, it is unclear when would the deleterious implications of over-draft for nature and water quality be felt. In contrast, users feel any cut in allocations immediately and directly, and will attribute these losses to decisionmakers. From a decision-makers' perspective any cut in allocations is thus a certain loss. Following Kahenman and Tversky's (1979) prospect theory... decision-makers will prefer a probabilistic loss to a certain loss even if the mean 
value of the probabilistic loss [is greater] than the certain loss. Therefore, they prefer to over-pump the aquifer, rather than to cut allocations to farmers, in contrast to the advice of water managers. In other words, the extensive abstraction from aquifers above the rate of recharge, especially in drought situations, is politically rational, and therefore should not be seen as an aberration or misconception by decision-makers." (Feitelson 2005:415)

Feitelson writes from what is essentially "a sustainable management perspective" and with the overall purpose of suggesting "improvement in the management of the aquifers". (Feitelson 2005:415,420). From this perspective, the problem is seen in terms of the inability of water managers to effect the kinds of controls that are deemed necessary to promote "sustainable development of aquifers." (2005:413) His prescription is, in effect, to put more power into the hands of water managers. Because "a system that constrains and regulates abstraction is largely a function of the ability of professional or government agencies...to push through [sustainable management] proposals" (2005:414), Feitelson argues it is necessary to vest more authority in these professionals and agencies. He thus proposes to "overhaul the decision-making structures in the water-sector" specifically by giving the Water Commissioner authority to set water tariffs (prices) and to order alternative supplies (desalination and recycled wastewater) in addition to his authority for licensing abstractions from aquifers. "In essence, the Water Commissioner should be allowed to determine allocations, rates and the use of revenues, thereby allowing him to fund supply enhancement and quality assurance infrastructure." (2005:420) Furthermore, it is proposed that "all major policy decisions" must be approved by a revamped "Water Council" attached to the office of the Water Commissioner. Currently an advisory body, Feitelson proposes that the Water 
Council be enlarged and empowered to approve or reject important policy decisions:

"In this manner, the Water Council, which will represent all the affected parties ${ }^{17}$ as well as independent professionals representing different disciplines, will have real power to determine policy. Actually, this means that the [office of the Water Commissioner] will become the focal point of water politics. As this commission will be more representative than the current government structures, and will be more specialized than the forums in which politics take place today (the Knesset and Treasury) it can be hoped that this body will indeed strike the necessary balance between all the interests and considerations that have to be taken into account in determining abstractions from the aquifers." (2005:420-421)

Feitelson's proposal can thus be seen to comprise two basic moves: First, it concentrates authority for all matters pertaining to the management of aquifers in the office of the Water Commissioner; second, it provides this office with the means to represent the various political interests involved or affected by water management decisions. This proposal, in other words, calls for expanding the power and scope of the central agency responsible for water management so that it embodies broader interests and concerns that were formerly beyond its remit; it thereby diversifies and expands the idea of water management and vests this new idea in a revamped water management structure/agency:

"The conclusion that can be drawn from these findings is that the management of aquifers should not be considered mainly as a technical-hydrological issue.

Rather, it should be analysed within the societal, institutional and political setting of water management and politics." (421)

17 These include farmers, urban water users, industry, the Nature and Parks authority, the tourism health and environmental ministries, as well as environmental NGOs. (Feitelson 2005:422 n.13) 
In building on Feitelson's article to present an example of analytical hydrolectics, I would highlight this latter observation: managing aquifers (and water generally) should emphatically "not be considered mainly as a technical-hydrological issue." But I would go further: The article provides a very good basis for illustrating the thoroughgoing social nature of water. By identifying the main players involved in this particular water issue, Feitelson already covers the first step in my rudimentary framework for hydrolectic analysis. It remains to take the second step - to identify the various waters of these different players:

Each of the four actors identified by Feitelson who are involved in this particular "political game", we might say, has a different understanding of water and promotes a different water discourse. First, there are the users (the farmers). The farmers are concerned with the water itself, as a material substance; their aim is to get more of it. Second, there are the "water managers." The managers are less interested in the water itself than in the hydroeconomic abstraction they make known as an "aquifer"; their concern is to "manage" the aquifer sustainably - i.e. so as to ensure the long-term balance of outputs (abstractions) with inputs (recharge). Third, there are the "decision-makers." While comprising the managerial view to some extent, the decision makers are more attentive to the broader political interests involved in making allocations of water, their role can be seen as mediating between users and managers. To the decision-makers, water is an abstract resource to be allocated so as to procure the greatest social/political benefit. As Feitelson points out, they may decide to deplete the aquifers, a 
decision that is perfectly rational because it produces an immediate and certain political benefit. Fourth, there is the "electorate," which figures in Feitelson's analysis only as having relatively little influence against that of the users-farmers.

The relationship of such an aggregation of people to water is difficult to generalize. However, it might be taken to reflect and sustain the discourse of water as a national preoccupation in Israel. Something of the flavour of this discourse is suggested in the opening paragraph of Lonergan and Brooks' study of the role of water in the Israeli-Palestinian conflict:

"Both Biblical and modern Israel have been vitally concerned with water. The first explicit ecological reference in the Bible relates to the carrying capacity of pastures and water supplies that were coming under stress from the growth of the herds owned by Abraham and by his nephew Lot. One of the periodic droughts of the region starts the drama that leads to the Exodus story. More recently, the challenge to "make the desert bloom" brought Jewish settlers into what was first a Turkish colony and then a British protectorate. Later projects, such as the draining of the Hula wetlands and construction of the National Water Carrier, were hailed a symbols of the potential to live productively and comfortably in an arid region..." (Lonergan and Brooks 1994:3)

Clearly, the four groups of "players" identified in Feitelson's article and the four corresponding views of water are interrelated in complex ways, a fact that is suggested by noting that the electorate comprises all the members of the three other groups. Nevertheless analyzing the dynamics of water management in Israel from a hydrolectic approach draws attention not just to the different actors and different interests that are at play here, but to the fact that each involves a different view, understanding, and discourse of the "thing" in question. Farmers, water managers, decision-makers and the national electorate each consider water at a 
different level of abstraction, such that it is something different for each of them. In addition to the administrative and institutional reforms that may be necessary to promote "improved water management", it may therefore be desirable, or necessary, to procure some means of mutually recognizing and mediating between these heterogeneous discourses. In the particular instance examined here, perhaps the revamped Water Council - inasmuch as it represents all affected parties - could be given this function. Here, it should be pointed out, the language and preconceptions entailed in the notion of bringing together various "stakeholders" with different "interests" in water would need to give way to what Bruce Braun has described in terms of "a sustained examination and appreciation" of the ways that a single aspect of nature (in Braun's case, a forest) may be invested with various meanings and values by different people, "an examination of our passionate attachments" to such things. (Braun 2002:4-5) Furthermore, instead of presuming to identify a common consensus among all such groups, Braun points out that a positive upshot of such an examination would be to move toward a co-construction: "... if any consensus is to be reached, it will have to be something built rather than found, provisional rather than final, always open to examining its own constitutive exclusions." (2002:6) This kind of practice might be suggested as the main role of a reorganized Water Council. In the course of fulfilling such a role, it might be surmised that the present overall aim of promoting "improved water management" might be abandoned to give way to a less singular formulation. 
To conclude, let me repeat that the case presented here is meant to serve as an illustration of practicing analytical hydrolectics. The management of aquifers in Israel is but one problem among a practically infinite number of water problems and issues. Each of these problems is unique, involving different actors and different waters. The basic aim of analytical hydrolectics is to identify these so as to gain a comprehensive appreciation of the full range of actors and waters involved with respect to the problem or issue in question. Where things go from there - how such an analysis might be applied towards particular ends - entails a practical hydrolectics, a cultural politics of water. 


\section{Socio-Natural Dialectics}

O water and patience, pressure and time

Cuts through the faces of rocks we have climbed...1

If writing a thesis is like paddling upstream, I must be at the source. In this concluding chapter, l'Il try and describe the way things look from here. In broad terms, this thesis adds some water to social nature. I understand "social nature" to denote the latest effort to theorize the relationship between nature and culture in the tradition of human geography. As shown in Chapter 2, sprinkled throughout this and other literatures there are intimations of the need to consider the particular nature of water itself. For the most part, however, water has remained some-thing taken for granted, even by those who are most critical of the various ways it is disposed of by different people in different places. ${ }^{2}$

That a critical examination of water has not been a more prominent feature of social nature is perhaps a reflection of the general tendency in human geography (critical and otherwise) to stake out its territory on more solid ground. If the most recent edition of the Dictionary of Human Geography can be taken as an indication

\footnotetext{
${ }^{1}$ From "I Could Be Nothing", written by Tony Dekker and performed by the Great Lakes Swimmers. (CD titled "Bodies and Minds", published by Harbour Songs, 2005)

2 Among geographers, perhaps the major exception to this statement, also discussed above, is the work of Erik Swyngedouw. Karen Bakker and Maria Kaika have also denaturalized water in their work. Denis Cosgrove has delved into the question of what water is and why this question is important to people as has, albeit rather more obliquely, Gilbert White. Among researchers in other fields, the collection of articles edited by anthropologists John Donahue and Barbara Rose Johnston stands out in this regard, as does the water-related work of Ivan Illich and Gaston Bachelard. David Brooks' work on water soft paths and local water management also suggests the need to reflect critically on the nature of water. (See the bibliographic references to the work of these authors)
} 
of the discipline's field of concern, water is allowed very little space to flow. While the Dictionary includes about 90 specific index headings under "land", "land management", "land ownership", "land reform," "land rent", "land rights", "land tenure", "land use", "land values", "landholdings" and "landscape" (Johnston et al. 2000:931), the word "water" doesn't even appear in the index. (Perhaps I can convince the editors to give more attention to water in the next edition!)

One of the key ideas that I hope to have conveyed is that in each particular instance, water is some-thing, the nature of which is contingent on the social circumstances in which it is found and on the hydrological circumstances in which it finds us. ${ }^{4}$ The specific thingness of any given water is what it is in relation to these circumstances. This relational ontology of water helps explain how it gets fixed conceptually and materially in different places and times, and helps provide a means of understanding that in every instance, water has a history.

By elaborating the history of modern water, my intention has been to illuminate the predominant, hegemonic, nature of water characteristic of the modern, Western world. Having fixed modern water in the pages of my thesis, I hope that it might possibly spill out to places beyond, where it might prove a useful addendum - or prologue - to much of the critical work relating to water that is being done by

\footnotetext{
${ }^{3}$ Nor fen, ocean, port, river, sea, swamp, waterway, waterworks wetland ... There is a single reference to "lakes", one to "canal", one to "ocean floor", and a couple to "ports". 4 The latter part of this phrase is intended to mean that the specific hydrological conditions in any given place can have great importance for the hydreifications that we produce there. To repeat an example used above, the hydrologic cycle could only have materialized in a temperate region. Similarly, the "living waters" of biblical fame owe as much to aridity as to theology.
} 
geographers, political ecologists, political economists and the like. I say this because I think of modern water as a (hitherto) unmarked abstraction, the invisibility of which has allowed the misapprehension that certain social problems and issues are purely hydrological in nature. The act of turning $\mathrm{H}_{2} \mathrm{O}$ into a commodity, for example, is preceded by the prerequisite act of turning water into $\mathrm{H}_{2} \mathrm{O}$; and both of these transformations/hydreifications are made possible by the habit of abstraction that l've called modern water. In this sense, marking modern water is perhaps useful to those who wish to change the social relations that sustain it.

This question of change raises another key idea that I hope to have conveyed: specifically, that in every instance, the nature of water is constitutionally susceptible to transformation. Indeed, the dynamic nature of hydrosocial relations means that change is the natural - perhaps the only - essential quality of water. Defining the nature of water in this way flows from a dialectical understanding of things. And in the long-standing spirit of such investigations, the dialectics of water that I have attempted to put forward - under the banner "hydrolectics" - is meant as a way of not only understanding, but of positively effecting changes in, water.

Having added water(s) to social nature, however, entails more than merely wetting the field. The particular manner in which these waters have been brought into the discussion above - i.e. relationally and dialectically - raises the very basic question of the place of nature in social nature. This question may at first seem 
redundant. After all, the whole point of social nature is to (re)locate nature's place in geographical investigations. But despite the various attempts to (re)place it that social nature comprises, it refuses to be pinned-down in any way that can we can all agree on. "In the current period," writes Noel Castree, "there is no disciplinary consensus on how to bring society and nature within one explanatory framework..." (Castree 2005:244) This, as Castree correctly points out, "is no bad thing". ${ }^{5}(2005: 220)$ But it seems the response of a growing number of critical geographers has been to move toward a consensus by which nature is obliterated entirely. Against what I see as a tendency to socialize nature out of existence, I want to, and I must, acknowledge the perennial reality of water, even while acknowledging the historical contingency of its myriad forms. In the last chapter, I made an attempt to show how a positive sense of the social nature of water might be put to practical use in realizing improvements in hydrosocial relations. But in order for us to exploit the potential of hydrolectics, the water process is no less dispensable than our ingenuity. In the remainder of this essay, I will attempt to make clear how my insistence on this process relates to current trends in social nature. This clarification is intended as a more theoretical contribution to the field a contribution that is only implicit in the preceding discussion of water's hydrolectic potential.

${ }^{5}$ On grounds that "the presence of nature-sceptical and nature-endorsing perspectives within one disciplinary space is intellectually healthy." (Castree 2005:220) 


\section{The End of (Social) Nature?}

In contrast to some of the more lugubrious end-of-nature writing ${ }^{6}$, most geographers writing socionatures have been far more sanguine: the end of nature as we knew it allows us - finally! - to explore "how, and to what ends, alternative natures might be produced... (Smith 1996:50) and to "discuss the kind of nature we hope to make." (Demeritt 1994:28) So far, this thesis has been situated squarely in this tradition of critical sanguinity. My argument that water is nothing but what we make of it is underlain by my faith that through conscientious and reflexive hydrolectic practice, good things can and will be made of water. But I have to admit that not just any-thing can be made of water. Nor can we make water out of nothing. In other words, even while insisting that water needs us to become what it is in every particular instance, so must I insist that in each of these instances (including that wherein water is the liquid necessary for our survival) we need water.

To say that we need water seems obvious enough, but it raises an extremely thorny problem: Precisely, what is the place of nature in social nature? Bruce Braun, I think, reflects the views of most critical geographers when he uses the term "social nature...to indicate the inevitable intertwining of society and nature in any and all social and ecological projects." (2002:10) So far so good; but buried within this formulation is an ambiguity that can't be resolved unless we are more specific: Should we take from this statement that nature is to be understood mainly

\footnotetext{
${ }^{6}$ The best, and most frequently-cited example is Bill McGibbon's The End of Nature. (1989)
} 
or entirely as a social category? Or that society is to be understood mainly or entirely as a natural category? Or that nature and society are related dialectically? Or that nature and society should be released from their dualistic embrace to produce a completely different sort of (hybrid) category? Each of these four options satisfies the basic need to "intertwine society and nature in any and all social and ecological projects." But, as I will argue below, they are also mutually contradictory. Subscribing to social nature obliges us to commit to one or another way of specifying of what this "intertwining" consists.

At first glance, it would seem that most critical geographers espouse the position that nature should be understood mainly or entirely as a social category. The more foundational statements in the social nature literature have hardly urged restraint: If the writing of Neil Smith, Bruce Braun, and Noel Castree may be taken as foundational, from these we are given to understand that "nature is nothing if it is not social" (Smith 1984:30, and quoted in Braun and Castree 2001:xi); it is "axiomatic that 'nature' is indeed social through and through..." (Braun and Castree 1998b:xii); "nature is intrinsically social..." (Braun and Castree 2001:xii) and "those things that appear to be natural are, in fact, social through and through." (Castree 2005:109) That there has been "a veritable explosion of geographical research that seeks to denaturalize nature..." seems only consistent with such a position. (Braun and Castree 2001:xi) 
However, such statements as these might give a misleading impression. For while social nature obviously (re)places nature within the social realm, few geographers would be willing to embrace the kind of idealism that is courted by this (re)placement. The attraction of socializing nature out of existence is something that Harvey cautions against in terms of what he calls the "Leibnizian conceit." (Harvey 1996:69-76) In essence, this "conceit" boils down to a metaphysics based on the concept of things as self-contained entities (monads), which admit of no internal relations, and are therefore neither amenable to dialectical investigation nor capable of sustaining dialectical transformation. ${ }^{7}$ Whether as individual human beings or as societies, Harvey points out that the conceptualization of such things as monads permits "a withdrawal" or "a retreat" from "the outside world", which, in turn, permits what he calls a "new radical idealism" (1996:75) Harvey levels this charge mainly against what he regards as the excesses of post-structuralst

7 In the Monadology, Harvey points out that Leibniz "proposes a metaphysics founded on the concept of a monad that internalizes everything there is. Each monad mirrors the universe: a principle of 'correspondence' internally constitutes each monad as the mirror of the universe." (1996:69) For Harvey, the main problem with Leibniz's monad is that it internalizes everything in a way that makes it impossible to submit to dialectical change. This is because by virtue of mirroring the universe, the monad exists only as a universal entity, constitutionally incapable of enduring transformation of its internal relations. Harvey quotes Whitehead in pointing out that in such a formulation, "there can be 'no concrete reality of internal relations' in the sense of actual processes of internalization open to investigation.... If all monads internalize everything there is, then under what impulses can they change except by their own internal volition?"(1996:72,73) For Harvey, all entities are nothing but relational, and they are always in flux - he favours the term "moments" - to describe their non-permanence. The internalization of everything in Leibniz' monads drives out these qualities, making it impossible to "recognize how those things and entities are constituted, sustained and ultimately dissolved in flows and how all entities are relationally defined with respect to the others." (1996:73) By contrast, "things look very different if the notion of internal relations is situated not in a world of monadic entities (which appear as "permanences") but as continuous transformations and internalizations of different "moments" (events, things, entities)..." (1996:74) 
critique. ${ }^{8}$ Moreover, in Remaking Reality, Castree and Braun warn that while "poststructuralist accounts of nature's construction provide provocative arguments for the centrality of discursive practices for both nature's intelligibility and its availability to forms of instrumental power...such accounts risk privileging active form over passive matter." (Castree and Braun 1998:26). They offer science studies as "a potential path beyond post-structuralism's 'Leibnizian conceit" by its attention to "the intersection and simultaneity of multiple material and discursive practices..." (ibid.)

Returning to the question of the idealistic tendency of "social nature", there is a sense in which the "Leibnizian conceit" is lodged in its literal construction. Social nature's particular ordering of terms qualifies nature in such a way that it, literally, can be nothing if it is not social. The implicit monism of "social nature" is perhaps more obvious if we reverse the terms so as to construct "natural society." This may indeed be one of the possibilities of the intertwining of society and nature, however it drops us squarely into the forbidden (at least to most practicing academic geographers) territory of environmentalism. Natural society is unthinkable in current geographic discourse because it implies the determination of society, morality, and ethics by the fixed substrate of an inviolable, pre-given natural order. Schools of thought ranging from E.O. Wilson's "sociobiology", to Arne Naess's "deep ecology", to the notion of a glorious future through genetic sequencing, have

\footnotetext{
8 His objection to the "Leibnizian conceit" and the "new radical idealism" is followed by a chapter titled, "The Dialectics of Discourse", in which he attempts to put discourse in its place, as it were, as one and only one of several "moments" in the broader social process. (Harvey 1996:77-95)
} 
correctly been rejected by dialectically-thinking critical geographers and others for their implicit and explicit biological determinism. (Harvey 1996:164-169; Levins and Lewontin 1985) ${ }^{9}$ With social nature, however, it seems that we have merely inverted the poles of determination. By arguing for social nature, do we not risk substituting the socialization of nature for the naturalization of society?

This is a problem that, as already suggested, hasn't gone unnoticed by proponents of social nature. A 1995 paper by Noel Castree "attempts to take seriously what I call the materiality of nature. By that term, I mean both the ontological reality of those entities we term "natural," and the active role those entities play in making history and geography." (Castree 1995:13) Here, Castree is especially critical of Neil Smith, who "in his eagerness to stress this novel idea of producing nature" reverts to "a monism centered on the labor process - the production of nature which tends to exaggerate the transformative powers of capitalism." (1995:20) Several years later, Castree argues "that even the most relational of Marxist imaginaries runs up against the problem of how to grasp nature's materiality. This is, I submit, a problem for all attempts to understand how culture/s make nature/s." (Castree 2002:169) Margaret Fitzsimmons, who introduced the term "social nature" into geographical discourse (Fitzsimmons 1989), has more recently brought attention to the need to "move beyond critique" and find ways to engage with "the

\footnotetext{
${ }^{9}$ In a more recent work, Harvey has shown new interest in this work, but only by exploiting "all sorts of interesting internal tensions in Wilson's argument", noting that "he never does solve the problem of how a reductionism to physical law can explain the rise of civilization or even the construction of knowledge (calculus and Mozart remain unexplained). He resorts to the pure belief (without any scientific evidence whatsoever) that reductionism can work 'in principle' even if the practical possibility is remote." (Harvey 2000:227)
} 
world that ecologists seek to know..." (Fitzsimmons 2004:46) ${ }^{10}$ Bruce Braun also has stressed the importance of attending to the "lively materiality of social nature", particularly with respect to water! (2005:645) In a recent review of critical geographies of urban nature, he points out that despite

"...a great deal of talk about the importance of nature to understanding the city, and urbanization processes, it is often unclear what nonhuman nature adds to these accounts except the presence of a static stock of 'things' that are necessarily mobilized in the urbanization process. A great deal is written about water, but nary a word is said about the properties of water, and how these might influence the sociospatial development of cities. Water flows. It reacts with certain chemicals and dissolves others... Do these properties matter to the material form of the technological networks and bureaucracies that control its movement, or to the narratives, hopes and fears that circulate around it? Can water be 'mobilized' in just any old way? Must the real actors in urban political ecology be always already social?" (Braun 2005:644-645)

It would seem therefore, that despite some rather categorical statements to the effect that "nature is nothing if it is not social" and "water is nothing but what we make of it", those of us who advocate social nature are nevertheless unwilling to allow that the "the real actors" must be "always already social". In this regard, it is significant that geographers such as Castree, Fitzsimmons, and Braun have eschewed - if not entirely left off the practice of - using the term "social nature" in their most recent writings. Where the arguments in The Intemperate Rainforest "turn[ed] on the concept of social nature" (Braun 2002:10; see also 10-14), Braun's

\footnotetext{
${ }^{10}$ While affirming the importance of challenging "uncritical assertions" about the objective reality of nature "made by those whose academic authority is not complemented by insight into the situated and contingent complexities of human social life..." Fitzsimmons nevertheless urges an appreciation for the production of knowledge by natural scientists: "[R]esentment of these occasional abuses" she points out, "should not lead us to overlook what natural scientists, in certain disciplines, are telling us about their own practices, concerns and commitments." (Fitzsimmons 2004:30)
} 
more recent work gives the term a lower profile. (e.g. Braun 2005) And the phrase is notably absent in Castree's recent (2005) survey, titled Nature. (cf. the 2001 publication edited by Braun and Castree, Social Nature.) Without wishing to read too much into the use and disuse of a term, it would seem that after an initial moment of enthusiasm, something of a more concerted effort is being made to bring nature into the discussion in a more positive way. After having witnessed the end of nature, have we now perhaps reached the end of social nature?

\section{Hybrid Ontologies}

Returning for the moment to the various ontological options identified above under the overall project of "intertwining of society and nature", it appears that neither natural nor social monism is currently viable among human geographers. Of the four options cited, we are then left with either a dialectical or a post-natural stance of the sort that I will refer to in this section by the term, "hybrid ontologies". Because I want to close this discussion by returning to dialectics, I will discuss hybrid ontologies first.

If there is a tendency to which geographers interested in social/nature are headed, it is not to do away with either nature or society, but to dispense with their mutual constitution. Nature and society, in this increasingly popular view, constitute each other as a dualism, and it is this dualism that must be rejected in a deliberate fashion by critical geographers. Most have opted for one or another approach that Castree has described as "'after'-' or 'post-natural' in their outlook." (2005:223; see 
also Demeritt 2005) Castree includes non-representational theory and "the new ecology" along with actor-network theory among these post-natural approaches ${ }^{11}$. However, their common root is an ontological stance that seeks a more radical alternative to the society-nature dualism. (2005:229-236) Early expressions of this tendency in critical geography can be found in the work of David Demeritt, who over a decade ago suggested that geographers adopt the use of metaphors employed by writers like Latour (1993) and Harraway (1991), whose hybrids, quasi-things, cyborgs, rhizomes and networks describe a reality that is both and neither natural and/nor social. (Demeritt 1994, see also 2001; 2001) The virtue of these metaphors, Demeritt points out, is in that they provide "a stunning new way to dispel the great modern divide separating the poles of culture and nature..." (1994:180) Bruce Braun's Intemperate Rainforest - arguably the outstanding study in the social nature field to date - provides an example of this shift toward the postnatural. At the beginning, Braun points out that the argument turns "on the concept of social nature" (2002:10) and states:

"The argument of this book... is informed by the belief that understanding nature as social - seeing the world in terms of nature-culture "hybrids" - presents the best way to understand and interrogate present-day social and environmental conditions and to imagine steps toward ecologically sustainable and socially just futures." (2002:10)

By the end of the book, Braun moves more resolutely toward hybridity:

\footnotetext{
11 I should clarify that Castree includes "the new dialectics" among these approaches. However, as $I$ argue in the following section, a distinction should be made between them.
} 
"Perhaps nature and culture have no prior, independent existence, but are merely rhetorical containers into which different worldly elements are somewhat arbitrarily assigned: the result may be conceptually tidy, but is a temporary measure at best, and...soon everything is a mess again." (2002:264)

Rather than interrogate nature (in this case, the B.C. rainforest) and society as separate entities, Braun's analysis reflects his indebtedness to thinkers who have made a "rigorous attempt to displace these terms and to replace them with a new vocabulary altogether", one that reflects the idea that such categories "have no existence apart from the relations that define them." (Braun 2002:264, 266) "There is", Braun points out, "a large and increasingly familiar set of metaphors that strive to capture this sort of relationality: networks, webs, assemblages, rhizomes, cyborgs, topologies, cartographies. Each in its own way seeks to avoid falling back into a nature-culture dualism." (2002:266) Braun's own preference is for Deluze and Guattrari's concept of "assemblages." (2002:263-267) But, in general, it is the growing use of such metaphors and the ideas they represent that marks what Braun, in the conclusion of his study describes in terms of "New Trajectories of Social/Nature." (2002:267)

Perhaps the most notable indication of the trend toward hybrid ontologies is found in the final chapter of Castree's 2005 survey, where he identifies a "growing cohort of geographers [who] take issue with the society-nature dualism that underpins most of the thinking" that has taken place under the banner of social nature as well as in physical geography. (Castree 2005:223) In this chapter, titled "After Nature", Castree describes the approaches of geographers who admit of "Neither Natural 
nor Social" (2005:226) and "thus might be described as 'after'-' or 'post-natural' in their outlook." (2005:223)This cohort, "currently considered de rigueur and cutting edge by many geographers" (2005:239), adopts a vocabulary "that captures the hybrid, chimeric, mixed-up world in which we are embedded" (2005:224)

It might seem that I should be happy to include myself among this cutting edge group. By having written the constitution of modern water in a distinctly Latourean style, it might appear that l've already done so! Moreover, Castree makes it rather easy for me to feel included, insofar as he identifies the followers of Harvey's relational dialectics - which he identifies in terms of the "new dialectics" - as among the "post-natural". (2005:232-234) But while I certainly have found Latour useful in understanding the constitution of "modern water", I think that something other than hybridity takes place in the process of hydreification, of which modern water is but one example. Furthermore, while it seems clear to me that material reality is neither/both social norland natural, we nevertheless need to acknowledge a distinction between processes that dialecticians call "social processes" and those which are natural in the sense that they would and do occur independently of people. Finally, while Castree may find the "new dialectics" consonant with the post-natural stance, I rather see them as being at odds. The latter is a point already alluded to above, where it was noted the four socionatural options are mutually contradictory. I will elaborate on how I see this contradiction in the last section of the chapter. To conclude the present section, I want to signal some uneasiness that I have with the post-natural generally. 
While the adoption of hybrid metaphors and ontologies certainly captures "the hybrid, chimeric, mixed-up world in which we are embedded" (Castree 2005:224), I'm not sure that this is a world in which any thing can be sustained - either ourselves, our human societies, or the more-than-human societies/environments in which we/these are embedded. To argue that things are what they are by virtue of, and in relation to, other things and processes doesn't mean that they are not real or are not important. To recognize the contingency of things - whether we are talking about the modern state or $\mathrm{H}_{2} \mathrm{O}$ - doesn't necessarily mean that we can or should get along without them. Rather, it means that we should make/use them responsibly, in full knowledge of their contingency. In every instance, nature is just such a thing, an abstraction and a contingency, which, while we must make/use responsibly, we can hardly get along without. Spivak's aphorism - introduced to many of us via Donna Harraway - by which "nature is that which we cannot not desire", seems to permit - if not encourage - the sort of idealism mentioned above. Nature, I think, is rather something that we cannot not have. Even the post-natural stream debouches into an estuary of brackish water, networks, hybrids, cyborgs, webs, rhizomes, assemblages and monsters, which, while (at least initially) stranger than nature, in a sense only repopulate it. ${ }^{12}$

As already noted, Castree and Braun, in an earlier survey, warn that while "poststructuralist accounts of nature's construction" provide a very effective means of critiquing nature's "availability to forms of instrumental power... such accounts risk

\footnotetext{
12 In any case, they can hardly be stranger than quarks!
} 
privileging active form over passive matter." (Castree and Braun 1998:26) Hybrid ontologies, however, dissolve both form and matter into a mixture that negates the very possibility of a mixture, which allows for practically nothing to stand on. While Latour's explanation and analysis of the (post)modern predicament is certainly insightful, it hardly provides a workable means of egress, unless someone can actually figure out how to make his "Parliament of Things" get down to business! $!^{13}$ The possibility of working within such a framework to produce useful, practical knowledges of any sort, and/or to effect changes in political practices, is problematic. As Joel Wainwright has put it with respect to the latter: "he [Latour] produces a kind of constitution made up of political roles, forms of power, collective requirements, and responsibilities to different actors in a manner that is stultifying in its wonkishness." (Wainwright 2005:118) ${ }^{14}$ And as for the role of scientific practice, it seems reasonable to presume that there are few natural scientists that

\footnotetext{
${ }^{13}$ This refers to the title of the final chapter of Latour's book, We Have Never Been Modern. (Latour 1993). It has been pointed out that the point of the "Parliament of Things" is less to prescribe a radically new form of constitution than to describe what is actually going on in the never-been-modern world:

"Just as different human groups have people to represent them in different political decision-making processes, Latour argues that scientists and engineers are representatives of nature and things. Actually The Parliament of Things only brings to light what is already happening. 'We have never been modern', Latour writes, and by that he means that our world is less than ever populated with pure natural objects and pure human subjects of pure social relations. He wants us to admit this, thus making it more possible to discuss which of the hybrids/quasi-objects we want to live with." (Gram-Hanssen 1996:90-91)

I don't disagree with this assessment, but the point I want to make is that Latour offers no way least of all through the Parliament of Things - to discuss and decide "which of the hybrids/quasiobjects we want to live with", considering that the "we" who must discuss and decide is now comprised of the very hybrids and quasi-objects themselves/ourselves.

${ }^{14}$ This comment is in reference to Latour's more recent essay, Politics of Nature. (Latour 2004) I agree with Wainwright's assessment that Latour's critique of the bifurcation of reality into the natural and the social is useful, while the normative prescriptions that follow from this are not: "The problem is not that Latour is simply too philosophically abstract. It is that his shift to a political register is asserted with so little historical and theoretical care that one cannot but demand some stronger arguments and illustrations... Latour does not inquire into the political and historical conditions under which realities actually emerge... The thorny problems of power, discourse, and history are wholly elided." (Wainwright 2005:119)
} 
could imagine how their practice might possibly fit into such a scheme, considering that they and the object(s) of their investigations have been unmasked as storytellers and fictions.

\section{A Slight Diversion Across the Geographical Divide}

I raise the interesting question of the place of the natural sciences here partly in order to make good on an earlier commitment. In the introduction of this thesis, it might be recalled that I promised to "make an effort in the concluding chapter to describe a way of proceeding on the basis that [physical and human geography] are no different." 15 So far, particularly in Chapters 4 and 5 , l've dealt at some length with the history of science, especially in regard to hydrology, which I take as one aspect of physical geography. This, I have to admit, is like barely sticking a toe across the great divide. In an effort to go slightly further, let me start by pointing out that while it may have produced the hydrologic cycle, hydrology didn't invent water. Rather, it merely made itself known to the water process and made the water process known to itself in a systematic way that has yielded at least one highly robust and useful - if not universally relevant - hydreification. Hydrological practice is extremely useful to the process of understanding - albeit a facet of - water, and constitutes a formal hydrolectic practice that has been and remains of immeasurable importance to people. Further, in my own project of gaining critical

\footnotetext{
${ }^{15}$ In what follows, I should note that I understand physical geography to be, more or less, a natural science. Also, I should point out that even if some physical geographers do suffer from what Doreen Massey has described as "physics envy" (Castree 2005:213), this need not be regarded as a bad thing.
} 
knowledge of water and of its possibilities, studying hydrology in the way I have has been of critical importance. In this respect at least, I have to regard critical social theory and positivistic investigations of water as complementary activities. From hydrology, we might generalize to include various other aspects of physical geography: Should I have used a similar approach to study the construction of soils, or weather, or a particular socionatural landscape - such as a city, forest, or field - a similar amalgamation of (the relevant) physical and critical human geographies would have been in order. ${ }^{16}$

To summarize the preceding paragraph, physical geography has to be accorded an important place (and even on its own terms) in any relational-dialectical study of geographic things. This, however, is a role that seems more difficult to place in critical practices that tend toward the total socialization or hybridization/eradication of nature. Bruce Braun has suggested that attending to the "lively materiality of social nature" provides "room for thoughtful - and critical - collaboration between physical and human geographers...", which is certainly helpful as far as it goes. But the scope of this collaboration seems restricted by a view that constrains Braun to add that this is "a possibility that will be enhanced as more and more physical

\footnotetext{
16

Cities, for example, don't materialize out of the circulation of capital alone; rather, they take form where flows of capital have been brought to bear on non social process including flows of water, various forms of solar energy, the geological process by which "raw materials" like sand and gravel get produced, and the like. Cities, in other words, are things that occur in perpetually transient form, in places where social and natural process are brought together in concentration. In the process of making cities, the importance of natural (non-social) processes needs to be examined as carefully as social processes. While New Orleans undoubtedly has owed its transient forms to flows of capital at various scales, it is equally the product of flows of water down the Mississippi, which have both enabled and challenged (as in the great flood of 1928) its permanence. And the significance of the water process to the form (and the existence) of New Orleans hardly needs elaboration after the changes wrought by Hurricane Katrina in the summer of 2005.
} 
scientists begin to study social, rather than external nature." (2005:645) It seems reasonable to point out that a collaborative effort would be more likely to succeed if it also allowed for the quid pro quo by which critical human geographers should pay some attention to external, as well as social nature. ${ }^{17}$

The difficulties entailed in any sort of collaboration between physical geographers and critical human geographers who suppose the radical socialization or hybridization/eradication of nature is perhaps best illustrated by Castree's treatment of the subject in his book, Nature. (Castree 2005) Here, Castree treats "geography's failure to prevent a progressive split between human and physical geography" as something of a theme (2005:71), and points out "how the coexistence of constructivist and realist approaches to nature within geography is central to the ongoing estrangement of human and physical geography." (2005:179) But considering the manner in which this difference is analysed, it could be said that the book only makes a further contribution to this "estrangement". Castree divides the geographical tradition into what he calls (after Soper 1995) "nature endorsing perspectives" and "nature sceptical positions." (2005:90, 109-111) "There are", he points out, "several human and environmental geographers who still believe that what we call 'nature' matters in a biophysical sense. But for the most part, present-day human geographers and several

\footnotetext{
17 Among critical geographers, Margaret Fitzimmons seems to anticipate this in calling for engagement of critical human geographers with the work of environmental scientists, particularly ecologists: "To say that ecology is constructed as an embedded social process is not to say that the world that ecologists seek to know is somehow not real." (2004:46) And it is by acknowledging the reality of this world "That we, as geographers can engage with ecologists as potential allies in a wide range of conscious socio-ecological projects." (2004:46)
} 
environmental geographers hold to a 'nature-sceptical' (denaturalizing) stance." (2005:109)

In the part of the book were he gives serious attention to "nature-endorsing perspectives" within geography, Castree associates such perspectives with physical geography. Physical geographers, he states, "mostly take it as given that the biophysical world is a real and objectively knowable entity. Whether studying 'natural' or modified environments, they see their role as producing accurate knowledge about the earth's surface." (Castree 2005:218) The radical divide between physical and human geography is made very clear in pointing out that "the naturalism of physical geography is the mirror opposite of the de-naturalising thrust." (2005:179) "Mirror opposites" can be understood in different ways, but it is difficult to understand how such a metaphor might provide a basis for collaboration between human and physical geography. This difficulty is even more apparent when Castree argues (apparently with Demeritt) that a constructionist approach to scientific knowledge is needed in order "to get physical geographers and other earth scientists involved in a more honest discussion about the status of the knowledge they produce." (2005:191, my emphasis) I'm not sure whether this is quite what Castree intended to say - or possibly l've misinterpreted him? In any case, I cite the passage to illustrate the immense difficulties involved in promoting any kind of collaboration between physical and human geography so long as we begin by emphasizing (and purifying) the epistemological differences between them. I must admit to having made a great deal (in Chapter 5) of the differences 
between the constructivist and the conventional approaches to the history of science. But in making this distinction, I don't mean to suggest that either is more or less honest than the other - rather the point I hope to have made is to show that they produce different histories of different things. Similarly, it is obvious that human and physical geography produce different kinds of knowledges of what is ultimately the same reality, but surely neither is better or more honest than the other.

Physical and human geography might rather be considered in a relationaldialectical sense as constituting each other in a dynamic process of exchange: Progress in the overall scientific project of producing knowledge of geomorphic structures and processes cannot be understood outside of the social context in which physical geography is practiced. This relational understanding of geographic practice has been emphasized in modern times at least since Vidal de la Blache, who cautioned against considering "the earth as 'the scene on which the activity of man unfolds itself,' without reflecting that this scene is itself living." (quoted in Sauer 1963:321) For Vidal, "Human geography does not oppose itself to a geography from which the human element is excluded; such as one has not existed except in the minds of a few exclusive specialists." (ibid.325) On this view, Carl Sauer argued that all geographers "are interested in that part of the areal scene that concerns us as human beings because we are part of it, live with it, are limited by it, and modify it." (Sauer 1963:325) To a growing extent, the aspect of the "areal scene" that interests physical geographers today arises out of broader 
social concerns about human-induced modifications of the physical environment. The remarkable progress that has been made in measuring the extent of anthropogenic impact on the face of the earth can best be understood within and in response to this social context;

But just as physical geographers need to acknowledge nature's sociality (and the extent to which their project becomes what it is in relation to social context) so do we critical human geographers need to recognize that our own project is what it is in relation to the very practice of physical geographers and other scientists capable of producing positive knowledge about changes in the land. From Neil Smith's (1984:xiv) recognition that "capital transforms the shape of the entire world. No God-given stone is left unturned, no original relation with nature unaltered, no living thing unaffected...."; to William Cronon's (1995b:25) affirmation that "human beings have been manipulating ecosystems for as long as we have records of their passage; to Braun and Castree's assertion that nature is "more than ever before, social nature, a nature ordered up, manipulated and constructed..." (1998b:xi) we might draw the conclusion that social nature is at least partly rooted in physical geography ${ }^{18}$

The practice of studying and writing social natures, in turn, is beginning to influence the practice of physical geography. As already noted, a general shift of

\footnotetext{
${ }^{18}$ Also, it might be pointed out that some of the most recent explorations in social nature are underlain by - albeit more ecological than geographic - scientific study of disequilibria and disturbance in nature (Castree and Braun 1998:13; Castree 2005:234-236
} 
interest toward socionatural phenomena has been evident among physical geographers for some time: "One of the most significant trends which characterizes physical geography over the last 25 years or so has been a concern for the effects of humans on the environment." (Sims 2003:15) ${ }^{19}$ Physical geographers have taken a greater interest in "linking pure with applied research" (2003:16) in attending to questions such as restoration of landscapes, engineering of ecosystems and adjustment to climate change. More profoundly, geomorphologists Michael Urban and Bruce Rhoads have observed "incipient" changes in the practice of physical geography that correspond to the most recent human geographers' tendency to denaturalize nature. (Urban and Rhoads 2003) Engaging directly with the social nature literature, they argue that the idea of the "social construction of nature" is beginning to find its way into a [physical geography] practice that takes "the dissolution of the human-nature" dichotomy as a starting point. (2003:220, 224)

It can arguably be said that physical and human geography are what they are in relation to one another. Rather than trying to find some common ground, or stressing the sharp distinctions between them, it might be more helpful to consider the sense in which together, they constitute a process of mutual becoming that is

\footnotetext{
${ }^{19}$ Sims suggests that the shared interest in "sustainable environmental management" that flows from this concern already serves as a catalyst for bringing human and physical geography together. (Simms 2003:16) This sense in which "physical and human geography are brought closer together" (ibid.) corresponds approximately to what Castree calls a "people and environment" perspective, which he associates with efforts to re-integrate physical and human aspects of geography to tackle "the big questions of our era concerning the problems and possibilities resulting from human alteration of natural resources, environments and organisms." (Castree 2001:2)
} 
geography. The way forward may be less a matter of physical geographers appreciating social nature, or critical human geographers appreciating external nature, than in both appreciating that the external and the social realities that arise in their respective practices can be understood in a relational sense.

\section{Socio-natural Dialectics}

"Perhaps one of the most interesting findings... is that singular processes can give rise to highly diversified and highly complex as well as often quite unpredictable results." (Harvey 1996:58)

This conclusion brings me back where I began at the very beginning of this thesis to relational dialectics. However, l'm going to add something new in light of everything that has come in-between. So far l've remained more or less faithful to Harvey's dialectical approach, but I need to diverge somewhat now into what I'll call socio-natural dialectics, a general practice of which hydrolectics is but one specific example.

It has been noted that Noel Castree includes "the new dialectics" among the postnatural approaches in his recent book. Noting that David Harvey has been "the most vocal exponent" of this approach in geography, Castree's description approximates the approach that l've taken:

[T] [socio-natural] networks... This perspective takes issue with the Cartesian, Newtonian and neo-Kantian worldwiews that, in Harvey's view, dominate Western thought. These worldviews imagine the human and non-human worlds 
to be composed of discrete physical things which can be analysed prior to, and separate from any contingent relationships they may have with other things...

As a Marxist, the key process that Harvey uses to illustrate his internal relations perspective is capitalism... Harvey argues that people (e.g. as wage workers) and non humans become the 'arteries' through which an invisible process of ceaseless value expansion flows. Because this process is seamless, Harvey argues, we should not make the mistake of fixating on the different things that become embroiled in it. While these differences matter, they do so only in relation to the abstract process that conjoins them.

Overall, Harvey ... regards particular human and non-human things as the expressions of general processes. He terms these things 'moments' that give physical form to the general processes involved... The 'dialectical' element of all this is that from time to time particular moments (physical things) contradict the 'demands' being placed on them by the logic of process." (Castree 2005:232233)

The major point of contention that I have with "the new dialectics", as described here, is that it includes among the "overarching processes" only what are referred to in Marxist terminology as "social processes," of which capitalism is the most "overarching" of all. This restriction to social processes, it seems, is what allows Castree to include relational dialectics among the different "post-natural" approaches that are being taken by geographers concerned with the question of the relationship between nature and society. (Castree 2005:232-234) My reading of Harvey's relational dialectics, however, suggests that although they are given little formal recognition, non-social (i.e. natural) processes are at least insinuated among the "underlying generative processes" out of which specific systems, moments and things, are constituted. In other words, the new dialectics, as I understand it, doesn't let go of nature(al processes) at all. 
In his most explicit elaboration of relational dialectics - and in that wherein he addresses most directly questions relating to the question of nature the environment (1996:46-68) - Harvey discusses the importance of biological and thermodynamic processes ${ }^{20}$ and even notes that "different processes intersect and intertwine - capital circulation and ecological processes intersect, for example, to create complex forms of environmental transformation..." (1996:59) Furthermore, the importance of generative (natural) processes that exist independently of people may be inferred from Harvey's frequent reference to dialectically-minded scientists and philosophers of science - such as A.N. Whitehead, David Bohm and F. Peat, and particularly Richard Levins and Richard Lewontin - throughout his discussion of relational dialectics. But unlike (social) processes - such as the circulation of capital - which are objects of central interest to Harvey's (and Marx's) science, Harvey doesn't find it particularly necessary to identify and investigate these nonsocial processes. ${ }^{21}$ Therefore, it might be said that relational dialectics neither quite lets go of nature, nor makes it exactly clear where it belongs. What I intend by the term "socio-natural dialectics" is to signify a relational-dialectical approach

\footnotetext{
20

"The metabolic processes which permit...internal self-reconstruction to proceed entail exchanges with my environment and a whole range of transformative processes which are necessary for the maintenance of my bodily individuality... To put the matter this way is not to view the "thing" (or the system) as a passive product of external processes (I certainly do not view myself that way). What is remarkable about living systems is the way they capture diffuse (and often high entropy) energy or information flows and assemble them into complex but well-ordered (low entropy) forms. Human individuals, furthermore, have a remarkable capacity to capture and reorganize energy and information flows in ways which are creative rather than passive." (1996:51) 21 The specific underlying processes that really count in Harvey's analysis are always capitalism or aspects of capitalism abstracted as processes - the labour process, the production process, capital flows, commodity flows, etc. Harvey discusses "flows of goods, money and people" (1996:49); the labour process (65); the circulation of capital (65); and dialectical enquiry itself (55) as examples of "generative underlying processes" that give rise to the things or "moments" that are available to us for empirical investigation.
} 
that formally includes natural as well as social processes in its method of investigation.

An obvious difficulty arises in asking on what basis a distinction can be made between these two categories of process. At first glance, making such a distinction seems to contradict the entire project of social nature, i.e. to recognize and elaborate on "the inevitable intertwining of society and nature". Certainly, it contradicts the ontological stance by which nature and society are always already dissolved into each other in various manifestations of hybridity. Distinguishing between social and natural processes also contradicts the total collapse of nature into society, as well as the total collapse of society into nature. However, making such a distinction is not inconsistent with the remaining ontological option available under social nature - namely, that of intertwining nature and society dialectically. Not only does "the new dialectics" permit such a mode of intertwining, but as shown above, both social and natural processes are at least implied in Harvey's formulation of relational dialectics.

To be as precise, and as formal, as possible, I would add that in every instance, "things" take form where natural and social processes come together. A "river", for example, occurs where the water process comes together with people who, for various reasons, may conceptualize a given portion of the hydrologic cycle as a "river" rather than say, a stream, a lake, a canal, a strait, or a reservoir... A river is a thing because we make it known thus. I live near a body of transient water that is 
formed by a dam and generating station at Chelsea, Quebec. For everyone whose home is located nearby - including myself - this place is known as "the Gatineau River". "For those who work at the dam and generating station, it is known as "the reservoir." Were it not for us dwellers and workers, the water process would certainly exist in this place, and perhaps in exactly the manner with which we are all familiar. But in this latter case, it would be neither a river nor a reservoir. As l've been saying, in every particular instance, water needs us, just as we need the water process. The same principle applies to every-thing that we make known of water.

Another, and related, difficulty arising from the notion of socio-natural dialectics concerns the matter of how it might be possible to specify a natural process. What, for example, is the water process? All along, I have elaborated on the sociality of water while insisting on the independent reality of this process; but so far, I have to admit that the water process has been little more than an allusion. ${ }^{22}$ I can now express myself in slightly more positive terms: some progress has been made in the preceding chapters towards illuminating the nature of the water process through the investigations of the various hydreifications discussed therein. This includes, for example, investigations of the various hydrologic cycles (Chapters 4 and 5), $\mathrm{H}_{2} \mathrm{O}$ (Chapters 1 and 3), as well as the various sacred, ancient, and "premodern" waters discussed in Chapter 3. Finally, in Chapter 10, I did my best to

\footnotetext{
22 I've referred to it as an "underlying generative process", to use Harvey's phrase, and as a process that "is only slightly approximated by what many of us habitually call 'the hydrologic cycle." (Chapter 1)
} 
describe the water process as the first principle of hydrolectics, noting that the water process itself cannot be described or represented in an objective way, because it shows up for us only in relation to the social processes that engage it.

This might seem but meagre progress, but if so, that is what is demanded by the method that has been applied here. The difficulty of defining or specifying the water process more exactly (for the time being at least) is the same as for any generative process understood in dialectical terms, "given the epistemological problem that we must always start with 'things' and systems as they are, to identify underlying processes and to specify them exactly right." (Harvey 1996:59) ${ }^{23}$ But the problem is certainly not insurmountable. A dialectical method of investigation has most successfully been applied by Marxists to the specification of social processes - with capitalism as the foremost social process thereby illuminated. The water process (and others that comprise the "ecological processes" referred to by Harvey above) may be considered analogous to capitalism in the sense that they too can be made known through a method that begins by a dialectical

\footnotetext{
23 I have to acknowledge that there is something of an epistemological chicken-and-egg occurring here: While Harvey starts with things and systems, Bertell Ollman points out that Marx's method begins with the recognition of capitalism as the predominant/overarching social process extant. From this Marx proceeds toward a fuller understanding of this process through dialectical investigation of the specific things and systems to which it gives rise. Thus "Capitalism serves Marx as his jumping-off point for an examination of anything that takes place within it." (Ollman 1993:12) The method progresses as a kind of virtuous cycle, by which the knowledge of things permits a wider inquiry into the processes from which they arise, the improved knowledge of which provides a wider basis for the investigation of things, and so on...."In Marx's study of any specific event or institutional form, these two types of inquiry are always interwoven. The fuller understanding of capitalism that is the major result of such a study is now ready to serve as a more effective starting point for the next series of investigations." (1993:13) By likening the water process to capitalism, I mean only to say that we may obtain a "fuller understanding" of this process through dialectical investigation of the specific events and institutional forms (hydreifications) to which it gives rise in conjunction with social processes, including capitalism.
} 
investigation of their various (hyd)reifications. It has to be admitted that because each hydreification - as with all things - is produced at the confluence of social processes and natural processes - specifying the water process itself is not easy. But if we agree that it is possible to specify social processes by way of a dialectical investigation of things, the same must be the case for natural processes: For surely every commodity, every instantiation of capital, every moment of labour, internalizes both social and natural processes. If we can gain insights about capitalism as a process through dialectics, why can't we do so for water and other natural processes $?^{24}$

I want to finish by speculating on why it seems to have been so difficult to get beyond the analysis of social processes and to consider natural processes in Marxist discourse as well as in recent critical geography. If we can take the Dictionary of Marxist Thought as our guide, "Nature is, for humankind, a matter of utility, not a power for itself." While it may have "autonomous laws", the purpose in trying to discover such laws is "to subjugate nature to human needs, as an object of consumption or means of production." (Young 1999:399) Thus instead of comprising generative processes in its own right, "the world of nature" tends to be

\footnotetext{
${ }^{24}$ That we might be able to do so seems to have been thought worth pursuing by at least some Marxists. Engels' speculations on the "Dialectics of Nature" for example, have been described as involving "an attempt to integrate certain conceptions of historical materialism into the philosophy of nature - to show, in effect, that Marxism could formulate laws of nature and tat a single ontology could embrace nature and humanity Analytic tools which can be used to gain insight into natural and social processes were thereby reduced to dialectical laws." (Young 1999b:151) Young points out that "As a philosophy of science, dialectics of nature has found little favour in the West" (ibid.), possibly for reasons described below. Levins and Lewontin's relational-dialectical investigations of biological processes are the best example of applying dialectical thinking to natural processes that I'm aware of. (Levins and Lewontin 1985)
} 
reduced in Marxist discourse to "an object", or to a thing, particularly as "raw material". 25

A clue as to how this tendency to disregard the dialectical importance of natural processes took root in geographical discourse can be found in a seminal article written by David Harvey himself in 1974. "Population, Resources and the Ideology of Science" applied a "relational and dialectical approach to things" to great effect in laying bare the biases inherent in the ideology of nature that underlay contemporary discourses of general resource scarcity. (Harvey 1974:271) Rather than accept the prevalent idea of resources as absolute things-in-themselves, Harvey showed how, in a relational and dialectical sense, resources are more correctly understood as expressions of particular sets of social circumstances, particularly "the mode of production which seeks to make use of them and which simultaneously 'produces' them..."(1974:265) Thus, rather than devoting our attention to accommodating society to the dictates of resource scarcity, we might rather deliberately change society (i.e. the current mode of production) so as to transform the entire range of resource possibility. This article, it has been pointed out, was the first to elaborate "the counterintuitive idea of 'social nature" in the geographic literature (Castree 2001:10) and has been identified as the first

25

Consider the labour process as described in the Dictionary of Marxist Thought: "Labour is here an interaction between the person who works and the natural world such that elements of the latter are consciously altered in a purposive manner. Hence the elements of the labour process are threefold: first, the work itself, a purposive productive activity; second the object(s) on which that work is performed; and third, the instruments which facilitate the process of work. The objects on which work is performed, commonly provided by a previous labour process, are called 'raw materials." (Mohun 1999:298) 
"precedent for the current attempts by geographers to de-naturalize nature." (Castree 2005:111; see also 2005:111-117)

The success of this article in dismantling contemporary neo-Malthusian arguments is beyond doubt. But perhaps this very success, and the article's subsequent influence in the discipline have made it more difficult to see what has been left out. By stressing the social circumstances relative to which resources become what they are, the importance of the non-social (natural) processes that are equally necessary to "produce" any and all resources gets completely ignored. This omission, ironically enough, permits a kind of idealism, not of the post-structural variety that Harvey critiques in terms of the "Leibnizian conceit", but by virtue of a dialectics that fails to acknowledge the constitutive role of natural processes:

\begin{abstract}
"Only if we let ourselves be imprisoned within the system of knowledge handed down to us will we fail to innovate. Further, it is unnecessarily restrictive to think that human inventiveness and creativity apply only in the sphere of technology human beings can and do create social structures as well as machines. This process Marx regards as essential and inevitable precisely because man could and would respond to the necessities of survival. The only danger lies in the tendency to place restrictions on ourselves and, thereby, to confine our own creativity. In other words, if we become the prisoners of an ideology, prisoners of the concepts and categories handed down to us, we are in danger of making the neo-Malthusian conclusions true, of making environmental determinism a condition of our existence." (Harvey 1974:259)
\end{abstract}

While it is clearly incorrect to make environmental determinism a condition of our existence, it seems equally incorrect to fail to recognize the reality and the importance of non-social processes that exist independently of "the concepts and categories handed down to us". By excluding such processes from relational- 
dialectical theorizing, we not only risk falling into a kind of idealism; we also might fail to recognize the real potential that inheres in these processes. As noted by Harvey himself, and quoted at the beginning of this section, "one of the most interesting findings... is that singular processes can give rise to highly diversified and highly complex as well as often quite unpredictable results." (Harvey 1996:58) If there's a single conclusion to my thesis, it is that when the process that we call water is combined with the process that we call society, the outcome is an astonishing array of quite unpredictable results. 


\section{References Cited}

Adams, Frank Dawson. 1928. The Origin of Springs and Rivers: An Historical Review. Fennia 50, no. 1: 3-18.

Adams, Frank Dawson. 1938. The Birth and Development of the Geological Sciences. Reprint of 1938 edition. Baltimore: The Williams and Wilkins Company.

Adams, Robert M. 1974. Historic Patterns of Mesopotamian Irrigation Agriculture. In Irrigation's Impact on Society, ed. Theodore E. Downing and McGuire Gibson:1-6. Tucson: University of Arizona Press.

Adams, W.M. 1996. Irrigation, Erosion and Famine: Visions of Environmental Change in Marakwet, Kenya. In The Lie of the Land: Challenging Received Wisdom on the African Environment, ed. Melissa Leach and Robin Mearns:155-167. Oxford and Portsmouth: The International African Institute in Association with James Currey and Heinemann.

Aguilera-Klink, Frederico, Eduardo Perez-Moriana and Juan Sanches-Garcia. 2000. The social construction of scarcity: The case of water in Tenerife (Canary Islands). Ecological Economics 34, no. 2: 233-245.

Aldhous, Peter. 2003. The Forgotten Crisis. Nature 422: 251.

Allan, J.A. 2003. IWRM/IWRAM: a New Sanctioned Discourse? London: Occasional Paper 50, School of Oriental and African Studies, King's College, University of London.

American Society of Civil Engineers (ASCE), Hydrology Committee. 1949. Hydrology Handbook. New York: American Society of Civil Engineers.

Antipode. 2003. Special Issue: Urban Political Ecology, Justice and the Politics of Scale. Antipode 35, no. 5.

Arnold, David and Ramachandra Guha. 1995. Introduction: Themes and Issues in the Environmental History of South Asia. In Nature, Culture and Imperialism: Essays on the Environmental History of South Asia, ed. David Arnold and Ramachandra Guha:120. Delhi: Oxford University Press.

Bachelard, Gaston. 1983 [1942]. Water and Dreams: An Essay on the Imagination of Water. Dallas: The Dallas Institute of Humanities and Culture.

Back, William. 1987. Foreword. In The History of Hydrology, ed. Edward R. Landa and Simon Ince: ix-x. Washington DC: American Geophysical Union.

Baker, M.N. 1949. The Quest for Pure Water: The History of Water Purification From the Earliest Records to the Twentieth Century. New York: American Water Works Association Inc. 
Baker, M.N and R. E. Horton. 1936. Historical development of ideas regarding the origin of springs and groundwater. Transactions of the American Geophysical Union 17: 395400.

Bakker, Karen J. 1999. Privatizing Water, Producing Scarcity: The Yorkshire Drought of 1995. Economic Geography 76, no. 1: 4-27.

Bakker, Karen J. 2003a. An Uncooperative Commodity: Privatizing Water in England and Wales. Oxford, UK: Oxford University Press.

Bakker, Karen. 2003b. A Political Ecology of Water Privatization. Studies in Political Economy 70. Spring, 2003: 35-58.

Balanya, Belen, Brid Brennan, Olivier Hoedman, Satoko Kishimoto and Philipp Terhorst, ed. 2005a. Reclaiming Public Water: Achievements, struggles and visions from around the world. Amsterdam: Transnational Institute and Corporate Europe Observatory.

Balanya, Belen, Brid Brennan, Olivier Hoedman, Satoko Kishimoto and Philipp Terhorst. 2005b. Empowering Public Water - Ways Forward. In Reclaiming Public Water: Achievements, struggles and visions from around the world, ed. Brid Brennan Belen Balanya, Olivier Hoedman, Satoko Kishimoto and Philipp Terhorst:247-274. Amsterdam: Transnational Institute and Corporate Europe Observatory.

Ball, Philip. 2001. Life's Matrix: A Biography of Water. Berkeley and Los Angeles: University of California Press.

Barlow, Maude. 2001. Blue Gold: The Global Water Crisis and the Commodification of the World's Water Supply, (revised edition). San Francisco: International Forum on Globalization.

Barlow, Maude and Tony Clarke. 2002. Blue Gold: The Battle Against Corporate Theft of the World's Water. Toronto: Stoddart.

Barry, R.G. 1969. The World Hydrological Cycle. In Introduction to Physical Hydrology, ed. Richard J. Chorley:8-26: Methuen and Co. Ltd.

Bassin, Mark. 1997. History and philosophy of geography. Progress in Human Geography 21, no. 4: 663-572.

Baumgartner, A. and E. Reichel. 1972. Preliminary results of new investigations of world's water balance. In World Water Balance: Proceedings of the Reading Symposium, July 1970, ed. IASH-Unesco-WMO:580-592. Gentbrugge-Paris-Geneve: IASH-UnescoWMO.

Beardmore, Nethaniel. 1862. Manual of Hydrology. London: Waterlow.

Bell, Morag. 1992. The water decade valedictory, New Delhi 1990: where pre-and postmodernism meet. Area 24, no. 1: 82-89. 
Bennett, John W. 1974. Anthropological Contributions to the Cultural Ecology and Management of Water Resources. In Man and Water, ed. L. Douglas James:34-81. Lexington: The University Press of Kentucky.

Berkes, Fikret. 1999. Sacred ecology : traditional ecological knowledge and resource management. Philadelphia, PA: Taylor \& Francis.

Beven, Keith. 1987. Some reflections on the future of hydrology. In Water for the Future: Hydrology in Perspective, ed. J.C. Rodda and N.C. Matalas:393-403. Wallingford: International Association of Hydrological Sciences.

Bhaskar, Roy. 1999. Dialectics. In A Dictionary of Marxist Thought, ed. Laurence Harris Tom Bottomore, V.G. Kiernan, Ralph Miliband:143-150. Oxford and Malden: Blackwell.

Biagioli, Mario. 1999. Introduction. In The Science Studies Reader, ed. Mario Biagioli: xixviii. New York and London: Routledge.

Biro, Andrew. 2002. Wet Dreams: Ideology and the Debates Over Canadian Water Exports. Capitalism, Nature, Socialism 13, no. 4: 29-50.

Biswas, Asit K. 1965. The Hydrologic Cycle. Civil Engineering - ASCE 35, no. 4: 70-74.

Biswas, Asit K. 1967. The Automatic Rain-gauge of Christopher Wren, F.R.S. Notes and Records of the Royal Society of London 22: 94-104.

Biswas, Asit K. 1970. History of Hydrology. Amserdam, London, New York: North-Holland Publishing Company and American Elsevier Publishing Company.

Biswas, Asit K. 1998. Deafness to Global Water Crisis: Causes and Risks. Ambio 27, no. 6: 492-3.

Biswas, Asit K. 2004. Integrated Water Resources Management: A Reassessment. Water International 29, no. 2: 248-256.

Blackman, Deane R. and A. Trevor Hodge. 2001. Frontinus' Legacy: Essays on Frontinus' 'de aquis urbis Romae'. Ann Arbor: University of Michigan Press.

Blaikie, Piers, Terry Cannon, lan Davis and Ben Wisner. 1994. At Risk: natural hazards, people's vulnerability, and disasters. New York and London: Routledge.

Bocking, Richard C. 1972. Canada's Water: For Sale? Toronto: James Lewis and Samuel.

Bond, Patrick. 2001. Valuing Water beyond "Just Price It": Costs and Benefits of Water for People and Nature. Paper presented at Water for People and Nature, a conference organized by the Council of Canadians. Vancouver, B.C.: July 7, 2001.

Bord, Janet and Colin Bord. 1985. Sacred Waters: Holy Wells and Water Lore in Britain and Ireland. London, Toronto, Sydney, New York: Granada.

Bowden, Charles. 1977. Killing the Hidden Waters. Austin and London: University of Texas Press. 
Bradley, Charles C. 1967. Some population limits. In The Water Crisis, ed. George A.Nikolaieff:23-24. New York: The H.W. Wilson Company.

Bradnock, Robert W. and Patricia L. Saunders. 2000. Sea-level rise, subsistence and submergence: The political ecology of environmental change in the Bengal Delta. In Political Ecology: Science, Myth and Power, ed. Philip Stott and Sian Sullivan:66-90. London: Arnold.

Brandes, Oliver M. and David B. Brooks. 2005. The Soft Path for Water In a Nutshell:21. Ottawa and Victoria: Friends of the Earth Canada and the POLIS Project on Ecological Governance.

Bras, Rafael and Peter S. Eagleson. 1987. Hydrology, The Forgotten Earth Science. EOS 68, no. 16: 227.

Braun, Bruce. 2002. The Intemperate Rainforest: Nature, Culture, and Power on Canada's West Coast. Minneapolis and London: University of Minnesota Press.

Braun, Bruce. 2005. Environmental Issues: Writing a more-than-human urban geography. Progress in Human Geography 29, no. 5: 635-650.

Braun, Bruce and Noel Castree, ed. 1998a. Remaking Reality: Nature at the Millennium. London and New York: Routledge.

Braun, Bruce and Noel Castree. 1998b. Foreword. In Remaking Reality: Nature at the Millennium, ed. Bruce Braun and Noel Castree, xi-xii. London and New York: Routledge.

Braun, Bruce and Noel Castree. 2001. Preface. In Social Nature: Theory, Practice and Politics, ed. Noel Castree and Bruce Braun, xi-xiv. Malden, Mass. and Oxford: Blackwell.

Brooks, David. 2003. Another Path Not Taken: A Methodological Exploration of Water Soft Paths for Canada and Elsewhere - Unpublished Report Submitted to Environment Canada. Ottawa.

Brooks, David B. 2002. Water: Local-Level Management. Ottawa: International Development Research Centre.

Brooks, David B. 2005. Beyond Greater Efficiency: The Concept of Water Soft Paths. Canadian Water Resources Journal 30, no. 1: 83-92.

Brown, Robert M. 1933. Man and Water Supply. The Journal of Geography 32, no. 6: 250253.

Buckley, Richard (editor). 2001. The Water Crisis: A matter of life and death. Cheltenham, England: Understanding Global Issues Limited. 
Carbonnel, J.P. 2001. Introduction. In De l'origine des fontaines, ed. Comite National Français des Sciences Hydrologiques, Commission de terminologie. Asnieres France: Association Internationale des Sciences Hydrologiques, Comite National Français des Sciences Hydrologiques.

Castree, Noel. 1995. The Nature of Produced Nature: Materiality and Knowledge Construction in Marxism. Antepode 27: 12-48.

Castree, Noel. 1996. Birds, mice and geography: Marxisms and dialectics. Transactions of the Institute of British Geography NS 21: 342-362.

Castree, Noel. 2001. Socializing Nature: Theory, Practice and Politics. In Social Nature: Theory, Practice and Politics, ed. Noel Castree and Bruce Braun:1-21. Malden, Mass. and Oxford: Blackwell Publishers.

Castree, Noel. 2002. Geographies of Nature in the Making. In Handbook of Cultural Geography, ed. Mona Domosh Kay Anderson, Steve Pile and Nigel Thrift:168-183. London: Sage Publications.

Castree, Noel. 2005. Nature. London and New York: Routledge.

Castree, Noel and Bruce Braun. 1998. The Construction of Nature and the Nature of Construction. In Remaking Reality: Nature at the Millennium, ed. Bruce Braun and Noel Castree:3-42. London and New York: Routledge.

Castree, Noel and Bruce Braun, ed. 2001. Social Nature: Theory, Practice and Politics. Malden, Mass. and Oxford: Blackwell Publishers.

Cayley, David. 1992. Ivan Ilich In Conversation. Concorde, Ontario: House of Anasi Press.

Chorley, Richard J., ed. 1969. Water, Earth, and Man: A Synthesis of Hydrology, Geomorphology, and Socio-Economic Geography. Methuen.

Chorley, R.J. and R. W. Kates. 1969a. Introduction. In Water, Earth, and Man: A Synthesis of Hydrology, Geomorphology, and Socio-Economic Geography, ed. Richard J. Chorley:1-7: Methuen.

Chorley, R.J. and R. W. Kates. 1969b. Introduction. In Introduction to Physical Hydrology, ed. Richard J. Chorley:1-7: Methuen and Co Ltd.

Chow, Ven Te. 1964. Handbook of Applied Hydrology: A Compendium of Water-resources Technology. New York: McGraw-Hill Book Company.

Chow, Ven Te. 1979. Water as a World Resource. Water International 4, no. 1: 3-24.

Clarke, Robin. 1991. Water: The International Crisis. London: Earthscan Publications.

Clarke, Robin and Jannet King. 2004. The Water Atlas. New York and London: The New Press.

Collingwood, R.G. 1945. The Idea of Nature. Oxford: Oxford University Press. 
Conca, Ken. 2006. Governing Water: Contentious Transnational Politics and Global Institution Building. Cambridge and London: The MIT Press.

Coopey, R. and T. Tvedt, ed. 2006. The Political Economy of Water. Volume 2 of A History of Water. London and New York: I.B. Tauris.

Cosgrove, Dennis. 1990. An elemental division: water control and engineered landscape. In Water, Engineering and Landscape: Water control and landscape transformation in the modern period, ed. Dennis Cosgrove and Geoff Petts:1-11. London and New York: Bellhaven Press.

Cosgrove, Dennis and Geoff Petts. 1990a. Water, Engineering and Landscape: Water control and landscape transformation in the modern period. London and New York: Bellhaven Press.

Cosgrove, Dennis and Geoff Petts. 1990b. Preface. In Water, Engineering and Landscape: Water control and landscape transformation in the modern period, ed. Dennis Cosgrove and Geoff Petts: i-xv. London and New York: Bellhaven Press.

Cosgrove, William J. and Frank R. Rijsberman. 2000. World Water Vision: Making Water Everybody's Business. London: Earthscan Publications.

Cronon, William. 1983. Changes in the Land: Indians, Colonists, and the Ecology of New England. New York: Hill and Wang.

Cronon, William. 1991. Nature's Metropolis: Chicago and the New West. New York: WW Norton and Company.

Cronon, William, ed. 1995a. Uncommon Ground: Toward Reinventing Nature. New York and London: W.W. Norton and Company.

Cronon, William. 1995b. Introduction: In Search of Nature. In Uncommon Ground: Toward Reinventing Nature, ed. William Cronon:23-56. New York and London: W.W. Norton and Company.

Cronon, William, ed. 1995c. Toward a Conclusion. In Uncommon Ground: Toward Reinventing Nature, ed. William Cronon:447-459. New York and London: W.W. Norton and Company.

Crosby, Alfred W. 1997. The Measure of Reality: Quantification and Western Society, 1250-1600. Cambridge: Cambridge University Press.

Dalby, Simon. 2002. Environmental Security. Minneapolis and London: University of Minnesota Press.

Daly, Herman and John B. Cobb, Jr. 1989. For the Common Good: Redirecting the Economy Toward Community, the Environment and a Sustainable Future. Boston: Beacon Press.

de Villiers, Marq. 1999. Water. Toronto: Stoddart. 
de Villiers, Marq. 2000. Water Works. Canadian Geographic 120, no. 4 (May-June, 2000): 50-58.

Dear, Peter. 1995. Discipline and Experience: The Mathematical Way in the Scientific Revolution. Chicago and London: University of Chicago Press.

Dear, Peter. 2001. Revolutionizing the Sciences: European Knowledge and its Ambition, 1500-1700. Princeton: University of Princeton Press.

Demeritt, David. 1994. Ecology, objectivity and critique in writings on nature and human societies. Journal of Historical Geography 20, no. 1: 22-37.

Demeritt, David. 2001a. Being Constructive about Nature. In Social Nature: Theory, Practice and Politics, ed. Noel Castree and Bruce Braun:22-40. Malden, Mass. and Oxford: Blackwell Publishers.

Demeritt, David. 2001b. The Construction of Global Warming and the Politics of Science. Annals of the Association of American Geographers 91, no. 2: 307-337.

Demeritt, David. 2002. What is the 'social construction of nature'? A typology and sympathetic critique. Progress in Human Geography 26, no. 6: 767-790.

Demeritt, David. 2005. Hybrid Geographies, Relational Ontologies and Situated Knowledges. Antipode : 818-823.

Derman, Bill. 1998. Balancing the Waters: Development and Hydropolitics in Contemporary Zimbabwe. In Water, Culture, and Power: Local Struggles in a Global Context, ed. John M. Donahue and Barbara Rose Johnston:73-93. Washington DC: Island Press.

Desbiens, Caroline. 2004. A political geography of hydro development in Quebec. The Canadian Geographer 48, no. 2: 101-118.

Detay, Michel and Didier Gaujous. 2001. De la cosmologie au cycle de l'eau. In Colloque International OH2, "Origines et Histoire de l'Hydrologie". Dijon, 9-11 mai, 2001 (paper published on conference CD): Université de Bourgogne.

Diamond, Jared. 1999. Guns, Germs and Steel: The Fates of Human Societies. New York and London: W.W. Norton and Company.

Donahue, John M. and Barbara Rose Johnston. 1998. Conclusion. In Water, Culture, and Power: Local Struggles in a Global Context, ed. John M. Donahue and Barbara Rose Johnston:339-346. Washington DC: Island Press.

Dooge, J.C.I., A.B. Costin and L.H.J. Finkel. 1973. Man's Influence on the Hydrological Cycle. Irrigation and Drainage Paper no. 17. Rome: FAO.

Dooge, J. C. I. 1974. The development of hydrological concepts in Britain and Ireland between 1674 and 1874. Hydrological Sciences Bulletin XIX, no. 9: 279-302. 
Dooge, J.C.I. 1983. On the Study of Water. Hydrological Sciences Journal 28, no. 1: 2348.

Dooge, J.C.I. 1984. The Waters of the Earth. Hydrological Sciences Journal 29, no. 2: 149-176.

Dooge, James C.I. 1986. Looking for Hydrologic Laws. Water Resources Research 22, no. 9: 46s-58s.

Dooge, James C.I. 1988. Hydrology in Perspective. Hydrological Sciences Journal 33, no. 1/2: 61-85.

Dooge, James C.I. 2001. Concepts of the Hydrologic Cycle, Ancient and Modern. In International Symposium OH2 "Origins and History of Hydrology":1-10. Dijon, France, May 9-11, 2001: Universite de Bourgogne.

Downing, Thomas E. and Karen Bakker. 1997. Drought Discourse and Vulnerability. In Hazards and Disasters: A Series of Definitive Major Works, ed. Donald A. Wilhite. London: Routledge.

Downing, Theodore E. and McGuire Gibson, ed. 1974. Irrigation's Impact on Society. Tucson: University of Arizona Press.

Eagleson, Peter S. 1970. Dynamic Hydrology. New York: McGraw-Hill.

El Sammani, Mohamed Osman and Sayed Mohamed Ahmed Dabloub. 1996. Making the most of local knowledge: Water harvesting in the Red Sea Hills of Northern Sudan. In Sustaining the Soil: Indigenous Soil and Water Conservation in Africa, ed. lan Scoones and Camilla Toulmin Chris Reij:28-43. London: Earthscan.

Eliade, Mircea. 1958. Patterns in Comparative Religion. Translated by Rosemary Sheed. London and New York: Sheed and Ward.

Environment Canada. 1992. Water - Here, There and Everywhere. Freshwater Series A-2. Ottawa: Minister of Supply and Services, Canada.

Escobar, Arturo. 1995. Encountering Development: The making and unmaking of the Third World. Princeton: Princeton University Press.

Escobar, Arturo. 1996. Constructing Nature: Elements for a Poststructural Political Ecology. In Liberation Ecologies: Environment, development, social movements, ed. Richard Peet and Michael Watts:46-68.

Escobar, Arturo. 1999. After Nature: Steps to an Antiessentialist Political Ecology. Current Anthropology 40, no. 1: 1-16.

Escobar, Arturo. 2001. Culture sits in places: reflections on globalism and subaltern strategies of localization. Political Geography 20: 139-174. 
Ettenger, Kreg. 1998. "A River That Was Once So Strong and Deep" Local Reflections on the Eastmain Diversion, James Bay Hydroelectric Project. In Water, Culture, and Power: Local Struggles in a Global Context, ed. John M. Donahue and Barbara Rose Johnston:47-71. Washington DC: Island Press.

Fairhead, J. and M. Leach. 1996. Misreading the African Landscape. Cambridge: University of Cambridge Press.

Falkenmark, M. 1986. Fresh Water - Time For a New Approach. Ambio 15, no. 4: 192-200.

Falkenmark, Malin. 1989. The Massive Water Scarcity Now Threatening Africa - Why Isn't It Being Addressed? Ambio 18, no. 2: 112-118.

Falkenmark, Malin. 1996. Approaching the Ultimate Constraint: Water Shortage in the Third World. In Resources and Population: National, Institutional and Demographic Dimensions of Development, ed. Paul Demeny and Max F. Perutz Bernardo Colombo: 71-81. Oxford: Clarendon Press.

Falkenmark, Malin. 2005. Towards Hydrosolidarity: Ample Opportunities for Human Ingenuity (Fifteen-Year Message from the Stockholm Water Symposia). Stockholm: Stockholm International Water Institute.

Fasso, C. 1987. Birth of Hydraulics during the Renaissance Period. In Hydraulics and Hydraulic Research, A Historical Review, ed. Gunther Garbrecht: 55-79. Rotterdam/Boston: A.A. Balkema.

Feitelson, Eran. 2005. Political Economy of Groundwater Exploitation: The Israeli Case. Water Resources Development 21, no. 3: 413-423.

Ferrari-Comeau, Lisa and Elizabeth L. Chalecki. 2002. International Relations Theory and the Commodification of Canadian Water. Paper prepared for the annual meeting of the International Studies Association, New Orleans, March 2002.

Ferroukhi, Lyes and Srinivas Chokkakula. 1996. Indigenous Knowledge of Water Management. In Reaching the Unreached: Challenges for the 21st Century. Selected papers of the 22nd WEDC Conference, New Delhi, India, 1996, ed. John Pickford et al. Loughborough: Intermediate Technology Publications in association with The Water, Engineering and Development Centre.

Figuertes, Caroline M., Cecilia Tortajada and Johan Rockstrom. 2003. Conclusion: The way forward. In Rethinking Water Management: Innovative Approaches to Contemporary Issues, ed. Cecilia Tortajada and Johan Rockstrom Caroline M. Figuertes: 228-236. London: Earthscan.

Finnegan, William. 2002. Letter from Bolivia: Leasing the Rain. The New Yorker, no. April 8, 2002: 43-53.

Fitzsimmons, Margaret. 1989. The Matter of Nature. Antipode 21, no. 2: 106-20.

Fitzsimmons, Margaret. 2004. Engaging Ecologies. In Envisioning Human Geographies, ed. Philip Crang Paul Cloke, Mark Goodwin: 30-47. New York: Arnold Publishers. 
Forsyth, Tim. 2003. Critical Political Ecology: The Politics of Environmental Science. London and New York: Routledge.

Foucault, Michel. 1970. The Order of Things: An Archaeology of the Human Sciences. New York: Pantheon Books.

Fournier, F. 1974. Preface. In Effects of Man on the Interface of the Hydrological Cycle with the Physical Environment. Paris: IASH-Unesco-WMO.

Fry, Al (Lead author). 2005. Water: Facts and Trends: 16. Geneva: World Business Council on Sustainable Development.

Fukuyama, Francis. 1992. The End of History and the Last Man. New York and Toronto: Free Press and Maxwell Macmillan Canada.

Furon, Raymond. 1967[1963]. The Problem of Water: A World Study. (English edition of French original). Translated by Paul Barnes. London: Faber and Faber.

Garbrecht, Gunther, ed. 1987a. Hydraulics and Hydraulic Research, A Historical Review. Rotterdam/Boston: A.A. Balkema.

Garbrecht, Gunther. 1987b. Hydrologic and Hydraulic Concepts in Antiquity. In Hydraulics and Hydraulic Research, A Historical Review, ed. Gunther Garbrecht: 1-22. Rotterdam/Boston: A.A. Balkema.

Gare, Arran E. 1995. Postmodernism and the Environmental Crisis. London and New York: Routledge.

Geertz, Clifford. 1972. The Wet and the Dry: Traditional Irrigation in Bali and Morocco. Human Ecology 1, no. 1: 23-39.

Geertz, Clifford. 1996. Afterword. In Senses of Place, ed. Steven Feld and Keith H. Basso: 259-262. Santa Fe, New Mexico: School of American Research Press.

Giblett, R. 1996. Postmodern Wetlands: culture, history, ecology. Edinburgh: Edinburgh University Press.

Gilmartin, David. 1994. Scientific Empire and Imperial Science: Colonialism and Irrigation Technology in the Indus Basin. Journal of Asian Studies 53, no. 4: 1127-1149.

Gilmartin, David. 1995. Models of the Hydraulic Environment: Colonial Irrigation, State Power and Community in the Indus Basin. In Nature, Culture and Imperialism: Essays on the Environmental History of South Asia, ed. David Arnold and Ramachandra Guha: 210-236. Delhi: Oxford University Press.

Glacken, Clarence J. 1967. Traces on the Rhodian Shore: Nature and Culture in Western Thought from Ancient Times to the End of the Eighteenth Century. Berkeley, Los Angeles, London: University of California Press.

Gleick, Peter H., ed. 1993a. Water in Crisis: A Guide to the World's Freshwater Resources. New York and Oxford: Oxford University Press. 
Gleick, Peter H. 1993b. An introduction to global fresh water issues. In Water in Crisis: A Guide to the World's Freshwater Resources, ed. Peter H. Gleick:3-12. New York and Oxford: Oxford University Press.

Gleick, Peter H. 1998a. Water in Crisis: Paths to Sustainable Water Use. Ecological Applications 8, no. 3: 571-579.

Gleick, Peter H. 1998b. The World's Water 1998-1999. Washington D.C. and Covelo California: Island Press.

Gleick, Peter H. 1998c. The Changing Water Paradigm. In The World's Water 1998-1999, ed. Peter Gleick: 5-37. Washington D.C. and Covelo California: Island Press.

Gleick, Peter H. 2000a. The Changing Water Paradigm: A Look at Twenty-first Century Water Resources Development. Water International 25, no. 1: 127-138.

Gleick, Peter H. 2000b. The World's Water 2000-2001. Washington D.C. and Covelo California: Island Press.

Gleick, Peter H., Gary Wolff, Elizabeth L. Chalecki, and Rachel Reyes. 2002. Globalization and International Trade of Water. In The World's Water 2002-2003: The Biennial Report on Freshwater Resources: 33-56. Washington D.C. and Covelo California: Island Press.

Gleick, Peter H. 2003. Global Freshwater Resources: Soft Path Solutions for the 21st Century. Science 302, no. 28 November, 2003: 1524-1528.

Gleick, Peter H. et al. 2004. The World's Water 2004-2005. Washington D.C. and Covelo California: Island Press.

Global Water Partnership. 2000. Towards Water Security: A Framework for Action - report prepared for presentation at the Second World Water Forum, The Hague, Netherlands, March 17-22, 2000. Stockholm: Global Water Partnership.

Goldsmith, Edward. 1982. Traditional Agriculture in Sri Lanka. The Ecologist 12, no. 5.

Goldsmith, Edward and Nicholas Hildyard. 1984. The Social and Environmental Effects of Large Dams (two volumes). Bordeaux, France: European Ecological Action Group.

Golinsky, Jan. 1998. Making Natural Knowledge: Constructivism and the History of Science. Cambridge, U.K.: Cambridge University Press.

Gordon, R.G. and F.G. Thompson. 1930. The Physiological Principles of Hydrology. London: Jonathan Cape.

Gossage, Peter. 1985. "Water in Canadian History: An Overview" - Inquiry on Federal Water Policy Research Paper \#11. Ottawa: Environment Canada.

Goubert, Jean-Pierre. 1986. The Conquest of Water: The Advent of Health in the Industrial Age. Princeton: Princeton University Press. 
Goudie, Andrew. 2000a. water crisis. In The New Fontana Dictionary of Modern Thought, ed. Allan Bullock and Stephen Trombley: 916. London: Harper-Collins.

Goudie, Andrew. 2000b. Hydrology. In The Dictionary of Physical Geography, ed. David S.G. Thomas and Andrew Goudie: 256-257. Oxford: Blackwell.

Goudie, Andrew. 2000c. Hydrological Cycle. In The Dictionary of Physical Geography, ed. David S.G. Thomas and Andrew Goudie: 254-256. Oxford: Blackwell.

Gram-Hanssen, Kirsten. 1996. Objectivity in the Description of Nature: Between Social Construciton and Essentialism. In Between Monsters Goddesses and Cyborgs: Feminist Confrontations with Science, Medicine and Cyberspace, ed. Ninba Lykke and Rosi Braidotti: 88-102. London and New Jerzey: Zed Books.

Gregory, Derek. 2000. post-colonialism. In The Dictionary of Human Geography, ed. Derek Gregory R.J. Johnston, Geraldine Pratt and Michael Watts: 612-615. Malden, Massachusetts: Blackwell.

Gregory, Derek. 2001. (Post)Colonialism and the Production of Nature. In Social Nature: Theory, Practice and Politics, ed. Noel Castree and Bruce Braun: 84-111. Malden, Mass. and Oxford: Blackwell Publishers.

Gregory, Derek. 2004. The Colonial Present: Afghanistan, Palestine, Iraq. Malden, Mass. and Oxford, UK: Blackwell.

Groenfeldt, David. 1991. Building on Tradition: Indigenous Irrigation Knowledge and Sustainable Development in Asia. Agriculture and Human Values 8: 114-120.

Grossman, Elizabeth. 2002. Watershed: The Undamming of America. New York: Counterpoint.

Hacking, lan. 1999. The Social Construction of What? Cambridge, Mass. and London, England: Harvard University Press.

Hall, Bert S. 1996. The Didactic and the Elegant: Some Thoughts on Scientific and Technological Illustrations in the Middle Ages and Renaissance. In Picturing Knowledge: Historical and Philosophical Problems Concerning the Use of Art in Science, ed. Brian S. Baigrie: 3-39. Toronto: University of Toronto Press.

Hall, David. 2005. Introduction. In Reclaiming Public Water: Achievements, struggles and visions from around the world, ed. Brid Brennan Belen Balanya, Olivier Hoedman, Satoko Kishimoto and Philipp Terhorst: 15-24. Amsterdam: Transnational Institute and Corporate Europe Observatory.

Hall, Francis R. 1987. Contributions of Robert E. Horton. In History of Geophysics, Volume 3: The History of Hydrology, ed. Edward R. Landa and Simon Ince: 113-117. Washington, DC: American Geophysical Union.

Hamlin, Christopher. 1990. A Science of Impurity: Water Analysis in Nineteenth Century Britain. Bristol: Adam Hilger. 
Hamlin, Christopher. 2000. 'Waters' or 'Water'? - Master narratives in water history and their implications for contemporary water policy. Water Policy 2: 313-325.

Hanor, Jefrey S. 1987. History of Thought on the Origin of Subsurface Sedimentary Brines. In History of Geophysics, Volume 3: The History of Hydrology, ed. Edward R. Landa and Simon Ince: 81-91. Washington, DC: American Geophysical Union.

Haraway, Donna. 2004 [1985]. A Manifesto for Cyborgs: Science, Technology, and Socialist Feminism in the 1980s. In The Haraway Reader. 7-45. New York and London: Routledge.

Haraway, Donna J. 1999 [1991]. Situated Knowledges. In The Science Studies Reader, ed. Mario Biagioli:172-188. New York and London: Routledge.

Hardiman, David. 1995. Small-Dam systems of the Sahyadris. In Nature, Culture and Imperialism: Essays on the Environmental History of South Asia, ed. David Arnold and Ramachandra Guha: 185-209. Delhi: Oxford University Press.

Hartley, Dorothy. 1964. Water in England. London: Macdonald and Jane's.

Harvey, David. 1974. Population, Resources and the Ideology of Science. Economic Geography 50: 256-277.

Harvey, David. 1996. Justice, Nature and the Geography of Difference. Oxford: Blackwell.

Harvey, David. 2000. Spaces of Hope. Berkeley and Los Angles: University of California Press.

Hassoun, Rosina. 1998. Water Between Arabs and Israelis: Researching Twice-Promised Resources. In Water, Culture, and Power: Local Struggles in a Global Context, ed. John M. Donahue and Barbara Rose Johnston:313-338. Washington DC: Island Press.

Hastings, James (ed). 1921. Encyclopaedia of Religion and Ethics. Edinburgh: T. and T. Clark.

Hayles, N. Katherine. 1995. Searching for Common Ground. In Reinventing Nature? Responses to Postmodern Deconstruction, ed. Michael E. Soule and Gary Lease: 4763. Washington D.C. and Covelo California: Island Press.

Hays, Samuel P. 1959. Conservation and the Gospel of Efficiency: The Progressive Conservation Movement, 1890-1920. Cambridge: Harvard University Press.

Heidegger, Martin. 1977. The Question Concerning Technology and Other Essays. Translated by William Lovitt. New York: Harper and Row.

Hewitt, K., ed. 1983. Interpretations of Calamity. Boston: Allen and Unwin.

Hodge, Trevor A. 2000a. Engineering Works. In Handbook of Ancient Water Technology, ed. Orjan Wikander: 67-94. Leiden, Boston, Koln: Brill. 
Hodge, Trevor A. 2000b. Purity of Water. In Handbook of Ancient Water Technology, ed. Orjan Wikander: 95-99. Leiden, Boston, Koln: Brill.

Horton, Robert E. 1931. The Field, Scope, and Status of the Science of Hydrology. Transactions, Am. Geophysical Union 12: 189-202.

Horton, Robert E. 1937. Hydrologic Research. Science 86, no. 2241: 527-530.

Houghton, J.T. 1983. Introduction to Techniques of Management and Analysis: Atmospheric Processes. In Variations in the Global Water Budget, ed. Max Beran and Robert Ratcliffe Alayne Street-Perrot: 1-4. Dordrecht/Boston/Lancaster: D.Reidel Publishing Company.

Hubbard, Phil, Rob Kitchen, Brendan Bartley and Duncan Fuller. 2002. Thinking Geographically: Space, Theory and Contemporary Human Geography. London and New York: continuum.

Hunt, Constance Elizabeth. 2004. Thirsty Planet: Strategies for Sustainable Water Management. London and New York: Zed Books.

Hunt, Eva and Robert C. Hunt. 1974. Irrigation, Conflict and Politics: A Mexican Case. In Irrigation's Impact on Society, ed. Theodore E. Downing and McGuire Gibson:129-157. Tucson: University of Arizona Press.

Huxley, T.H. 1907 [1877]. Physiography: An Introduction to the Study of Nature. Reprint of 1st edition. New York: D. Appleton and Company.

Illich, Ivan. 1981. Shadow Work. London: Marion Boyars.

Illich, Ivan. 1985. $\mathrm{H}_{2} \mathrm{O}$ and the Waters of Forgetfulness. Dallas: Dallas Institute of Humanities and Culture.

Indian and Northern Affairs Canada. 2003a. National Assessment of Water and Wastewater Systems in First Nations Communities: Summary Report. Ottawa: Indian and Northern Affairs Canada.

Indian and Northern Affairs Canada. 2003b. FIRST NATIONS WATER TOP PRIORITY FOR GOVERNMENT OF CANADA. Press Release, May 14, 2003. Ottawa.

James, Preston E. 1972. All Possible Worlds: A History of Geographical Ideas. Indianapolis and New York: The Odyssey Press.

Jankovic, Vladimir. 1998. Meteors Under Scrutiny: Private, Public and Professional Weather in Britain, 1660-1800. Doctoral Dissertation, University of Notre Dame.

Jenkins, George. 1940. Forests, Land and Sea in Rainmaking. Journal of Geography 34, no. 8: 309-314. 
Jiaqu, Chen. 1987. The new stage of development of hydrology - Water Resources Hydrology. In Water for the Future: Hydrology in Perspective (Proceedings of the Rome Symposium, April 1987), ed. J.C. Rodda and N.C. Matalas: 17-26: International Association of Hydrologcal Sciences Publication No. 164.

Johnson, President Lyndon B. 1967. Welcoming Address by the President of the United States. In Water for Peace, Volume 1:10-12. Washington, D.C.

Johnston, Barbara Rose. 1998. Culture, Power, and the Hydrological Cycle: Creating and Responding to Scarcity on St. Thomas, Virgin Islands. In Water, Culture, and Power: Local Struggles in a Global Context, ed. John M. Donahue and Barbara Rose Johnston: 285-312. Washington DC: Island Press.

Johnston, Barbara Rose. 2003. An Introduction to the Political Ecology of Water. Capitalism, Nature, Socialism 14, no. 3 (September, 2003): 73-90.

Johnston, R.J, Derek Gregory, Geraldine Pratt and Michael Watts. 2000. The Dictionary of Human Geography. Malden, Massachusetts: Blackwell.

Jones, J.A.A. 1997. Global Hydrology: processes, resources and environmental management. Essex: Longman.

Jones, P.B., G.D. Walker, R.W. Harden and L.L. McDaniels. 1963. The Development of the Science of Hydrology ( 35 pp. booklet): Texas Water Commission.

Kaika, Maria. 2003. Constructing Scarcity and Sensationalizing Water Politics: 170 Days that Shook Athens. Antipode : 919-954.

Kaika, Maria. 2005. City of Flows: Modernity, Nature, and the City. London and New York: Routledge.

Kalaora, Bernard. 2001. De l'eau sensible a OH2. In Colloque International OH2, "Origines et Histoire de l'Hydrologie". Dijon, 9-11 mai, 2001. (paper published on conference CD) Université de Bourgogne.

Kalinin, G.P. 1971[1968]. Global Hydrology. Translated by N. Kaner. Jerusalem: Israel Program for Scientific Translation.

Kates, Robert W., B.L. Turner II and William C. Clarke. 1990. The Great Transformation. In The Earth as Transformed by Human Action: Global and Regional Changes in the biosphere over the Past 300 Years, ed. William C. Clark B.L. Turner II, Robert W. Kates, John F. Richards, Jessica T. Mathews, William B. Meyer: 1-17. Cambridge: Cambridge University Press with Clark University.

Kazmann, Raphael G. 1965. Modern Hydrology. New York: Harper and Row.

Kazmann, Raphael G. 1972. Modern Hydrology. Second Edition. New York: Harper and Row.

Klemes, V. 1988. A Hydrological Perspective. Journal of Hydrology 100: 3-28. 
Knight, David. 1996. Illustrating Chemistry. In Picturing Knowledge: Historical and Philosophical Problems Concerning the Use of Art in Science, ed. Brian S. Baigrie: 134-163. Toronto: University of Toronto Press.

Korzun, V.I et al. (USSR Committee for the International Hydrological Decade). 1978 [1974]. World Water Balance and Water Resources of the Earth. Paris: Unesco.

Kreutzwiser, Reid D. 1995. Water Resource Management: Canadian Perspectives and the Great Lakes Water Levels Issue. In Resource and Environmental Management in Canada: Addressing Uncertainty, ed. Bruce Mitchell. Don Mills, Ontario: Oxford University Press.

Krynine, Paul D. 1960. On the antiquity of "sedimentation" and hydrology. Bulletin of the Geological Society of America 71: 1721-1726.

Kuhn, Thomas S. 1970. The Structure of Scientific Revolutions. Second Edition. Chicago: University of Chicago Press.

Kuhn, Thomas S. 1990. Dubbing and Redubbing: The Vulnerability of Rigid Designation. In Scientific Theories, ed. C. Wade Savage: 298-318. Minneapolis: University of Minnesota Press.

Kula, Witold. 1986. Measures and Men. Translated by R. Szreter. Princeton, N.J.: Princeton University Press.

Ladourie, Emmanuel Le Roy. 1989. Introduction. In The Conquest of Water: The Advent of Health in the Industrial Age, by Jean-Pierre Goubert: 1-17. Princeton: Princeton University Press.

Lamers, Owen. 1999. IRN at Ten. International Rivers Network. Accessed October 21 2005. . Available from http://www.irn.org/pubs/wrr/9609/comment.html.

Landa, Edward R. and Simon Ince, ed. 1987. The History of Hydrology. Washington DC: American Geophysical Union.

Langbein, Walter B. and William G. Hoyt. 1959. Water Facts for the Nation's Future. New York: The Ronald Press Company.

Lansing, J. Stephen. 1987. Balinese "Water Temples" and the Management of Irrigation. American Anthropologist 89: 326-341.

Lansing, J. Stephen. 1991. Priests and Programmers: Technologies of Power in the Engineered Landscape of Bali. Princeton: Princeton University Press.

Larocque, Aurele. 1967. Translator's Introduction. In On the Origin of Springs, by Pierre Perrault:1-16. New York and London: Hafner Publishing Co.

Latour, Bruno. 1987. Science in Action: How to follow scientists and engineers through society. Milton Keynes, England: Open University Press. 
Latour, Bruno. 1993. We Have Never Been Modern. Cambridge, Mass.: Harvard University Press.

Latour, Bruno. 1999. Pandora's Hope: Essays on the Reality of Science Studies. Cambridge: Harvard University Press.

Latour, Bruno. 2004. Politics of Nature: How to Bring Sciences into Democracy. Cambridge: Harvard University Press.

Leach, M. and R. Mearns, ed. 1996a. The Lie of the Land: Challenging Received Wisdom on the African Environment. Oxford: James Currey.

Leach, Melissa and Robin Mearns. 1996b. Environmental Change and Policy: Challenging Received Wisdom in Africa. In The Lie of the Land: Challenging Received Wisdom on the African Environment, ed. Melissa Leach and Robin Mearns: 1-33. Oxford and Portsmouth: The International African Institute in Association with James Currey and Heinemann.

Lefebvre, Henri. 1991 [1972]. The Production of Space. Translated by Donald NicholsonSmith. Oxford and Cambridge, MA: Blackwell.

Leighly, John. 1938. The Role of Atmospheric Circulation in the Hydrologic Cycle of the Lands. The Geographical Review 28: 334-335.

Leighton, M.O. 1909. Water Power in the United States. Annals of the American Academy of Political and Social Science 33: 535-565.

Leiss, William. 1974. The Domination of Nature. Boston: Beacon Press.

Leopold, Luna B. 1987. The Alexandrian Equation. In The History of Hydrology, ed. Edward R. Landa and Simon Ince: 27-29. Washington DC: American Geophysical Union.

Leslie, Jacques. 2000. Running Dry: What happens when the world no longer has enough freshwater? Harper's Magazine, July, 2000: 37-52.

Levins, Richard and Richard Lewontin. 1985. The Dialectical Biologist. Cambridge, Massachusetts and London, England: Harvard University Press.

Linton. 1997. Beneath the Surface: The State of Water in Canada. Ottawa: Canadian Wildlife Federation.

Linton, Jamie. 2006. The Social Nature of Natural Resources - the Case of Water. reconstruction: studies in contemporary culture 6, no. 3 (Summer, 2006): available online at: http://reconstruction.eserver.org/063/contents.shtml.

Lipsey, Richard G., Gordon R. Sparks, and Peter O. Steiner. 1976. Economics. Second Edition. New York: Harper and Row.

Littlehales, G.W. 1923. Status, scope, and problems of the section of Oceanography. Transactions American Geophysical Union 4: 68-71. 
Littlehales, G.W. 1931. The inception and development of the International Section of Hydrology. Transactions American Geophysical Union 12: 189.

Livingstone, David N. 1992. The Geographical Tradition: Episodes in the History of a Contested Enterprise. Malden MA and Oxford UK: Blackwell.

Livingstone, David N. 2003. Putting Science in its Place: Geographies of Scientific Knowledge. Chicago and London: University of Chicago Press.

Lonergan, Stephen C. and David B. Brooks. 1994. Watershed: The Role of Fresh Water in the Israeli-Palestinian Conflict. Ottawa: International Development Research Centre.

Lovins, Amory. 1977. Soft Energy Paths: Toward a Durable Peace. Cambridge, MA: Ballinger/Friends of the Earth.

L'Vovich, Mark and Gilbert F. White with the collaboration of A.V. Belyaev, Janusz Kindler, N.I. Koronkevic, Terence R. Lee and G.V. Voropaev. 1990. Use and Transformation of Terrestrial Water Systems. In The Earth as Transformed by Human Action: Global and Regional Changes in the biosphere over the Past 300 Years, ed. William C. Clark et al.: 235-252. Cambridge: Cambridge University Press with Clark University.

L'vovich, M.I. 1979 [1974]. World Water Resources and their Future. (English translation of 1974 Russian original) Translated by Raymond L. Nace. Chelsea, Michigan: American Geophysical Union.

Lvovitch, Professor M.I. 1972. World Water Balance (General Report). In World Water Balance: Proceedings of the Reading Symposium, July 1970: 401-415. GentbruggeParis-Geneve: IASH-Unesco-WMO.

Maass, Arthur. 1970. Public Investment Planning in the United States: Analysis and Critique. Public Policy 18, no. 2: 211-243.

Macagno, Enzo, O. 1987. Leonardo da Vinci: Engineer and Scientist. In Hydraulics and Hydraulic Research, A Historical Review, ed. Gunther Garbrecht: 33-53. Rotterdam/Boston: A.A. Balkema.

Maccagni, Carlo. 1987. Galileo, Castelli, Torricelli and others: The Italian school of hydraulics in the 16th and 17th centuries. In Hydraulics and Hydraulic Research, $A$ Historical Review, ed. Gunther Garbrecht: 55-79. Rotterdam/Boston: A.A. Balkema.

Maffioli, Cesare S. 1994. Out of Galileo: The Science of Waters, 1628-1718. Rotterdam: Erasmus Publishing.

Maidment, David R. 1993. Handbook of Hydrology. New York: McGraw-Hill Inc.

Marsh, James H., ed. 1985. The Canadian Encyclopedia. Edmonton: Hurtig Publishers.

Marvin, C.F. 1920. The Status and Problems of Meteorology. Transactions, Am. Geophysical Union 1: 561-572. 
Marvin, C.F. 1923. Status, Scope and Present-Day Problems of Meteorology. Transactions, Am. Geophysical Union 4: 54-60.

Mather, J.D. 2004. 200 years of British hydrogeology - an introduction and overview. In 200 Years of British Hydrogeology, ed. J.D. Mather: 1-14. London: The Geological Society.

Matless, D. 1992. A modern stream: water, landscape, modernism, and geography. Environment and Planning D: Society and Space 10: 569-588.

Mautner, Thomas, ed. 1996. The Penguin Dictionary of Philosophy. London: Penguin Books.

McCully, Patrick. 1996. Silenced Rivers: The Ecology and Politics of Large Dams. London and New Jersey: Zed Books.

McCutcheon, Sean. 1991. Electric Rivers: The Story of the James Bay Project. Montreal/New York: Black Rose Books.

McGee, W.J. 1895. The Beginning of Agriculture. The American Anthropologist 8: 350375.

McGee, W.J. 1907. Our Great River: What it is and may be made for commerce, agriculture, and sanitation - the largest inland water project of our time. The World's Work 13: 8576-8584.

McGee, W.J. 1909. Water as a Resource. Annals of the American Academy of Political and Social Science 33: 521-534.

McGee, W.J. 1911. Principles of Water-Power Development. Science 34, no. 885: 813825.

Mead, Daniel W. 1919. Hydrology: The Fundamental Basis of Hydraulic Engineering. New York and London: McGraw-Hill Book Company, Inc. - Hill Publishing Co.

Mead, Daniel W. 1950. Hydrology: The Fundamental Basis of Hydraulic Engineering. Second Edition. New York and London: McGraw-Hill Book Company, Inc.

Meigs, Peveril. 195_. Water Problems in the United States. The Geographical Review : 346-366.

Meinzer, O.E. 1931. Formation of the Section of Hydrology of the American Geophysical Union. Transactions, Am. Geophysical Union 12: 227-229.

Meinzer, Oscar Edward. 1934. The history and development of ground-water hydrology. Journal of the Washington Academy of Sciences 24, no. 1: 6-32.

Meinzer, Oscar E., ed. 1942. Hydrology. (Physics of the Earth series - IX). New York: Dover.

Melville, Herman. 1972. Moby Dick. London: Penguin Books. 
Meyer, Adolph F. 1917. The Elements of Hydrology. New York and London: John Wiley and Sons Inc.; Chapman \& Hall, Limited.

Meyer, Adolph F. 1928. The Elements of Hydrology. Second Edition. New York and London: John Wiley and Sons Inc.; Chapman \& Hall, Limited.

Millennium Ecosystem Assessment. 2005. Millennium Ecosystem Assessment Synthesis Report. Available from wwsw.millenniumassessment.org.

Miller, Peter. 1994. John Wesley Powell: Vision for the West. National Geographic 85, no. 4: 89-115.

Millner, Andrew. 2000. post-colonialism. In The New Fontana Dictionary of Modern Thought, ed. Allan Bullock and Stephen Trombley: 669-70. London: Harper-Collins.

Mitchell, Timothy. 1998. Fixing the Economy. Cultural Studies 12, no. 1: 82-101.

Mohamed, Yagoub Abdalla. 1996. Drought and the need to change: The expansion of water harvesting in Central Darfur, Sudan. In Sustaining the Soil: Indigenous Soil and Water Conservation in Africa, ed. lan Scoones and Camilla Toulmin Chris Reij: 35-43. London: Earthscan.

Mohun, Simon. 1999. Labour Process. In A Dictionary of Marxist Thought, ed. Laurence Harris Tom Bottomore, V.G. Kiernan, Ralph Miliband: 297-301. Oxford and Malden: Blackwell.

Mol, Arthur P. J. and David A. Sonnenfeld. 2000. An Introduction. In Ecological Modernisation Around the World, ed. Arthur P. J. Mol and David A. Sonnenfeld: 3-16. London and Portland: Frank Cass.

Morello, Nicoletta. 2001. La question des eaux douces au XVIle siècle :parcours des eaux, parcours des hypothèses. In International Symposium $\mathrm{OH} 2$ "Origins and History of Hydrology": 1-16. Dijon, France, May 9-11, 2001 (paper published on conference CD). Université de Bourgogne.

Morse, Bradford and Thomas Berger. 1992. Sardar Sarovar: Report of the Independent Review. Ottawa, Canada: Resource Futures International.

Moser, Paul H. 1996. Hydrological Cycle. In Encyclopedia of Climate and Weather, ed. Stephen H. Schneider: 1:415-417. New York and Oxford: Oxford Universtity Press.

Mosse, David. 1995. Local institutions and power: The history and practice of community management of tank irrigation systems in south India. In Power and Participatory Development: Theory and Practice, ed. Nici Nelson and Susan Wright: 144-156: Intermediate Technology Publications.

Mosse, David. 2003. The Rule of Water: Statecraft, Ecology and Collective Action in South India. New Delhi: Oxford University Press.

Mumford, Lewis. 1934. Technics and Civilization. 
Myler, Joseph L. 1970. The Dirty Animal - Man. Book summarized in Eco-Crisis, ed. Cecil E. Johnson: 116-148. New York: John Wiley and Sons Inc.

Nace, R. 1974. General evolution of the concept of the hydrological cycle. In Three centuries of scientific hydrology: Key papers submitted on the occasion of the celebration of the Tercentenary of Scientific Hydrology. 40-49. Paris: Unesco-WMO.

Nace, Raymond L. 1964. Water of the World: Distribution of man's liquid assets is a clue to future control. Natural History 73, no. 1: 10-19.

Nace, Raymond L. 1967. Water Resources: A Global Problem with Local Roots. Environmental Science and Technology 1, no. 7: 550-560.

Nace, R.L. 1969. World Water Inventory and Control. In Water, Earth, and Man, ed. Richard J. Chorley: 31-42. London: Methuen.

Nace, Raymond L. 1972. World hydrology: Status and prospects. In World Water Balance: Proceedings of the Reading Symposium, July 1970, ed. IASH-Unesco-WMO: 1-10. Gentbrugge-Paris-Geneve: IASH-Unesco-WMO.

Nace, Raymond L. 1975. The Hydrological Cycle: Historical Evolution of the Concept. Water International 1, no. 1: 15-21.

Nace, R.L. 1978. Development of Hydrology in North America. Water International 3, no. 3: $20-26$.

Nace, R.L. 1979. Editor's Preface. In World Water Resources and their Future, by M.I. L'vovich:iv. Chelsea, Michigan: American Geophysical Union Translation Board.

Naranjo, Maria Francisca and Bernard Bobee. 2001. Le cycle hydrologique et les systèmes d'irrigation de la ville de Mexico à l'époque préhispanique. In Colloque International $\mathrm{OH} 2$ « Origines et Histoire de l'Hydrologie » (paper published on conference CD). Dijon: Université de Bourgogne.

NASA. 2003. Black Soot and Snow: A Warmer Combination. NASA Goddard Institute for Space Studies. Accessed December 22 2003. . Available from http://www.giss.nasa.gov/research/stories/20031222/.

Nash, J.E. 1992. Hydrology and hydrologists - Reflections. In Advances in Theoretical Hydrology: A Tribute to James Dooge, ed. J.P. O'Kane. Amsterdam: Elsevier.

National Research Council (NRC), Committee on Opportunities in the Hydrologic Sciences. 1991. Opportunities in the Hydrologic Sciences. Washington D.C.: National Academy Press.

National Resources Board. 1934. A Report on National Planning and Public Works in Relation to Natural Resources including Land Use and Water Resources with Findings and Recommendations. Washington D.C.: United States Government Printing Office. 
National Resources Committee. 1937. Deficiencies in Basic Hydrologic Data: Report of the Special Advisory Committee on Standards and Specifications for Hydrologic Data of the Water Resources Committee. Washington D.C.: US Government Printing Office.

National Resources Committee (Water Resources Committee). 1938. Drainage Basin Problems and Programs, 1937 Revision. Washington D.C.: US Government Printing Office.

Nelles, H.V. 1974. The Politics of Development: Forests, Mines and Hydro-Electric Power in Ontario, 1849-1941. Toronto: Macmillan of Canada.

Nemec, J. 1976. International Aspects of Hydrology. In Facets of Hydrology, ed. John C. Rodda: 331-362. London: John Wiley and Sons.

Nevarez, Leonard. 1996. Just wait until there's a drought: Mediating environmental crises for urban growth. Antipode 28, no. 3: 246-272.

Newell, Frederick Haynes. 1920. Water Resources: Present and Future Uses. New Haven and London: Yale University Press and Oxford University Press.

Nikolaieff, George A., ed. 1967a. The Water Crisis. New York: The H.W. Wilson Company.

Nikolaieff, George A. 1967b. Editor's Introduction. In The Water Crisis, ed. George A.Nikolaieff: 9. New York: The H.W. Wilson Company.

Nuttle, William K. 2002a. Taking Stock of Water Resources. EOS 85, no. 513: 1-2.

Nuttle, William K. 2002b. Is ecohydrology one idea or many? Hydrological Sciences Journal 45, no. 5: 805-808.

Ohisson, Leif, ed. 1995. Hydropolitics: Conflicts over Water as a Development Constraint. London and New Jersey: Zed Books.

Ohisson, Leif and Antony R. Turton. 1999. The Turning of a Secrew: Social Resource Scarcity as a Bottle-Neck in Adaptation to Water Scarcity. London: School of Oriental and Asian Studies, Water Study Group, University of London.

Ollman, Bertell. 1993. Dialectical Investigations. New York, London: Routledge.

Parfit, Michael. 1993. Sharing the Wealth of Water. National Geographic Special Edition: "Water": 20-37.

Parizek, Richard R. 1963. The Hydrologic Cycle Concept and Our Challenge in the 20th Century. Mineral Industries 32, no. 7: 1-13.

Patrick, Ruth. 1994. Is Water our Next Crisis? Proceedings of the American Philosophical Society 128, no. 3: 371-76.

Pawluk, Roman R., Jonathan A. Sandor, and Joseph A. Tabor. 1992. The role of indigenous soil knowledge in agricultural development. Journal of Soil and Water Conservation 47, no. (July-August): 298-302. 
Pazwash, H. 1983. Iran's Modes of Modernization: Greening the Desert, Deserting the Greenery? Civil Engineering March 1983.

Pearce, Fred. 1992. The Dammed: Rivers, dams, and the coming water crisis. London: The Bodley Head.

Peet, Richard. 1998. Modern Geographical Thought. Oxford: Blackwell.

Perrault, Pierre. 1967 [1674]. On the Origin of Springs. Translated by Aurele La Rocque. New York and London: Hafner Publishing Co.

Perrault, Pierre. 2001[1674]. De l'origine des fontaines. Edited by le Comité National Français des Sciences Hydrologiques. Séries: Textes fondateurs de l'hydrologie N. 2. Asnieres France: Association Internationale des Sciences Hydrologiques, Comité National Français des Sciences Hydrologiques.

Petrella, Riccardo. 1998. Le Manifeste de l'eau: Pour un contrat mondial. Brussels: Labor.

Petrella, Riccardo. 2000. Blue Gold of the 21st Century. March, 2000. Le Monde Diplomatique. Accessed September 4 2003. . Available from http://www.globalpolicy.org/globaliz/special/water.htm.

Pliny. 1938. Natural History. Cambridge and London: Harvard University Press and William Heinemann Ltd.

Polanyi, Karl. 2001[1944]. The Great Transformation: The Political and Economic Origins of Our Time. Boston: Beacon Press.

Postel, Sandra. 1992. Last Oasis: Facing Water Scarcity. New York and London: W.W. Norton and Company.

Postel, Sandra. 1999. Pillar of Sand: Can the Irrigation Miracle Last. New York and London: W.W. Norton and Company.

Postel, S.L., G.C. Daily and P.R. Ehrlich. 1996. Human appropriation of renewable fresh water. Science 271 (Feb.9, 1996): 785-788.

Progress in Human Geography. 1997. Classics in Geography Revisited: Gilbert White, Human Adjustment to Floods. Progress in Human Geography 21, no. 2: 243-250.

Rattue, James. 1995. The Living Stream: Holy Wells in Historical Context. Woodbridge, Suffolk and Rochester, New York: The Boydell Press.

Ray, John. 1692. The Wisdom of God Manifested in the Works of the Creation. Second Edition. London: Samuel Smith.

Rees, Judith. 1990. Natural Resources: Allocation, economics and policy. London and New York: Routledge.

Reij, Chris, lan Scoones and Camilla Toulmin, ed. 1996. Sustaining the Soil: Indigenous Soil and Water Conservation in Africa. London: Earthscan. 
Reisner, Marc. 1986. Cadillac Desert: The American West and its Disappearing Water. New York: Penguin Books.

Reuss, Martin. 2001a. Hydrology. In The History of Science in the United States: An Encyclopedia, ed. Marc Rothenberg:274-276. New York and London: Garland Publishing Inc.

Reuss, Martin. 2001b. Surface Water Hydrology and the "Big Dam Era" in the United States. Unpublished paper presented at the Conference of the Internatioal Association of Water History, Bergen, Norway.

Rockstrom, Johan. 2003. Managing rain for the future. In Rethinking Water Management: Innovative Approaches to Contemporary Issues, ed. Cecilia Tortajada and Johan Rockstrom Caroline M. Figuertes: 70-101. London: Earthscan.

Rodda, J. and L. Ubertini, ed. 2004. The Basis of Civilization - Water Science? Oxford: International Association of Hydrologic Science - Centre for Ecology and Hydrology.

Rodda, J.C. 1995a. Guessing or Assessing the World's Water Resources? Journal of the Institute of Water and Environmental Management 9, no. 4: 360-368.

Rodda, John C. 1995b. Whither World Water? Water Resources Bulletin 31, no. 1: 1-7.

Rodda, John C. 1997. Foreword. In Global Hydrology: processes, resources and environmental management, ed. J.A.A. Jones: xi. Essex: Longman.

Rodda, J.C. and N.C. Matalas, ed. 1987. Water for the Future: Hydrology in Perspective. IAHS Publication No. 164. Wallingford: International Association of Hydrological Sciences.

Rogers, Peter. 1990. Hydrology and Water Quality. In The Earth as Transformed by Human Action: Global and Regional Changes in the biosphere over the Past 300 Years, ed. William C. Clark et al.: 231-257. Cambridge: Cambridge University Press with Clark University.

Rogers, Peter. 1996. America's Water: Federal Roles and Responsibilities. Cambridge and London: MIT Press.

Rogers, Peter P. 1985. Fresh Water. In The Global Possible: Resources, Development and the New Century, ed. Robert Repetto. New Haven and London: Yale University Press.

Ross, Andrew. 1996. The Lonely Hour of Scarcity. Capitalism, Nature, Socialism 7, no. 3: 3-26.

Rouse, Hunter and Simon Ince. 1957. History of Hydraulics: lowa Institute of Hydraulic Research, State University of lowa. 
Roy, Andre and Stuart Lane. 2003. Putting the morphology back into fluvial geomorphology: the case of river meanders and tributary junctions. In Contemporary Meanings in Physical Geography: From what to why?, ed. Stephen Trudgill and Andre Roy:103-125. London: Arnold.

Saberwal, V.K. 1997. Science and the Desiccationist Discourse of the 20th Century. Environment and History 3: 309-343.

Saeijs, H.L.F. and M.J. van Berkel. 1995. Global water crisis: the major issue of the 21st century, a growing and explosive problem. European Water Pollution Contro/ 5, no. 4: 26-40.

Said, Edward. 2000 [1988]. Yeats and Decolonization. In The Edward Said Reader, ed. Moustafa Bayoumi and Andrew Rubin: 291-313. New York: Vintage Books.

Sambursky, S. 1962. The Physical World of the Greeks. Translated by Merton Dagut. New York: Collier Books.

Sandbach, Francis. 1980. Environment, Ideology and Policy. Oxford: Basil Blackwell.

Sardar, Ziauddin. 2001. Above, Beyond, and at the center of the science wars: a postcolonial reading. In After the Science Wars, ed. K.M and PS. Baringer K.M. Ashman.

Sauer, Carl Ortwin. 1963[1925]. The Morphology of Landscape. In Land and Life: a selection from the writings of Carl Ortwin Sauer, ed. John Leighly: 315-350. Berkely and Los Angeles: University of California Press.

Saville, Thorndike. 1937. Basic Principles of Water Behavior. In Headwaters Control and Use: A summary of fundamental principles and their application in the conservation and utilization of waters and soils throughout headwater areas. Papers presented at the Upstream Engineerging Conference held in Washington, D.C., September 22 and 23, 1936. Washington D.C.: Soil Conservation Service and Forest Service of the United States Department of Agriculture with the cooperation of Rural Electrification Administration.

Schama, Simon. 1995. Landscape and Memory. Toronto: Random House of Canada.

Scheuerlein, Helmut. 1987. Fluvial hydraulics throughout history. In Hydraulics and Hydraulic Research, A Historical Review, ed. Gunther Garbrecht: 185-190. Rotterdam/Boston: A.A. Balkema.

Scientific American. 1989. Special Issue: Managing Planet Earth. Scientific American .

Scoones, lan, Chris Reij and Camilla Toulmin. 1996. Sustaining the Soil: Indigenous Soil and Water Conservation in Africa. In Sustaining the Soil: Indigenous Soil and Water Conservation in Africa, ed. lan Scoones and Camilla Toulmin Chris Reij: 1-27. London: Earthscan.

Scott, James C. 1998. Seeing Like a State: How Certain Schemes to Improve the Human Condition Have Failed. New Haven and London: Yale University Press. 
Section Internationale d'Hydrologie Scientifique, Conseil International de Recherches, Union Géodésique et Géophysique International. 1924. Première Réunion plénière de la Section, Bulletin N.1. Madrid, Octobre 1924.

Seenivasan, R., ed. 2003. Neerkattis: The Rural Water Managers. Madurai, Tamil Nadu, India: DHAN Foundation.

Seenivasan, R, P. and Anand Kumar. 2004. Vision for Village Tanks of Tamil Nadu. Madurai, Tamil Nadu, India: DHAN (Development of Humane Action) Foundation.

Seneca, Lucius Annaeus. 1972. Naturales Quaestiones. Cambridge and London: Harvard University Press and William Heinemann Ltd.

Shapin, Steven. 1996. The Scientific Revolution. Chicago: University of Chicago Press.

Shapin, Steven and Simon Schaffer. 1985. Leviathan and the Air-Pump: Hobbes, Boyle, and the Experimental Life. Princeton: Princeton University Press.

Shiklomanov, Igor A. 1993. World Fresh Water Resources. In Water in Crisis: A Guide to the World's Freshwater Resources, ed. Peter H. Gleick: 13-24. New York and Oxford: Oxford University Press.

Shiklomanov, I.A. and John C. Rodda, ed. 2003. World Water Resources at the Beginning of the Twenty-First Century. Cambridge: Cambridge University Press.

Shiva, Vandana. 1988. Staying Alive: Women, Ecology, and Development in India. London: Zed Books.

Shiva, Vandana. 2002. Water Wars: Privatization, Pollution, and Profit. Toronto: Between the Lines.

Sims, Peter. 2003. Previous actors and current influences: trends and fashions in physical geography. In Contemporary Meanings in Physical Geography: From what to why?, ed. Stephen Trudgill and Andre Roy: 3-23. London: Arnold.

Smith, Neil. 1984. Uneven Development: Nature, Capital and the Production of Space. Oxford: Basil Blackwell.

Smith, Neil. 1996. The Production of Nature. In FutureNatural: Nature, Science Culture, ed. Melinda Mash George Robertson, Lisa Tickner, Jon Bird, Barry Curtis and Tim Putnam: 36-54. London and New York: Routledge.

Smith, Norman A.F. 1975. Man and Water: a history of hydro-technology. New York: Scribner.

Soper, Kate. 1995. What is Nature? Oxford, UK and Cambridge, USA: Blackwell.

Soper, Kate. 1996. Nature/'nature'. In FutureNatural: Nature, Science Culture, ed. Melinda Mash George Robertson, Lisa Tickner, Jon Bird, Barry Curtis and Tim Putnam: 22-34. London and New York: Routledge. 
Soule, Michael E. and Gary Lease. 1995. Reinventing Nature? Responses to Postmodern Deconstruction. Washington D.C. and Covelo California: Island Press.

Soullard, Éric. 2001. Les Académiciens des Sciences :Claude, Charles et Pierre Perrault, l'Abbé Picard, La Hire...et le chantier des eaux de Versailles, sous Louis XIV. In Colloque International $\mathrm{OH} 2$ " Origines et Histoire de l'Hydrologie », Dijon, 9-11 mai 2001: (paper published on conference CD): Université de Bourgogne.

Spidel, David H. and Allen F. Agnew. 1988. The World Water Budget. In Perspectives on Water: Uses and Abuses, ed. Lon C. Ruedisili, David H. Spidel, and Allen F. Agnew. New York and Oxford: Oxford University Press.

Stehlik, Daniela, Geoffrey Lawrence and lan Gray. 2000. Gender and Drought: Experiences of Australian Women in the Drought of the 1990s. Disasters 24, no. 1: 3853.

Stichweh, Rudolf. 1992. The Sociology of Scientific Disciplines: On the Genesis and Stability of the Disciplinary Structure of Modern Science. Science in Context 5, no. 1: 3-15.

Stiglitz, Joseph. 2002. Globalization and its Discontents. New York and London: WW Norton.

Stott, Philip and Sian Sullivan, ed. 2000. Political Ecology: Science, Myth and Power. London: Arnold.

Strang, Veronica. 2004. The Meaning of Water. Oxford and New York: Berg.

Sutcliffe, R.C. 1972. Introduction. In World Water Balance: Proceedings of the Reading Symposium, July 1970: A contribution to the International Hydrological Decade, 1: xii. Gentbrugge-Paris-Geneve: IASH-Unesco-WMO.

Swift, Jeremy. 1996. Desertification: Narratives, Winners and Losers. In The Lie of the Land: Challenging Received Wisdom on the African Environment, ed. Melissa Leach and Robin Mearns: 73-90. Oxford and Portsmouth: The International African Institute in Association with James Currey and Heinemann.

Swyngedouw, Erik. 1996. The City As a Hybrid: On Nature, Society and Cyborg Urbanization. Culture, Nature, Socialism 7, no. 2: 65-80.

Swyngedouw, Eric. 1997. Power, Nature and the City. The Conquest of Water and the Political Ecology of Urbanization in Guayaquil, Ecuador: 1880-1990. Environment and Planning A 29: 311-332.

Swyngedouw, Erik. 1999. Modernity and Hybridity: Nature, Regeneracionismo, and the Production of the Spanish Waterscape, 1890-1930. Annals of the Association of American Geographers 89, no. 3: 443-465. 
Swyngedouw, Erik. 2000. The Marxian Alternative: Historical-Geographical Materialism and the Political Economy of Capitalism. In A Companion to Economic Geography, ed. Eric Sheppard and Trevor J. Barnes: 41-59. Oxford and Malden, Mass.: Blackwell Publishers.

Swyngedouw, Erik. 2004. Social Power and the Urbanization of Water: Flows of Power. Oxford: Oxford University Press.

Tanner, R.G. 1987. Philosophical and cultural concepts underlying water supply in antiquity. In Water for the Future: Hydrology in Perspective (Proceedings of the Rome Symposium, April 1987), ed. J.C. Rodda and N.C. Matalas: 27-36: International Association of Hydrological Sciences Publication No. 164.

Tarnas, Richard. 1991. The Passion of the Western Mind. New York: Ballantine Books.

Taylor, Peter J. and Frederick H. Buttel. 1992. How do we Know we have Global Environmental Problems? Science and the Globalization of Environmental Discourse. Geoforum 23, no. 3: 405-416.

The Permutit Company. 1943. Water Conditioning Handbook. New York: The Permutit Company.

Thomas, Harold E. 1956. Changes in Quantities and Qualities of Ground and Surface Water. In Man's Role in Changing the Face of the Earth, ed. William L. Thomas Jr: 542-563. Chicago: University of Chicago Press.

Thomas, William L., Jr. et al., ed. 1956. Man's Role in Changing the Face of the Earth. Chicago and London: The University of Chicago Press.

Thornwaite, C.W. 1937-8. The Hydrologic Cycle Re-Examined. Soil Conservation 3, no. 4: 85-91.

Tixeront, J. 1974. L'Hydrologie en France au XVIle siècle. In Three centuries of scientific hydrology: Key papers submitted on the occasion of the celebration of the Tercentenary of Scientific Hydrology:24-36. Paris: Unesco-WMO.

Todd, David Keith. 1970. The Water Encyclopedia: A compendium of useful information on water resources. Port Washington, New York: Water Information Center.

Tonini, D. 1977. The evolution of the concept of the hydrological cycle in the western world, with special regard to the contributions of Italian scholars. Water International 2, no. 4: 16-31.

Tozer, H.F. 1971. A History of Ancient Geography. 2nd. New York: Billo and Tannen.

Tuan, Yi-Fu. 1968a. The Hydrologic Cycle and the Wisdom of God: A Theme in Geoteleology. University of Toronto Department of Geography Research Publications. Toronto: University of Toronto Press.

Tuan, Yi-Fu. 1968b. Discrepancies between environmental attitude and behaviour: Examples from Europe and Asia. The Canadian Geographer 12, no. 3: 176-191. 
Turner, B.L. II et al., ed. 1990. The Earth as Transformed by Human Action: Global and Regional Changes in the Biosphere over the Past 300 Years. Cambridge: Cambridge University Press.

Tvedt, T and E. Jakobsson, ed. 2006. Water Control and River Biographies. Volume 1 of $A$ History of Water. London and New York: I.B. Tauris.

Tvedt, T. and Oestigaard, ed. 2006. The World of Water. Volume 3 of A History of Water. London and New York: I.B. Tauris.

Unesco. 1971. Scientific Framework of world water balance. Paris: Unesco.

unesco. 1974a. Textbooks on hydrology. Technical Papers in Hydrology \#6. Vol. 1, Analyses and synoptic tables of contents of selected textbooks.

unesco. 1974b. Textbooks on hydrology. Technical Papers in Hydrology \#6. Vol. 2, Analyses of selected textbooks.

Unesco. 2003. Water for People, Water for Life: The United Nations World Water Development Report: United Nations Educational, Scientific and Cultural Organization and the World Water Assessment Programme.

Unesco-WMO-IAHS. 1974. Foreword. In Three centuries of scientific hydrology: Key papers submitted on the occasion of the celebration of the Tercentenary of Scientific Hydrology: 11. Paris: Unesco-WMO.

United Nations Commission on Sustainable Development. 1997. Comprehensive Assessment of the Freshwater Resources of the World. United Nations document E/EN.17/1997/9. February 4, 1997.

United Nations Environment Programme. 2002. Vital Water Graphics: An overview of the state of the world's fresh and marine waters. New York: UNEP and GRID Arendal.

United Nations, Secretariat of UN-Water. 2005. Water for Life Decade: 2005-2015. New York: UN Department of Public Information.

United States. 1962. Scientific Hydrology. Report of the Federal Council for Science and Technology, Ad Hoc Panel on Hydrololgy. Walter Langbein, Chair.

Unwin, Tim. 1992. The Place of Geography. Essex: Longman Scientific and Technical.

Urban, Michael and Bruce Rhoads. 2003. Conceptions of nature: implications for an integrated geography. In Contemporary Meanings in Physical Geography: From what to why?, ed. Stephen Trudgill and Andre Roy: 211-231. London: Arnold.

van der Leeden, Frits. 1975. Water Resources of the World: Selected Statistics. Port Washington: Water Information Center, Inc.

van der Leeden, Frits, Fred L. Troise and David Keith Todd. 1990. The Water Encyclopedia. Second edition. Chelsea, Michigan: Lewis Publishers. 
van Hylckama, T.E.A. 1956. The Water Balance of the Earth. Centerton, New Jersey: Drexel Institute of Technology, Laboratory of Climatology.

Varela, Francisco J., Evan Thompson and Eleanor Rosch. 1991. The Embodied Mind. Cambridge and London: The MIT Press.

Varenius. 1693. Cosmography and Geography. London: Samuel Roycroft, for Richard Blome.

Veissman Jr., Warren and Gary L. Lewis. 1996. Introduction to Hydrology. $4^{\text {th }}$ Edition: Harper and Collins College Publishers.

Vitruvius. 1999. Ten Books on Architecture. Translated by Ingrid D. Rowland. Cambridge: Cambridge University Press.

Volker, A. 1983. International Cooperation in Hydrology and Water Resources Development. Hydrological Sciences Journal 28, no. 1: 49-56.

Wainwright, Joel. 2005. Politics of Nature: A Review of Three Recent Works by Bruno Latour. Capitalism, Nature, Socialism 16, no. 1: 115-122.

Ward, Colin. 1997. Reflected in Water: A Crisis of Social Responsibility. London and Washington: Cassell.

Ward, R.C. and M. Robinson. 2000. Principles of Hydrology. $4^{\text {th }}$ Edition. London and New York: McGraw-Hill.

Watts, Michael. 2000. Political Ecology. In A Companion to Economic Geography: 257274. Oxford and Malden, Mass: Blackwell.

Wescoat, James L. Jr. and Gilbert F. White. 2003. Water for Life: Water Management and Environmental Policy. Cambridge U.K.: Cambridge University Press.

Wescoat, James L. 1987. The practical range of choice in water resources geography. Progress in Human Geography 11, no. 1: 41-59.

Whatmore, Sarah. 2002. Introduction: More than Human Geographies. In Handbook of Cultural Geography, ed. Mona Domosh Kay Anderson, Steve Pile and Nigel Thrift: 165-167. London: Sage Publications.

Whitcombe, Elizabeth. 1995. The Environmental Costs of Irrigation in British India: Waterlogging, Salinity, Malaria. In Nature, Culture and Imperialism: Essays on the Environmental History of South Asia, ed. David Arnold and Ramachandra Guha: 237259. Delhi: Oxford University Press.

White, G.F. 1945. Human Adjustment to Floods. University of Chicago, Department of Geography Research Papers Research Paper 29.

White, Gilbert F. 1969. Strategies of American Water Management. Ann Arbor: University of Michigan Press. 
White, Gilbert F. 1984. Water Resource Adequacy: Illusion and Reality. In The Resourceful Earth: A Response to Global 2000, ed. Julian L. Simon and Herman Kahn: 250-266. Oxford: Blackwell.

White, Richard. 1995. The Organic Machine: The Remaking of the Columbia River. New York: Hill and Wang.

Whitehead, Alfred North. 1925. Science and the Modern World: Lowell Lectures, 1925. New York: The Macmillan Company.

Whitehead, Mark. 2005. Maria Kaika. City of Flows: Modernity, Nature, and the City. H-Net Book Review published by H-HistGeog@h-net.msu.edu. (April, 2005).

Whitely, Peter and Vernon Masayesva. 1998. The Use and Abuse of Aquifers: Can the Hopi Indians Survive Multinational Mining? In Water, Culture, and Power: Local Struggles in a Global Context, ed. John M. Donahue and Barbara Rose Johnston: 934. Washington DC: Island Press.

Wisler, C.O. and E.F. Brater. 1949. Hydrology. New York and London: John Wiley and Sons, Chapman and Hall.

Wittfogel, Karl A. 1956. The Hydraulic Civilizations. In Man's Role in Changing the Face of the Earth, ed. William L. Thomas Jr.:1 52-164. Chicago: University of Chicago Press.

Wittfogel, Karl August. 1957. Oriental Despotism : A Comparative Study of Total Power. New Haven: Yale University Press.

Wolf, Aaron T. 2003. The present and future of transboundary water management. In Rethinking Water Management: Innovative Approaches to Contemporary Issues, ed. Cecilia Tortajada and Johan Rockstrom Caroline M. Figuertes: 164-179. London: Earthscan.

Wolff, Gary and Peter H. Gleick. 2002. The Soft Path for Water. In The World's Water:2002-2003, The Biennial Report on Freshwater Resources, ed. Peter H. Gleick:1-32. Washington: Island Press.

World Commission on Dams. 2000. Dams and Development, A New Framework for Decision-Making: The Report of the World Commission on Dams. London and Sterling VA: Earthscan Publications.

World Commission on Environment and Development. 1987. Our Common Future. Oxford and New York: Oxford University Press.

World Resources Institute. 1992. World Resources 1992-1993. New York: Oxford University Press.

World Resources Institute. 2000. World Resources 2000-2001: People and Ecosystems: The Fraying Web of Life. Washington D.C.: World Resources Institute.

Worster, Donald. 1985. Rivers of Empire: Water, Aridity, and the Growth of the American West. New York: Pantheon Books. 
Worster, Donald. 2006. Water in the Age of Imperialism - and Beyond. In A History of Water, ed. T.Tvedt and T. Oestigaard, Volume 3: The World of Water: 5-17. London and New York: I.B. Tauris.

Wright, Jim. 1966. The Coming Water Famine. New York: Coward-McCann.

Wulff, H.E. 1968. The Quanats of Iran. Scientific American 218, no. 4.

Xenos, Nicholas. 1989. Scarcity and Modernity. London and New York: Routledge.

Yearley, Steven. 1996. Sociology, Environmentalism, Globalization: Reinventing the Globe. London: Sage Publications.

Young, Gordon J., James C.I. Dooge, and John C. Rodda. 1994. Global Water Resource Issues. Cambridge: Cambridge University Press.

Young, Robert M. 1999. Nature. In A Dictionary of Marxist Thought, ed. Laurence Harris Tom Bottomore, V.G. Kiernan, Ralph Miliband:399. Oxford and Malden: Blackwell.

Young, Robert M. 1999b. Dialectics of Nature. In A Dictionary of Marxist Thought, ed. Laurence Haqrris Tom Bottomore, V.G. Kiernan, Ralph Miliband:150. Oxford and Malden: Blackwell.

Zimmermann, Erich W. 1933. World Resources and Industries: A functional appraisal of the availability of agricultural and industrial resources. New York and London: Harper and Brothers Publishers.

Zimmermann, Erich W. 1951. World Resources and Industries: A functional appraisal of the availability of agricultural and industrial materials. Revised Edition. New York: Harper and Brothers. 